\title{
Use of tacrolimus in Chinese renal transplant recipients
}

Citation for published version (APA):

Cheung, C. Y. (2009). Use of tacrolimus in Chinese renal transplant recipients. [Doctoral Thesis, Maastricht University]. Universitaire Pers Maastricht. https://doi.org/10.26481/dis.20091210cc

Document status and date:

Published: 01/01/2009

DOI:

10.26481/dis.20091210cc

Document Version:

Publisher's PDF, also known as Version of record

\section{Please check the document version of this publication:}

- A submitted manuscript is the version of the article upon submission and before peer-review. There can be important differences between the submitted version and the official published version of record.

People interested in the research are advised to contact the author for the final version of the publication, or visit the DOI to the publisher's website.

- The final author version and the galley proof are versions of the publication after peer review.

- The final published version features the final layout of the paper including the volume, issue and page numbers.

Link to publication

\footnotetext{
General rights rights.

- You may freely distribute the URL identifying the publication in the public portal. please follow below link for the End User Agreement:

www.umlib.nl/taverne-license

Take down policy

If you believe that this document breaches copyright please contact us at:

repository@maastrichtuniversity.nl

providing details and we will investigate your claim.
}

Copyright and moral rights for the publications made accessible in the public portal are retained by the authors and/or other copyright owners and it is a condition of accessing publications that users recognise and abide by the legal requirements associated with these

- Users may download and print one copy of any publication from the public portal for the purpose of private study or research.

- You may not further distribute the material or use it for any profit-making activity or commercial gain

If the publication is distributed under the terms of Article $25 \mathrm{fa}$ of the Dutch Copyright Act, indicated by the "Taverne" license above, 


\section{Use of tacrolimus in Chinese renal transplant recipients}


(C) Chi Yeun Cheung, Maastricht 2009

ISBN: 9789052788883

Layout: Tiny Wouters

Production: Datawyse | Universitaire Pers Maastricht 


\section{Use of tacrolimus in Chinese renal transplant recipients}

PROEFSCHRIFT

ter verkrijging van de graad van doctor

aan de Universiteit Maastricht,

op gezag van de Rector Magnificus, Prof. mr. G.P.M.F. Mols, volgens het besluit van het College van Decanen, in het openbaar te verdedigen

op donderdag 10 december 2009 om 16.00 uur

door

Chi Yeun Cheung

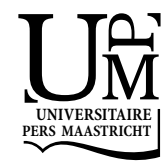




\section{Promotor}

Prof. dr. J.P. van Hooff

Copromotores

Dr. M.H.L. Christiaans

Mr. C.S. Li

Beoordelingscommissie

Prof. dr. V.A. Bruggeman, voorzitter

Dr. T. van Gelder, Erasmus Medisch Centrum, Rotterdam

Prof. dr. L.W.E. van Heurn

Prof. dr. C. Neef

Prof. dr. M.G.J. Tilanus 


\section{Contents}

$\begin{array}{lll}\text { Chapter } 1 & \text { Introduction } & 7\end{array}$

Chapter 2 Paired kidney analysis of tacrolimus and cyclosporine 37 microemulsion-based therapy in Chinese cadaveric renal transplant recipients

Transplant International 2006;19:657-666

Chapter 3 Can daclizumab reduce acute rejection and improve long term 55 renal function in tacrolimus-based primary renal transplant recipients

Nephrology 2008;13:251-255

Chapter 4 Prevalence of abnormal glucose metabolism in Chinese renal 67 Transplant recipients: a single center study Nephrol Dial Transplant 2008;23:3337-3342

Chapter 5 Prevalence of metabolic syndrome in Chinese renal transplant recipients Hong Kong Medical Journal 2008;14:379-84

Chapter 6 Influence of different allelic variants of the cytochrome $3 \mathrm{~A}$ and adenosine triphosphate-binding cassette B1 gene on the tacrolimus pharmacokinetic profile of Chinese renal transplant recipients Pharmacogenomics 2006;7:563-574

Chapter 7 Tacrolimus pharmacokinetics and pharmacogenetics: influence of adenosine triphosphate-binding cassette B1 (ABCB1) and cytochrome (CYP) 3A polymorphisms Fundamental \& Clinical Pharmacology 2007;21:427-435

Chapter 8 Dried blood spot measurement: application in tacrolimus monitoring using limited sampling strategy and abbreviated AUC estimation

Transplant International 2008;21:140-145

Chapter 9 Summary and general discussion

Samenvatting

Acknowledgement

List of publications

Curriculum Vitae 



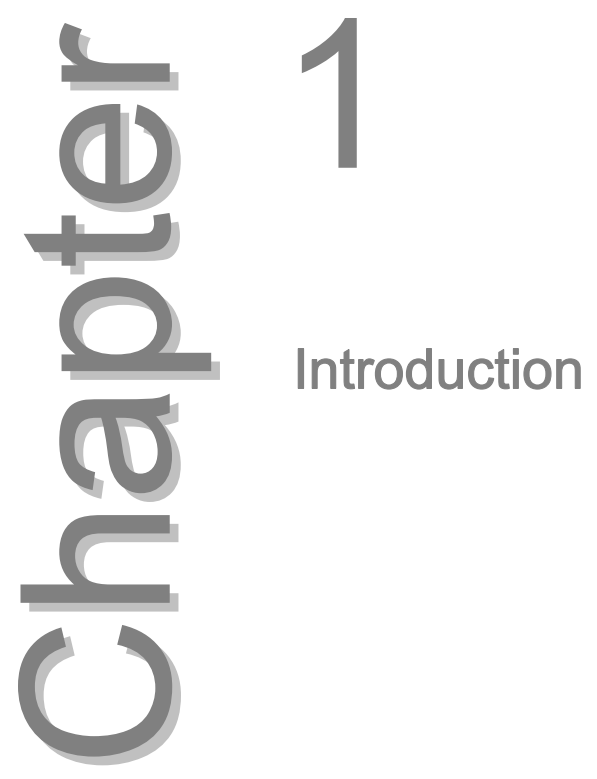




\section{Introduction}

Transplantation has significantly reduced mortality and morbidity in patients with end stage renal disease. One of the most important developments in renal transplantation is the introduction of new immunosuppressive agents for the prevention of acute rejection. Until the 1980s, the conventional immunosuppressive therapy consisted of a purine synthesis inhibitor azathioprine and corticosteroids. They were the only immunosuppressive agents for maintenance therapy. Sometimes an induction course of anti-lymphocyte globulin (ALG) was also administered together in order to reduce the risk of acute rejection ${ }^{1}$. Cyclosporine $\mathrm{A}$, a calcineurin inhibitor $(\mathrm{CNI})$, was introduced in renal transplantation in early $1980 \mathrm{~s}^{2}$. The major advantage was a reduction in the incidence of acute rejection and improvement in 1-year graft survival ${ }^{3-5}$. Several randomized studies also demonstrated that cyclosporine-based immunosuppression had advantages over conventional immunosuppression as it resulted in a reduced need to use corticosteroids ${ }^{6-8}$. Consequently, in combination with corticosteroids and azathioprine, cyclosporine became the standard immunosuppressive agent and it remained so through the mid 1990s. Cyclosporine/Sandimmun (Sandoz, Switzerland) was later replaced by cyclosporine/Neoral (Novartis, Switzerland), a microemulsion formula with a bile-independent and consistent absorption profile, which led to lower interpatient and intra-patient variability than Sandimmun ${ }^{9}$. In the 1990s, a number of new immunosuppressive agents were introduced in clinical transplantation.

- In the group of CNI: tacrolimus (FK 506, Prograf; Fujisawa/Astellas, Japan).

- In the group of lymphocyte-selective purine synthesis inhibitors: mycophenolate mofetil (Cellcept; Roche, Switzerland) and mycophenolic acid (Myfortic; Novartis, Switzerland).

- In the group of mammalian target of rapamycin (mTOR, inhibitors of cytokine signal transduction): the macrolides sirolimus (Rapamune; Wyeth, USA) and everolimus (Certican; Novartis, Switzerland).

- In the group of interleukin-2 (IL-2) receptor antagonist: basiliximab (Simulect, Novartis, Switzerland) and daclizumab (Zenapax, Roche, Switzerland).

The sites of action of different immunosuppressive agents are shown in Figure 1.1. Most patients currently undergoing solid organ transplantation are started on either cyclosporine or tacrolimus. There has been a shift towards a more frequent use of tacrolimus after kidney transplantation in worldwide, especially in the United States ${ }^{10}$. Optimization of both efficacy and safety of the immunosuppressive regimen is key to improving long-term transplant outcome. This thesis will focus on different aspects of optimizing tacrolimus therapy, especially in Chinese renal transplant recipients. 


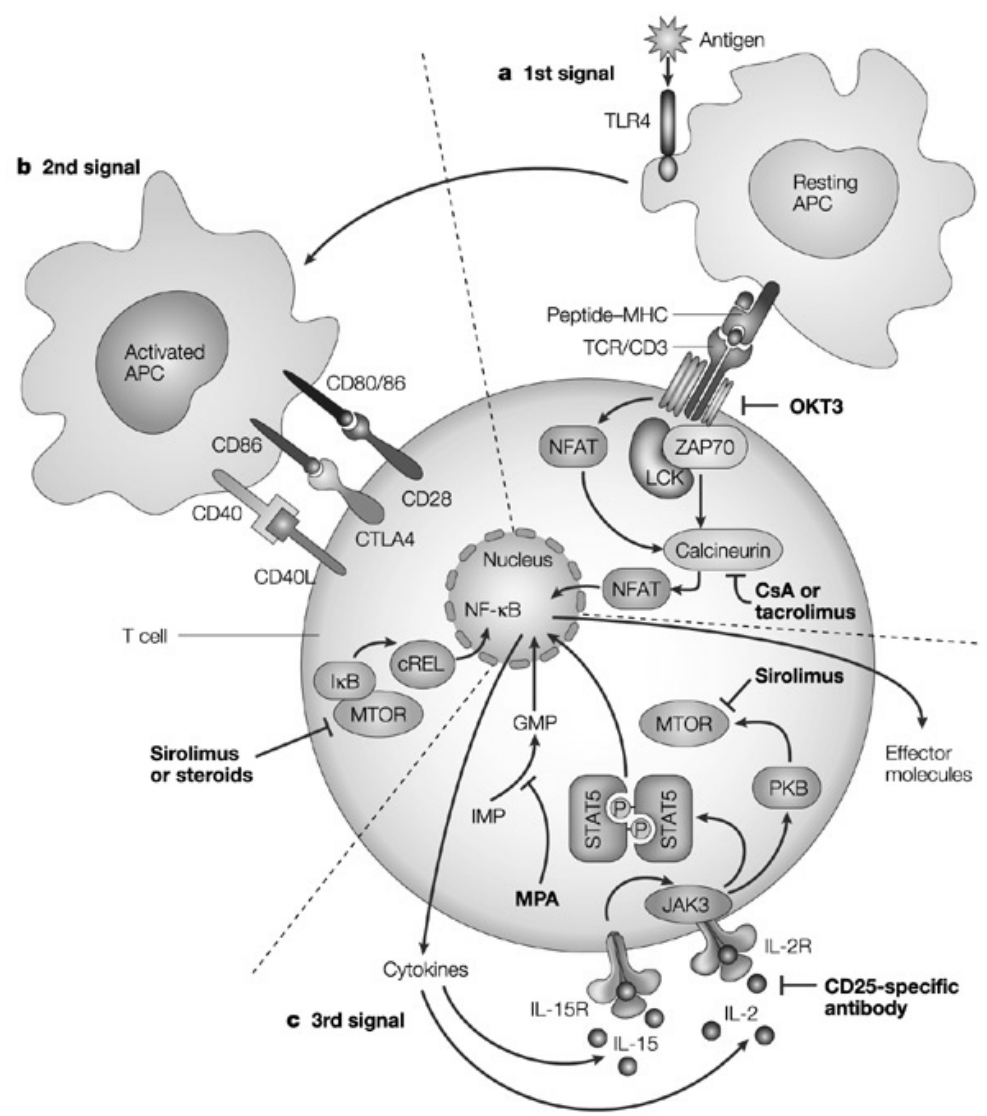

Nature Reviews | Immunology

Figure 1.1 Sites of intervention for immunosuppressive drugs. The calcineurin inhibitors cyclosporine and/or tacrolimus inhibit the phosphatase calcineurin. CD25-specific monoclonal antibodies disrupt the binding interleukin-2 (IL-2) to its receptor; sirolimus acts on cytokine-signal transduction (signal 3); and mycophenolic acid (MPA) on guanosine-base synthesis (S phase). The monoclonal antibody OKT3 binds the T-cell receptor, resulting in T-cell depletion. APC, antigen-presenting cell; CTLA4, cytotoxic T lymphocyte antigen 4; GMP, guanosine monophosphate; I $\mathrm{k} B$, inhibitory $\kappa \mathrm{B}$; IMP, inosine monophosphate; JAK3, Janus kinase 3; L, ligand; MTOR, mammalian target of rapamycin; NFAT, nuclear factor of activated T-cells; NF-kB, nuclear factor-kB; PKB, protein kinase B; R, receptor; STAT5, signal transducer and activator of transcription 5; TCR, T-cell receptor; TLR4, Toll-like receptor 4; ZAP70, zeta-chain-associated protein 70 . Adapted by permission from Macmillan Publishers Ltd: Nature Immunology Reviews (Kahan BD. Nat Rev. Imm 3, 831-838), copyright (2003). 


\section{Tacrolimus and cyclosporine}

Despite structural differences, tacrolimus and cyclosporine share a similar cellular mechanism of action, though tacrolimus is 100 times more potent than cyclosporine in vitro in inhibiting T-cell proliferative responses, including mixed lymphocyte reactivity and cytotoxic T-cell generation ${ }^{11}$. After entry into the cell, both agents bind to their respective cytosolic immunophilins: cyclosporine to cyclophilin and tacrolimus to the FK506-binding protein (FKBP-12 and FKBP-52). The drug-immunophilin complex binds to and inhibits the activity of the calcineurin, a calcium/calmodulin-dependent protein phosphatase that is expressed in all mammalian tissues ${ }^{12,13}$. As a result, the complex interrupts the calcium-dependent signal transduction pathway in T-cells ${ }^{14,15}$. Inhibition of calcineurin by cyclosporine or tacrolimus leads to interference with the nuclear translocation of various nuclear factors such as the cytosolic subunit of the nuclear factor of activated T-cells (NF-AT) which are involved in the transcription of cytokine genes. Moreover, inhibition of calcineurin also antagonizes the interaction of another transcription factor, cyclic adenosinemonophosphate (c-AMP) response element-binding protein (CREB), with its DNA-binding site CRE, inhibiting c-AMP-directed transcriptional events ${ }^{16,17}$. As a result, the transcription of early $\mathrm{T}$-cell activation genes is suppressed, affecting the production of many cytokines, namely IL-2, IL-3, IL-4, TNF- $\alpha$, interferon- $\gamma, \mathrm{GM}-\mathrm{CSF}$, and the ligand of $\mathrm{CD} 40^{18,19}$. In addition, the drugimmunophilin complex has recently been recognized as blocking the calcineurin-independent jun $\mathrm{N}$-terminal kinase (JNK) and p38 signalling pathways in the activation of T-cells ${ }^{20,21}$. JNK and p38 are subgroups of protein kinases belonging to a super-family of mitogen-activated protein kinases (MAPK). A cascade of MAPK is activated after activation of T-cell receptor in the presence of the CD28 co-stimulatory receptor. Cooperative activation of JNK and p38 in conjunction with ERK (another subgroup of MAPK) leads to activation of transcription factors like activator-protein-1 (AP-1 $)^{18}$.

\section{Differences between tacrolimus and cyclosporine in mode of action and side effects}

Although both tacrolimus and cyclosporine inhibit the enzyme calcineurin and, subsequently, IL-2 transcription, the greater immunosuppressive efficacy of tacrolimus on molar base, as discussed in this introduction, suggests that it has additional immunomodulating properties over cyclosporine that favor graft acceptance. Moreover, several molecular differences have been documented in experimental studies, animal studies and studies in various organ 
transplantations that may provide additional explanation for the differences in efficacy as well as in safety that have been observed in clinical practice (Table 1.1). The major side effects of tacrolimus and cyclosporine are shown in Table 1.2.

Table 1.1 Mechanistic differences between tacrolimus and cyclosporine.

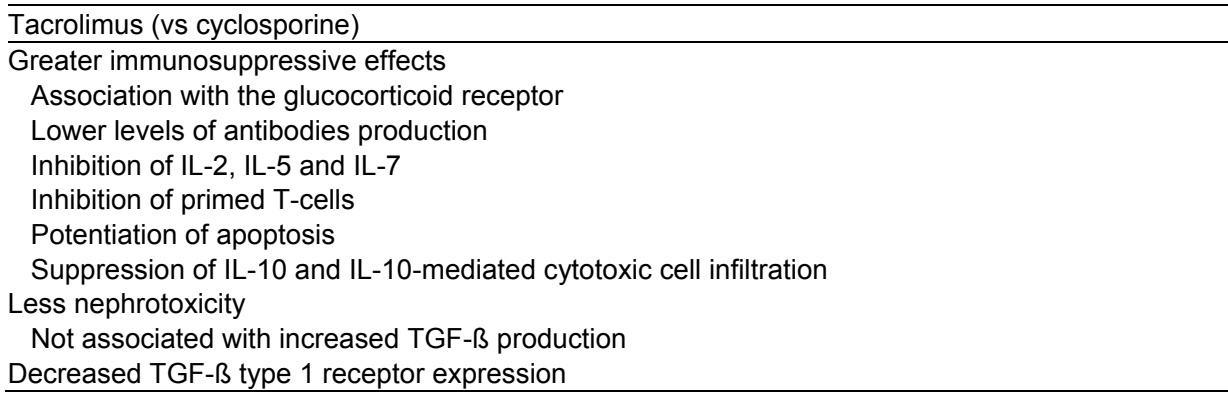

Table 1.2 Major side effects of the calcineurin inhibitors cyclosporine and tacrolimus.

\begin{tabular}{lcc}
\hline Side effects & Tacrolimus & Cyclosporine \\
\hline Nephrotoxicity & $\uparrow$ & $\uparrow \uparrow$ \\
Hypertension & $\uparrow$ & $\uparrow \uparrow$ \\
Post-transplant diabetes mellitus & $\uparrow \uparrow$ & $\uparrow$ \\
Hyperlipidemia & - & $\uparrow \uparrow$ \\
Neurotoxicity & $\uparrow \uparrow$ & $\uparrow$ \\
Hirsutism & - & $\uparrow \uparrow$ \\
Gingival hyperplasia & - & $\uparrow \uparrow$ \\
\hline
\end{tabular}

$\uparrow \uparrow$ large increase, $\uparrow$ small increase, - no increase

In contrast to cyclosporine-binding protein, FKBP-52 is associated with the glucocorticoid receptor complex. Usually the glucocorticoid receptor is released from this complex by the binding of steroids. The released receptor then migrates to the nucleus, where it binds to the glucocorticoid response elements (GRE) in the regulatory regions of genes or modulates the binding of other transcription factors, such as AP-1, and the signal transducers and activators of transcription (STAT) factors. Moreover, the released glucocorticoid receptor inhibits other transcription factors, like nuclear factor kappa-B (NF-kB). AP-1, STAT, and NF-kB all play a role in the regulation of genes involved in the immune response. Binding of tacrolimus to FKBP-52 may alter the affinity of the glucocorticoid receptor for steroids. This may release the receptor from the complex and create a steroid mimetic effect which may explain the steroid sparing effect of tacrolimus compared to cyclosporine ${ }^{22}$. 
Due to the blockade of cytokine production by T-cells, proliferation of B-cells and production of antibodies are also inhibited ${ }^{23}$. There is more inhibition of antibody production by tacrolimus than by cyclosporine ${ }^{24}$. Tacrolimus also has an effect on cytokine formation induced by IL-2. It suppresses the production of IL-5 induced by IL-2 stimulation of the IL-2 receptor ${ }^{25}$. In contrast to cyclosporine which only inhibits naïve T-cells, tacrolimus was found to inhibit both native T-cells and primed T-cells in clinically relevant concentrations ${ }^{26}$. Tacrolimus was able to enhance apoptosis in antigen-stimulated T-cells while cyclosporine had no effect ${ }^{27}$. Tacrolimus potentiates T-cell apoptosis induced by steroids ${ }^{28}$. It also inhibits the migration of activated lymphocytes and the production of chemotactic factors by these cells ${ }^{29}$. In contrast to cyclosporine, tacrolimus appears to suppress intragraft IL-10 production and subsequent local infiltration of cytotoxic T-cells and natural killer cells by decreasing the release of such cytotoxic factors as granzyme B and perforin- $1^{30}$. All these findings may explain the observation that tacrolimus can reverse steroidresistant rejections in patients receiving cyclosporine ${ }^{31,32}$.

Another mechanism among the immunosuppressive properties of cyclosporine, but not tacrolimus, is mediated by its augmentation of the production of TGF- $\beta^{33-35}$. In addition to its immunosuppressive properties, TGF- $\beta$ can induce fibrosis formation, leading to chronic allograft dysfunction. FKBP-12 binds to the TGF- $\beta$ type 1 receptor ${ }^{36,37}$. It acts as an anchor of calcineurin to the receptor. The complex of FKBP-12 and calcineurin prevents the receptor from being activated. Tacrolimus, which binds to FKBP-12 and inactivates calcineurin, has appeared to exhibit growth inhibition mediated by TGF- $\beta^{37}$. The downstream blockade of calcineurin and subsequent gene transcription is important for interruption of the TGF- $\beta$ effects. This may be essential in the aspect of development of renal fibrosis. On the other hand, cyclosporine induces the expression of type 1 TGF- $\beta$ receptors ${ }^{38}$. In fact, tacrolimus has been shown to have less fibrogenic potential than cyclosporine ${ }^{39}$.

\section{Interleukin-2 receptor antagonist}

The IL-2 receptor antagonists basiliximab and daclizumab have become widely adopted since their introduction in the mid-90s. Initially, IL-2 receptor antagonists were administered only as adjunctive immunosuppression within full-exposure CNI-based regimens. Nowadays, clinicians have increasingly investigated the use of IL-2 receptor antagonists in other protocols including steroid-sparing and CNI-sparing regimens. IL-2 is the messenger for many parts of the acute rejection process. For messages to be transmitted from cell to cell, IL-2 must bind to the IL-2 receptor on the receiving cell. The receptor is expressed only on activated T-cells and consists of three transmembrane 
protein chains: $\alpha(C D 25), \beta(C D 122)$, and $\gamma(C D 132)$. Also known as the CD25 antigen, IL-2 receptor $\alpha$ must associate with the ß-subunit to form the IL-2 binding site. Binding of IL-2 with the receptor transduces a signal across the cell membrane and triggers $\mathrm{T}$ lymphocytes to undergo clonal expansion. Engineered antibody products directed at this receptor are designed to block the activation of antigen-specific $T$ lymphocytes selectively by binding the $\alpha$-subunit and inhibiting formation of the complete binding site, therefore inhibiting binding of IL-2 and transduction of the signal ${ }^{40}$.

Daclizumab was the first IL-2 receptor antagonist approved by the Food and Drug Administration (FDA) in December 1997. It is a modified human $\operatorname{lgG}_{1}$ monoclonal antibody consisting of $90 \%$ human and $10 \%$ murine amino acid sequences. The murine sequences are the complementarity-determining regions to CD25 and are fused with human constant and variable regions of the IgG molecule. Basiliximab was approved by the FDA in May 1998 for the prevention of kidney allograft rejection in patients receiving concomitant cyclosporine and steroids. Basiliximab is a monoclonal antibody produced by chimerization of a CD25-specific murine antibody with the constant regions of human $\operatorname{lgG}_{1}$ heavy chain and kappa light chain. This chimerized monoclonal antibody is obtained from a mouse myeloma cell line that has been engineered to express plasmids that contain the human heavy chain- and light chainconstant regions and mouse heavy chain- and light chain-variable regions.

\section{Pharmacokinetics of tacrolimus}

Oral tacrolimus, in a solid dispersible formulation developed for clinical use, is rapidly absorbed throughout the whole gut. However, the absorption shows a large inter- and intra-individual variability. The oral bioavailability is roughly 25 percent mainly as a result of extensive metabolism by enzymes in the bowel mucosa (Figure 1.2). The mean tacrolimus exposure after a single $5 \mathrm{mg}$ oral dose in healthy Latin American and African American subjects was 18 and 39 percent less, respectively, than in Caucasians ${ }^{41}$, suggesting a racial difference in pharmacokinetics of tacrolimus. The total drug exposure throughout the period from one dose until the next is the area under the concentration-time curve $(A \cup C)$. Time to reach plasma peak concentrations $\left(C_{\max }\right)$ usually occur within two hours. However, tacrolimus absorption is decreased if administered immediately after a standard American breakfast rich in fat content ${ }^{42}$. After ingestion of tacrolimus 0.25 to 1.5 hours after such meal, $\mathrm{C}_{\max }$ decreased by $50-75 \%$ and the AUC decreased by $25-40 \%$ relative to fasting condition. Therefore, in order to maximize absorption, all patients were advised not to eat or drink anything from two hours before until one hour after ingestion of tacrolimus. However, in another study by Christiaans et al., there was only 
minor difference in tacrolimus AUC, no matter whether the drug is taken fasting or together with a standardized continental breakfast ${ }^{43}$.

\section{Absorption process}

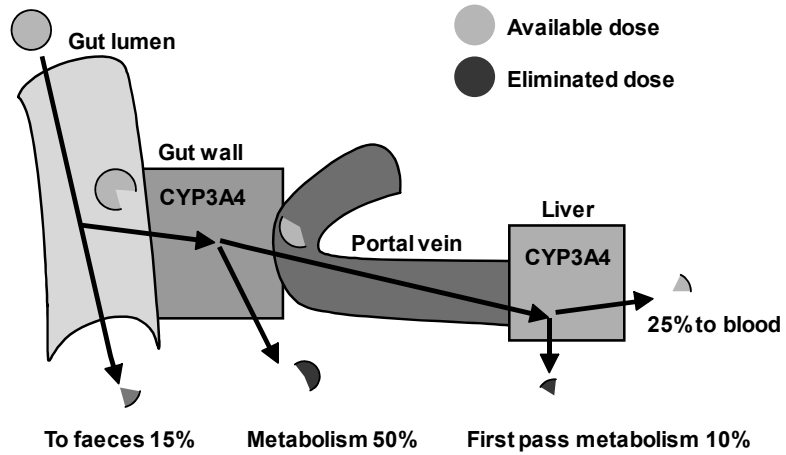

Figure 1.2 Pharmacokinetics of tacrolimus after absorption.

Tacrolimus is lipophilic and can undergo extensive body distribution. In the blood, most of the absorbed drug is taken up by erythrocytes. In the plasma, it binds to proteins. Tacrolimus accumulates mainly in lung, spleen, heart, kidney, and pancreas.

Tacrolimus is extensively metabolized by the cytochrome P450 3A in the liver $(>99 \%)$. There is also some metabolism in the gut mucosa via intestinal cytochrome P450. Tacrolimus is metabolized to at least 15 metabolites, the predominant being 13-O-demethyl-tacrolimus. 13-O-demethyl-tacrolimus has an immunosuppressive activity which is one-tenth of that of the parent compound. The minor metabolite 31-O-demethyl-tacrolimus may possess equal immunosuppressive potency to the parent drug ${ }^{44-46}$.

Tacrolimus metabolites are mainly (>90\%) biliary eliminated with around $5 \%$ being excreted in the urine. The elimination half-life is nine hours but liver dysfunction can prolong its half-life ${ }^{47-50}$. Drug levels then fall until they are at the lowest, or trough, level $\left(\mathrm{C}_{0}\right)$ immediately before the next dose.

\section{Drug interactions}

Since tacrolimus is metabolized by hepatic cytochrome P450 3A isoenzymes, a variety of important drug interactions with drugs that either affect or are metabolized by these enzymes can occur. ${ }^{46}$ Table 1.3 shows inhibitors and 
inducers of cytochrome P450 3A that have been reported to interact with tacrolimus metabolism.

Table 1.3 Potential inhibitors and inducers of cytochrome P450 3A isoenzymes which can interfere tacrolimus metabolism.

\begin{tabular}{lc}
\hline CYP3A inhibitors & Increase tacrolimus levels \\
\hline Bromocriptine & Gestodene \\
Cimetidine & Itraconazole \\
Ciprofloxacin & Ketoconazole \\
Cisapride & Metoclopramide \\
Clarithromycin & Grapefruit juice \\
Clotrimazole & Nicardipine \\
Danazol & Nifedipine \\
Diltiazem & Protease inhibitors \\
Erythromycin & Troleandromycin \\
Fluconazole & Verapamil \\
\hline CYP3A inducers & Decrease tacrolimus level \\
\hline Barbiturates & Rifabutin \\
Carbamazepine & Rifampicin \\
Phenobarbital & St John's wort \\
Phenytoin & \\
\hline
\end{tabular}

\section{Therapeutic drug monitoring}

The main concern regarding the immunosuppressive drugs is their narrow therapeutic indices. Subtherapeutic blood concentrations are associated with an increased risk of acute rejection while overdosing may increase the risk of over-immunosuppression, with subsequent increased risk of infection and malignancies. Additionally there are also numerous drug-specific adverse effects. The large inter-patient variability in oral bioavailability of tacrolimus and cyclosporine, the narrow therapeutic window, and drug interaction mean that the dosage needs to be individualized. As a result, therapeutic drug monitoring (TDM) is essential for dosage guiding. The most exact way to monitor drug exposure is by making pharmacokinetic profiles: from immediately before one drug dose is ingested until immediately before the next drug dose is ingested, drug levels are measured at several time points (e.g. 10-12 times). From the curve thus obtained, the total drug exposure $\left(\mathrm{AUC}_{0-12}\right), \mathrm{C}_{0}, \mathrm{C}_{\max }$, the time when the maximum concentration is reached $\left(t_{\max }\right)$, and the half life $\left(t_{1 / 2}\right)$ can be calculated (Figure 1.3). Because obtaining complete pharmacokinetic profiles for every patient is not feasible in clinical practice, a parameter strongly correlating with $\mathrm{AUC}_{0-12}$ was sought.

Many centres rely on measurements of tacrolimus $\mathrm{C}_{0}$ because it is generally thought that they can reflect $\mathrm{AUC}_{0-12}{ }^{51}$. Indeed there are different 
pharmacokinetics studies showing good correlation between $\mathrm{C}_{0}$ and $\mathrm{AUC}_{0-12}{ }^{52-55}$. In the US and European trials, whole blood tacrolimus and cyclosporine trough levels were used for drug monitoring and dosage adjustment ${ }^{56-59}$. However, there have been different studies yielding different results. In a pharmacokinetic study reported by our group ${ }^{60}$, it was found that $\mathrm{C}_{0}$ did not have a significant correlation with $\mathrm{AUC}_{0-12}$ in Chinese renal transplant recipients $\left(R^{2}=0.12 ; P=0.17\right)$. On the other hand, abbreviated AUC obtained by two-time point regression equation using 2-hour $\left(\mathrm{C}_{2}\right)$ and 4-hour $\left(\mathrm{C}_{4}\right)$ tacrolimus concentrations obtained an $\mathrm{R}^{2}$ of 0.93 . In a study of 40 liver transplant patients, Macchi-Andanson et al. ${ }^{61}$ investigated the ability of Bayesian fitting procedures to predict $\mathrm{C}_{0}$ concentrations. They found that $\mathrm{C}_{0}$ provided the least information about the dynamic behaviour of the drug in the patient and they suggested two samples a day could provide increased information about drug absorption, distribution and elimination. It was agreed by Stolk et $a l^{62}$ who studied eight stable renal transplant patients for the prediction of $\mathrm{AUC}_{0-12}$. By using multiple stepwise regression analysis, they found that the predictive power of $C_{5}$ and $C_{2}\left(R^{2}=0.983\right)$ were much higher than $\mathrm{C}_{0}\left(\mathrm{R}^{2}=0.642\right)$. Recently, Scholten et al. reported that the $95 \%$ prediction interval was reduced by $50 \%$, when a two-point sampling strategy was used consisting of a $\mathrm{C}_{0}$ level and a second sample obtained between 2-4 hours post dose $^{63}$. As a result, limited sampling strategy and abbreviated AUC method was used for dose optimization in our centre.

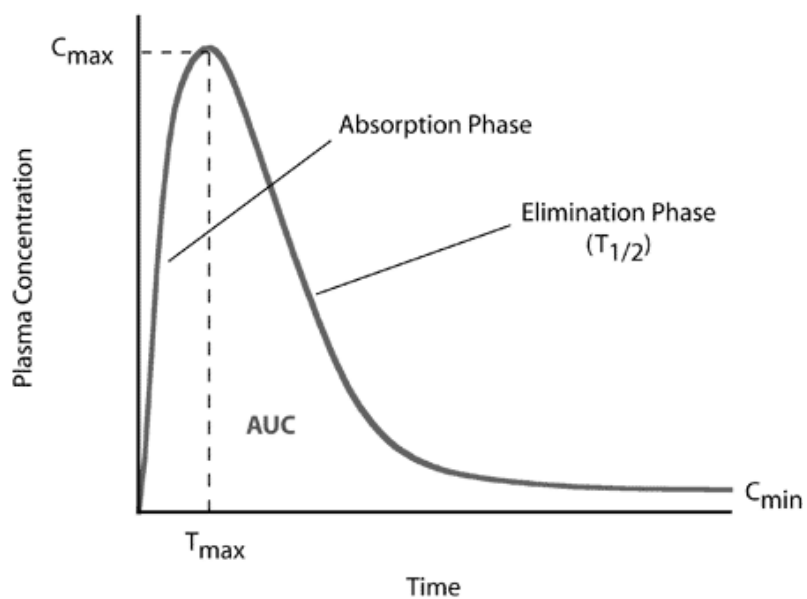

Figure 1.3 Pharmacokinetic profile of tacrolimus: AUC as parameter for total drug exposure, and the main pharmacokinetic description parameters. 
Cyclosporine $\mathrm{C}_{0}$ is also not a sensitive indicator of total drug exposure and subsequent clinical events ${ }^{64}$. As a result, the optimal way for cyclosporine monitoring has been reviewed in recent years. Investigators have advocated using time point sampling to estimate $\mathrm{AUC}_{0-12}{ }^{65}$. Each clinician has a choice of several equations, involving the use of two or three time-points, which produce results with similar accuracy and precision ${ }^{66,67}$. Meier-Kriesche et al. found that limited sampling strategies using a 1.5-hour sample may predict $\mathrm{AUC}_{0-12}$ more accurately than those using a 2-hour sample ${ }^{67}$. In Hong Kong, we used the two-time point regression equation obtained from the Chinese population to estimate the $\mathrm{AUC}_{0-12}{ }^{68}$.

\section{Pharmacogenetics and renal transplantation}

At present, TDM is used to address the issue of inter-individual variation in pharmacokinetics of CNIs. However, many patients experience a significant delay in achieving target blood concentrations, significantly increasing the risk of acute graft rejection ${ }^{69}$. The narrow therapeutic index of these agents prevents use of a strategy based on a higher initial dose for all patients. There is a clear unmet need for a strategy to allow individualized immunosuppressive drug dosing in the period immediately following transplantation.

Prior knowledge of genetic polymorphisms, combined with critical patient data and concomitant medications may aid initial dosing, allowing early attainment of therapeutic blood concentrations, potentially reducing adverse events related to over- or underdosing. In the general population, it is estimated that genetics accounts for $20 \%$ to $95 \%$ of the variability in drug disposition and effects ${ }^{70}$. Other non-genetic factors, such as organ function, drug interactions, and the nature of the disease will also influence the effects of medication. The recent identification of genetic polymorphisms in drug-metabolizing enzymes and drug transporters led to the hypothesis that genetic factors may be implicated in the inter-individual variability of the pharmacokinetic or pharmacodynamic characteristics of immunosuppressive drugs, major side effects, and immunologic risks. The promising role of pharmacogenetics and pharmacogenomics in the effort to elucidate the inherited basis of differences between individual responses to drugs lies in the potential ability to identify the right drug and dose for each patient. By definition, pharmacogenetics deals with the role of few candidate genes, whereas pharmacogenomics uses a genome-wide approach for polymorphisms determination. After administration, the drug is absorbed and distributed to its site of action, where it interacts with targets such as receptors and enzymes, undergoes metabolism, and is then excreted. Each of these processes might involve clinically significant genetic variations. 
Most of the pharmacogenetic traits first identified were discovered by phenotypic analysis detecting a bi- or trimodality of an enzymatic activity ${ }^{71}$. Azathioprine, metabolized in part by $\mathcal{S}$-methylation catalyzed by the enzyme thiopurine methyltransferase (TPMT), is an example. Large inter-individual differences were reported in TPMT activity, which was found to be inherited in an autosomal codominant fashion ${ }^{72}$. When individuals with low or undetectable TPMT activity received standard doses of azathioprine, they had elevated concentrations of the active metabolites 6-thioguanine nucleotides and druginduced myelosuppression. On the other hand, azathioprine efficacy will be reduced in patients with very high levels of TPMT activity which can be attributed to its rapid metabolization ${ }^{73,74}$. TPMT activity correlates with both short- and long-term results after renal transplantation ${ }^{75}$. Subsequently, these variations in TPMT activity were attributed to genetic polymorphisms within the TPMT gene. TPMT ${ }^{*} 3 \mathrm{~A}$, the most common variant allele responsible for low TPMT activity in whites, encodes a protein with two single nucleotide polymorphisms (SNP), G460A in exon 7 and A719G in exon 10, leading to modifications in the amino acid sequence. The phenotypic test for TPMT activity determination in red blood cells and, subsequently, DNA-based tests, were among the first pharmacogenetic tests to be used in clinical practice.

Cytochrome P450 (CYP) proteins can be classified into families and subfamilies on the basis of amino acid sequence similarities. Members of the CYP3A subfamily are implicated in the metabolism of structurally diverse endobiotics, drugs, and protoxic or procarcinogenic molecules. Substantial inter-individual differences in CYP3A expression contribute greatly to variations in the oral bioavailability and systemic clearance of CYP3A substrates ${ }^{76}$. Human CYP3A activities reflect the heterogeneous expression of at least three CYP3A members, CYP3A4, CYP3A5, and CYP3A7, which are adjacent to each other on chromosome band 7q21. CYP3A7 is normally only expressed in fetal liver. CYP3A4 and CYP3A5 have been identified as the major enzymes responsible for the disposition of tacrolimus ${ }^{77}$. Although a number of CYP3A4 polymorphisms have been identified, they are rare and do not contribute significantly to CYP3A4 expression variability. On the other hand, analysis revealed that only individuals with at least one CYP3A5*1 allele (A at position 6986) produce high levels of full-length CYP3A5 mRNA and express CYP3A5, which then accounts for at least $50 \%$ of the total CYP3A content ${ }^{78}$. Those with the CYP3A5*3 allele ( $G$ at position 6986 ) display sequence variability in intron 3 that creates a cryptic splice site and encodes an aberrantly spliced mRNA with a premature stop codon, leading to the absence of protein expression.

Tacrolimus is also a substrate of P-gp which is encoded by the human ABCB1 gene (also called multidrug resistance-1 [MDR1]). One of the main functions of $\mathrm{P}$-gp is to ensure the energy-dependent cellular efflux of substrates. The P-gp 
expression in the intestinal wall and in the proximal tubular cells of the kidneys suggests that it may have a role in the absorption and excretion of xenobiotics. In the gut, alteration in its expression, function, or both raises the absorption of its substrates ${ }^{79}$. Various SNP have been identified within the ABCB1 gene over the recent few years ${ }^{80}$. An SNP, located in exon 26 (exon $263435 \mathrm{C}>\mathrm{T}$ ), was associated with variations in the intestinal expression and function of P-gp. However, this SNP is a silent polymorphism that does not result in any amino acid changes. It was suggested that it may be in linkage disequilibrium with other functional polymorphisms within the ABCB1 gene. A co-segregation of exon 26 3435T with the T allele of the non-synonymous exon 21 SNP (exon 21 $2677 \mathrm{G}>\mathrm{T}$ ), resulting in an A893S amino acid change, and also with the $T$ allele of the synonymous exon 12 SNP (exon 12 1236C>T) was reported. This disequilibrium led to haplotype analysis of the $A B C B 1$ gene, to identify the links between the genomic variations represented by each haplotype on ABCB1 function, because this approach takes into account the combination of SNP present in an allele ${ }^{80}$ and might be more predictive of changes in response to drugs than SNP-based approaches.

\section{Application of dried blood spot in renal transplantation}

Dried blood spot (DBS) is very common for screening metabolic disorders in newborns ${ }^{81}$. Moreover, its use in TDM has been reported for several drugs such as antimalarials and antiretrovirals ${ }^{82,83}$. There are several possible advantages of DBS over venous sampling. First of all, blood sampling in centers may involve a long journey and absence from work duty. DBS can be performed easily at home by patients and the sampling papers containing the DBS can be mailed back to centers using envelopes. Moreover, use of DBS can relieve the burden of blood sampling of clinical staff. Use of DBS in cyclosporine monitoring in solid organ transplantation has been explored ${ }^{84-87}$. Recently, a method for measurement of tacrolimus level, based on DBS and high-performance liquid chromatography tandem-mass spectrometry (HPLC-MS), has been developed ${ }^{88,89}$.

Most of the published studies correlate the clinical outcomes with tacrolimus level using immunoassay-based methods. It should be realized that these methods measure both the parent drug and several of its metabolites. Enzymelinked immunosorbent assay (ELISA), though reliable in routine use, is very time-consuming, and the results are not available for at least 24 hours. Two other methods are more suitable for routine quantification of tacrolimus in whole blood. The first is the manual immunoassay Incstar Proc-Trac (Diasorin Inc, Italy), modified in 1996 (Incstar Proc-Trac II, Diasorin Inc), with an analyzer time of 3-4 hours. The very high sensitivity $(0.5 \mathrm{ng} / \mathrm{ml})$ makes it useful in 
special cases ${ }^{90}$. The second method is a semiautomatic, microparticulate enzyme immunoassay (MEIA, Abbott, USA). The initial version had a detection limit of $5 \mathrm{ng} / \mathrm{ml}$, thus lacking the sensitivity required for monitoring patients maintained on low levels of tacrolimus. In 1997, the second generation assay (TAC II, IMx analyzer, Abbott), with a sensitivity of $1.5 \mathrm{ng} / \mathrm{ml}$, became available. With this method, results can be obtained in less than an hour ${ }^{90}$. This is the assay commonly used for testing large patient populations and used in hospitals for clinical practice. Nowadays HPLC-MS is the most accurate, sensitive and specific assay for TDM of tacrolimus, with a detection limit of $0.2 \mathrm{ng} / \mathrm{ml}$. It can separately quantify the parent compound and its metabolites ${ }^{90}$. Clinical outcome studies revealed that tacrolimus monitoring with HPLC-MS is safe and effective ${ }^{91,92}$.

\section{Preservation of renal function}

The most important immunological reason for graft failure in the initial period after transplantation is acute rejection. Acute rejections are confirmed by performing renal biopsy. In the last decennium, consensus was reached to grade the severity of a rejection on histological grounds ${ }^{93}$. The most important risk factors for acute rejections are mismatches in the human leukocyte antigen (HLA) system, especially HLA-DR mismatches ${ }^{94-96}$. Blacks and young age are also associated with increased risk of rejection ${ }^{95,97-101}$. Sensitized patients with antibodies to HLA antigens, as reflected in the percentage of panel-reactive antibodies (PRA), also have an enhanced risk of rejection ${ }^{95,102-104}$. Patients may become sensitized by previous blood transfusions, pregnancies, or organ transplantations.

After the initial six months, a major cause of graft dysfunction is chronic allograft nephropathy (CAN). CAN is characterized by a gradual decrease in transplant function and development of hypertension and proteinuria ${ }^{105,106}$. The current criteria for CAN are given by the Banff Working Classification of Renal Allograft Pathology, which originated in a meeting held in Banff, Canada in $1991^{107}$ The Banff 97 working classification of renal allograft pathology is followed worldwide ${ }^{93}$. Histology shows vasculopathy: initimal thickening, smooth muscle cell proliferation, and multi-layering of peri-tubular capillary basement membranes, glomerulopathy, tubular atrophy (TA), and interstitial fibrosis $(\mathrm{IF})^{108}$. Renal function and proteinuria one year after transplantation are important surrogate markers for the development of CAN and graft survival $^{109-113}$. In the last decennium, it became clear that several factors, including immunologic and non-immunologic factors are involved in the

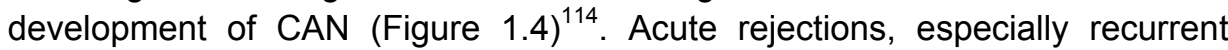
acute rejections ${ }^{115}$ and vascular rejections ${ }^{116}$, are known risk factors for CAN. 
Moreover, donor and transplant characteristics predispose to CAN. Graft survival is related to the number of nephrons transplanted ${ }^{117,118}$. Thus kidneys from marginal donors usually perform less well than kidneys from optimal donors. ${ }^{119,120}$ Ischemia-reperfusion damage is also reflected in graft survival. The longer the period of ischemia, the worse the graft survival will be ${ }^{119,121,122}$. Hyperfiltration, relative overflow in remaining nephrons, is an important factor in the development of $\mathrm{CAN}^{111}$. Cardiovascular risk factors such as hypertension $^{123,124}$, hyperlipidemia ${ }^{125-127}$ and diabetes mellitus ${ }^{19,128}$ all contribute to the development of CAN. Finally nephrotoxicity by both CNIs, cyclosporine and tacrolimus, contribute to CAN as well.

\section{Chronic allograft nephropathy}

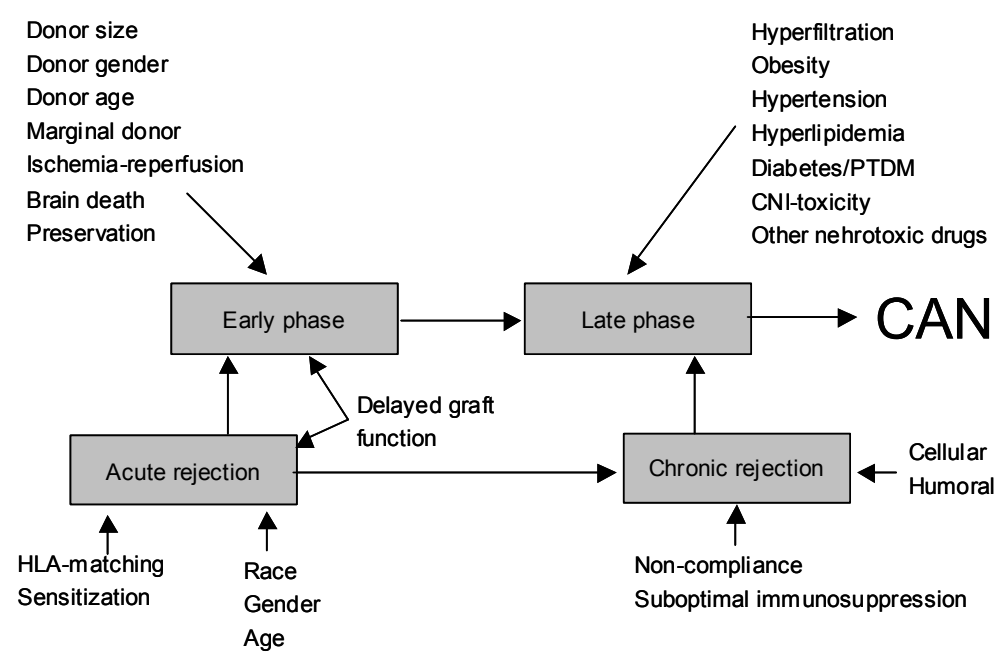

Figure 1.4 Risk factors for the development of chronic allograft nephropathy.

Both CNIs differ considerably in nephrotoxicity (Table 1.4). In healthy volunteers, glomerular filtration rate, renal plasma flow and renal blood flow were decreased while renal vascular resistance, blood pressure and serum creatinine were increased significantly during Neoral cyclosporine treatment. On the other hand, all these parameters remained unchanged while using tacrolimus ${ }^{129}$. In renal transplant recipients, the effects of tacrolimus and Neoral cyclosporine on renal hemodynamics were different. After a dose of Neoral cyclosporine, but not after tacrolimus, a phasic hypoperfusion of variable severity within small-to-medium-sized intrarenal arteries was induced soon after dosing ${ }^{130}$. Therefore renal function is expected to be better with 
tacrolimus-based therapy. This difference in functional nephrotoxicity might contribute to structural lesions found in chronic CNI nephrotoxicity ${ }^{129}$. Van Duijnhoven et al. analyzed uncomplicated transplantations from living donors and showed that the creatinine clearance achieved at one year posttransplantation in tacrolimus-treated recipients was comparable to the remaining creatinine clearance of the donors ${ }^{131}$. Moreover, in a randomized trial comparing tacrolimus and mycophenolate mofetil (MMF) versus rapamycin and MMF, there was no difference in GFR between tacrolimus-based and CNIfree arms up to two years post-transplantation ${ }^{132}$.

The difference in nephrotoxic properties of both CNIs was also shown in conversion studies. Patients with chronic transplant dysfunction had improved creatinine after conversion from Neoral cyclosporine to tacrolimus ${ }^{133-137}$. Moreover, some case reports also showed disappearance of nephrotoxicity in histology after conversion ${ }^{138}$. Jurewicz observed a better GFR from three months up to five years post-transplantation in the tacrolimus-treated patients compared to the Neoral cyclosporine-treated patients. He also showed that the slope of the GFR in Neoral cyclosporine-treated patients significantly declined in contrast to the tacrolimus-treated patients ${ }^{139}$.

Table 1.4 Evidence that tacrolimus has a low nephrotoxic potential.

\begin{tabular}{|c|c|}
\hline Evidence & Reference \\
\hline No effect on renal hemodynamics in healthy volunteers & Klein $^{129}$ \\
\hline $\begin{array}{l}\text { Hypoperfusion within small to medium-sized intrarenal arteries in renal grafts } \\
\text { shortly after cyclosporine microemulsion but absent in tacrolimus }\end{array}$ & Nankivell ${ }^{130}$ \\
\hline $\begin{array}{l}\text { Comparable creatinine clearance between recipient and living donor after one } \\
\text { year }\end{array}$ & Duijnhoven $^{131}$ \\
\hline Stable creatinine clearance after first year post-transplantation & Jurewicz ${ }^{139}$ \\
\hline Improvement in renal function by conversion from cyclosporine to tacrolimus & $\operatorname{Artz}^{133}$ \\
\hline \multirow[t]{3}{*}{ Rescue of cyclosporine toxicity or CAN by conversion to tacrolimus } & Cantarovitch $^{134}$ \\
\hline & Margreiter $^{135}$ \\
\hline & Hohage $^{136}$ Meier $^{137}$ \\
\hline $\begin{array}{l}\text { Tacrolimus+MMF+prednisolone produces similar GFR compared with CNI-fre } \\
\text { regimen using sirolimus+MMF+prednisolone }\end{array}$ & \\
\hline
\end{tabular}

\section{Post-transplant diabetes mellitus}

In the first year after transplantation, abnormal glucose metabolism, especially transient hyperglycemia, occur frequently. However, there was a lack of uniform definition. Depending on the definition, incidences of post-transplant diabetes mellitus (PTDM) of approximately $5-40 \%$ have been reported in patients after renal transplantation ${ }^{140-142}$. Some investigators only include those patients using insulin treatment for a period of at least 30 days ${ }^{56}$, while others also include patients taking oral glucose-lowering drugs (need for drug 
treatment). These definitions underreport the actual incidence of PTDM. Diagnosis should be made on the World Health Organization (WHO) or the American Diabetes Association (ADA) criteria in the maintenance phase without infection or rejection, and with stable defined dosages and levels of immunosuppressive agents.

Several risk factors for the occurrence of PTDM have been described. These include genetic factors, race, family history of diabetes, older age, high body mass index, hepatitis C virus positivity, and the use of CNIs and corticosteroids $^{56,57,142-145}$. In fact, PTDM is not a separate entity but just a sign of an underlying abnormal glucose metabolism that is uncovered by immunosuppression. Abnormal glucose metabolism is common in pretransplant patients. Only by using CNIs in combination with corticosteroids will more patients develop PTDM than with other agents in combination with steroids $^{146}$.

Steroids disturb glucose tolerance by enhancing insulin resistance ${ }^{147}$. They play a significant role in the development of PTDM ${ }^{148,149}$. Ten milligram of prednisolone can result in a $250 \%$ increased insulin demand for maintaining normoglycemia ${ }^{150}$. Withdrawal of steroids in cyclosporine-treated patients has been shown to reduce the incidence of PTDM and to improve glycemic control $^{151}$. Cyclosporine also has an effect on glucose metabolism. Renal transplant patients using cyclosporine and corticosteroids were seen to have a higher incidence of PTDM than patients treated with azathioprine and even higher dosages of steroids ${ }^{152}$. Reducing the dose of cyclosporine reversed the diabetes in the majority of affected patients ${ }^{152}$. Glucose tolerance also improved after conversion from cyclosporine to azathioprine ${ }^{153}$. In vitro experiments have shown that cyclosporine dose-dependently inhibited insulin secretion ${ }^{154,155}$. High-dose tacrolimus was shown to decrease insulin mRNA transcription and reduce insulin production in rats. When tacrolimus was stopped after two weeks, insulin production returned to normal. There are high levels of FKBP-52 in pancreatic beta-cells, which might account for the peculiar sensitivity of these cells to tacrolimus ${ }^{156}$. A study by van Duijnhoven et al. also showed that tacrolimus affects insulin release but does not affect insulin resistance $^{157}$. Cyclosporine and tacrolimus can both induce glucose intolerance, although the risk of developing PTDM appears to be higher in patients using tacrolimus, especially when combined with corticosteroids ${ }^{158}$. Low incidence of PTDM has been reported in tacrolimus-based regimens without corticosteroids ${ }^{137,159}$.

PTDM has been associated with a decreased quality of life and substantial morbidity resulting from an increased susceptibility to infections and most importantly, cardiovascular complications. Development of PTDM or impaired fasting glucose (IGF) after renal transplantation increases the risk of cardiac events, peripheral vascular disease, graft failure and death ${ }^{128,160,161}$. PTDM is 
associated with more than $60 \%$ increase in risk of graft failure and an almost a $90 \%$ increase in risk of death ${ }^{160}$. Less severe hyperglycemic abnormalities are also associated with increased cardiovascular risk. In renal transplant recipients, Cosio et al. have demonstrated that IFG $(5.6-6.9 \mathrm{mmol} / \mathrm{l})$ is associated with a significantly higher incidence of cardiac events and peripheral vascular disease compared to normoglycemic recipients ${ }^{162}$. In view of the high incidence of cardiovascular mortality and morbidity among renal transplant recipients, aggressive management of glucose metabolism abnormalities is essential.

\section{Metabolic syndrome}

Metabolic syndrome (MS) is a topic of considerable interest nowadays. It has been argued that the spectacular continuous increase in life expectancy and general health during the last decades may come to a halt or even be reversed by the ongoing epidemic of obesity ${ }^{163}$. MS is a cluster of interrelated common clinical disorders, including obesity, insulin resistance, glucose intolerance, hypertension and dyslipidemia. Obesity is considered the phenotypic hallmark of MS that contributes to insulin resistance, hyperinsulinemia, and dyslipidemia. Among the numerous definitions of MS (World Health Organization, European Group for the Study of Insulin Resistance, American Association of Clinical Endocrinologists, and International Diabetes Federation [IDF]), the one proposed by the National Cholesterol Education Program (NCEP) Expert Panel on Detection, Evaluation, and Treatment of High Blood Cholesterol in Adults (Adult Treatment Panel III [NCEP-ATPIII]) ${ }^{164}$ is most widely used. In this thesis, both NCEP-ATPIII and IDF were used (Table 1.5). The concept of MS was originally created to predict cardiovascular risk. It has been well recognized that MS is closely associated with atherosclerotic cardiovascular disease in the general population ${ }^{165}$. Given the link between cardiovascular and renal risks, it is not surprising that obesity and MS are related to renal malfunction ${ }^{166-169}$. A community-based population study demonstrated that established cardiovascular disease risk factors are associated with the development of new-onset kidney disease ${ }^{170}$. The reason why obesity increases the risk for end stage renal failure in the general population is the link between obesity and diabetes on one hand and with hypertension on the other hand ${ }^{171}$. Even when corrected for these two indirect mechanisms, the relation between obesity and chronic kidney disease persists ${ }^{172}$. The proposed mechanisms include increased glomerular filtration rate and renal blood flow, glomerulomegaly, podocyte damage, and even focal segmental glomerulosclerosis ${ }^{173-175}$. The increased risk of mortality and morbidity related to MS and its components occur not only in Caucasian, but also extend to Chinese population ${ }^{176}$. 
Table 1.5 Definition of metabolic syndrome according to NCEP-ATIII and IDF criteria ${ }^{164,185}$.

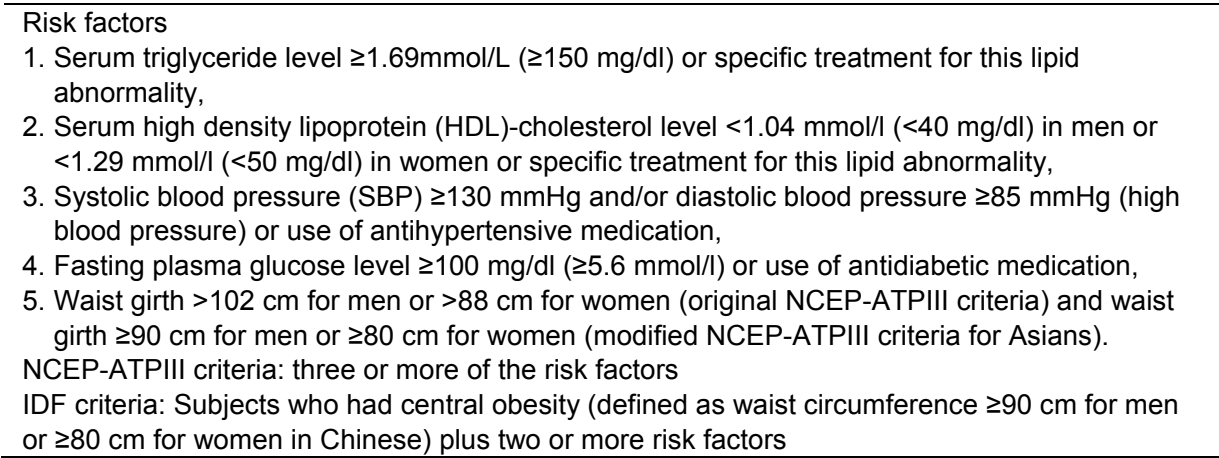

Recently it has been found that MS is also common in renal transplant recipients ${ }^{177}$. As in the general population, MS is associated with an increased risk of renal dysfunction and cardiovascular mortality in renal transplant recipients ${ }^{177-179}$. A number of factors, other than obesity, may contribute both to insulin resistance and modification of MS parameters in these patients. In early post-transplant period, use of high dose corticosteroids, together with CNIs are likely to play a major role in the development of $\mathrm{MS}^{180}$. By steroid-free transplantation, both the insulin resistance and chance of obesity might decrease, thereby reducing the incidence of MS. Previous studies showed that $\mathrm{HDL}$ cholesterol and diabetes were strong independent risk factors for atherosclerotic events after transplantation ${ }^{181,182}$. Factors contributing to MS are closely interconnected and define a very high-risk population for atherosclerotic events. MS is also associated with other cardiovascular risk factors such as low-grade inflammation, higher urine protein excretion, and progressive loss of renal function ${ }^{183,184}$. All together, clustering of both traditional and nontraditional risk factors in renal transplant recipients with MS contribute to the greater incidence of atherosclerotic events in this population. 


\section{Aim of the thesis}

The purpose of this thesis is to study the following

\section{Preservation of long-term renal graft function}

1. Whether there is any difference in maintaining renal graft function between tacrolimus- and Neoral cyclosporine-based immunosuppressive therapy in renal transplant recipients using paired kidney analysis. (Chapter 2)

2. Whether addition of IL-2 receptor antagonist can further improve acute rejection and renal function in tacrolimus-based primary Chinese renal transplant recipients. (Chapter 3 )

3. Use of tacrolimus and other risk factors associated with the development of glucose metabolism abnormalities in Chinese renal transplant recipients using ADA criteria. (Chapter 4)

4. Prevalence of metabolic syndrome in Chinese renal transplant recipients using NCEP-ATIII and IDF criteria. (Chapter 5)

\section{Therapeutic drug monitoring and pharmacogenetics in renal transplantation}

1. Influence of CYP $3 A$ and $A B C B 1$ gene polymorphisms in tacrolimus pharmacokinetics in Chinese renal transplant recipients. (Chapter 6)

2. Influence of CYP3A and ABCB1 gene polymorphisms in tacrolimus pharmacokinetics in early and late post renal transplant Caucasian patients. (Chapter 7)

3. Use of DBS and HPLC-MS in tacrolimus monitoring in renal transplant recipients. (Chapter 8 ) 


\section{Reference}

1. Starzl TE, Marchioro TL, Porter KA, Iwasaki Y, Cerilli GJ. The use of heterologous antilymphoid agents in canine renal and liver homotransplantation and in human renal homotransplantation. Surg Gynecol Obstet 1967;124:301-8.

2. Calne RY, Rolles K, White DJ, Thiru S, Evans DB, McMaster P, Dunn DC, Craddock GN, Henderson RG, Aziz S, Lewis P. Cyclosporin A initially as the only immmunosuppressant in 34 recipients of cadaveric organs: 32 kidneys, 2 pancreases, and 2 livers. Lancet 1979;2: 1033-6.

3. European Multicentre Trial Group. Cyclosporine in cadaveric renal transplantation: oneyear follow-up of a multicentre trial. Lancet 1983;2:986-9.

4. Hall BM, Tiller DJ, Hardie I, Mahony J, Mathew T, Thatcher G, Miach P, Thomson N, Sheil AG. Comparison of three immunosuppressive regimens in cadaveric renal transplantation: long-term cyclosporine, short-term cyclosporine followed by azathioprine and prednisolone, and azathioprine and prednisolone without cyclosporine. N Engl J Med 1988;318:1499-507.

5. The Canadian Multicentre Transplant Study Group. A randomized clinical trial of cyclopsorine in a cadaveric renal transplantation. N Engl J Med 1983;309:809-15.

6. Sheil AG, Hall BM, Tiller DJ, Stephen M, Harris JP, Duggin GG, Horvath JS, Johnson J, Rogers J, Boulas J. Australian trial of cyclosporine (CsA) in cadaveric donor renal transplantation. Transplant Proc 1983;15(S1):2485-9.

7. McMaster P, Haynes IG, Michael J, Adu D, Vlassis T, Roger S, Turney J, Stock S, Buckels $J$, Mackintosh $P$, Ezzideh M. Cyclosporine in cadaveric renal transplantation: a prospective randomized trial. Transplant Proc 1983;15(S1):2523-7.

8. Najarian JS, Fryd DS, Strand M, Canafax DM, Ascher NL, Payne WD, Simmons RL, Sutherland DE. A single institution, randomized, prospective trial of cyclosporin versus azathioprine-antilymphocyte globulin for immunosuppression in renal allograft recipients. Ann Surg 1985;201:142-57.

9. Friman S, Backman L. A new microemulsion formulation of cyclosporine: pharmacokinetic and clinical features. Clin Pharmacokinet 1996;30:181-93.

10. Kaufman DB, Shapiro R, Lucey MR, Cherikh WA, Bustami RT, Dyke DB. Immunosuppression: practice and trends. Am J Transplant 2004;4(S9):38-53.

11. Goto T, Kino T, Hatanaka H, Nishiyama M, Okuhara M, Kohsaka M, Aoki H, Imanaka H. Discovery of FK-506, a novel immunosuppressant isolated from Streptomyces tsukubaensis. Transplant Proc 1987;19:4-8.

12. Liu J, Farmer JD Jr, Lane WS, Friedman J, Weissman I, Schreiber SL. Calcineurin is a common target of cyclophilin-cyclosporin A and FKBP-FK506 complexes. Cell 1991;66: 807-15.

13. Halloran PF, Helms LM, Kung L, Noujaim J. The temporal profile of calcineurin inhibition by cyclosporine in vivo. Transplantation 1999;68:1356-61.

14. O'Keefe SJ, Tamura J, Kincaid RL, Tocci MJ, O'Neill EA. FK-506- and Sensitive-sensitive activation of the interleukin-2 promoter by calcineurin. Nature 1992;357:692-4.

15. Clipstone NA, Crabtree GR. Identification of calcineurin as a key signalling enzyme in Tlymphocyte activation. Nature 1992;357:695-7.

16. Schwaninger M, Blume R, Krüger M, Lux G, Oetjen E, Knepel W. Involvement of the $\mathrm{Ca}(2+)$-dependent phosphatase calcineurin in gene transcription that is stimulated by cAMP through cAMP response elements. J Biol Chem 1995;270:8860-6.

17. Almawi WY, Melemedjian OK. Clinical and mechanistic differences between FK506 (tacrolimus) and cyclosporin A. Nephrol Dial Transplant 2000;15:1916-8.

18. Matsuda S, Koyasu S. Mechanisms of action of cyclosporine. Immunopharmacology 2000; 47:119-25.

19. Lang P, Baron C. Molecular mechanisms of immunosuppressive chemical agents recently introduced in clinical transplantation protocols. Nephrol Dial Transplant 1997;12:2050-4. 
20. Matsuda S, Moriguchi T, Koyasu S, Nishida E. T lymphocyte activation signals for interleukin-2 production involve activation of MKK6-p38 and MKK7-SAPK/JNK signaling pathways sensitive to cyclosporin A. J Biol Chem 1998;273:12378-82.

21. Matsuda S, Shibasaki F, Takehana K, Mori H, Nishida E, Koyasu S. Two distinct action mechanisms of immunophilin-ligand complexes for the blockade of T-cell activation. EMBO Rep 2000;1:428-34.

22. Hutchinson IV, Bagnall W, Bryce P, Pufong B, Geraghty P, Brogan I. Differences in the mode of action of cyclosporine and FK 506. Transplant Proc 1998;30:959-60.

23. Suzuki N, Sakane T, Tsunematsu T. Effects of a novel immunosuppressive agent, FK506, on human B cell activation. Clin Exp Immunol 1990;79:240-5.

24. Jurcevic S, Dunn MJ, Crisp S, Busing K, Rinaldi M, Pellegrini C, Yacoub MH, Vigano M, Banner NL, Rose ML. A new enzyme-linked immunosorbent assay to measure antiendothelial antibodies after cardiac transplantation demonstrates greater inhibition of antibody formation by tacrolimus compared with cyclosporine. Transplantation 1998;65: 1197-202.

25. Mori A, Suko M, Kaminuma O, Inoue S, Ohmura T, Hoshino A, Asakura $Y$, Terada E, Miyazawa K, Nosaka C, Okumura Y, Ito K, Okudaira H. IL-2-induced IL-5 synthesis, but not proliferation, of human CD4+ T cells is suppressed by FK506. J Immunol 1997;158: 3659-65.

26. Roelen DL, van Bree FP, Schanz U, van Rood JJ, Claas FH. Differential inhibition of primed alloreactive CTLs in vitro by clinically used concentrations of cyclosporine and FK506. Transplantation 1993;56:190-5.

27. Migita K, Origuchi T, Kawabe Y, Tominaga M, Ida H, Kawakami A, Eguchi K. FK506 markedly enhances apoptosis of antigen-stimulated peripheral $\mathrm{T}$ cells by down-regulation of Bcl-xL. Transplantation 1999;68:1018-23.

28. Migita K, Eguchi K, Kawabe Y, Origuchi T, Tominaga M, Nagataki S. FK506 potentiates steroid-induced T-cell apoptosis. Transplantation 1997;64:1365-9.

29. Adams DH, Liu Q. FK506 inhibits human lymphocyte migration and the production of lymphocyte chemotactic factors in liver allograft recipients. Hepatology 1996;23:1476-83.

30. Jiang H, Wynn C, Pan F, Ebbs A, Erickson LM, Kobayashi M. Tacrolimus and cyclosporine differ in their capacity to overcome ongoing allograft rejection as a result of their differential abilities to inhibit interleukin-10 production. Transplantation 2002;73:1808-17.

31. Woodle ES, Thistlethwaite JR, Gordon JH, Laskow D, Deierhoi MH, Burdick J, Pirsch JD, Sollinger H, Vincenti F, Burrows L, Schwartz B, Danovitch GM, Wilkinson AH, Shaffer D, Simpson MA, Freeman RB, Rohrer RJ, Mendez R, Aswad S, Munn SR, Wiesner RH, Delmonico FL, Neylan J, Whelchel J. A multicenter trial of FK506 (tacrolimus) therapy in refractory acute renal allograft rejection. A report of the Tacrolimus Kidney Transplantation Rescue Study Group. Transplantation 1996;62:594-9.

32. Jordan ML, Naraghi R, Shapiro R, Smith D, Vivas CA, Scantlebury VP, Gritsch HA, McCauley J, Randhawa P, Demetris AJ, McMichael J, Fung JJ, Starzl TE. Tacrolimus rescue therapy for renal allograft rejection--five-year experience. Transplantation 1997;63: 223-8.

33. Li B, Sehajpal PK, Khanna A, Vlassara H, Cerami A, Stenzel KH, Suthanthiran M. Differential regulation of transforming growth factor beta and interleukin 2 genes in human T cells: demonstration by usage of novel competitor DNA constructs in the quantitative polymerase chain reaction. J Exp Med 1991;174:1259-62.

34. Khanna A, Li B, Stenzel KH, Suthanthiran M. Regulation of new DNA synthesis in mammalian cells by cyclosporine. Demonstration of a transforming growth factor betadependent mechanism of inhibition of cell growth. Transplantation 1994;57:577-82.

35. Shin GT, Khanna A, Ding R, Sharma VK, Lagman M, Li B, Suthanthiran M. In vivo expression of transforming growth factor-beta1 in humans: stimulation by cyclosporine. Transplantation 1998;65:313-8.

36. Wang T, Donahoe PK, Zervos AS. Specific interaction of type I receptors of the TGF-beta family with the immunophilin FKBP-12. Science 1994;265:674-6. 
37. Wang T, Li BY, Danielson PD, Shah PC, Rockwell S, Lechleider RJ, Martin J, Manganaro T, The immunophilin FKBP12 functions as a common inhibitor of the TGF beta family type I receptors. Cell 1996;86:435-44.

38. Waiser J, Dell K, Böhler T, Dogu E, Gaedeke J, Budde K, Neumayer HH. Cyclosporine A up-regulates the expression of TGF-beta1 and its receptors type I and type II in rat mesangial cells. Nephrol Dial Transplant 2002;17:1568-77.

39. Jain S, Bicknell GR, Nicholson ML. Tacrolimus has less fibrogenic potential than cyclosporine A in a model of renal ischemia-reperfusion injury. Br J Surg 2000;87:1563-8.

40. Feldmann F. Cell cooperation in the antibody response. In: Roitt I, Bronstoff J, Male D, eds. Immunology, 4th ed. London: Times Mirror International Publishers. 1996:8.1-8.16.

41. Mancinelli LM, Frassetto L, Floren LC, Dressler D, Carrier S, Bekersky I, Benet LZ, Christians $U$. The pharmacokinetics and metabolic disposition of tacrolimus: a comparison across ethnic groups. Clin Pharmacol Ther 2001;69:24.

42. Bekersky I, Dressler D, Mekki Q. Effect of time of meal consumption on bioavailability of a single oral $5 \mathrm{mg}$ tacrolimus dose. J Clin Pharmacol 2001;41:289.

43. Christiaans M, van Duijnhoven E, Beysens T, Undre N, Schäfer A, van Hooff J. Effect of breakfast on the oral bioavailability of tacrolimus and changes in pharmacokinetics at different times posttransplant in renal transplant recipients. Transplant Proc 1998;30: 1271-3.

44. Venkataramanan R, Swaminathan A, Prasad T, Jain A, Zuckerman S, Warty V, McMichael J, Lever J, Burckart G, Starzl T. Clinical pharmacokinetics of tacrolimus. Clin Pharmacokinet 1995;29:404-30.

45. Spencer CM, Goa KL, Gillis JC. Tacrolimus. An update of its pharmacology and clinical efficacy in the management of organ transplantation. Drugs 1997;54:925-75.

46. Plosker GL, Foster RH. Tacrolimus: a further update of its pharmacology and therapeutic use in the management of organ transplantation. Drugs 2000;59:323-89.

47. Iwasaki K, Shiraga T, Matsuda H, Nagase K, Tokuma Y, Hata T, Fujii Y, Sakuma S, Fujitsu T, Fujikawa A. Further metabolism of FK506 (Tacrolimus). Drug Metab Dispos 1995;23:28.

48. Jusko WJ, Piekoszewski W, Klintmalm GB, Shaefer MS, Hebert MF, Piergies AA, Lee CC, Schechter P, Mekki QA. Pharmacokinetics of tacrolimus in liver transplant patients. Clin Pharmacol Ther 1995;57:281.

49. Gruber SA, Hewitt JM, Sorenson AL, Barber DL, Bowers L, Rynders G, Arrazola L, Matas AJ, Rosenberg ME, Canafax DM. Pharmacokinetics of FK506 after intravenous and oral administration in patients awaiting renal transplantation. J Clin Pharmacol 1994;34:859.

50. Manez R, Martin M, Raman V, Silverman D, Jain A, Warty V, Gonzalez-Pinto I, Kusne S, Starzl TE. Fluconazole therapy in transplant recipients receiving FK506. Transplantation 1994;57:1521.

51. Mahalati K, Kahan BD. Pharmacological surrogates of allograft outcome. Ann Transplant 2000;5:14-23.

52. Braun F, Schutz E, Peters B, Talaulicar R, Grupp C, Undre N, Schäfer A, Armstrong VW, Oellerich M, Ringe B. Pharmacokinetics of tacrolimus primary immunosuppression in kidney transplant recipients. Transplant Proc 2001;33:2127-28.

53. Shishido S, Asanuma H, Tajima E, Honda M, Nakai H. Pharmacokinetics of tacrolimus in paediatric renal transplant recipients. Transplant Proc 2001;33:1066-8.

54. Webb NJA, Stevenson PJ, Lewis MA, Postlethwaite RJ, Bradbury MG, Undre NA. Pharmacokinetics of tacrolimus in paediatric renal transplant recipients. Transplant Proc 2002;34:1948-50.

55. Kimikawa M, Kamoya K, Toma H, Teraoka S. Effective oral administration of tacrolimusin renal transplant recipients. Clin Transplant 2001;15:324-9.

56. Pirsch JD, Miller J, Deierhoi MH, Vincenti F, Filo RS. A comparison of tacrolimus (FK506) and cyclosporine for immunosuppression after cadaveric renal transplantation. FK506 Kidney Transplant Study Group. Transplantation 1997;63:977-83. 
57. Mayer AD, Dmitrewski J, Squifflet JP, Besse T, Grabensee B, Klein B, Eigler FW, Heemann $\mathrm{U}$, Pichlmayr R, Behrend M, Vanrenterghem Y, Donck J, van Hooff J, Christiaans M, Morales JM, Andres A, Johnson RW, Short C, Buchholz B, Rehmert N, Land W, Schleibner $\mathrm{S}$, Forsythe JL, Talbot D, Pohanka E. Multicenter randomized trial comparing tacrolimus (FK506) and cyclosporine in the prevention of renal allograft rejection: a report of the European Tacrolimus Multicenter Renal Study Group. Transplantation 1997;64:436-43.

58. Jensik SC and the FK 506 Kidney Transplant Study Group. Tacrolimus (FK506) in Kidney Transplantation: Three-Year Survival Results of the US Multicenter, Randomized, Comparative Trial. Transplant Proc 1998;30:1216-9.

59. Vincenti $F$ and the Tacrolimus Kidney Transplant Study Group. Tacrolimus (FK506) in kidney Transplantation: Five-Year Survival Results of the US Multicenter, Randomized, Comparative Trial. Transplant Proc 2001;33:1019-20.

60. Wong KM, Shek CC, Chau KF, Li CS. Abbreviated tacrolimus area-under-the-curve monitoring for renal transplant recipients. Am J Kidney Dis 2000;35:660-6.

61. Macchi-Andanson M, Charpiat B, Jelliffe RW, Ducerf C, Fourcade N, Baulieux J. Failure of traditional trough levels to predict tacrolimus concentrations. Therapeutic Drug Monitoring 2001;23:129-33.

62. Stolk L, Van Duijnhoven EM, Christiaans MHL, van Hooff JP. Trough levels of tacrolimus (discussion). Therapeutic Drug Monitoring 2002;24:573-4.

63. Scholten EM, Cremers SC, Schoemaker RC, Rowshani AT, van Kan EJ, den Hartigh J, Paul LC, de Fijter JW. AUC-guided dosing of tacrolimus prevents progressive systemic overexposure in renal transplant recipients. Kidney Int 2005;67:2440-7.

64. Mahalati K, Belitsky P, Sketris I, West K, Panek R. Neoral monitoring by simplified sparse sampling area under the concentration-time curve: its relationship to acute rejection and cyclosporine nephrotoxicity early after kidney transplantation. Transplantation 1999;68: 55-62.

65. Keown P, Kahan BD, Johnston A, Levy G, Dunn SP, Cittero F, Grino JM, Hoyer PF, Wolf P, Halloran PF. Optimization of cyclosporine therapy with new therapeutic drug monitoring strategies: Report from the International Neoral TDM Advisory Consensus Meeting (Vancouver, November 1997). Transplant Proc. 1998;30:1645-9.

66. Gaspari F, Caruso R, Cattaneo D, Perico N, Remuzzi G. Optimization of Cyclosporine Therapy in the Neoral Era: Abbreviated AUC, Single Blood Sampling? Transplant Proc 2001;33:3117-9.

67. Meier-Kriesche HU, Alloway R, Gaber AO, Canafax DM, Kaplan B. A limited sampling strategy for the estimation of 12-hour SangCya and neoral AUCs in renal transplant recipients. J Clin Pharmacol 1999;39:166-71.

68. Tsang WK, Ho YW, Tong KL, Chan WH, Chan A. Safety, tolerability, and pharmacokinetics of Sandimmun Neoral: conversion study in stable renal transplant recipients. Transplant Proc 1996;28:1330-2.

69. Undre NA, Van Hooff J, Christiaans M, Vanrenterghem Y, Donck J, Heeman U, Kohnle M, Zanker B, Land W, Morales JM, Andrés A, Schäfer A, Stevenson P. Low systemic exposure to tacrolimus correlates with acute rejection. Transplant Proc 1999;31:296-8.

70. Kalow W, Tang BK, Endrenyi L. Hypothesis: Comparisons of inter- and intra-individual variations can substitute for twin studies in drug research. Pharmacogenetics 1998;8: 283-9.

71. Weinshilboum R. Inheritance and drug response. N Engl J Med 2003;348:529-37.

72. Weinshilboum RM, Otterness DM, Szumlanski CL. Methylation pharmacogenetics: Catechol O-methyltransferase, thiopurine methyltransferase, and histamine N-methyltransferase. Annu Rev Pharmacol Toxicol 1999;39:19-52.

73. Soria-Royer C, Legendre C, Mircheva J, Premel S, Beaune P, Kreis H. Thiopurine-methyltransferase activity to assess azathioprine myelotoxicity in renal transplant recipients. Lancet 1993;341:1593-4.

74. Chocair PR, Duley JA, Simmonds HA, Cameron JS. The importance of thiopurine methyltransferase activity for the use of azathioprine in transplant recipients. Transplantation 1992;53:1051-6. 
75. Thervet E, Anglicheau D, Toledano N, Houllier AM, Noel LH, Kreis H, Beaune P, Legendre C. Long-term results of TMPT activity monitoring in azathioprine-treated renal allograft recipients. J Am Soc Nephrol 2001;12:170-6.

76. Nebert DW, Russell DW. Clinical importance of the cytochromes P450. Lancet 2002;360: 1155-62.

77. Sattler M, Guengerich FP, Yun CH, Christians U, Sewing KF. Cytochrome P-450 3A enzymes are responsible for biotransformation of FK506 and rapamycin in man and rat. Drug Metab Dispos 1992;20:753-61.

78. Kuehl P, Zhang J, Lin Y, Lamba J, Assem M, Schuetz J, Watkins PB, Daly A, Wrighton SA, Hall SD, Maurel P, Relling M, Brimer C, Yasuda K, Venkataramanan R, Strom S, Thummel $\mathrm{K}$, Boguski MS, Schuetz E. Sequence diversity in CYP3A promoters and characterization of the genetic basis of polymorphic CYP3A5 expression. Nat Genet 2001;27:383-91.

79. Ambudkar SV, Dey S, Hrycyna CA, Ramachandra M, Pastan I, Gottesman MM. Biochemical, cellular, and pharmacological aspects of the multidrug transporter. Annu Rev Pharmacol Toxicol 1999;39:361-98.

80. Kim RB. MDR1 single nucleotide polymorphisms: Multiplicity of haplotypes and functional consequences. Pharmacogenetics 2002;12:425-7.

81. Chace DH, Kalas TA, Naylor EW. Use of tandem mass spectrometry for multianalyte screening of dried blood specimens from newborns. Clin Chem 2003;49:1797-817.

82. Malm M, Lindegardh N, Bergquist $\mathrm{Y}$. Automated solid-phase extraction method for the determination of piperaquine in capillary blood applied onto sampling paper by liquid chromatography. J Chromatogr B Analyt Technol Biomed Life Sci 2004;809:43-9.

83. Koal T, Burhenne H, Romling R, Svoboda M, Resch K, Kaever V. Quantification of antiretroviral drugs in dried blood spot samples by means of liquid chromatography/tandem mass spectrometry. Rapid Commun Mass Spectrom 2005;19:2995-3001.

84. Profumo RJ, Foy TM, Kane RE. Correlation between venous and capillary blood samples for cyclosporine monitoring in pediatric liver transplant recipients. Clin Transplant 1995;9: 424-6.

85. Merton G, Jones K, Lee M, Johnston A, Holt DW. Accuracy of cyclosporine measurements made in capillary blood samples obtained by skin puncture. Ther Drug Monit 2000;22: 594-8.

86. Keevil BG, Tierney DP, Cooper DP, Morris MR, Machaal A, Yonan N. Simultaneous and rapid analysis of cyclosporin $A$ and creatinine in finger prick blood samples using liquid chromatography tandem mass spectrometry and its application in $\mathrm{C} 2$ monitoring. Ther Drug Monit 2002;24:757-67.

87. Yonan N, Martyszczuk R, Machaal A, Baynes A, Keevil BG. Monitoring of cyclosporine levels in transplant recipients using self-administered fingerprick sampling. Clin Transplant 2006;20:221-5.

88. Webb NJ, Roberts D, Preziosi R, Keevil BG. Fingerprick blood samples can be used to accurately measure tacrolimus levels by tandem mass spectrometry. Pediatr Transplant 2005;9:729-33.

89. Hoogtanders K, van der Heijden J, Christiaans M, Edelbroek P, van Hooff JP, Stolk LM. Therapeutic drug monitoring of tacrolimus with the dried blood spot method. J Pharm Biomed Anal 2007;44:658-64.

90. Shaw LM, Holt DW, Keown P, Venkataramanan R, Yatscoff RW. Current opinions on therapeutic drug monitoring of immunosuppressive drugs. Clin Ther 1999;21:1632-52.

91. Borrows R, Chusney G, Loucaidou M, James A, Stichbury J, Van Tromp J, Cairns T, Griffith M, Hakim N, McLean A, Palmer A, Papalois V, Taube D. Clinical outcomes of renal transplantation using liquid chromatographic monitoring of tacrolimus. Ther Drug Monit 2006;28:269-73.

92. Napoli KL. Is microparticle enzyme-linked immunoassay (MEIA) reliable for use in tacrolimus TDM? Comparison of MEIA to liquid chromatography with mass spectrometric detection using longitudinal trough samples from transplant recipients. Ther Drug Monit 2006;28:491-504. 
93. Racusen LC, Solez K, Colvin RB, Bonsib SM, Castro MC, Cavallo T, Croker BP, Demetris AJ, Drachenberg CB, Fogo AB, Furness P, Gaber LW, Gibson IW, Glotz D, Goldberg JC, Grande J, Halloran PF, Hansen HE, Hartley B, Hayry PJ, Hill CM, Hoffman EO, Hunsicker LG, Lindblad AS, Yamaguchi Y. The Banff 97 working classification of renal allograft pathology. Kidney Int 1999;55:713-23.

94. Pirsch JD, Ploeg RJ, Gange S, D'Alessandro AM, Knechtle SJ, Sollinger HW, Kalayoglu M, Belzer FO. Determinants of graft survival after renal transplantation. Transplantation 1996; 61:1581-6.

95. Lindholm A, Ohlman S, Albrechtsen D, Tufveson G, Persson H, Persson NH. The impact of acute rejection episodes on long-term graft function and outcome in 1347 primary renal transplants treated by 3 cyclosporine regimens. Transplantation 1993;56:307-15.

96. Richards E, Schleibner S, Talbot D. An exploratory analysis of prognostic factors for patient outcome during the first year following renal transplantation. European Tacrolimus Multicentre Renal Study Group. Transplant Proc 1998;30:1386-8.

97. Ishikawa A, Flechner SM, Goldfarb DA, Myles JL, Modlin CS, Boparai N, Papajcik D, Mastroianni B, Novick AC. Quantitative assessment of the first acute rejection as a predictor of renal transplant outcome. Transplantation 1999;68:1318-24.

98. Isaacs RB, Nock SL, Spencer CE, Connors AF Jr, Wang XQ, Sawyer R, Lobo PI. Racial disparities in renal transplant outcomes. Am J Kidney Dis 1999;34:706-12.

99. Neylan JF. Immunosuppressive therapy in high-risk transplant patients: dose-dependent efficacy of mycophenolate mofetil in African-American renal allograft recipients. U.S. Renal Transplant Mycophenolate Mofetil Study Group. Transplantation 1997;64:1277-82.

100. Roodnat JI, Zietse R, Mulder PG, Rischen-Vos J, van Gelder T, IJzermans JN, Weimar W. The vanishing importance of age in renal transplantation. Transplantation 1999;67:576-80.

101. Humar A, Hassoun A, Kandaswamy R, Payne WD, Sutherland DE, Matas AJ. Immunologic factors: the major risk for decreased long-term renal allograft survival. Transplantation 1999;68:1842-6.

102. Chapman JR, Taylor CJ, Ting A, Morris PJ. Immunoglobulin class and specificity of antibodies causing positive $T$ cell crossmatches. Relationship to renal transplant outcome. Transplantation 1986;42:608-13.

103. Taylor CJ, Chapman JR, Ting A, Morris PJ. Characterization of lymphocytotoxic antibodies causing a positive crossmatch in renal transplantation. Relationship to primary and regraft outcome. Transplantation 1989;48:953-8.

104. Sanfilippo F, Vaughn WK, LeFor WM, Spees EK. Multivariate analysis of risk factors in cadaver donor kidney transplantation. Transplantation 1986;42:28-34.

105. Halloran PF, Melk A, Barth C. Rethinking chronic allograft nephropathy: the concept of accelerated senescence. J Am Soc Nephrol 1999;10:167-81.

106. Monaco AP, Burke JF Jr, Ferguson RM, Halloran PF, Kahan BD, Light JA, Matas AJ, Solez $\mathrm{K}$. Current thinking on chronic renal allograft rejection: issues, concerns, and recommendations from a 1997 roundtable discussion. Am J Kidney Dis 1999;33:150-60.

107. Solez K, Axelsen RA, Benediktsson H, Burdick JF, Cohen AH, Colvin RB, Croker BP, Droz D, Dunnill MS, Halloran PF. International standardization of criteria for the histologic diagnosis of renal allograft rejection: the Banff working classification of kidney transplant pathology. Kidney Int 1993;44:411-22.

108. Kasiske BL, Kalil RS, Lee HS, Rao KV. Histopathologic findings associated with a chronic, progressive decline in renal allograft function. Kidney Int 1991;40:514-24.

109. Hariharan S, McBride MA, Cherikh WS, Tolleris CB, Bresnahan BA, Johnson CP. Posttransplant renal function in the first year predicts long-term kidney transplant survival. Kidney Int 2002;62:311-8.

110. Sund S, Reisaeter AV, Fauchald P, Bentdal O, Hall KS, Hovig T. Living donor kidney transplants: a biopsy study 1 year after transplantation, compared with baseline changes and correlation to kidney function at 1 and 3 years. Nephrol Dial Transplant 1999;14: 2445-54.

111. Terasaki PI, Koyama H, Cecka JM, Gjertson DW. The hyperfiltration hypothesis in human renal transplantation. Transplantation 1994;57:1450-4. 
112. Alcalde G, Escallada R, Rodrigo E, Cotorruelo JG, Zubimendi JA, de Francisco AL, Arias M. Disproportion between kidney graft and recipient size is the main predictor of long-term proteinuria. Transplant Proc 1997;29:127-8.

113. Nankivell BJ, Fenton-Lee CA, Kuypers DR, Cheung E, Allen RD, O'Connell PJ, Chapman JR. Effect of histological damage on long-term kidney transplant outcome. Transplantation 2001;71:515-23.

114. Pascual M, Theruvath T, Kawai T, Tolkoff-Rubin N, Cosimi AB. Strategies to improve longterm outcomes after renal transplantation. N Engl J Med 2002;346:580-90.

115. Humar A, Payne WD, Sutherland DE, Matas AJ. Clinical determinants of multiple acute rejection episodes in kidney transplant recipients. Transplantation 2000;69:2357-60.

116. van Saase JL, van der Woude FJ, Thorogood J, Hollander AA, van Es LA, Weening JJ, van Bockel JH, Bruijn JA. The relation between acute vascular and interstitial renal allograft rejection and subsequent chronic rejection. Transplantation 1995;59:1280-5.

117. Brenner BM, Cohen RA, Milford EL. In renal transplantation, one size may not fit all. J Am Soc Nephrol 1992;3:162-9.

118. Kasiske BL, Snyder JJ, Gilbertson D. Inadequate donor size in cadaver kidney transplantation. J Am Soc Nephrol 2002;13:2152-9.

119. Morris PJ, Johnson RJ, Fuggle SV, Belger MA, Briggs JD. Analysis of factors that affect outcome of primary cadaveric renal transplantation in the UK. HLA Task Force of the Kidney Advisory Group of the United Kingdom Transplant Support Service Authority (UKTSSA). Lancet 1999;354:1147-52.

120. Nickerson P, Jeffery J, Gough J, McKenna R, Grimm P, Cheang M, Rush D. Identification of clinical and histopathologic risk factors for diminished renal function 2 years posttransplant. J Am Soc Nephrol 1998;9:482-7.

121. Mange KC, Cherikh WS, Maghirang J, Bloom RD. A comparison of the survival of shipped and locally transplanted cadaveric renal allografts. N Engl J Med 2001;345:1237-42.

122. Asderakis A, Dyer P, Augustine T, Worthington J, Campbell B, Johnson RW. Effect of cold ischemic time and HLA matching in kidneys coming from "young" and "old" donors: do not leave for tomorrow what you can do tonight. Transplantation 2001;72:674-8.

123. Opelz G, Wujciak T, Ritz E. Association of chronic kidney graft failure with recipient blood pressure. Collaborative Transplant Study. Kidney Int 1998;53:217-22.

124. Mange KC, Cizman B, Joffe M, Feldman HI. Arterial hypertension and renal allograft survival. JAMA 2000;283:633-8.

125. Peschke B, Scheuermann EH, Geiger H, Bölscher S, Kachel HG, Lenz T. Hypertension is associated with hyperlipidemia, coronary heart disease and chronic graft failure in kidney transplant recipients. Clin Nephrol 1999;51:290-5.

126. Dimény $\mathrm{E}$, Wahlberg J, Lithell H, Fellström B. Hyperlipidaemia in renal transplantation--risk factor for long-term graft outcome. Eur J Clin Invest 1995;25:574-83.

127. Roodnat JI, Mulder PG, Zietse R, Rischen-Vos J, van Riemsdijk IC, IJzermans JN, Weimar W. Cholesterol as an independent predictor of outcome after renal transplantation. Transplantation 2000;69:1704-10.

128. Miles AM, Sumrani N, Horowitz R, Homel P, Maursky V, Markell MS, Distant DA, Hong JH, Sommer BG, Friedman EA. Diabetes mellitus after renal transplantation: as deleterious as non-transplant-associated diabetes? Transplantation 1998;65:380-4.

129. Klein IHHT, Abrahams A, van Ede T, Hene RJ, Koomans HA, Ligtenberg G. Different effects of Tacrolimus and Cyclosporine on renal haemodynamics and blood pressure in healthy subjects. Transplantation 2002;73:732-6.

130. Nankivell BJ, Chapman JR, Bonovas G, Gruenewald SM. Oral cyclosporine but not tacrolimus reduces renal transplant blood flow. Transplantation 2004;77:1457-9.

131. van Duijnhoven EM, Dackus HJA, Christiaans MHL, van Heurn ELW, van Hooff JP. Comparable renal function in living kidney donors and their recipients on tacrolimus-based immunosuppression. ICI San Diego 2004; Abstract P-54. 
132. Larson TS, Dean PG, Stegall MD, Griffin MD, Textor SC, Schwab TR, Gloor JM, Cosio FG, Lund WJ, Kremers WK, Nyberg SL, Ishitani MB, Prieto M, Velosa JA. Complete avoidance of calcineurin inhibitors in renal transplantation: a randomized trial comparing sirolimus and tacrolimus. Am J Transplant 2006;6:514-22.

133. Artz MA, Boots JM, Ligtenberg G, Roodnat JI, Christiaans MH, Vos PF, Moons P, Borm G, Hilbrands LB. Conversion from cyclosporine to tacrolimus improves quality-of-life indices, renal graft function and cardiovascular risk profile. Am J Transpl 2004;4:937-45.

134. Cantarovich D, Renou M, Megnigbeto A, Giral-Classe M, Hourmant M, Dantal J, Blancho G, Karam G, Soulillou JP. Switching from cyclosporine to tacrolimus in patients with chronic transplant dysfunction or cyclosporine-induced adverse events. Transplantation 2005;79: 72-8.

135. Margreiter R, Pohanka E, Sparacino V, Sperschneider H, Kunzendorf U, Huber W, Lameire N, Andreucci VE, Donati D, Heemann U; the European Switch to Tacrolimus Study Group. Open prospective multicenter study of conversion to tacrolimus therapy in renal transplant patients experiencing ciclosporin-related side-effects. Transpl Int 2005;18:816-23.

136. Hohage H, Welling U, Zeh M, Gerhardt U, Suwelack B. Switching immunosuppression from cyclosporine to tacrolimus improves long-term kidney function: a 6-year study. Transplant Proc 2005;37:1898-9.

137. Meier M, Nitschke M, Weidtmann B, Jabs WJ, Wong W, Suefke S, Steinhoff J, Fricke L. Slowing the progression of chronic allograft nephropathy by conversion from cyclosporine to tacrolimus: a randomized controlled trial. Transplantation 2006;81:1035-40.

138. Andres A, Toso C, Morel P, Demuylder-Mischler S, Bosco D, Baertschiger R, Pernin N, Bucher P, Majno PE, Bühler LH, Berney T. Impairment of renal function after islet transplant alone or islet-after-kidney transplantation using a sirolimus/tacrolimus-based immunosuppressive regimen. Transpl Int 2005;18:1226-30.

139. Jurewicz WA. Tacrolimus versus cyclosporin immunosuppression: long-term outcome in renal transplantation. Nephrol Dial Transplant 2003;18(S1):i7-11.

140. Weir MR and Fink JC. Risk for posttransplant diabetes mellitus with current immunosuppressive medications. Am J Kidney Dis 1999;34:1-13.

141. Krentz AJ, Dmitrewski J, Mayer D and Natrass M. Effects of immunosuppressive agents on glucose metabolism. Clin Immunother 1995;4:103-23.

142. Jindal RM, Sidner RA and Milgrom ML. Post-transplant diabetes mellitus. The role of immunosuppression. Drug Saf 1997;16:242-57.

143. Sumrani NB, Delaney V, Ding ZK, Davis R, Daskalakis P, Friedman EA, Butt KM, Hong JH. Diabetes mellitus after renal transplantation in the cyclosporine era - an analysis of risk factors. Transplantation 1991;51:343-7.

144. Hjelmesaeth J, Hartman A, Kofstad J, Stenstrøm J, Leivestad T, Egeland T, Fauchald P. Glucose intolerance after renal transplantation depends upon prednisolone dose and recipient age. Transplantation 1997;64:979-83.

145. Cosio FG, Pesavento TE, Osei K, Henry ML, Ferguson RM. Post-transplant diabetes mellitus. Increasing incidence in renal allograft recipients transplanted in recent years. Kidney Int 2001;9:732-7.

146. van Hooff JP, Christiaans MH, van Duijnhoven EM. Glucose metabolic disorder after transplantation. Am J Transplant 2007;7:1435-6.

147. Pagano G, Bruno A, Cavallo-Perin P, Cesco L, Imbimbo B. Glucose intolerance after shortterm administration of corticosteroids in healthy subjects. Prednisone, deflazacort, and betamethasone. Arch Intern Med 1989;149:1098-101.

148. Veenstra DL, Best JH, Hornberger J, Sullivan SD, Hricik DE. Incidence and long-term cost of steroid-related side effects after renal transplantation. Am J Kidney Dis 1999;33:829-39.

149. Hricik DE, Bartucci MR, Moir EJ, Mayes JT, Schulak JA. Effects of steroid withdrawal on posttransplant diabetes mellitus in cyclosporine-treated renal transplant recipients. Transplantation 1991;51:374-7 
150. Christiansen E, Andersen HB, Rasmussen K, Christensen NJ, Olgaard K, Kirkegaard P, Tronier B, Vølund A, Damsbo P, Burcharth F. Pancreatic beta-cell function and glucose metabolism in human segmental pancreas and kidney transplantation. Am J Physiol 1993; 264: E441-9.

151. Hollander AAMJ, Hené RJ, Hermans J, Es LA van, Woude FJ van Der. Late prednisone withdrawal in cyclosporine-treated kidney transplant patients: a randomized study. J Am Soc Nephrol 1997;8;294-301.

152. Yamamoto H, Akazawa S, Yamaguchi Y, Yokota A, Yamasaki H, Nakanishi T, Tahara D, Matsuya F, Saito Y, Nagataki S. Effects of cyclosporine A and low dosages of steroid on posttransplantation diabetes in kidney transplant recipients. Diabetes Care 1991;14:867-70.

153. Harris KP, Russell GI, Parvin SD, Veitch PS, Walls J. Alterations in lipid and carbohydrate metabolism attributable to cyclosporine A in renal transplants. Br MED J 1986;292:16-9.

154. Robertson RP. Cyclosporin-induced inhibition of insulin secretion in isolated rat islets and HIT cells. Diabetes 1986;35:1016-9.

155. Gillison SL, Bartlett ST, Curry DL. Inhibition by cyclosporine of insulin secretion- -a beta cell-specific alteration of islet tissue function. Transplantation 1991;52:890-5.

156. Tamura K, Fujimura T, Tsutsumi T, Nakamura K, Ogawa T, Atumaru C, Hirano Y, Ohara K, Ohtsuka K, Shimomura K. Transcriptional inhibition of insulin of insulin by FK506 and possible involvement of FK506 binding protein-12 in pancreatic beta-cell. Transplantation 1995;59:1606-13.

157. van Duijhoven EM, Boots JMM, Christiaans MHL, Wolffenbuttel BHR, van Hooff JP. Influence of tacrolimus on glucose metabolism before and after renal transplantation: a prospective study. J Am Soc Nephrol 2001;12:583-8.

158. Webster AC, Woodroffe RC, Taylor RS, Chapman JR, Craig JC. Tacrolimus versus ciclosporin as primary immunosuppression for kidney transplant recipients: meta-analysis and meta-regression of randomised trial data. BMJ 2005;331:810-20.

159. Ter Meulen CG, van Riemsdijk I, Hené RJ, Christiaans MH, Borm GF, van Gelder T, Hilbrands LB, Weimar W, Hoitsma AJ. Steroid-withdrawal at 3 days after renal transplantation with anti-IL-2 receptor alpha therapy: a prospective, randomized, multicenter study. Am J Transplant 2004;4:803-10.

160. Kasiske BL, Snyder JJ, Gilbertson D, Matas AJ. Diabetes mellitus after kidney transplantation in the United States. Am J Transplant 2003;3:178-85.

161. Davidson J, Wilkinson A, Dantal J, Dotta F, Haller H, Hernández D, Kasiske BL, Kiberd B, Krentz A, Legendre C, Marchetti P, Markell M, van der Woude FJ, Wheeler DC; International Expert Panel. New-onset diabetes after transplantation: 2003 International consensus guidelines. Transplantation 2003;75(10 Suppl):S3-24.

162. Cosio FG, Kudva Y, van der Velde M, Larson TS, Textor SC, Griffin MD, Stegall MD. New onset hyperglycemia and diabetes are associated with increased cardiovascular risk after kidney transplantation. Kidney Int 2005;67:2415-21.

163. Olshansky SJ, Passaro DJ, Hershow RC, Layden J, Carnes BA, Brody J, Hayflick L, Butler RN, Allison DB, Ludwig DS. A potential decline in life expectancy in the United States in the 21st century. N Engl J Med 2005;352:1138-45.

164. Third Report of the National Cholesterol Education Program (NCEP) Expert Panel on Detection, Evaluation, and Treatment of High Blood Cholesterol in Adults (Adult Treatment Panel III) final report. Circulation 2002;106:3143-421.

165. Eckel RH, Grundy SM, Zimmet PZ. The metabolic syndrome. Lancet 2005;365:1415-28.

166. Pinto-Sietsma SJ, Navis G, Janssen WM, de Zeeuw D, Gans RO, de Jong PE; PREVEND Study Group. A central body fat distribution is related to renal function impairment, even in lean subjects. Am J Kidney Dis 2003;41:733-41.

167. Chen J, Muntner P, Hamm LL, Jones DW, Batuman V, Fonseca V, Whelton PK, He J. The metabolic syndrome and chronic kidney disease in U.S. adults. Ann Intern Med 2004;140: 167-74.

168. Chen J, Muntner P, Hamm LL, Fonseca V, Batuman V, Whelton PK, He J. Insulin resistance and risk of chronic kidney disease in nondiabetic US adults. J Am Soc Nephrol. 2003;14:469-77. 
169. Kurella M, Lo JC, Chertow GM. Metabolic syndrome and the risk for chronic kidney disease among nondiabetic adults. J Am Soc Nephrol 2005;16:2134-40.

170. Fox CS, Larson MG, Leip EP, Culleton B, Wilson PW, Levy D. Predictors of new-onset kidney disease in a community-based population. JAMA 2004;291:844-50.

171. Bakker SJ, Gansevoort RT, de Zeeuw D. Metabolic syndrome: a fata morgana? Nephrol Dial Transplant 2007;22:15-20.

172. Hsu CY, McCulloch CE, Iribarren C, Darbinian J, Go AS. Body mass index and risk for endstage renal disease. Ann Intern Med 2006;144:21-28.

173. Hall JE, Kuo JJ, da Silva AA, de Paula RB, Liu J, Tallam L. Obesity-associated hypertension and kidney disease. Curr Opin Nephrol Hypertens 2003;12:195-200.

174. Nagase M, Yoshida S, Shibata S, Nagase T, Gotoda T, Ando K, Fujita T. Enhanced aldosterone signaling in the early nephropathy of rats with metabolic syndrome: possible contribution of fat-derived factors. J Am Soc Nephrol 2006;17:3438-46.

175. Kambham N, Markowitz GS, Valeri AM, Lin J, D'Agati VD. Obesity-related glomerulopathy: an emerging epidemic. Kidney Int 2001;59:1498-509.

176. Thomas GN, Schooling CM, McGhee SM, Ho SY, Cheung BM, Wat NM, Janus ED, Lam KS, Lam TH; Hong Kong Cardiovascular Risk Factor Prevalence Study Steering Committee. Metabolic syndrome increases all-cause and vascular mortality: the Hong Kong Cardiovascular Risk Factor Study. Clin Endocrinol (Oxf). 2007;66:666-71.

177. de Vries AP, Bakker SJ, van Son WJ, van der Heide JJ, Ploeg RJ, The HT, de Jong PE, Gans RO. Metabolic syndrome is associated with impaired long-term renal allograft function; not all component criteria contribute equally. Am J Transplant 2004;4:1675-83.

178. Porrini E, Delgado P, Bigo C, Alvarez A, Cobo M, Checa MD, Hortal L, Fernández A, García JJ, Velázquez S, Hernández D, Salido E, Torres A. Impact of metabolic syndrome on graft function and survival after cadaveric renal transplantation. Am J Kidney Dis 2006; 48:134-42.

179. Holdaas H, Fellstrom B, Jardine A, Gimpelewicz C, Staffler B, Logan J. ALERT investigsters: Prevalence and cosequences of metabolic syndrome in a renal transplant population (Abstract). Am J Soc Nephrol 2004;15:572A.

180. Hjelmesaeth $\mathrm{J}$, Midtvedt $\mathrm{K}$, Jenssen $\mathrm{T}$, Hartmann $\mathrm{A}$. Insulin resistance after renal transplantation: Impact of immunosuppressive and antihypertensive drugs. Diabetes Care 2001;24:2121.

181. Kasiske BL, Chakkera HA, Roel J. Explained and unexplained ischemic heart disease risk after renal transplantation. J Am Soc Nephrol 2000;11:1735-43.

182. Ducloux D, Kazory A, Chalopin JM. Posttransplant diabetes mellitus and atherosclerotic events in renal transplant recipients: a prospective study. Transplantation 2005;79:438-43.

183. Ducloux D, Kazory A, Chalopin JM. Predicting coronary heart disease in renal transplant recipients: a prospective study. Kidney Int 2004;66:441-7.

184. Fellström B, Jardine AG, Soveri I, Cole E, Grönhagen-Riska C, Neumayer HH, Maes B, Gimpelewicz C, Holdaas H. Assessment of Lescol in Renal Transplantation trial. Renal dysfunction as a risk factor for mortality and cardiovascular disease in renal transplantation: experience from the Assessment of Lescol in Renal Transplantation trial. Transplantation 2005;79:1160-3.

185. Alberti KG, Zimmet P, Shaw J. The metabolic syndrome - a new worldwide definition. Lancet 2005;366:1059-62. 


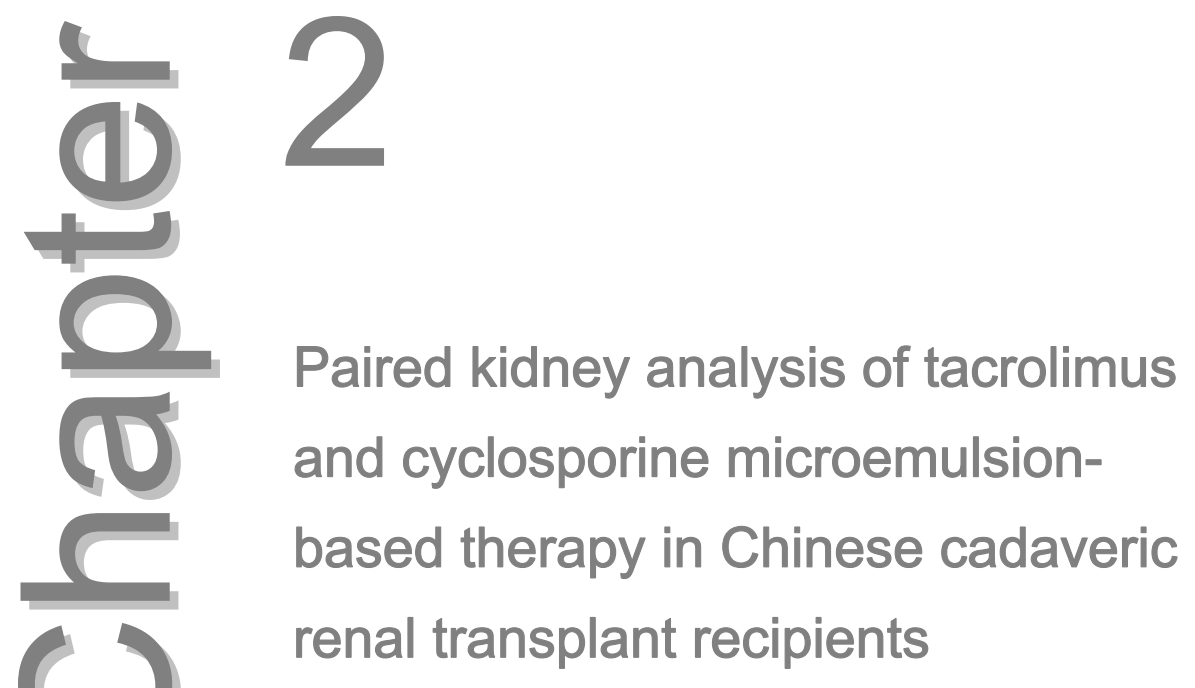

Chi Yuen Cheung, Kim Ming Wong, Hoi Wong Chan, Yan Lun Liu, Yiu Han Chan, Ho Sing Wong, Wai Leung Chak, Koon Shing Choi, Ka Foon Chau, Chun Sang Li

Transplant International 2006; 19:657-66 


\section{Abstract}

Few studies used paired kidneys for comparison between tacrolimus and cyclosporine in renal transplantation. Most of the published data used whole blood trough levels for drug monitoring. However, use of limited sampling strategy and abbreviated formula to estimate the 12-hour area under concentration-time curve $\left(\mathrm{AUC}_{0-12}\right)$ allowed better prediction of drug exposure. Sixty-six first cadaveric renal transplant recipients receiving paired kidneys were randomized to receive either tacrolimus-based $(n=33)$ or cyclosporine microemulsion (Neoral)-based therapies $(n=33)$. Abbreviated $A U_{0-12}$ was used for drug monitoring and dose titration. Mean follow-up duration was $2.8+/-2$ years. The patient and graft survival were comparable. Fewer incidence of acute rejection was observed in tacrolimus group (15\% vs. $27.3 \%)$ though the difference was not significant $(P=0.23)$. The absolute value and the rate of decline of creatinine clearance were both significantly better in tacrolimus-treated patients. Prevalence of hypertension, post-transplant diabetes mellitus, infection and malignancy were similar in both groups. Prevalence of hypercholesterolemia (11/33 vs. 4/33) and gum hypertrophy (6/33 vs $1 / 33)$ were more common in cyclosporine-treated patients $(P=0.04$ in both parameters). This was the first prospective, randomized study with paired kidney analysis showing the renal function was significantly better in tacrolimus-treated patients than in cyclosporine-treated patients. 


\section{Introduction}

One of the most important developments in renal transplantation in recent years was the introduction of new immunosuppressive agents for the prevention of acute rejection. Until the 1980s, corticosteroids and azathioprine were the main immunosuppressive agents. Cyclosporine was introduced in renal transplantation in the $1984^{1}$. The major advantages included reduction in the incidence of acute rejection and improvement in 1-year graft survival ${ }^{2-4}$.

Since 1995, cyclosporine/Sandimmune (Sandoz, Switzerland) was gradually replaced by cyclosporine/Neoral (Novartis, Switzerland), a microemulsion formula with a bile-independent and consistent absorption profile which led to lower intra-patient variability than Sandimmune ${ }^{5}$. In controlled trials, Neoral had proven to be superior to Sandimmune in the prevention of acute rejection ${ }^{6-8}$. After 1995, tacrolimus (FK 506) (Prograf, Fujisawa, Japan), another calcineurin inhibitor, was employed by many centers as an alternative therapy to Neoral.

Acute allograft rejection was significantly reduced with tacrolimus-based therapy compared with cyclosporine-based therapy in different large-center randomized trials and meta-analysis ${ }^{9-14}$. It had been argued that this superior effect of tacrolimus over cyclosporine might not be observed with the improved microemulsion formulation of cyclosporine. In this regard, randomized trials had been performed to compare tacrolimus and Neoral cyclosporine ${ }^{15-22}$. The superior results of tacrolimus-based therapy persisted even after changing to Neoral cyclosporine which had a more consistent absorption. The better shortterm results had translated into improved long-term outcome. Long-term follow up results from the two multicenter trials revealed a more stable renal function and longer projected half-life in those patients receiving tacrolimus-based therapy compared to cyclosporine-based therapy ${ }^{23,24}$. Use of tacrolimus resulted in advantages in cardiovascular risk profile in terms of reduction in the prevalence of hypertension and hyperlipidemia, ${ }^{911,12,17,18,25}$. Although tacrolimus-therapy was associated with an increased incidence of posttransplant diabetes mellitus ${ }^{9,10,14}$, most of them were reversible and dose dependent ${ }^{14,23}$.

Despite of the available information, there were few published comparative data on paired kidney analysis. Moreover, majority of the published data used whole blood trough level for dose monitoring and titration of tacrolimus and cyclosporine therapies. It had been shown that the trough level had a poor correlation with $\mathrm{AUC}_{0-12}{ }^{26-31}$. Our group favoured the use of limited sampling strategy and abbreviated formula to estimate the $A \mathrm{CC}_{0-12}$ which allowed better prediction of drug exposure ${ }^{26}$.

This was the first open-label controlled randomized trial with paired kidney analysis to compare the efficacy and safety of tacrolimus with Neoral 
cyclosporine-based immunosuppressive therapy in first cadaveric renal transplant recipients using estimated $\mathrm{AUC}_{0-12}$ approach for dose titration.

\section{Materials and methods}

\section{Trial design}

This was a prospective, open-label, randomized, parallel group study. All Chinese patients receiving paired kidneys in their first cadaveric renal transplants consecutively between $1^{\text {st }}$ June 1998 and $31^{\text {st }}$ December 2004 in Queen Elizabeth Hospital, Hong Kong were included in the study. Follow-up outcome data were collected until $31^{\text {st }}$ March 2005.

The study was performed in accordance with Declaration of Helsinki. Informed and written consent were obtained and the patients were randomized to receive triple immunosuppressive therapy with either tacrolimus or Neoral cyclosporine, concomitantly with prednisolone and azathioprine therapy. The randomization process occurred pre-operatively and was on 1:1 basis.

\section{Immunosuppressive regimens}

Neoral cyclosporine was initially administered orally as a loading dose of $10 \mathrm{mg} / \mathrm{kg}$ within 12 hours of surgery and then $5 \mathrm{mg} / \mathrm{kg}$ twice daily. Abbreviated formula based on limited sampling strategy was used in this study to estimate the cyclosporine area under 12-hour concentration- time curve $\left(\mathrm{AUC}_{0-12}\right)$. Calculation of cyclosporine $\mathrm{AUC}_{0-12}$ was based on the formula: $452.4+\mathrm{C}_{0}$ * $17.5+C_{1.5} * 1.89\left[C_{0}\right.$ : cyclosporine trough level; $C_{1.5}: 1.5-h r$ post dose cyclosporine level] ${ }^{31}$. The dose of cyclosporine was gradually titrated to maintain the abbreviated $\mathrm{AUC}_{0-12}$ at around $6000-8000 \mathrm{ng}$ hr/ml in the first 3 months post-transplant and $4000-6000 \mathrm{ng}{ }^{*} \mathrm{hr} / \mathrm{ml}$ from three months posttransplant onwards ${ }^{33}$. Whole blood levels of cyclosporine were monitored by Abbott TDX monoclonal specific assay (Abbott Laboratories, Abbott Park, IL, USA).

Tacrolimus was administered orally as capsules with loading dose of $0.3 \mathrm{mg} / \mathrm{kg}$ within 12 hours of surgery and then $0.15 \mathrm{mg} / \mathrm{kg}$ twice daily. Abbreviated tacrolimus $\mathrm{AUC}_{0-12}$ monitoring was used. Calculation of tacrolimus $\mathrm{AUC}_{0-12}$ was by the formula: $16.2+\mathrm{C}_{2} * 2.4+\mathrm{C}_{4} * 5.9\left[\mathrm{C}_{2}\right.$ : 2-hr post dose tacrolimus level; $\mathrm{C}_{4}$ : 4-hr post dose tacrolimus level]. Based on our previous pilot study in stable patients on tacrolimus, $A U_{0-12}$ value was kept at around $100-150 \mathrm{ng}{ }^{*} \mathrm{hr} / \mathrm{ml}$ in first three months and around $80-100 \mathrm{ng}^{*} \mathrm{hr} / \mathrm{ml}$ after three months ${ }^{26}$. Whole blood levels of tacrolimus were monitored by means of IMx tacrolimus II assay (Abbott Laboratories, Abbott Park, IL, USA). 
Concomitant immunosuppressive therapy was identical in the two arms of the trial. A bolus dose of intravenous methylprednisolone $500 \mathrm{mg}$ was given on day 1. This was followed by intravenous hydrocortisone $100 \mathrm{mg}$ every six hours for three days and followed by oral prednisolone $30 \mathrm{mg}$ daily. The dose of prednisolone was gradually tapered after the first month at a rate of $2.5 \mathrm{mg}$ every two weeks and then maintained at $5 \mathrm{mg}$ daily. Azathioprine was given at a dose of $1.5 \mathrm{mg} / \mathrm{kg}$ daily since day 1 .

Since 1999, some of our patients also received interleukin-2 (IL-2) receptor antagonist during induction therapy on a voluntary basis. Patients on Neoral cyclosporine was given Basiliximab (Simulect, Novartis, Switzerland) while patients on tacrolimus was given Daclizumab (Zenapax, Roche, USA). Basiliximab was given at a dose of $20 \mathrm{mg}$ around two hours before transplantation and the second dose was given four days after transplantation. Daclizumab was given at $1 \mathrm{mg} / \mathrm{kg}$ infusion around two hours before transplantation and then every 14 days for four more doses.

If a rejection episode occurred, our protocol prescribed pulse methylprednisolone therapy as first-line treatment with the dosage of $500 \mathrm{mg}$ daily for three days. In case of steroid resistant rejection, appropriate antibody therapy was started.

\section{Clinical outcome parameters}

Primary endpoints were patient survival, graft survival and the overall rate of acute rejection. Graft loss was defined as the need to resume long term dialysis, re-transplantation, transplant nephrectomy or death. Rejection was defined as any episode with the relevant clinical and laboratory signs and symptoms and all clinically apparent episodes of rejection were confirmed by core biopsy. Rejection was classified according to Banff 97 classification $^{34}$ after assessment by local pathologists.

The secondary endpoints were the course of renal function, the cardiovascular risk profile, the incidence of infection and malignancy. Renal function parameters were serum creatinine and estimated creatinine clearance $(\mathrm{CrCl})$ by means of Cockcroft-Gault formula and expressed in $\mathrm{ml} / \mathrm{min}^{35}$. The annualized change of $\mathrm{CrCl}(\mathrm{ml} / \mathrm{min}$ per year) was used to monitor the progression of renal function decline. Positive value means improvement or stabilization of renal function while negative value means decline in $\mathrm{CrCl}$.

The cardiovascular risk profile was assessed by the incidence of hypertension, hypercholesterolemia and diabetes mellitus. Hypercholesterolemia was defined as total cholesterol greater than $5.8 \mathrm{mM}(224 \mathrm{mg} / \mathrm{dl})$ or requiring lipid-lowering agent. The use of drugs for hypertension or hypercholesterolemia was established from the medical record. Post-transplant diabetes mellitus was defined as fasting blood glucose more than $7 \mathrm{mM}(126 \mathrm{mg} / \mathrm{dl})$ on two occasions 
at any time after transplantation in those patients with no previous history of diabetes mellitus.

\section{Statistical analysis}

The intention-to-treat population was used for analyses of both efficacy and safety and included all randomized patients who underwent transplantation and received at least one dose of study medication. Values were expressed as mean (standard deviation) or median (range). Baseline and demographic data were compared by Student's t test, Pearson's $\chi^{2}$ test or Fisher's exact test where appropriate. Pearson's $\chi^{2}$ test or Fisher's exact test was used to compare the rates of adverse events between treatment groups. Kaplan-Meier Model and log-rank test were used to compare the patient survival, graft survival and rejection-free survival. The annualized change of $\mathrm{CrCl}$ for each patient was determined using simple linear regression. At least three estimates over two consecutive years of follow-up were required to calculate the annualized change of $\mathrm{CrCl}$. A $P$-value of $<0.05$ was considered to be statistically significant.

\section{Results}

One hundred consecutive Chinese cadaveric renal transplant recipients were performed during the study period. Among them, 66 patients received paired cadaveric kidneys (for each pair of graft kidneys from the same donor, one was transplanted in tacrolimus group and the other transplanted in cyclosporine group). The remaining 34 patients received unpaired cadaveric kidneys (when only one kidney was available for transplantation because of single kidney donation or sharing with other transplant centers). In this study, only those paired kidney recipients were analyzed.

There were 33 patients randomized to each group and the mean follow-up duration was $2.8+/-2$ years. The baseline characteristics were depicted in Table 2.1. No statistically significant differences were observed in baseline parameters in both groups of patients. There were also no differences between those with or without IL-2 receptor antagonists (Table 2.2).

\section{Patient survival}

Two patients in the tacrolimus group (6.1\%) died with a functioning graft during the study. One patient died one year after renal transplantation because of acute myocardial infarction while the other died of carcinoma of stomach 3.5 years after kidney transplant. On the other hand, the patient survival in the 
cyclosporine group was $100 \%$ during the study. There was no significant difference in patient survival $(P=0.16)$.

Tabel 2.1 Baseline characteristics of the paired kidneys.

\begin{tabular}{lccc}
\hline & $\begin{array}{c}\text { Tacrolimus } \\
(\mathrm{n}=33)\end{array}$ & $\begin{array}{c}\text { Cyclosporine } \\
(\mathrm{n}=33)\end{array}$ & $P$ value \\
\hline Age (years) & $42.4+/-7.5$ & $41.2+/-12.6$ & $0.65^{\mathrm{a}}$ \\
Male (n (\%)) & $17(51.5)$ & $20(60.6)$ & $0.46^{\mathrm{b}}$ \\
HLA-AB $(\geq 2$ mismatch)(n(\%)) & $27(81.8)$ & $28(84.8)$ & $0.74^{\mathrm{b}}$ \\
HLA-DR $(\geq 1$ mismatch)(n(\%)) & $27(81.8)$ & $31(93.9)$ & $0.13^{\mathrm{b}}$ \\
& & & \\
PRA (\%) & $22.3+/-33.2$ & $19.3+/-26.7$ & $0.69^{\mathrm{a}}$ \\
& & & \\
Donor age (years) & $47.4+/-13.6$ & $47.4+/-13.6$ & $1.00^{\mathrm{a}}$ \\
Donor kidney weight (grams) & $182.5+/-42.7$ & $182.1+/-47.6$ & $0.97^{\mathrm{a}}$ \\
Cold ischemic time (hours) & $10.0+/-6.8$ & $7.9+/-4.8$ & $0.15^{\mathrm{a}}$ \\
Anastomotic time (minutes) & $47.2+/-9.8$ & $50.9+/-16.8$ & $0.28^{\mathrm{a}}$ \\
Use of IL-2 receptor antagonist $(\mathrm{n}(\%))$ & $20(60.6)$ & $19(57.6)$ & $0.80^{\mathrm{b}}$ \\
Primary cause of renal failure (n (\%)) & & & \\
$\quad$ Chronic glomerulonephritis & $20(60.6)$ & $20(60.6)$ & $1.00^{\mathrm{b}}$ \\
Diabetes mellitus & $3(9.1)$ & $2(6.1)$ & $1.00^{\mathrm{b}}$ \\
Polycystic kidney disease & $2(6.1)$ & $0(0)$ & $0.47^{\mathrm{b}}$ \\
Others/unknown & $8(24.2)$ & $11(33.3)$ & $0.41^{\mathrm{b}}$ \\
\hline
\end{tabular}

Values expressed as mean $+/$ - standard deviation or number (percentage)

a Student's t test, ${ }^{\text {b }}$ Pearson's chi squared test

PRA (panel-reactive antibody)

Tabel 2.2 Baseline characteristics of the patients with or without IL-2 receptor antagonists.

\begin{tabular}{lccc}
\hline & $\begin{array}{c}\text { Patients with IL-2R } \\
\text { antagonists }(\mathrm{n}=39)\end{array}$ & $\begin{array}{c}\text { Patients without IL-2R } \\
\text { antagonists }(\mathrm{n}=27)\end{array}$ & $P$ value \\
\hline Age (years) & $40.9+/-10.0$ & $43.1+/-10.9$ & $0.39^{\mathrm{a}}$ \\
HLA-A\&-B( $\geq 2$ mismatch)(n(\%)) & $33(84.6)$ & $22(81.5)$ & $0.73^{\mathrm{b}}$ \\
HLA-DR ( $\geq 1$ mismatch)(n(\%)) & $34(87.1)$ & $24(88.9)$ & $0.84^{\mathrm{b}}$ \\
PRA (\%) & $17.5+/-28.0$ & $25.5+/-32.5$ & $0.29^{\mathrm{a}}$ \\
Donor age (years) & $48.6+/-18.2$ & $44.6+/-10.8$ & $0.39^{\mathrm{a}}$ \\
Donor kidney weight (grams) & $189.6+/-36.1$ & $171.5+/-54.2$ & $0.12^{\mathrm{a}}$ \\
Cold ischemic time (hours) & $9.5+/-6.4$ & $8.5+/-5.0$ & $0.51^{\mathrm{a}}$ \\
Anastomotic time (minutes) & $48.2+/-8.8$ & $50.0+/-18.6$ & $0.62^{\mathrm{a}}$ \\
\hline
\end{tabular}

Values expressed as mean $+/$ - standard deviation or number (percentage)

${ }^{a}$ Student's t test, ${ }^{\mathrm{b}}$ Pearson's chi squared test

PRA (panel-reactive antibody)

\section{Graft survival}

A total of five patients had graft failure in the first year. Three of them belonged to the tacrolimus group while two belonged to cyclosporine group. Early graft nephrectomy was done in two patients because of graft vascular thrombosis (one in either group), in two patients (one in either group) because of graft artery anastomotic leakage and in one patient (tacrolimus group) because of 
rupture of graft kidney. The ruptured graft was shown to have Banff type III acute rejection on histology. The first-year graft survival rate, not censored for death, in the tacrolimus group during the study was $91 \%$ while in the cyclosporine group, it was $94 \%$. There was also no difference between both groups $(P=0.25)$.

\section{Acute rejection}

A total of 14 patients (five patients in tacrolimus group and nine patients in cyclosporine group) were treated for acute rejection. All were confirmed by renal biopsy. The histological type of the rejection was depicted in Table 2.3. All patients responded to pulse steroid therapy except the patient in the tacrolimus group with type III rejection requiring graft nephrectomy for ruptured graft kidney while the one in the cyclosporine group with type IIB required plasmapheresis. The patient with type III rejection in the cyclosporine group responded well with pulse steroid. Fewer acute rejections were observed in the tacrolimus group: $15 \%(5 / 33)$ vs. $27.3 \%$ (9/33) but the difference was not statistically significant $(P=0.23)$. The rejection free survival was similar $(P=0.25$; Figure 2.1).

Tabel 2.3 Types of acute rejection (Banff 97 classification).

\begin{tabular}{lcc}
\hline Episodes of acute rejection & Tacrolimus $(\mathrm{n}=5)$ & Cyclosporine $(\mathrm{n}=9)$ \\
\hline Borderline & 0 & 1 \\
Type IA & 0 & 3 \\
Type IB & 3 & 1 \\
Type II A & 1 & 2 \\
Type II B & 0 & 1 \\
Type III & 1 & 1 \\
\hline
\end{tabular}

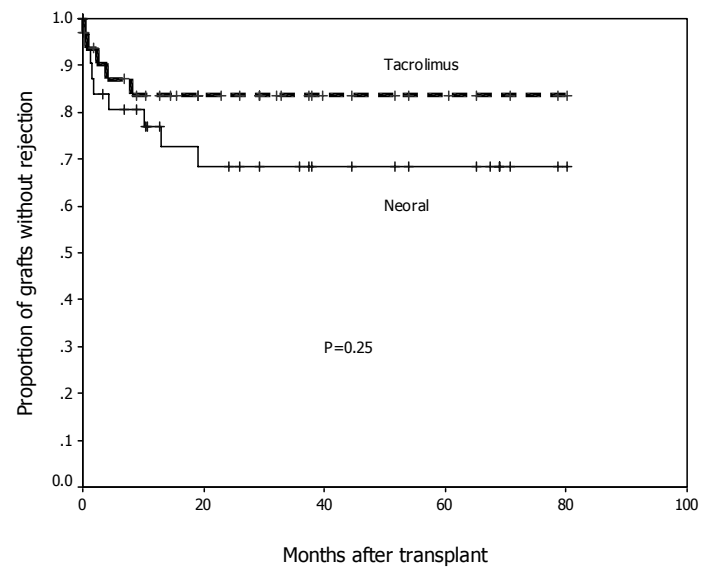

Figure 2.1 Kaplan-Meier estimates of rejection-free survival. 


\section{Renal function}

The creatinine clearance $(\mathrm{CrCl})$ was calculated using Cockcroft-Gault formula and was shown in Table 2.4 and Figure 2.2. In the first three months, there was no significant difference between both groups. However, the creatinine clearance was significantly better with tacrolimus therapy than cyclosporine therapy from six months onwards. There was no difference in the use of angiotensin converting enzyme inhibitors or angiotension II receptor blockers between them $(2 / 33$ in tacrolimus group vs. $3 / 33$ in cyclosporine group, $P=0.64$ ).

Table 2.4 Changes of creatinine clearance over time (intention to treat).

\begin{tabular}{lccccc}
\hline $\begin{array}{l}\text { Mean +/- SD CrCl } \\
\text { (ml/min) }\end{array}$ & $\begin{array}{c}\text { Tacrolimus } \\
\text { group }\end{array}$ & $\begin{array}{c}\text { Number of } \\
\text { patients }\end{array}$ & $\begin{array}{c}\text { Cyclosporine } \\
\text { group }\end{array}$ & $\begin{array}{c}\text { Number of } \\
\text { patients }\end{array}$ & $P$ value \\
\hline 1-month & $49+/-15$ & 30 & $42+/-18$ & 31 & 0.143 \\
3-month & $60+/-18$ & 30 & $51+/-18$ & 31 & 0.072 \\
6-month & $54+/-14$ & 30 & $46+/-16$ & 31 & 0.043 \\
12-month & $60+/-15$ & 30 & $46+/-14$ & 31 & 0.002 \\
24-month & $61+/-16$ & 24 & $48+/-15$ & 26 & 0.012 \\
36-month & $66+/-20$ & 22 & $50+/-14$ & 24 & 0.033 \\
48-month & $64+/-16$ & 15 & $48+/-15$ & 18 & 0.050 \\
60-month & $79+/-7$ & 10 & $56+/-17$ & 13 & 0.012 \\
\hline
\end{tabular}

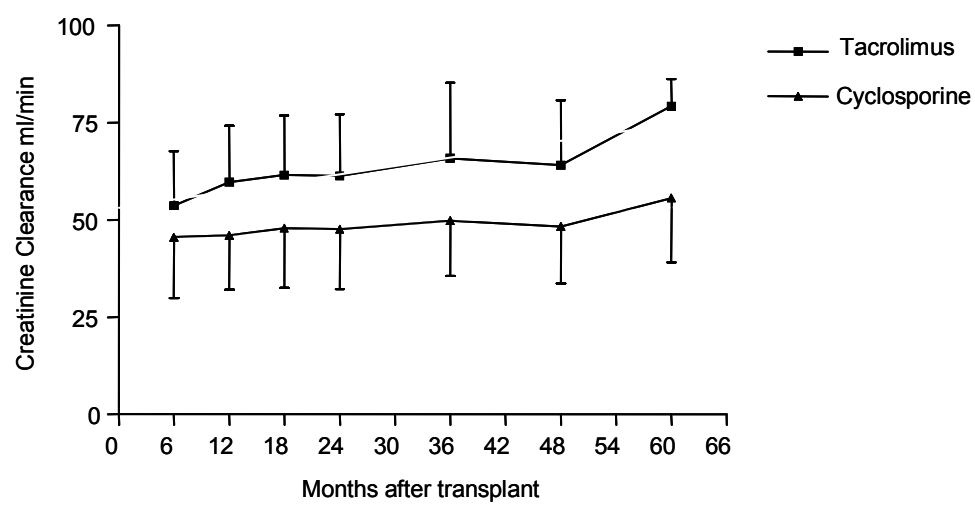

Figure 2.2 Changes of creatinine clearance over time.

If we excluded those with acute clinical rejection and compared the paired kidneys again, the creatinine clearance was still significantly better with tacrolimus therapy than cyclosporine therapy from one year onwards (Table 2.5). 
After excluding a pair of primary non functioning kidneys, we compared the remaining 32 pairs of kidneys separately. Twenty four patients belonging to tacrolimus group had a better creatinine clearance than their counterparts. On the other hand, only eight patients belonging to cyclosporine group had a better creatinine clearance.

Table 2.5 Changes of creatinine clearance over time after excluding those with acute rejection.

\begin{tabular}{lccccc}
\hline $\begin{array}{l}\text { Mean +/- SD CrCl } \\
\text { (ml/min) }\end{array}$ & $\begin{array}{c}\text { Tacrolimus } \\
\text { group }\end{array}$ & $\begin{array}{c}\text { Number of } \\
\text { patients }\end{array}$ & $\begin{array}{c}\text { Cyclosporine } \\
\text { group }\end{array}$ & $\begin{array}{c}\text { Number of } \\
\text { patients }\end{array}$ & $P$ value \\
\hline 6-month & $55+/-14$ & 27 & $45+/-18$ & 26 & 0.176 \\
12-month & $61+/-14$ & 26 & $50+/-14$ & 24 & 0.025 \\
24-month & $61+/-16$ & 24 & $51+/-15$ & 24 & 0.050 \\
36-month & $66+/-20$ & 22 & $50+/-14$ & 24 & 0.033 \\
48-month & $64+/-17$ & 15 & $48+/-15$ & 18 & 0.050 \\
60-month & $79+/-7$ & 10 & $56+/-17$ & 13 & 0.012 \\
\hline
\end{tabular}

\section{Stability of renal function over time}

The annualized change in $\mathrm{CrCl}$ in the tacrolimus group was $2.73+/-5.14$ $\mathrm{ml} / \mathrm{min}$ per year while in the cyclosporine group, the annualized change in $\mathrm{CrCl}$ was $-1.13+/-4.08 \mathrm{ml} / \mathrm{min}$ per year. The difference was statistically significant $(P<0.01)$. A total of $80 \%$ of tacrolimus-treated patients had improvement in $\mathrm{CrCl}$ while $20 \%$ had a decline. This was significantly better than cyclosporinetreated patients $(42.1 \%$ had improvement while $57.9 \%$ showed a decline) $(P=0.02)$.

\section{Dose of immunosuppressive agents}

In the tacrolimus group, the starting dose was $0.3 \mathrm{mg} / \mathrm{kg} / \mathrm{day}$ and gradually decreased to $0.07+/-0.01 \mathrm{mg} / \mathrm{kg} /$ day as the maintenance dose. In the cyclosporine group, the starting dose was $10 \mathrm{mg} / \mathrm{kg} / \mathrm{day}$ and gradually decreased to the maintenance dose at $2.86+/-0.71 \mathrm{mg} / \mathrm{kg} / \mathrm{day}$ (Table 2.6).

Table 2.6 Change of dose of immunosuppressive agents over time.

\begin{tabular}{lcc}
\hline Mean +/- SD dose of drug & Tacrolimus $(\mathrm{mg} / \mathrm{kg} /$ day) & Neoral $(\mathrm{mg} / \mathrm{kg} /$ day $)$ \\
\hline 0-day & 0.30 & 10 \\
2-week & $0.21+/-0.06$ & $7.20+/-1.16$ \\
1-month & $0.18+/-0.07$ & $5.84+/-1.71$ \\
3-month & $0.12+/-0.06$ & $4.08+/-1.20$ \\
6-month & $0.09+/-0.05$ & $3.61+/-0.99$ \\
12-month & $0.07+/-0.03$ & $3.61+/-1.06$ \\
24-month & $0.06+/-0.02$ & $3.28+/-0.78$ \\
36-month & $0.06+/-0.02$ & $3.18+/-0.80$ \\
48-month & $0.07+/-0.01$ & $3.06+/-0.81$ \\
60-month & $0.07+/-0.01$ & $2.86+/-0.71$
\end{tabular}




\section{Level of immunosuppressive agents}

For monitoring and dosage adjustment, $\mathrm{AUC}_{0-12}$ levels of tacrolimus and cyclosporine were estimated by using abbreviated equations ${ }^{26,32}$. These were shown in Table 2.7.

Table 2.7 Change of AUC of immunosuppressive agents over time.

\begin{tabular}{lcc}
\hline Mean +/-SD AUC & Tacrolimus & Cyclosporine \\
\hline 2-week & $149+/-42$ & $9828+/-4839$ \\
1-month & $143+/-53$ & $7573+/-1389$ \\
3-month & $126+/-33$ & $5482+/-1661$ \\
6-month & $109+/-24$ & $4813+/-1351$ \\
12-month & $98+/-25$ & $4007+/-948$ \\
24-month & $96+/-26$ & $3706+/-652$ \\
36-month & $90+/-22$ & $4438+/-1028$ \\
48-month & $97+/-26$ & $4843+/-2280$ \\
60-month & $98+/-10$ & $4951+/-308$ \\
\hline
\end{tabular}

\section{Hypercholesterolemia}

Significantly more patients in the cyclosporine group (11/33, 33.3\%) suffered from hypercholesterolemia when compared with tacrolimus group (4/33, 12.1\%) $(P=0.04$; Table 2.8).

Table 2.8 Complications in tacrolimus and Neoral cyclosporine group.

\begin{tabular}{lccc}
\hline Complications, $\mathrm{n}(\%)$ & $\begin{array}{c}\text { Tacrolimus } \\
(\mathrm{n}=33)\end{array}$ & $\begin{array}{c}\text { Cyclosporine } \\
(\mathrm{n}=33)\end{array}$ & $P$ value \\
\hline Hypertension & $27(81.8 \%)$ & $25(75.8 \%)$ & 0.52 \\
Hypercholesterolemia & $4(12.1 \%)$ & $11(33.3 \%)$ & 0.04 \\
Diabetes mellitus & $3(9.1 \%)$ & $2(6.1 \%)$ & 0.64 \\
Urinary tract infection & $10(30.3 \%)$ & $8(24.2 \%)$ & 0.58 \\
Opportunistic infection & $13(39.4 \%)$ & $16(48.4 \%)$ & 0.25 \\
Malignancy & $2(6.1 \%)$ & $2(6.1 \%)$ & 1 \\
\hline
\end{tabular}

\section{Hypertension}

There was no significant difference between the cyclosporine group (25/33, $75.8 \%)$ and tacrolimus group $(27 / 33,81.8 \%)(P=0.52$; Table 2.8). Patients in the cyclosporine group tended to use more antihypertensive medications $(2.1+/-1.6$ in cyclosporine group versus $1.9+/-1.3$ in tacrolimus group), however, it did not reach statistically significant level $(P=0.61)$. 


\section{Post-transplant diabetes mellitus}

The incidence of post-transplant diabetes mellitus was higher in tacrolimus group, but the difference was not statistically significant $[9.1 \%(3 / 33)$ in tacrolimus group versus $6.1 \%(2 / 33)$ in cyclosporine group, $P=0.64$; Table 2.8]. Of the three patients suffering from post-transplant diabetes mellitus in the tacrolimus group, one was able to withdraw all diabetic medications within the first year. On the other hand, the two patients in the cyclosporine group required diabetic medications during the study period.

\section{Infection}

The episodes of bacterial urinary tract infection were slightly more common in tacrolimus group (10/33 in tacrolimus group versus $8 / 33$ in cyclosporine group). However, the difference was not significant $(P=0.58$; Table 2.8). For opportunistic infection, the incidence in both groups was also comparable (13/33 in tacrolimus group versus $16 / 33$ in cyclosporine group, $P=0.25$; Table 2.8).

\section{Malignancy}

There were two patients in each group (6.1\%) who developed malignancy after transplant. In the tacrolimus group, one had carcinoma of stomach while the other had carcinoma of thyroid. In the cyclosporine group, one had Kaposi sarcoma and the other had hepatocellular carcinoma. No statistical significant differences were observed between them (Table 2.8).

\section{Neurotoxicity}

There were more tremor and numbness in tacrolimus group (21/33 in tacrolimus group versus $16 / 33$ in cyclosporine group) but the difference was not statistically significant $(P=0.21)$.

\section{Cosmetic side effects}

Acne and hirsutism were comparable in both groups but the gum hypertrophy was more common in cyclosporine group (1/33 in tacrolimus group versus $6 / 33$ in cyclosporine group, $P=0.04$ ). 


\section{Discussion}

Although there were many studies comparing tacrolimus and cyclosporine Sandimmune or Neoral in renal transplant recipients in recent years, most of the patients involved were Caucasian. There were very few similar comparative studies in Chinese patients. All of the patients in our study were from a homogeneous population. They were Chinese patients undergoing first cadaveric renal transplantation. To eliminate the confounding factors attributed to differences in the donor kidney status, patients recruited in this study received paired cadaveric kidneys (one to each group) which allowed better comparison between the two groups under similar donor factors. To the best of our knowledge, this was the first published single center and randomized trial with paired kidney analysis for direct comparison of tacrolimus and cyclosporine therapies. Furthermore, all the published data were based on the drug trough level for dose titration of both tacrolimus and cyclosporine. To improve the accuracy of therapeutic drug monitoring, we employed area under the curve $\left(\mathrm{AUC}_{0-12}\right)$ estimated by limited sampling equations to compare the efficacy and safety of tacrolimus and cyclosporine therapies.

In the U.S. and European trials, whole blood tacrolimus and cyclosporine trough levels were used for drug monitoring and dosage adjustment ${ }^{9-12}$. On the other hand, abbreviated AUC method was used for dose optimization in our center. Many centers relied on measurements of tacrolimus trough level $\left(\mathrm{C}_{0}\right)$ because it was generally thought that they could reflect $\mathrm{AUC}_{0-12}{ }^{36}$. However, different studies yielded different results recently ${ }^{26,27,37,38}$. Our group had reported a pharmacokinetic study in 18 stable Chinese renal transplant recipients ${ }^{26}$. We found that $C_{0}$ had a poor correlation with $A \cup C_{0-12}\left(R^{2}=0.12\right)$. On the other hand, abbreviated $\mathrm{AUC}_{0-12}$ obtained by two-time point regression equation using 2-hour $\left(\mathrm{C}_{2}\right)$ and 4-hour $\left(\mathrm{C}_{4}\right)$ tacrolimus concentrations obtained a $R^{2}$ value of 0.93 . In present study, the target abbreviated $A \cup C_{0-12}$ for tacrolimus was $100 \mathrm{ng}^{*} \mathrm{hr} / \mathrm{ml}$ after three months. By extrapolation of the relationship between $\mathrm{C}_{0}$ and $A \cup \mathrm{C}_{0-12}$, this corresponded to a $\mathrm{C}_{0}$ of around $6 \mathrm{ng} / \mathrm{ml}$. This explained the lower tacrolimus dose and lower incidence of posttransplant diabetes in our center. Moreover, cyclosporine trough level was not a reliable indicator of total drug exposure and subsequent clinical events ${ }^{39}$. As a result, investigators had advocated using time point sampling to estimate $\mathrm{AUC}_{0-12}{ }^{29-32}$. In our study, we used the two-time point regression equation obtained from the Chinese population to estimate the $\mathrm{AUC}_{0-12}{ }^{32}$.

The use of IL-2 receptor antagonists in some of our patients might introduce bias to this study. However, we showed that there were no differences in the baseline characteristics between those receiving IL-2 receptor antagonists and those did not. Moreover, there was also no difference in the percentage of patients on IL-2 receptor antagonists in both treatment groups. Although two 
different preparations of IL-2 receptor antagonists were used, there were no controlled studies showing any differences between basiliximab and daclizumab in terms of prevention of acute rejection, incidence of infections and malignancies ${ }^{40}$. We could say that use of IL-2 receptor antagonists were identical in both arms.

Both tacrolimus and cyclosporine were nephrotoxic drugs ${ }^{41}$. Many studies showed that the renal function was comparable between tacrolimus and cyclosporine after transplantation ${ }^{9-11,15,16,18,21}$. In a study using paired kidney analysis ${ }^{42}$, serum creatinine was significant lower in tacrolimus group. However, the slope of $1 / \mathrm{Cr}$ did not appear to be different between the two agents. In present study, we calculated the creatinine clearance using Cockcroft-Gault formula. Equation derived from the Modification of Diet in Renal Disease (MDRD) study was not used in our study because it had not been validated in Chinese population ${ }^{43-45}$. We found that patients treated with tacrolimus had a significant better creatinine clearance starting from six months after transplantation. The difference sustained throughout the 5-year period. The maintenance of renal function in the tacrolimus group was further evident by slower decline of creatinine clearance during the follow-up period. We also found that more patients in Neoral cyclosporine group suffered from deterioration in renal function. Since this was a paired kidney analysis, the difference was unlikely due to the differences in any donor variables. One of the main reasons for this deterioration could be due to the development of chronic allograft nephropathy in the cyclosporine group. In a study of healthy volunteers by Klein et al, tacrolimus had no effect on renal hemodynamics and systemic blood pressure. In contrast, cyclosporine led to a decrease in GFR and renal plasma flow and an increase in blood pressure. This difference in functional nephrotoxicity might contribute to structural lesions found in chronic calcineurin-inhibitor nephrotoxicity ${ }^{46}$. This would affect the long term renal graft survival. Another possible explanation for the better renal function in tacrolimus-based patients might be related to the lower incidence of subclinical rejection. Subclinical rejection was shown to correlate closely with subsequent allograft dysfunction ${ }^{47,48}$. However, it could not be shown in this study because protocol biopsies were not performed in our center.

In conclusion, we found that both the absolute value and the rate of decline in creatinine clearance over time were significantly better in tacrolimus group compared to cyclosporine group in this paired kidney analysis. A lower incidence of acute rejection was also observed in our Chinese patients when compared with the Caucasian. The use of abbreviated $\mathrm{AUC}_{0-12}$ might provide an alternate tool for drug monitoring, especially with the many limitations of using trough level as discussed above. Although there was a lower incidence of acute rejection in tacrolimus group, the difference was not statistically significant. The patient and graft survival were comparable in both groups of 
patients. No significant differences were noted between tacrolimus and cyclosporine-based therapies in terms of prevalence of hypertension, posttransplant diabetes mellitus, infection, malignancy and neurotoxicity. However, hyperlipidemia and gum hypertrophy were more common in cyclosporine group. 


\section{References}

1. Calne RY, Rolles K, White DJ, Thiru S, Evans DB, McMaster P, Dunn DC, Craddock GN, Henderson RG, Aziz S, Lewis P. Cyclosporin A initially as the only immmunosuppressant in 34 recipients of cadaveric organs: 32 kidneys, 2 pancreases, and 2 livers. Lancet 1979;2: 1033-6.

2. European Multicentre Trial Group. Cyclosporine in cadaveric renal transplantation: one-year follow-up of a multicentre trial. Lancet 1983;2:986-9.

3. Hall BM, Tiller DJ, Hardie I, Mahony J, Mathew T, Thatcher G, Miach P, Thomson N, Sheil AG. Comparison of three immunosuppressive regimens in cadaveric renal transplantation: long-term cyclosporine, short-term cyclosporine followed by azathioprine and prednisolone, and azathioprine and prednisolone without cyclosporine. N Engl J Med 1998;318:1499-507.

4. The Canadian Multicentre Transplant Study Group. A randomized clinical trial of cyclopsorine in a cadaveric renal transplantation. N Engl J Med 1983;309:809-15.

5. Friman S, Backman L. A new microemulsion formulation of cyclosporine: pharmacokinetic and clinical features. Clin Pharmacokinet 1996;30:181-93.

6. Keown P, Niese D on behalf of the International Sandimmun Neoral Study Group. Cyclosporine microemulsion increases drug exposure and reduces acute rejection without incremental toxicity in de novo renal transplantation. Kidney Int 1998;54:938-44.

7. Niese D on behalf of the International Sandimmun Neoral Study Group. A double-blind randomized study of Sandimmun Neoral versus Sandimmun in new renal transplant recipients: results after 12 months. Transplant Proc 1995;27:1849-56.

8. Pollard SG, Lear PA, Ready AR, Moore RH, Johnson RWG on behalf of the UK Neoral Renal Study Group. Comparison of microemulsion and conventional formulations of cyclosporin $A$ in preventing acute rejection in de novo kidney transplant patients. Transplantation 1999;68: 1325-31.

9. Pirsch JD, Miller J, Deierhoi MH, Vincenti F, Filo RS. A comparison of tacrolimus (FK506) and cyclosporine for immunosuppression after cadaveric renal transplantation. FK506 Kidney Transplant Study Group. Transplantation 1997;63:977-83.

10. Mayer AD, Dmitrewski J, Squifflet JP, Besse T, Grabensee B, Klein B, Eigler FW, Heemann U, Pichlmayr R, Behrend M, Vanrenterghem Y, Donck J, van Hooff J, Christiaans M, Morales JM, Andres A, Johnson RW, Short C, Buchholz B, Rehmert N, Land W, Schleibner S, Forsythe JL, Talbot D, Pohanka E, et al. Multicenter randomized trial comparing tacrolimus (FK506) and cyclosporine in the prevention of renal allograft rejection: a report of the European Tacrolimus Multicenter Renal Study Group. Transplantation 1997;64:436-43.

11. Jensik SC and the FK 506 Kidney Transplant Study Group. Tacrolimus (FK506) in kidney transplantation: three-year survival results of the US Multicenter, Randomized, Comparative Trial. Transplant Proc 1998;30:1216-9.

12. Vincenti $F$ and the Tacrolimus Kidney Transplant Study Group. Tacrolimus (FK506) in kidney transplantation: five-year survival results of the US Multicenter, Randomized, Comparative Trial. Transplant Proc 2001;33:1019-20.

13. Knoll GA, Bell RC. Tacrolimus versus cyclosporin for immunosuppression in renal transplantation: meta-analysis of randomized trials. BMJ 1999;318:1104-7.

14. Webster AC, Woodroffe RC, Taylor RS, Chapman JR, Craig JC. Tacrolimus versus ciclosporin as primary immunosuppression for kidney transplant recipients: meta-analysis and meta-regression of randomized trial data. BMJ 2005;331:810-20.

15. Ghasemian SR, Light JA, Currier C, Sasaki TM, Aquino A. Tacrolimus vs Neoral in renal and renal/pancreas transplantation. Clin Transplant 1999;13:123-5.

16. Morris-Stiff G, Ostrowski K, Balaji V, Moore R, Darby C, Lord R, Jurewicz WA. Prospective randomized study comparing tacrolimus (Prograf) and cyclosporine (Neoral) as primary immunosuppression in cadaveric renal transplants at a single institution: interim report of the first 80 cases. Transpl Int 1998;11(S1):S334-6.

17. Jurewicz WA. Immunological and non-immunological risk factors with tacrolimus and Neoral in renal transplant recipients: an interim report. Transplant Proc 1999:31(S7A): 64S-66S. 
18. Boots JMM, van Duijnhoven E, Christiaans M, Nieman FHM, van Suylen RJ, van Hooff JP. Single-center experience with tacrolimus versus cyclosporine-Neoral in renal transplant recipients. Transpl Int 2001;14:370-83.

19. Gurkan A, Tuncer M, Colak T, Erdoğan O, Demirbas A, Dosemeci L, Yakupoglu G. Comparison of tacrolimus and Neoral-based immunosuppressive regimens in renal transplantation patients: single-center experience. Transplant Proc 2002;34:1661-2.

20. Pascual J, Marcen R, Burgos FJ, Tenorio MT, Merino JL, Arambarri M, Villafruela JJ, Liaño F, Mampaso F, Ortuño J. One-center comparison between primary immunosuppression based on Neoral cyclosporine and tacrolimus for renal transplantation. Transplant Proc 2002;34: 94-5.

21. Margreiter $\mathrm{R}$ for the European Tacrolimus vs Ciclosporin Microemulsion Renal Transplantation Study Group. Efficacy and safety of tacrolimus compared with ciclosporin microemulsion in renal transplantation: a randomized multicenter study. Lancet 2002:359: $741-6$.

22. Trompeter R, Filler G, Webb NJ, Watson AR, Milford DV, Tyden G, Grenda R, Janda J, Hughes D, Ehrich JH, Klare B, Zacchello G, Bjorn Brekke I, McGraw M, Perner F, Ghio L, Balzar E, Friman S, Gusmano R, Stolpe J. Randomized trial of tacrolimus versus cyclosporin microemulsion in renal transplantation. Pediatr Nephrol 2002;17:141-9.

23. Vincenti F, Jensik SC, Filo RS, Miller J, Pirsch J. A long-term comparison of tacrolimus (FK506) and cyclosporine in kidney transplantation: evidence for improved allograft survival at five years. Transplantation 2002;73:775-82.

24. Mayer AD for the European Tacrolimus Multicenter Renal Study Group. Chronic rejection and graft half-life: five-year follow-up of the European Tacrolimus Multicenter Renal Study. Transplant Proc 2002:34:1491-2.

25. Hohage H, Bruckner D, Arlt M, Buchholz B, Zidek W, Spieker C. Influence of cyclosporine A and FK506 on 24 hour blood pressure monitoring in kidney transplant recipients. Clin Nephrol 1996;45:342-4.

26. Wong KM, Shek CC, Chau KF, Li CS. Abbreviated tacrolimus area-under-the-curve monitoring for renal transplant recipients. Am J Kidney Dis 2000;35: 660-6.

27. Stolk L, van Duijnhoven EM, Christiaans MHL, van Hooff JP. Trough levels of tacrolimus (discussion). Therapeutic Drug Monitoring 2002;24:573-4.

28. Pisitkun T, Elam-Ong S, Chusil S, Praditpornsilpa K, Pansin P, Tungsanga K. The roles of C4 and AUC 0-4 in monitoring of tacrolimus in stable kidney transplant patients. Transplant Proc 2002;34:3173-5.

29. Keown $\mathrm{P}$, Kahan BD, Johnston A. Optimization of cyclosporine therapy with new therapeutic drug monitoring strategies: Report from the International Neoral TDM Advisory Consensus Meeting (Vancouver, November 1997). Transplant Proc. 1998;30:1645-9.

30. Gaspari F, Caruso R, Cattaneo D, Perico N, Remuzzi G. Optimization of cyclosporine therapy in the Neoral era: abbreviated AUC, single blood sampling? Transplant Proc 2001;33:3117-9.

31. Meier-Kriesche HU, Alloway R, Gaber AO, Canafax DM, Kaplan B. A limited sampling strategy for the estimation of 12-hour SangCya and neoral AUCs in renal transplant recipients. J Clin Pharmacol 1999;39:166-71.

32. Tsang WK, Ho YW, Tong KL, Chan WH, Chan A. Safety, tolerability, and pharmacokinetics of Sandimmun Neoral: conversion study in stable renal transplant recipients. Transplant Proc 1996;28:1330-2.

33. International Neoral Renal Transplantation Study Group. Cyclosporine microemulsion (Neoral) absorption profiling and sparse-sample predictors during the first 3 months after renal transplantation. Am J Transpl 2002;2:148-58.

34. Racusen LC, Solez K, Colvin RB, et al. The Banff 97 working classification of renal allograft pathology. Kidney Int 1999;55:713-23.

35. Gault MH, Longerich LL, Harnett JD, Wesolowski C. Predicting glomerular function from adjusted serum creatinine (editorial). Nephron 1992;62:249.

36. Mahalati K, Kahan BD. Pharmacological surrogates of allograft outcome. Ann Transplant 2000;5:14-23. 
37. Macchi-Andanson M, Charpiat B, Jelliffe RW, Ducerf C, Fourcade N, Baulieux J. Failure of traditional trough levels to predict tacrolimus concentrations. Therapeutic Drug Monitoring 2001;23:129-33.

38. Scholten EM, Cremers SC, Schoemaker RC, Rowshani AT, van Kan EJ, den Hartigh J, Paul LC, de Fijter JW. AUC-guided dosing of tacrolimus prevents progressive systemic overexposure in renal transplant recipients. Kidney International 2005;67:2440-7.

39. Mahalati K, Belitsky P, Sketris I, West K, Panek R. Neoral monitoring by simplified sparse sampling area under the concentration-time curve: its relationship to acute rejection and cyclosporine nephrotoxicity early after kidney transplantation. Transplantation 1999;68:55-62.

40. Van Gelder T, Warle M, Ter Meulen RG. Anti-interleukin-2 recepetor antibodies in transplantation: what is the basis for choice? Drugs 2004;64:1737-41

41. Mihatsch MJ, Kyo M, Morozumi K, Yamaguchi Y, Nickeleit V, Ryffel B. The side effects of cyclosporin A and tacrolimus. Clin Nephrol 1998;49:356-63.

42. Kaplan B, Schold JD, Meier-Kriesche H. Long-term graft survival with Neoral and tacrolimus: a paired kidney analysis. Journal of the American Society of Nephrology 2003;14:2980-4.

43. Levey AS, Bosch JP, Lewis JB, Greene T, Rogers N, Roth D. A more accurate method to estimate glomerular filtration rate from serum creatinine: a new prediction equation. Modification of Diet in Renal Disease Study Group. Ann Intern Med. 1999;16;130:461-70.

44. Levey AS, Coresh J, Balk E, Kausz AT, Levin A, Steffes MW, Hogg RJ, Perrone RD, Lau J, Eknoyan G; National Kidney Foundation.. National Kidney Foundation practice guidelines for chronic kidney disease: evaluation, classification, and stratification. Ann Intern Med 2003;139:137-47.

45. Zuo L, Ma YC, Zhou YH, Wang M, Xu GB, Wang HY. Application of GFR-estimating equations in Chinese patients with chronic kidney disease. Am J Kidney Dis 2005;45:463-72.

46. Klein IHHT, Abrahams A, van Ede T, Hene RJ, Koomans HA, Ligtenberg G. Different effects of Tacrolimus and Cyclosporine on renal haemodynamics and blood pressure in healthy subjects. Transplantation 2002;73:732-6.

47. Nankivell BJ. Borrows RJ. Fung CL, O'Connell PJ, Allen RD. Chapman JR. Natural history, risk factors, and impact of subclinical rejection in kidney transplantation. Transplantation 2004;78:242-9.

48. Miyagi M, Ishikawa $Y$, Mizuiri S, Aikawa A, Ohara T, Hasegawa A. Significance of subclinical rejection in early renal allograft biopsies for chronic allograft dysfunction. Clin Transplant 2005;19: 456-65. 


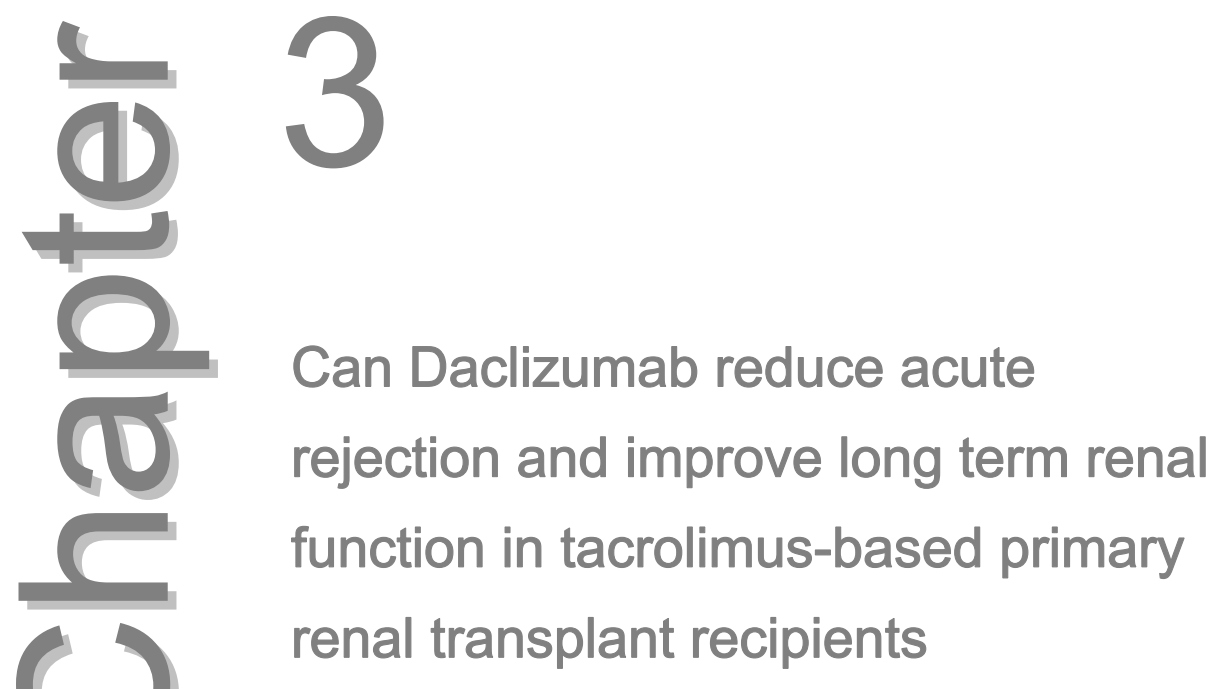

Chi Yuen Cheung, Yan Lun Liu, Kim Ming Wong, Hoi Wong Chan, Yiu Han Chan, Ho Sing Wong, Wai Leung Chak, Koon Shing Choi, Ka Foon Chau, Chi Chung Shek, Chun Sang Li

Nephrology (Carlton) 2008;13:251-255. 


\section{Abstract}

The aim of the study is to evaluate the efficacy and safety of a tacrolimus-based immuno-suppressive regimen with and without induction therapy using daclizumab in first cadaveric renal transplant recipients. Since January 2001, we studied the effect of daclizumab in a nonrandomized and prospective study of 36 sequential first cadaveric renal transplant recipients. They were compared with a historical control group of 21 sequential first cadaveric renal transplant recipients without induction therapy. All patients received tacrolimus, azathioprine and corticosteroids as concomitant immunosuppressive therapy. Daclizumab was given at $1 \mathrm{mg} / \mathrm{kg}$ infusion two hours before transplantation and then every 14 days for four more doses. Outcomes measured included incidence of acute rejection, patient survival, graft survival, annualized change in creatinine clearance $(\mathrm{CrCl})$, cardiovascular risk profile, infection and malignancy. Fewer biopsy proven acute rejections were observed in the induction treatment group: $11.1 \%(4 / 36)$ versus $19 \%$ (4/21) but the rejection free survival was similar $(P=0.37)$. The patient survival and graft survival were comparable. The renal function was similar in both groups. There were also no significant difference in infection, malignancy and cardiovascular risk profile in both groups. Adding daclizumab to a tacrolimus-based therapy is safe but cannot further improve clinical efficacy. 


\section{Introduction}

Daclizumab, a humanized anti-interleukin-2 (IL-2) receptor monoclonal antibody, was first approved for immunosuppressive treatment in renal transplantation in 1997. It inhibits IL-2 mediated activation of lymphocytes and impairs the immune response. Use of daclizumab could decrease the incidence of acute rejection ${ }^{1-3}$. However, there was no difference in patient and graft survival at three years post renal transplantation in patients treated with daclizumab when compared with placebo ${ }^{1,2}$.

Different studies have demonstrated that tacrolimus was superior than cyclosporine in the reduction of acute rejection and improve in long term graft survival ${ }^{4-6}$. Although it has been shown that combining IL-2 receptor antibody with cyclosporine can reduce the incidence of acute rejection, the benefits of use of IL-2 receptor antibody in tacrolimus-based patients were not well shown. In fact, comparative studies of IL-2 receptor antibody induction versus no induction in patients receiving tacrolimus-based immunosuppression are lacking $^{7}$. In a prospective and randomized trial in pediatric renal transplantation, use of IL-2 receptor antibody did not improve clinical efficacy. There was no difference in patient survival, graft survival and biopsy-proven acute rejection ${ }^{8}$. The aim of this study is to evaluate the efficacy and safety of a tacrolimusbased immunosuppressive regimen with and without induction therapy using daclizumab in our first cadaveric renal transplant recipients.

\section{Methods}

\section{Trial design}

This was a single center and prospective study. Since $1^{\text {st }}$ January 2001,36 sequential first cadaveric renal transplant recipients were put on induction treatment with daclizumab. This group was compared with 21 sequential first cadaveric renal transplant recipients between $1^{\text {st }}$ June 1998 and $31^{\text {st }}$ December 2000, who did not receive induction therapy regarded as a historic control group. All patients were Chinese and received tacrolimus-based therapy. Follow-up outcome data were analyzed until $31^{\text {st }}$ December 2006 . The trial was approved by ethical committee and conducted in accordance with the Declaration of Helsinki. Written consent was obtained.

\section{Immunosuppressive regimens}

Tacrolimus was administered orally as capsules with loading dose of $0.3 \mathrm{mg} / \mathrm{kg}$ within 12 hours of surgery and then $0.15 \mathrm{mg} / \mathrm{kg}$ twice daily. Abbreviated 
tacrolimus $\mathrm{AUC}_{0-12}$ monitoring was used. Calculation of tacrolimus $\mathrm{AUC}_{0-12}$ was by the formula: $16.2+\mathrm{C}_{2}{ }^{*} 2.4+\mathrm{C}_{4} * 5.9\left[\mathrm{C}_{2}\right.$ : 2-h post dose tacrolimus level; $\mathrm{C}_{4}$ : 4-h post dose tacrolimus level]. Based on our previous pilot study in stable patients on tacrolimus, $\mathrm{AUC}_{0-12}$ value was kept at around 100-150 $\mathrm{ng} \times \mathrm{h} / \mathrm{ml}$ in first three months and around $80-100 \mathrm{ng} \mathrm{x} \mathrm{h} / \mathrm{ml}$ after three months ${ }^{9}$. Whole blood levels of tacrolimus were monitored by means of IMx tacrolimus II assay (Abbott Laboratories, Abbott Park, IL, USA).

Concomitant immunosuppressive therapy was identical in the two arms of the trial. A bolus dose of intravenous methylprednisolone $500 \mathrm{mg}$ was given on day 1 . This was followed by intravenous hydrocortisone $100 \mathrm{mg}$ every six hours for three days and followed by oral prednisolone $30 \mathrm{mg}$ daily. The dose of prednisolone was gradually tailed down after the first month at a rate of $2.5 \mathrm{mg}$ every two weeks and then maintained at $5 \mathrm{mg}$ daily. Azathioprine was given at a dose of $1.5 \mathrm{mg} / \mathrm{kg}$ daily since day 1 .

Patients in the study group received induction therapy. Daclizumab (Zenapax, Roche, NJ, USA) was given at $1 \mathrm{mg} / \mathrm{kg}$ infusion two hours before transplantation and then every 14 days for four more doses.

If a rejection episode occurred, our protocol prescribed pulse methylprednisolone therapy as first-line treatment with the dosage of $500 \mathrm{mg}$ daily for three days. In case of steroid resistant rejection, appropriate antibody therapy was started.

\section{Clinical outcome parameters}

The primary endpoint was the incidence of acute rejection. Rejection was defined as any episode with the relevant clinical and laboratory signs and symptoms and all clinically apparent episodes of rejection were confirmed by core biopsy. Rejection was classified according to Banff 97 classification ${ }^{10}$ after assessment by local pathologists.

The secondary endpoints were patient survival, graft survival, the course of renal function, the incidence of infection and malignancy, and the cardiovascular risk profile. Graft loss was defined as the need to resume long term dialysis, re-transplantation, transplant nephrectomy or death. Renal function parameters were serum creatinine and estimated creatinine clearance $(\mathrm{CrCl})$ by means of Cockcroft-Gault formula and expressed in milliliter per minute $^{11}$. The annualized change of $\mathrm{CrCl}(\mathrm{ml} / \mathrm{min} /$ year $)$ was used to monitor the progression of renal function decline. Positive value means improvement or stabilization of renal function while negative value means decline in $\mathrm{CrCl}$. The cardiovascular risk profile was assessed by the incidence of hypertension, hypercholesterolemia and diabetes mellitus. Hypercholesterolemia was defined as total cholesterol greater than $5.8 \mathrm{mM}(224 \mathrm{mg} / \mathrm{dl})$ or requiring lipid-lowering agent. New onset diabetes mellitus (NODM) was defined as fasting blood 
glucose more than $7 \mathrm{mM}(126 \mathrm{mg} / \mathrm{dl})$ on two occasions at any time after transplantation in those patients with no previous history of diabetes mellitus.

\section{Statistical analysis}

The intention-to-treat population was used for analyses of both efficacy and safety and included all patients who received at least one dose of study medication. Values were expressed as mean (SD) or median (range). Baseline and demographic data were compared by Student's t-test, Pearson's chisquared test or Fisher's exact test where appropriate. Pearson's chi-squared test or Fisher's exact test was used to compare the rates of adverse events between treatment groups. Kaplan-Meier Model and log-rank test were used to compare the patient survival, graft survival and rejection-free survival. The annualized change of $\mathrm{CrCl}$ for each patient was determined using simple linear regression. At least three estimates over two consecutive years of follow-up were required to calculate the annualized change of $\mathrm{CrCl}$. A two-tailed $P$-value of $<0.05$ was considered to be statistically significant.

\section{Results}

Thirty six patients received tacrolimus/steroid/azathioprine+daclizumab (TSA+D arm) while 21 patients received tacrolimus/steroid/azathioprine (TSA arm). The mean follow-up duration was $56+/-12$ months and $85+/-13$ months in TSA+D arm and TSA arm respectively. The baseline characteristics were depicted in Table 3.1. No statistical significant differences were observed in baseline parameters in both groups of patients.

\section{Acute rejection}

A total of eight patients (four patients in each arm) were treated for acute rejection. All were confirmed by renal biopsy. The histological type of the rejection was depicted in Table 3.2. All patients responded to pulse steroid therapy except two patients in the TSA arm with type III rejection requiring graft nephrectomy for ruptured graft kidney. Fewer acute rejections were observed in the TSA+D arm: $11.1 \%(4 / 36)$ versus $19 \%(4 / 21)$. The rejection free survival was similar $(P=0.37)$. 
Table 3.1 Baseline characteristics of the patients with and without induction therapy.

\begin{tabular}{lccc}
\hline & $\begin{array}{c}\text { TSA+D arm } \\
(\mathrm{n}=36)\end{array}$ & $\begin{array}{c}\text { TSA arm } \\
(\mathrm{n}=21)\end{array}$ & $P$ value \\
\hline Age (years) & $41.6+/-9.2$ & $44.1+/-6.3$ & $0.28^{\mathrm{a}}$ \\
Male (n (\%)) & $19(52.8)$ & $12(57.1)$ & $0.75^{\mathrm{b}}$ \\
Pre-transplant diabetes mellitus(n(\%)) & $3(8.3)$ & $4(19.0)$ & $0.40^{\mathrm{b}}$ \\
HLA-AB ( $\geq 2$ mismatch)(n(\%)) & $26(72.2)$ & $16(76.2)$ & $0.74^{\mathrm{b}}$ \\
HLA-DR $\geq 1$ mismatch)(n(\%)) & $27(75.0)$ & $15(71.4)$ & $0.77^{\mathrm{b}}$ \\
PRA-T cell (\%) & $22.8+/-34.4$ & $26.4+/-33.5$ & $0.70^{\mathrm{a}}$ \\
Donor age (years) & $50.8+/-15.1$ & $45.7+/-11.0$ & $0.31^{\mathrm{a}}$ \\
Cold ischemic time (hours) & $10.0+/-6.4$ & $10.4+/-5.4$ & $0.84^{\mathrm{a}}$ \\
Anastomotic time (minutes) & $46.1+/-7.7$ & $48.1+/-11.4$ & $0.44^{\mathrm{a}}$ \\
Primary cause of renal failure (n (\%)) & & & \\
$\quad$ Chronic glomerulonephritis & $23(63.9)$ & $11(52.4)$ & $0.39^{\mathrm{b}}$ \\
Diabetes mellitus & $2(5.6)$ & $2(9.5)$ & $0.97^{\mathrm{b}}$ \\
Polycystic kidney disease & $0(0)$ & $3(14.3)$ & $0.09^{\mathrm{b}}$ \\
Others/unknown & $11(30.5)$ & $5(23.8)$ & $0.58^{\mathrm{b}}$ \\
\hline
\end{tabular}

Values expressed as mean $+/$ - standard deviation or number (percentage)

a Student's t test, ${ }^{b}$ Pearson's chi squared test. TSA: tacrolimus/steroid/azathioprine; TSA+D: tacrolimus/steroid/azathioprine+daclizumab.

Tabel 3.2 Types of acute rejection, change of dose of tacrolimus over time and cardiovascular risk factors.

\begin{tabular}{lccc}
\hline & $\begin{array}{c}\text { TSA+D arm } \\
(\mathrm{n}=36)\end{array}$ & $\begin{array}{c}\text { TSA arm } \\
(\mathrm{n}=21)\end{array}$ & $P$ value \\
\hline Episodes of acute rejection & 1 & 0 & \\
Borderline & 0 & 0 & \\
Type IA & 3 & 1 & \\
Type IB & 0 & 1 & \\
Type II A & 0 & 0 & \\
Type II B & 0 & 2 & \\
Type III & & & \\
Mean +/-SD tacrolimus dosage (mg/kg/day) & 0.30 & 0.30 & 1 \\
0-day & $0.08+/-0.03$ & $0.10+/-0.05$ & 0.25 \\
6-month & $0.07+/-0.03$ & $0.06+/-0.03$ & 0.33 \\
12-month & $0.06+/-0.02$ & $0.06+/-0.02$ & 0.76 \\
18-month & $0.06+/-0.02$ & $0.06+/-0.02$ & 0.74 \\
24-month & $0.06+/-0.02$ & $0.06+/-0.02$ & 0.80 \\
36-month & & & \\
Cardiovascular risk factors, $\mathrm{n}(\%)$ & $27(75.0 \%)$ & $16(76.2 \%)$ & 0.92 \\
Hypertension & $8(22.2 \%)$ & $1(4.7 \%)$ & 0.08 \\
Hypercholesterolemia & $4(11.1 \%)$ & $3(14.3 \%)$ & 0.73 \\
NODM & & & \\
\hline
\end{tabular}

NODM: new onset diabetes mellitus; TSA: tacrolimus/steroid/azathioprine; TSA+D: tacrolimus/ steroid/azathioprine+daclizumab. 


\section{Patient survival}

Three patients in the TSA+D arm (8.3\%) died with functioning grafts during the study. One patient died one year after renal transplantation because of acute myocardial infarction. One died of septicemia two months after kidney transplant. The remaining patient died of carcinoma of stomach 3.5 years after kidney transplant. On the other hand, one patient died of subarachnoid hemorrhage three years after transplant in the TSA arm. There was no significant difference in patient survival $(P=0.62)$.

\section{Graft survival}

Total four patients had graft failure in the first year. Three of them belonged to the TSA arm while one patient belonged to the TSA+D arm. The patient in the $T S A+D$ arm had graft thrombosis. One patient in the TSA arm had graft artery anastomotic leakage while the other two patients had renal graft rupture. Both of them showed Type III acute rejection. The first-year graft survival rate, censored for death, in the TSA arm group was $14.3 \%$ while in the TSA+D arm, it was $2.7 \%$. There was no significant difference between both groups $(P=0.10)$.

\section{Dose of tacrolimus}

The change of dose of tacrolimus over time was shown in Table 3.2. The starting dose of tacrolimus in all patients was $0.3 \mathrm{mg} / \mathrm{kg} /$ day. In both treatment groups, the maintenance dose was $0.06+/-0.02 \mathrm{mg} / \mathrm{kg} / \mathrm{day}$. There was no significant difference between them.

\section{Renal function}

There was no significant difference of $\mathrm{CrCl}$ in both treatment groups starting from the first month after transplantation up to five years (Figure 3.1). The annualized change of $\mathrm{CrCl}$ in the TSA+D arm and the TSA arm was $1.12+/-$ $4.91 \mathrm{ml} / \mathrm{min} /$ year and $-1.4+/-5.48 \mathrm{ml} / \mathrm{min} /$ year respectively. The difference between them was not statistically significant $(P=0.1)$. There was no difference in the use of angiotensin converting enzyme inhibitors or angiotensin II receptor blockers between them $(1 / 36$ in the TSA+D arm vs. $2 / 21$ in the TSA arm, $P=0.55$ ).

\section{Infection}

The episodes of bacterial urinary tract infection were more common in the TSA arm $(10 / 21$ in the TSA arm versus $9 / 36$ in the TSA+D arm). However, the difference was not significant $(P=0.08)$. The incidence of opportunistic infection 
in both groups was also comparable $(10 / 36$ in the TSA+D arm vs. $7 / 21$ in the TSA arm, $P=0.66)$. Among the opportunistic infection, CMV infection was documented in $11.1 \%(4 / 36)$ in the TSA+D arm and $14.3 \%(3 / 21)$ in the TSA arm. There was also no significant difference between them $(P=0.73)$.

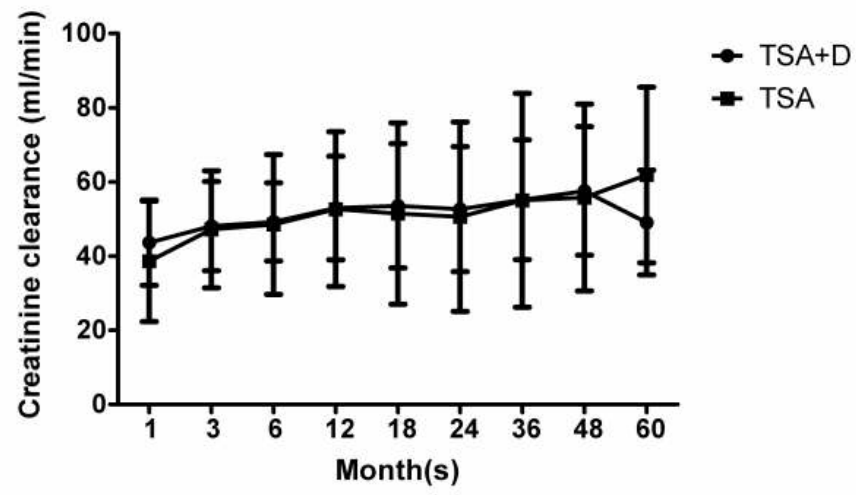

Figure 3.1 Calculated creatinine clearance (Cockcroft-Gault formula) over time since transplantation.

\section{Malignancy}

Only two patients in the TSA+D arm had malignancy. One of them had carcinoma of thyroid and the other one had carcinoma of stomach. On the other hand, none of the patients in the TSA arm had malignancy during the follow up period. However, the difference was not statistically significant $(P=0.53)$.

\section{Cardiovascular risk profile}

The incidence of hypertension, hypercholesterolemia, and NODM were shown in Table 3.2. There was no significant difference in these cardiovascular risk factors between the TSA+D arm and the TSA arm.

\section{Discussion}

This is a single center and prospective study to investigate the efficacy and safety of adding daclizumab to a tacrolimus-based therapy in Chinese first cadaveric renal transplant recipients. The incidence of biopsy-proven acute rejection was low in both treatment groups when compared with those reported in other studies combining IL-2 receptor antibody and cyclosporine-based 
therapy ${ }^{1,12}$. In this study, there was no significant difference in the incidence of acute rejection between both treatment arms. Induction with IL-2 receptor antibody might be of greater benefit for those patients with high immunological risk. Different studies had shown lower incidence of acute rejection in patients using IL-2 receptor antibody ${ }^{1,3}$. However, the study population was quite heterogeneous with different racial groups including African-Americans. It had been suggested that African-Americans might have stronger immune response than other racial groups, thus requiring more potent immunosuppressive regimens $^{13-15}$. On the other hand, the population was homogeneous in our study. They were all Chinese patients receiving first graft kidneys. The immunological risks might be lower than the African-American population. This factor, together with the use of tacrolimus-based therapy, could explain the low risk of acute rejection in our study. As a result, daclizumab induction seems to confer no additional clinical efficacy as shown by the similar incidence of acute rejection in both treatment arms. However, the severity of acute rejection might be even worse in the treatment arm without daclizumab as shown by the presence of type III acute rejection with graft rupture. Further studies with more patients might be needed to show the impact of induction therapy on the severity of acute rejection.

A retrospective study demonstrated that daclizumab was associated with improved patient and graft survival. ${ }^{3}$ However, we failed to prove this association in the present study. Concerning the renal function, calculated creatinine clearance using Cockcroft-Gault formula was used in our study. Equation derived from the Modification of Diet in Renal Disease (MDRD) study was not used because it had not been validated in Chinese population ${ }^{16-18}$. There was no significant difference in creatinine clearance between both groups up to five years. Moreover, there was also no difference in the annualized change of creatinine clearance. As a result, we failed to show better graft survival and long term renal graft function with daclizumab.

$A$ recent study suggested that even early and short exposure to induction treatment might create risk for late malignancy and infection-related complications $^{19}$. However, many studies had demonstrated that use of daclizumab was safe and did not result in more infectious complications and malignancies $^{1,3}$. This was similar to our results. The incidence of bacterial urinary tract infection and opportunistic infection were comparable between those with and without induction therapy. Although the incidence of malignancy was higher in patients with daclizumab, the difference between them was not statistically significant. Furthermore, there was no significant difference in cardiovascular risks between both treatment groups.

One of the main drawbacks in this study was the small sample size. A twosided log rank test with an overall sample size of 57 patients achieves only $20 \%$ power at a significance level of 0.05 to detect a difference of $9 \%$ between 
$89 \%$ and $80 \%$ - the percentage of patients without acute rejection in TSA+D arm and TSA arm respectively. Large randomized, controlled trials might be needed in order to demonstrate any difference between both treatment arms. However, we had a homogeneous group of patients in this study because all of them were Chinese following up in a single center with similar baseline characteristics. This would eliminate the influence of racial factors and different clinical protocols due to different centers.

In conclusion, we found that daclizumab was safe to use but we did not demonstrate clinical superiority in a tacrolimus-based immunosuppressive regimen. There was no difference demonstrated for acute rejection, patient survival, graft survival or creatinine clearance. 


\section{References}

1. Vincenti F, Kirkman R, Light S, Bumgardner G, Pescovitz M, Halloran P, Neylan J, Wilkinson A, Ekberg H, Gaston R, Backman L, Burdick J. Interleukin-2-receptor blockade with daclizumab to prevent acute rejection in renal transplantation. Daclizumab Triple Therapy Study Group. N Engl J Med 1998;338:161-5.

2. Vincenti F, Nashan B, Light S. Daclizumab: outcome of phase III trials and mechanism of action. Double Therapy and the Triple Therapy Study Groups. Transplant Proc 1998;30: 2155-8.

3. Morris JA, Hanson JE, Steffen BJ, Chu AH, Chi-Burris KS, Gotz VP, Gordon RD. Daclizumab is associated with decreased rejection and improved patient survival in renal transplant recipients. Clin Transplant 2005;19:340-5.

4. Vincenti F, Jensik SC, Filo RS, Miller J, Pirsch J. A long-term comparison of tacrolimus (FK506) and cyclosporine in kidney transplantation: evidence for improved allograft survival at five years. Transplantation 2002;73:775-82.

5. Mayer AD for the European Tacrolimus Multicenter Renal Study Group. Chronic rejection and graft half-life: five-year follow-up of the European Tacrolimus Multicenter Renal Study. Transplant Proc 2002:34:1491-2.

6. Margreiter $\mathrm{R}$ for the European Tacrolimus vs Ciclosporin Microemulsion Renal Transplantation Study Group. Efficacy and safety of tacrolimus compared with ciclosporin microemulsion in renal transplantation: a randomised multicenter study. Lancet 2002:359: 741-6.

7. Vincenti F, de Andrés A, Becker T, Choukroun G, Cole E, González-Posada JM, Kumar MA, Moore R, Nadalin S, Nashan B, Rostaing L, Saito K, Yoshimura N. Interleukin-2 receptor antagonist induction in modern immunosuppression regimens for renal transplant recipients. Transpl Int 2006;19:446-57.

8. Grenda R, Watson A, Vondrak K, Webb NJ, Beattie J, Fitzpatrick M, Saleem MA, Trompeter R, Milford DV, Moghal NE, Hughes D, Perner F, Friman S, Van Damme-Lombaerts R, Janssen F. A prospective, randomized, multicenter trial of tacrolimus-based therapy with or without basiliximab in pediatric renal transplantation. Am J Transplant 2006;6:1666-72.

9. Wong KM, Shek CC, Chau KF, Li CS. Abbreviated tacrolimus area-under-the-curve monitoring for renal transplant recipients. Am J Kidney Dis 2000;35:660-6.

10. Racusen LC, Solez K, Colvin RB, Bonsib SM, Castro MC, Cavallo T, Croker BP, Demetris AJ, Drachenberg CB, Fogo AB, Furness P, Gaber LW, Gibson IW, Glotz D, Goldberg JC, Grande J, Halloran PF, Hansen HE, Hartley B, Hayry PJ, Hill CM, Hoffman EO, Hunsicker LG, Lindblad AS, Yamaguchi $Y$, et al. The Banff 97 working classification of renal allograft pathology. Kidney Int 1999;55:713-23.

11. Gault MH, Longerich LL, Harnett JD, Wesolowski C. Predicting glomerular function from adjusted serum creatinine (editorial). Nephron 1992;62:249.

12. Kahan BD, Rajagopalan PR, Hall M. Reduction of the occurrence of acute cellular rejection among renal allograft recipients treated with basiliximab, a chimeric anti-interleukin-2-receptor monoclonal antibody. United States Simulect Renal Study Group. Transplantation 1999;67: 276-84.

13. Vasquez EM, Benedetti E, Pollak R. Ethnic differences in clinical response to corticosteroid treatment of acute renal allograft rejection. Transplantation 2001;71:229-33.

14. Vasquez EM, Benedetti E, Pollak R. Late acute rejection is more prevalent among AfricanAmerican renal allograft recipients and is frequently associated with allograft loss. Transplant Proc 1998;30:1173-5.

15. Ojo AO, Port FK, Held PJ, Wolfe RA, Turenne MN, Chung E, Mauger EA, Leichtman AB. Inferior outcome of two-haplotype matched renal transplants in blacks: role of early rejection. Kidney Int 1995;48:1592-9.

16. Levey AS, Bosch JP, Lewis JB, Greene T, Rogers N, Roth D. A more accurate method to estimate glomerular filtration rate from serum creatinine: a new prediction equation. Modification of Diet in Renal Disease Study Group. Ann Intern Med 1999;130: 461-70. 
17. Levey AS, Coresh J, Balk E, Kausz AT, Levin A, Steffes MW, Hogg RJ, Perrone RD, Lau J, Eknoyan G; National Kidney Foundation. National Kidney Foundation practice guidelines for chronic kidney disease: evaluation, classification, and stratification. Ann Intern Med. 2003;139:137-47.

18. Zuo L, Ma YC, Zhou YH, Wang M, Xu GB, Wang HY. Application of GFR-estimating equations in Chinese patients with chronic kidney disease. Am J of Kidney Dis 2005;45:46372.

19. Meier-Kriesche HU, Schold J, Titte R, et al. Long term risks of antibody induction therapy in kidney transplantation. Am J Transplant 2004;4(S8):264.. 


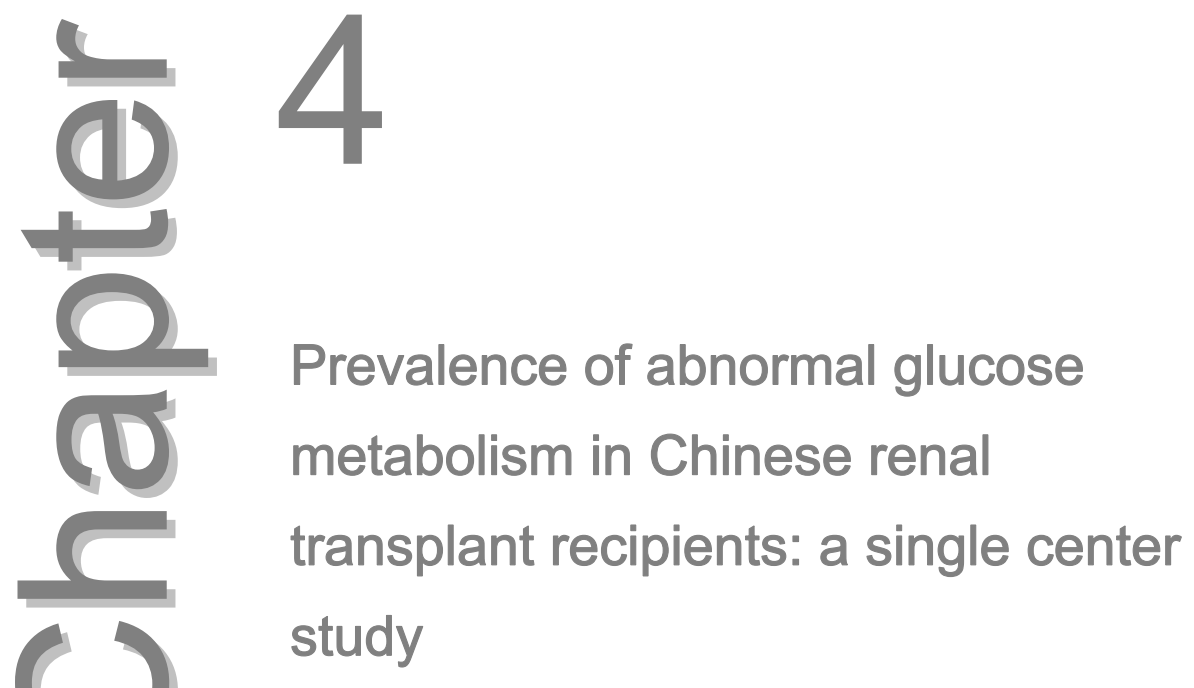

Hoi Wong Chan, Chi Yuen Cheung, Yan Lun Liu, Yiu Han Chan, Ho Sing Wong, Wai Leung Chak, Koon Shing Choi, Ka Foon Chau, Chun Sang Li 


\section{Abstract}

\section{Background}

Post-transplant diabetes mellitus (PTDM) after renal transplantation is associated with adverse outcome on patient and graft survival. Fasting blood glucose alone will underestimate diabetes and also ignores diagnosis of impaired glucose tolerance (IGT). IGT has great correlation with diabetes and cardiovascular risk.

\section{Methods}

In this cross-sectional study, we estimate the prevalence of abnormal glucose metabolism (AGM) using oral glucose tolerance test (OGTT) and identify its predictive factors. Patients who received kidney transplantation in our centre without pretransplant diabetes were recruited. OGTT was performed in patients with fasting glucose levels between 5.6 and $6.9 \mathrm{mmol} / \mathrm{l}$ for at least two occasions six months posttransplantation.

\section{Results}

Of 119 patients recruited, 31 had OGTT performed. The prevalence of PTDM, IGT and IFG was $21.8(26 / 119) \%, 6.7(8 / 119) \%$ and $3.4(4 / 119) \%$ respectively. Thus the overall prevalence of AGM was $31.9 \%$. Age ( $P=0.003)$, body mass index $(P=0.032)$, hepatitis $B$ seropositivity status $(P=0.01), \mathrm{CMV}$ infection $(P=0.02)$ and acute rejection $(P=0.002)$ were all associated with development of AGM. Using multivariate analysis, only older age at transplant (OR 1.09), history of acute rejection (OR 3.40) and hepatitis $B$ seropositivity (OR 3.13) were significantly associated with development of AGM.

\section{Conclusion}

Abnormal glucose metabolism is common in our renal transplant recipients. 


\section{Introduction}

Post-transplant diabetes mellitus (PTDM) after solid organ transplantation is a well-known serious metabolic complication. It can adversely affect the patient and graft survival ${ }^{1}$. Moreover, it has been shown that development of PTDM is a major determinant of cardiovascular mortality and morbidity in renal transplant recipients ${ }^{2}$.

The prevalence of PTDM varies widely among literature ${ }^{3,4}$. The main reason is that there is no consensus regarding the definition and diagnostic criteria. Clinical trials seldom included oral glucose tolerance test (OGTT) to determine the exact incidence of glycaemic abnormality in kidney transplant recipients.

Diagnosis of PTDM has been clarified by the International Consensus Guidelines, which is based on American Diabetic Association (ADA) and World Health Organization (WHO) guidelines ${ }^{5-7}$. Early recognition leads to early appropriate treatment. Moreover, the detection of "pre-diabetic state" (impaired fasting glucose (IFG) and/or impaired glucose tolerance (IGT)) is also important because of the increased risk of development of diabetes and cardiovascular risks $^{8}$. Fasting glucose is commonly used in clinical setting for diagnosis of diabetes when compared to OGTT because of its simplicity. However, it is less sensitive and specific than an OGTT in diagnosis ${ }^{9,10}$. Fasting glucose alone will underestimate diabetes ${ }^{9}$ and also ignores the diagnosis of IGT. IGT itself can only be diagnosed with OGTT and has been shown to have a great correlation with diabetes and cardiovascular risks ${ }^{11,12}$.

The aim of this study was to show the prevalence of abnormal glucose metabolism $(A G M=P T D M+\mid G T+I F G)$ after kidney transplantation when OGTT was used. In addition, the associated risk factors for its development were also studied.

\section{Subjects and Methods}

This was a cross-sectional study. All Chinese patients who received solitary living-related or cadaveric kidney transplantation from $1^{\text {st }}$ July 1997 to $31^{\text {st }}$ December 2005 in Queen Elizabeth Hospital, Hong Kong with follow up >6 months were recruited.

Patients with pre-transplant diabetes mellitus were excluded. The study was performed in accordance with the Declaration of Helsinki. A written consent was obtained from each patient. Demographic and clinical data were extracted from the patients' records.

Participants were initially classified into three categories: 1) PTDM with fasting blood glucose level $\geq 7.0 \mathrm{mmol} / \mathrm{l}$ for two occasions; 2) normal with fasting blood 
glucose level $<5.6 \mathrm{mmol} / \mathrm{l}$ and 3) fasting blood glucose level between 5.6 and $6.9 \mathrm{mmol} / \mathrm{l}$ for at least two occasions six months after transplantation.

For patients under the $3^{\text {rd }}$ category, an OGTT was performed. After an overnight 8-h fast, fasting blood glucose was taken. Patients were then administered $75 \mathrm{~g}$ of glucose (113 $\mathrm{ml}$ of Polycal) with post-prandial samples taken two hours after administration of glucose. The results of the test were classified by ADA criteria (Table 4.1).

Table 4.1 OGTT classification according to ADA criteria.

\begin{tabular}{lcc}
\hline OGTT criteria & Baseline glucose $(\mathrm{mmol} / \mathrm{l})$ & 2-hr glucose $(\mathrm{mmol} / \mathrm{l})$ \\
\hline Normal & $<5.6$ & $<7.8$ \\
Impaired fasting glucose (IFG) & $5.6-6.9$ & - \\
Impaired glucose tolerance (IGT) & - & $7.8-11.1$ \\
Diabetes & $>6.9$ & $>11$ \\
\hline
\end{tabular}

\section{Immunosuppressive Regimens}

Our patients were basically put on triple immunosuppressive therapy with either tacrolimus or Neoral cyclosporine, concomitantly with prednisolone and azathioprine therapy. All patients received $500 \mathrm{mg}$ of methylprednisolone at induction. This was followed by intravenous hydrocortisone $100 \mathrm{mg}$ every six hours for three days and followed by oral prednisolone $30 \mathrm{mg}$ daily. The dose of prednisolone was gradually tapered after the first month at a rate of $2.5 \mathrm{mg}$ every two weeks then maintained at $7.5 \mathrm{mg}$ daily. Azathioprine was given at a dose of $1.5 \mathrm{mg} / \mathrm{kg}$ daily since Day 1 after transplant. Cyclosporine (CsA) was initially administered orally as a loading dose of $10 \mathrm{mg} / \mathrm{kg}$ within $12 \mathrm{~h}$ of surgery and then $5 \mathrm{mg} / \mathrm{kg}$ b.i.d. An abbreviated formula based on limited sampling strategy was used in this study to estimate the cyclosporine area under 12-h concentration-time curve $\left(\mathrm{AUC}_{0-12}\right)$. Calculation of cyclosporine $\mathrm{AUC}_{0-12}$ was based on the formula: $452.4+\mathrm{C}_{0} \times 17.5+\mathrm{C}_{1.5} \times 1.89\left[\mathrm{C}_{0}\right.$ : cyclosporine trough level; $\mathrm{C}_{1.5}: 1.5$-h post-dose cyclosporine level]. ${ }^{13}$. The dose of cyclosporine was gradually titrated to maintain the abbreviated $\mathrm{AUC}_{0-12}$ at $\sim 6000-8000 \mathrm{ng} \times \mathrm{h} / \mathrm{ml}$ in the first 3-month post-transplant and 4000-6000 $\mathrm{ng} \mathrm{x} \mathrm{h/ml} \mathrm{from} \mathrm{3-month}$ post-transplant onwards ${ }^{14}$. On the other hand, tacrolimus was administered orally with loading dose of $0.3 \mathrm{mg} / \mathrm{kg}$ within 12-h of surgery and then $0.15 \mathrm{mg} / \mathrm{kg}$ b.i.d. Abbreviated tacrolimus $\mathrm{AUC}_{0-12}$ monitoring was used. Calculation of tacrolimus $\mathrm{AUC}_{0-12}$ was by the formula: $16.2+\mathrm{C}_{2} \times 2.4+\mathrm{C}_{4} \times 5.9$ $\left[\mathrm{C}_{2}\right.$ : 2-h post-dose tacrolimus level; $\mathrm{C}_{4}: 4$-h post-dose tacrolimus level]. Based on a previous pilot study in stable patients on tacrolimus in our center, $\mathrm{AUC}_{0-12}$ value was kept at $\sim 100-150 \mathrm{ng} \mathrm{h} / \mathrm{ml}$ in first three months and $\sim 80-100 \mathrm{ng} \times$ $\mathrm{h} / \mathrm{ml}$ after three months ${ }^{15}$. Some of our patients have received interleukin-2 receptor antagonist during induction therapy since 2001. Patient on 
cyclosporine was given Basiliximab (Simulect, Norvatis, Switzerland) while patients on tacrolimus was given Daclizumab (Zenapax, Roche, NJ, USA). Basiliximab was given at a dose of $20 \mathrm{mg} \sim 2 \mathrm{~h}$ before transplantation and the second dose was given four days after transplantation. Daclizumab was given at $1 \mathrm{mg} / \mathrm{kg}$ infusion 2-h before transplantation and then every 14 days for four more doses.

Acute rejection was defined as any episode with the relevant clinical and laboratory signs and symptoms and confirmed by renal biopsy. Episodes during which treatment against acute rejection was given and for which no biopsy could be performed due to contraindications were considered as acute rejection. There was clinical suspicion of rejection in the case of an unexplained rise or insufficient decrease of serum creatinine, with or without other signs, such as fever, graft tenderness, decreased renal perfusion on nuclear scan, or hypertension. Contraindications for biopsy were bleeding disorders or uncontrolled severe hypertension. Our protocol for treating acute cellular rejection was 500 mg methylprednisolone intravenously for three days. In case of steroid resistant rejection, appropriate antibody therapy was started.

\section{Statistical Analyses}

The statistical software SPSS (SPSS 13.0, Inc., Chicago, IL USA) was used to perform the analyses. Continuous data are expressed as means \pm standard deviation (SD); categorical data are expressed as percentages. Continuous data were analyzed by independent sample $t$-test to detect the difference between groups; categorical data are analyzed by chi-square test. Associations between the clinical variables and the development of AGM were estimated using both univariate and multivariate logistic regression analyses. The multivariate model incorporated a backward and stepwise elimination method using variables with a $P$-value of $<0.05$ from the univariate analysis. A $P$-value of less than 0.05 was defined as statistically significant in this study.

\section{Results}

From a total of 147 patients receiving a kidney allograft between July 1997 and December 2005, 14 patients were excluded due to pre-transplant diabetes mellitus, four due to primary non-functioning grafts or surgical complications requiring graft nephrectomy and 10 due to patient death or graft loss (4/10 had PTDM). As a result, 119 renal transplant recipients were included in our study. The baseline demographic and clinical variables were depicted in Table 4.2. The median follow-up duration after kidney transplant was 62 (15-120) months. The mean age at transplantation was $39 \pm 11$ years and $54.6 \%$ were male 
patients. All enrolled patients did not have past history of gestational diabetes mellitus and none of them were hepatitis $C$ carrier. All the patients were on prednisolone $7.5 \mathrm{mg}$ daily. None of them were on thiazide diuretics.

Table 4.2 Baseline demographic and clinical variables.

\begin{tabular}{llc}
\hline Total number $(\mathrm{n})$ & & 119 \\
Age $($ years) & & $39 \pm 11$ \\
Waist circumference $(\mathrm{cm})$ & & $81 \pm 11$ \\
Body weight $(\mathrm{kg})$ & & $57.1 \pm 10.9$ \\
BMI $\left(\mathrm{kg} / \mathrm{m}^{2}\right)$ & Male $(\%)$ & $22 \pm 3$ \\
Gender & Female (\%) & $65(54.6)$ \\
& $1^{\text {st }}$ transplant & $54(45.4)$ \\
No. of Transplantation, $\mathrm{n}(\%)$ & $111(93.3)$ \\
& $2^{\text {nd }}$ transplant & $8(6.7)$ \\
Mode of Transplantation, $\mathrm{n}(\%)$ & Cadaveric & $106(89.1)$ \\
& Living related & $13(10.9)$ \\
Hepatitis B carrier, $\mathrm{n}(\%)$ & Yes & $17(14.3)$ \\
& No & $102(85.7)$ \\
Hepatitis C carrier, $\mathrm{n}(\%)$ & Yes & $0(0)$ \\
& No & $119(100)$ \\
DM in first degree relatives, $\mathrm{n}$ (\%) & Yes & $30(25.2)$ \\
& No & $89(74.8)$ \\
Primary diagnosis, $\mathrm{n}(\%)$ & Chronic glomerulonephritis & $80(67.2)$ \\
& Hypertension & $5(4.2)$ \\
& Polycystic kidney disease & $4(3.4)$ \\
& Obstructive uropathy & $2(1.7)$ \\
& Others & $8(6.7)$ \\
& Unknown & $20(16.8)$ \\
\hline
\end{tabular}

Values expressed as mean \pm SD or number (percentage)

Of the 119 patients, 22 patients were classified as PTDM and 66 patients were normal based on fasting blood glucose level alone. The remaining 31 patients fulfilled our criteria of OGTT (fasting blood glucose level between 5.6 and 6.9 $\mathrm{mmol} / \mathrm{l}$ for at least two occasions six months after transplantation). Based on the results from OGTT, 4/31 (12.9\%) patients were diagnosed IFG, 8/31 (25.8\%) patients were diagnosed IGT, 4/31 (12.9\%) patients were diagnosed PTDM and 15/31 (48.4\%) patients were normal.

As a result, total 26 patients were classified as PTDM. Among them, seven patients were treated with diet only and 19 patients required medications. For patients requiring medical treatment, 13 patients required oral hypoglycemic agents alone while six required insulin therapy.

The prevalence of PTDM, IGT and IFG in our study was $21.8(26 / 119) \%, 6.7$ $(8 / 119) \%$ and $3.4(4 / 119) \%$ respectively. Thus the overall prevalence of AGM was $31.9 \%$.

Table 4.3 showed the factors associated with development of AGM by univariate analysis. Age $(P=0.003)$, body mass index $(P=0.032)$, hepatitis $B$ seropositivity status $(P=0.01), \mathrm{CMV}$ infection $(P=0.02)$ and acute rejection 
( $P=0.002)$ were all associated with the development of AGM. The follow-up duration after transplantation was significantly longer in the patients with AGM than the normal patients. Using multivariate analysis, only older age at transplant (OR 1.09), history of acute rejection (OR 3.40) and hepatitis B seropositivity (OR 3.13) were associated with development of AGM (Table 4.4).

Table 4.3 Comparison between patients who developed AGM and normal.

\begin{tabular}{|c|c|c|c|}
\hline & $\begin{array}{l}\text { AGM } \\
n=38\end{array}$ & $\begin{array}{c}\text { Normal } \\
\mathrm{n}=81\end{array}$ & $P$-value* \\
\hline Age of recipient (yr) & $44 \pm 10$ & $37 \pm 11$ & 0.003 \\
\hline Gender, n (males \%) & $19(50.0)$ & $46(56.8)$ & 0.488 \\
\hline Waist circumference $(\mathrm{cm})$ & $82.0 \pm 12.0$ & $80.5 \pm 10.5$ & 0.494 \\
\hline Body weight at transplant $(\mathrm{kg})$ & $58.9 \pm 10.9$ & $56.3 \pm 10.9$ & 0.229 \\
\hline Body mass index $\left(\mathrm{kg} / \mathrm{m}^{2}\right)$ & $23 \pm 4$ & $21 \pm 3$ & 0.032 \\
\hline Hepatitis B status (\%) & $10(26.3)$ & $7(8.6)$ & 0.010 \\
\hline Family history of DM, n (\%) & 13(34.2) & $17(21.0)$ & 0.092 \\
\hline Duration of dialysis (months) & $65.5 \pm 52.6$ & $57.6 \pm 44.8$ & 0.398 \\
\hline Time since transplantation (months) & $74 \pm 24$ & $53 \pm 21$ & 0.015 \\
\hline Hemoglobin A1c (\%) & $6.4 \pm 1.2$ & $5.8 \pm 0.4$ & 0.015 \\
\hline \multicolumn{4}{|l|}{ Immunosuppressants, n (\%) } \\
\hline Tacrolimus & $20(52.6)$ & $33(40.7)$ & 0.224 \\
\hline Dosage (mg/kg/day) & $0.08 \pm 0.04$ & $0.08 \pm 0.04$ & 0.821 \\
\hline $\mathrm{AUC}_{0-12}(\mathrm{ng} \times \mathrm{h} / \mathrm{ml})$ & $114 \pm 29$ & $106 \pm 19$ & 0.297 \\
\hline Cyclosporine & 18(47.4) & $48(59.3)$ & 0.224 \\
\hline Dosage (mg/kg/day) & $3.2 \pm 0.7$ & $3.5 \pm 0.7$ & 0.308 \\
\hline $\mathrm{AUC}_{0-12}(\mathrm{ng} \times \mathrm{h} / \mathrm{ml})$ & $4581 \pm 415$ & $4757 \pm 1244$ & 0.785 \\
\hline Basiliximab & $7(18.4)$ & $22(27.2)$ & 0.301 \\
\hline Daclizumab & $11(28.9)$ & $23(28.4)$ & 0.950 \\
\hline Prednisolone dosage (mg/day) & $7.5 \pm 0$ & $7.5 \pm 0$ & 1 \\
\hline Use of Beta-blocker, n (\%) & $27(71.1)$ & $52(64.2)$ & 0.460 \\
\hline Use of ACEI/ ARB, n (\%) & $2(5.3)$ & $6(7.4)$ & 0.663 \\
\hline CMV infection, n (\%) & $10(26.3)$ & $8(9.9)$ & 0.020 \\
\hline Acute rejection, n (\%) & $16(42.1)$ & $13(16.0)$ & 0.002 \\
\hline
\end{tabular}

Values expressed as mean $\pm S D$ or number (percentage). $\mathrm{ACEI}$, angiotensin converting enzyme blockers; ARB, angiotensin II receptor blockers; CMV, cytomegalovirus. * Continuous variables were analyzed with the use of t-tests, all categorical data were analyzed with the use of chi-square test.

Table 4.4 Factors predicting development of AGM according to multivariate analysis.

\begin{tabular}{lccc}
\hline & Odds ratio & 95\% Confidence Interval & $P$-value \\
\hline Age of recipients & 1.09 & $1.02-1.10$ & 0.008 \\
Acute rejection & 3.40 & $1.32-8.77$ & 0.011 \\
Hepatitis B seropositivity & 3.13 & $1.01-9.89$ & 0.050 \\
\hline
\end{tabular}

The types of acute rejection were shown in Table 4.5. All patients with acute rejection were given $500 \mathrm{mg}$ methylprednisolone intravenously for three days. For the 16 patients in the AGM group, five developed AGM before episodes of acute rejection. The median time for the development of AGM after acute rejection in the remaining 11 patients was 49 (1-104) months. 
Table 4.5 Types of acute rejection according to Banff 1997 classification $^{30}$.

\begin{tabular}{|c|c|c|}
\hline Banff classification & $\begin{array}{l}\text { AGM } \\
n=16\end{array}$ & $\begin{array}{c}\text { Normal } \\
n=13\end{array}$ \\
\hline Borderline & 5 & 2 \\
\hline Type IA & 2 & 4 \\
\hline Type IB & 3 & 3 \\
\hline Type IIA & 1 & 2 \\
\hline Type IIB & 1 & 0 \\
\hline Type III & 2 & 1 \\
\hline No histology & 2 & 1 \\
\hline
\end{tabular}

For patients who were finally classified as AGM $(n=38)$, there was no significant difference between those sorted out before OGTT $(n=22)$ and those diagnosed during OGTT $(n=16)$ (Table 4.6). On the other hand, there was also no significant difference between the patients sorted out as normal in the beginning $(n=66)$ and those diagnosed as normal during OGTT $(n=15)$ (Table 4.7).

Table 4.6 Comparison between patients who were diagnosed as AGM before and during OGTT.

\begin{tabular}{|c|c|c|c|}
\hline & $\begin{array}{c}\text { AGM before OGTT } \\
n=22\end{array}$ & $\begin{array}{l}\text { AGM during OGTT } \\
n=16\end{array}$ & $P$-value* \\
\hline Age of recipient (yr) & $46 \pm 9$ & $41 \pm 10$ & 0.118 \\
\hline Gender, $\mathrm{n}$ (males \%) & $10(45.5)$ & $9(56.3)$ & 0.511 \\
\hline Waist circumference (cm) & $80.2 \pm 10.7$ & $84.3 \pm 14.2$ & 0.351 \\
\hline Body weight at transplant $(\mathrm{kg})$ & $58.8 \pm 12.3$ & $59.0 \pm 8.9$ & 0.948 \\
\hline Body mass index $\left(\mathrm{kg} / \mathrm{m}^{2}\right)$ & $23 \pm 4$ & $22 \pm 3$ & 0.582 \\
\hline Hepatitis B status (\%) & $7(31.8)$ & $3(18.8)$ & 0.366 \\
\hline Family history of DM, n (\%) & $6(27.3)$ & $7(43.8)$ & 0.290 \\
\hline Duration of dialysis (months) & $65.8 \pm 58.3$ & $62.8 \pm 43.4$ & 0.867 \\
\hline Hemoglobin A1c (\%) & $6.6 \pm 1.4$ & $6.1 \pm 0.8$ & 0.295 \\
\hline \multicolumn{4}{|l|}{ Immunosuppressants, n (\%) } \\
\hline Tacrolimus & $12(54.5)$ & $8(50.0)$ & 0.782 \\
\hline Dosage (mg/kg/day) & $0.08 \pm 0.04$ & $0.08 \pm 0.04$ & 0.930 \\
\hline $\mathrm{AUC}_{0-12}(\mathrm{ng} \times \mathrm{h} / \mathrm{ml})$ & $87 \pm 21$ & $108 \pm 37$ & 0.242 \\
\hline Cyclosporine & $10(45.5)$ & $8(50.0)$ & 0.782 \\
\hline Dosage (mg/kg/day) & $3.3 \pm 0.9$ & $3.2 \pm 0.5$ & 0.877 \\
\hline $\mathrm{AUC}_{0-12}(\mathrm{ng} \times \mathrm{h} / \mathrm{ml})$ & $3860 \pm 1112$ & $4403 \pm 39$ & 0.551 \\
\hline Basiliximab & $3(13.6)$ & $4(25.0)$ & 0.372 \\
\hline Daclizumab & $7(31.8)$ & $4(25.0)$ & 0.647 \\
\hline Use of Beta-blocker, n (\%) & $15(68.2)$ & $12(75.0)$ & 0.647 \\
\hline Use of ACEI/ ARB, n (\%) & $1(4.5)$ & $1(6.3)$ & 0.816 \\
\hline CMV infection, $\mathrm{n}(\%)$ & $8(36.4)$ & $2(12.5)$ & 0.099 \\
\hline Acute rejection, $\mathrm{n}(\%)$ & $10(45.5)$ & $6(37.5)$ & 0.624 \\
\hline
\end{tabular}

Values expressed as mean \pm SD or number (percentage). ACEI, angiotensin converting enzyme blockers; ARB, angiotensin II receptor blockers; CMV, cytomegalovirus. * Continuous variables were analyzed with the use of t-tests, all categorical data were analyzed with the use of chi-square test. 
Table 4.7 Comparison between patients classified as normal before OGTT and during OGTT.

\begin{tabular}{|c|c|c|c|}
\hline & $\begin{array}{c}\text { Normal } \\
\text { Before OGTT } \\
n=66\end{array}$ & $\begin{array}{c}\text { Normal } \\
\text { During OGTT } \\
n=15\end{array}$ & $P$-value* \\
\hline Age of recipient (yr) & $37 \pm 11$ & $39 \pm 10$ & 0.377 \\
\hline Gender, $\mathrm{n}$ (males \%) & $36(54.5)$ & $10(66.7)$ & 0.392 \\
\hline Waist circumference $(\mathrm{cm})$ & $80.0 \pm 10.6$ & $82.6 \pm 10.0$ & 0.395 \\
\hline Body weight at transplant $(\mathrm{kg})$ & $55.9 \pm 11.3$ & $58.0 \pm 8.8$ & 0.506 \\
\hline Body mass index $\left(\mathrm{kg} / \mathrm{m}^{2}\right)$ & $21 \pm 3$ & $21 \pm 2$ & 0.750 \\
\hline Hepatitis B status (\%) & $5(7.6)$ & $2(13.3)$ & $0 . .474$ \\
\hline Family history of DM, n (\%) & $14(21.2)$ & $3(20.0)$ & 0.917 \\
\hline Duration of dialysis (months) & $55.9 \pm 45.8$ & $60.5 \pm 37.4$ & 0.719 \\
\hline \multicolumn{4}{|l|}{ Immunosuppressants, n (\%) } \\
\hline Tacrolimus & $25(37.9)$ & $8(53.3)$ & 0.272 \\
\hline Dosage (mg/kg/day) & $0.08 \pm 0.04$ & $0.08 \pm 0.04$ & 0.965 \\
\hline $\mathrm{AUC}_{0-12}(\mathrm{ng} \times \mathrm{h} / \mathrm{ml})$ & $100 \pm 28$ & $94 \pm 18$ & 0.545 \\
\hline Cyclosporine & $41(62.1)$ & $7(46.7)$ & 0.272 \\
\hline Dosage (mg/kg/day) & $3.4 \pm 0.7$ & $3.9 \pm 0.5$ & 0.110 \\
\hline $\mathrm{AUC}_{0-12}(\mathrm{ng} \times \mathrm{h} / \mathrm{ml})$ & $4370 \pm 983$ & $4829 \pm 1102$ & 0.571 \\
\hline Basiliximab & 18(27.3) & $4(26.7)$ & 0.962 \\
\hline Daclizumab & $19(28.8)$ & $4(26.7)$ & 0.869 \\
\hline Use of Beta-blocker, n (\%) & $40(60.6)$ & $12(80.0)$ & 0.157 \\
\hline Use of ACEI/ ARB, $n(\%)$ & $4(6.1)$ & $2(13.3)$ & 0.332 \\
\hline CMV infection, $\mathrm{n}(\%)$ & $6(9.1)$ & $2(13.3)$ & 0.619 \\
\hline Acute rejection, n (\%) & $10(15.2)$ & $3(20.0)$ & 0.644 \\
\hline
\end{tabular}

Values expressed as mean \pm SD or number (percentage). ACEI, angiotensin converting enzyme blockers; ARB, angiotensin II receptor blockers; CMV, cytomegalovirus. * Continuous variables were analyzed with the use of t-tests, all categorical data were analyzed with the use of chi-square test.

\section{Discussion}

The incidence and prevalence of PTDM varies widely in literature because of the lack of standard definition for the condition. Many studies used fasting blood glucose alone or need for insulin and/or oral hypoglycemic agents for at least 30 days as definition of PTDM ${ }^{16,17}$. Moreover, heterogeneity between study groups on background parameters (age, ethnicity) and types and dosage of immunosuppressive regimen may also attribute to the great difference in incidence of PTDM among literature. The International Consensus Guidelines in $2003^{6}$ attempted to bring consistency in the diagnosis and management of PTDM. Diagnosis was to be based on ADA and WHO criteria which included the OGTT for the diagnosis of diabetes.

The ADA guidelines in $2006^{10}$ highlight the increased sensitivity and specificity of the OGTT, compared to fasting glucose alone in diagnosing diabetes in the general population. Armstrong KA et al. have shown that the prevalence of PTDM is much higher with OGTT and fasting blood glucose alone will miss 
$65 \%$ of patients with diabetes in renal transplant recipients ${ }^{18}$. The ADA guidelines also recommend screening for pre-diabetes and diabetes in highrisk patients such as transplant recipients. Early detection of IFG and IGT is very important due to the associated increased risk of developing both PTDM and cardiovascular disease. Early diagnosis can allow early education for lifestyle modification and appropriate intensive intervention can be given to reduce different diabetic complications.

There are different criteria of defining IFG according to WHO and ADA guidelines. If ADA classification is used, more people will require OGTT and more people will be classified as IFG. The Decode study ${ }^{9}$ assessed the impact of sensitivity and specificity of variable cutoffs for IFG. If OGTT were performed in people with a fasting glucose level between $5.6-6.9 \mathrm{mmol} / \mathrm{l}, 46 \%$ of the population would require an OGTT. This would identify $93 \%$ of all people with diabetes and $69 \%$ of people with IGT. On the other hand, if OGTT were performed in people with a fasting glucose between $6.1-6.9 \mathrm{mmol} / \mathrm{l}$, only $12 \%$ of the population would require an OGTT. This would only identify $82 \%$ of all people with diabetes and $29 \%$ of people with IGT. In our study, we recruited patients for OGTT according to ADA classification. Twenty-six percent (31/119) of patients required OGTT. Among those with OGTT, 51.6\% (16/31) had AGM including IFG, IGT and PTDM.

There is consistent evidence that PTDM is more common in older individuals. Cosio et al. reported that recipients $>45$ years old were 2.9 times more likely to become diabetic post-transplant when compared with younger recipients ${ }^{19}$. Our results also showed that older recipients at the time of transplant were significantly associated with the development of AGM. The odds ratio corresponding to an increase of one year of recipient's age was 1.09.

Calcineurin inhibitors are important factors for the development of PTDM. There is consistent evidence that tacrolimus is more diabetogenic than cyclosporine ${ }^{17,20}$. A meta-analysis has revealed that the odds ratio for development of PTDM in renal transplantation with tacrolimus was $5.03(95 \%$ confidence interval 2.04-12.36) ${ }^{21}$. However, the above findings were not shown in our study. This can be explained by the use of limited sampling strategy and abbreviated AUC for drug monitoring and titration, resulting in lower tacrolimus dose used in our center ${ }^{22}$. Patients receiving tacrolimus experienced a delay in the restoration of glucose metabolism when compared with patients on cyclosporine. This delay could be caused by slow recovery of insulin secretion, possibly the result of a high exposure to tacrolimus ${ }^{23}$. The target abbreviated $\mathrm{AUC}_{0-12}$ in our patients was $\sim 80-100 \mathrm{ng} \mathrm{x} \mathrm{h} / \mathrm{ml}$ after three months, corresponding a tacrolimus trough level at $\sim 6 \mathrm{ng} / \mathrm{ml}^{22}$. Maintaining a low tacrolimus trough level may diminish the development of impaired glucose metabolism ${ }^{23}$. The mean age of our patients was 39 years. On the other hand, 
the United States Renal Data System Annual Report for 2007 showed an older recipient age. Sixty-two percent were $>45$ years. Our patients were young and had a low body mass index, thus counteracting the diabetogenic effect of tacrolimus and reducing the difference between tacrolimus- and cyclosporinebased therapy. However, the overall prevalence of AGM in our patients is $31.9 \%$. All the patients were on prednisolone $7.5 \mathrm{mg}$ daily during the study and they were relatively lean. The dosage of maintenance steroids might be high if expressed in milligram per body weight. This can explain the relatively high prevalence of AGM in our patients. In a recent comparative cohort study ${ }^{24}, 321$ patients were recruited with 301 of them had OGTT 10 weeks after kidney transplantation. The incidence of PTDM and IGT/IFG was $13 \%$ and $18 \%$ respectively, which was significantly lower when compared with a historical cohort. The major explanation of this beneficial change in glucose tolerance is probably related to the lower doses of steroids used in the early posttransplantation period. They found that 1-mg increase in daily prednisolone was associated with an $11 \%$ increased risk of PTDM in the multivariate model. There is limited evidence that PTDM is associated with at least one acute rejection episode $(64 \% \text { vs. } 27 \%, P<0.01)^{25}$. It may be related to higher cumulative corticosteroid dose for the treatment of acute rejection. Kasiske et al. have proposed that early acute rejection may explain the relationship between graft loss and onset of diabetes. Acute rejection predisposes to graft loss and tends to prompt an increase in intensity of immunosuppressive agents that in turn exacerbates the risk of $\mathrm{PTDM}^{20}$. In our center, rejection episodes were treated with $500 \mathrm{mg}$ methylprednisolone intravenously for three days and temporary increment of oral prednisolone. As a result, the cumulative dosage of steroid was much higher in patients treated with acute rejection. In fact our results also showed that acute rejection was significantly associated with the development of AGM.

Chronic hepatitis $\mathrm{C}$ infection is associated with an increased incidence of PTDM in liver transplantation. ${ }^{26}$ A meta-analysis has also shown a significant relationship between anti-HCV seropositive status with development of PTDM after renal transplantation with adjusted odds ratio $3.97^{4}$. All patients in our study were hepatitis $C$ seronegative, thus the association of AGM with HCV status could not be verified. In Hong Kong, chronic HCV infection is of minor epidemiological significance. On the other hand, chronic hepatitis B infection is endemic with a prevalence rate of $8.8 \%{ }^{27}$. The association of hepatitis B status with PTDM in renal transplant recipients is rarely addressed in the literature. $A$ study by Hirakauva EY et al. showed that there was no difference in prevalence of PTDM in patients infected with $\mathrm{HBV}$ in renal transplant recipients ${ }^{28}$. There are limited data concerning the prevalence of hepatitis B carrier in renal transplant recipients. In our study, the prevalence of hepatitis B seropositive status was $14.5 \%$. To the best of our knowledge, this was the first published 
single centre observational study which revealed that hepatitis $B$ seropositive status was a predictive factor for development of AGM after renal transplantation although it is only marginally significant (O.R.: $3.13, P=0.05)$. In populations with a low prevalence of HBV infection, this association may not be demonstrable. In fact, hepatitis B carrier is found to be significantly associated with development of gestational diabetes in Chinese women in Hong Kong ${ }^{29}$. The authors postulate that hepatitis B carrier status can aggravate pregnancyinduced hepatic insulin resistance leading to gestational diabetes. Similarly hepatitis B virus may also worsen steroid-induced insulin resistance in susceptible individuals. Further studies are necessary to evaluate the association, pathophysiological mechanisms and prognostic implications of hepatitis $B$ status with AGM in renal transplant recipients.

A limitation in our study might be the underestimation of patients with pretransplant diabetes mellitus. In the pre-transplant examination, the diagnosis of diabetes mellitus was based on routine fasting blood glucose only. Lack of mandatory use of OGTT might include patients with diabetes in our study and overestimate the prevalence of AGM after transplantation.

In conclusion, the prevalence of AGM including IFG, IGT and PTDM in our renal transplant recipients was $31.9 \%$. Older patients at time of transplant, history of acute rejection and hepatitis B seropositivity status were all independent predictive factors of development of AGM. A large scale prospective study with longer duration of follow up is necessary to assess whether the use of OGTT in renal transplant recipients can risk stratify each patient for the development of PTDM and cardiovascular disease. 


\section{References}

1. Cosio FG, Pesavento TE, Kim S, Osei K, Henry M, Ferguson RM. Patient survival after renal transplantation: IV. Impact of post-transplant diabetes. Kidney Int 2002;62:1440-6.

2. Kasiske BL, Chakkera HA, Roel J. Explained and unexplained ischemic heart disease risk after renal transplantation. J Am Soc Nephrol 2000;11:1735-43.

3. Montori VM, Basu A, Erwin PJ, Velosa JA, Gabriel SE, Kudva YC. Posttransplantation diabetes: a systematic review of the literature. Diabetes Care 2002;25:583-92.

4. Fabrizi F, Martin P, Dixit V, Bunnapradist S, Kanwal F, Dulai G. Post-transplant diabetes mellitus and HCV seropositive status after renal transplantation: meta-analysis of clinical studies. Am J Transplant 2005;5:2433-40.

5. Wilkinson A, Davidson J, Dotta F, Home PD, Keown P, Kiberd B, Jardine A, Levitt N, Marchetti P, Markell M, Naicker S, O'Connell P, Schnitzler M, Standl E, Torregosa JV, Uchida K, Valantine H, Villamil F, Vincenti F, Wissing M. Guidelines for the treatment and management of new-onset diabetes after transplantation. Clin Transplant 2005;19:291-8.

6. Davidson J, Wilkinson A, Dantal J, Dotta F, Haller H, Hernández D, Kasiske BL, Kiberd B, Krentz A, Legendre C, Marchetti P, Markell M, van der Woude FJ, Wheeler DC; International Expert Panel. New-onset diabetes after transplantation: 2003 International consensus guidelines. Transplantation 2003;75:SS3-24.

7. Davidson JA, Wilkinson A. New-onset Diabetes After Transplantation 2003 International Consensus Guidelines: an endocrinologist's view. Diabetes Care 2004;27:805.

8. Heldgaard PE, Olivarius Nde F, Hindsberger C, Henriksen JE. Impaired fasting glycaemia resembles impaired glucose tolerance with regard to cardiovascular risk factors: populationbased, cross-sectional study of risk factors for cardiovascular disease. Diabet Med 2004;21:363-70.

9. The DECODE-study group. European Diabetes Epidemiology Group. Diabetes Epidemiology: Collaborative analysis of Diagnostic Criteria in Europe. Is fasting glucose sufficient to define diabetes? Epidemiological data from 20 European studies. Diabetologia 1999;42:647-54.

10. American Diabetes Association. Standards of Medical Care in Diabetes-2006. Diabetes Care 2006;29(S1):S4-42.

11. Leiter LA, Ceriello A, Davidson JA, Hanefeld M, Monnier L, Owens DR, Tajima N, Tuomilehto J; International Prandial Glucose Regulation Study Group. Postprandial glucose regulation: New data and new implications. Clin Ther 2005; 27(S2):S42-56.

12. Tominaga $M$, Eguchi $H$, Manaka $H$, Igarashi $K$, Kato $T$, Sekikawa A. Impaired glucose tolerance is a risk factor for cardiovascular disease, but not impaired fasting glucose. The Funagata Diabetes Study. Diabetes Care 1999;22:920-4.

13. Tsang WK, Ho YW, Tong KL, Chan WH, Chan A. Safety, tolerability, and pharmacokinetics of Sandimmun Neoral: conversion study in stable renal transplant recipients. Transplant Proc 1996;28: 1330-2.

14. International Neoral Renal Transplantation Study Group. Cyclosporine microemulsion (Neoral) absorption profiling and sparse-sample predictors during the first 3 months after renal transplantation. American Journal of Transplantation 2002;2:148-58.

15. Wong KM SC, Chau KF, Li CS. Abbreviated tacrolimus area-under-curve monitoring for renal transplant recipients. Am J Kidney Dis 2000;35:660.

16. Mayer AD, Dmitrewski J, Squifflet JP, Besse T, Grabensee B, Klein B, Eigler FW, Heemann U, Pichlmayr R, Behrend M, Vanrenterghem Y, Donck J, van Hooff J, Christiaans M, Morales JM, Andres A, Johnson RW, Short C, Buchholz B, Rehmert N, Land W, Schleibner S, Forsythe JL, Talbot D, Pohanka E, et al. Multicenter randomized trial comparing tacrolimus (FK506) and cyclosporine in the prevention of renal allograft rejection: a report of the European Tacrolimus Multicenter Renal Study Group. Transplantation 1997;64:436-43.

17. Pirsch JD, Miller J, Deierhoi MH, Vincenti F, Filo RS. A comparison of tacrolimus (FK506) and cyclosporine for immunosuppression after cadaveric renal transplantation. FK506 Kidney Transplant Study Group. Transplantation 1997;63:977-83. 
18. Armstrong KA, Prins JB, Beller EM, Campbell SB, Hawley CM, Johnson DW, Isbel NM. Should glucose tolerance test be performed in all renal transplant recipients? . Clin J Am Soc Nephrol 2006;1:100.

19. Cosio FG, Pesavento TE, Osei K, Henry ML, Ferguson RM. Post-transplant diabetes mellitus: increasing incidence in renal allograft recipients transplanted in recent years. Kidney Int 2001;59:732-7.

20. Kasiske BL, Snyder JJ, Gilbertson D, Matas AJ. Diabetes mellitus after kidney transplantation in the United States. Am J Transplant 2003;3:178-85.

21. Knoll GA, Bell RC. Tacrolimus versus cyclosporin for immunosuppression in renal transplantation: meta-analysis of randomised trials. BMJ 1999;318:1104-7.

22. Cheung CY, Wong KM, Chan HW, Liu YL, Chan YH, Wong HS, Chak WL, Choi KS, Chau KF, Li CS. Paired kidney analysis of tacrolimus and cyclosporine microemulsion-based therapy in Chinese cadaveric renal transplant recipients. Transpl Int 2006;19:657-66.

23. David-Neto E, Lemos FC, Fadel LM, Agena F, Sato MY, Coccuza C, Pereira LM, de Castro MC, Lando VS, Nahas WC, lanhez LE. The dynamics of glucose metabolism under calcineurin inhibitors in the first year after renal transplantation in nonobese patients. Transplantation 2007;84:50-55.

24. Valderhaug TG, Hjelmesaeth J, Rollag H, Leivestad T, Røislien J, Jenssen T, Hartmann A. Reduced incidence of new-onset posttransplantation diabetes mellitus during the last decade. Transplantation 2007;84:1125-30.

25. Vesco L, Busson M, Bedrossian J, Bitker MO, Hiesse C, Lang P. Diabetes mellitus after renal transplantation: characteristics, outcome, and risk factors. Transplantation 1996;61:1475-8.

26. Knobler H, Stagnaro-Green A, Wallenstein S, Schwartz M, Roman SH. Higher incidence of diabetes in liver transplant recipients with hepatitis C. J Clin Gastroenterol 1998;26:30-3.

27. Fung KT, Fung J, Lai CL, Yuen MF. Etiologies of chronic liver diseases in Hong Kong. Eur J Gastroenterol Hepatol 2007;19:659-64.

28. Hirakauva EY, Ferraz ML, Perez RM, Ferreira AS, Silva AE, Hauache O, Pestana JO. Prevalence of diabetes mellitus in renal transplant patients with hepatitis $B$ or $C$ virus infection. Transplant Proc 2002;34:3220-2.

29. Lao TT, Tse KY, Chan LY, Tam KF, Ho LF. HBsAg carrier status and the association between gestational diabetes with increased serum ferritin concentration in Chinese women. Diabetes Care. 2003; 26:3011-6.

30. Racusen LC, Solez K, Colvin RB, Bonsib SM, Castro MC, Cavallo T, Croker BP, Demetris AJ, Drachenberg CB, Fogo AB, Furness P, Gaber LW, Gibson IW, Glotz D, Goldberg JC, Grande J, Halloran PF, Hansen HE, Hartley B, Hayry PJ, Hill CM, Hoffman EO, Hunsicker LG, Lindblad AS, Yamaguchi Y, et al. The Banff 97 working classification of renal allograft pathology. Kidney Int 1999;55:713-723. 


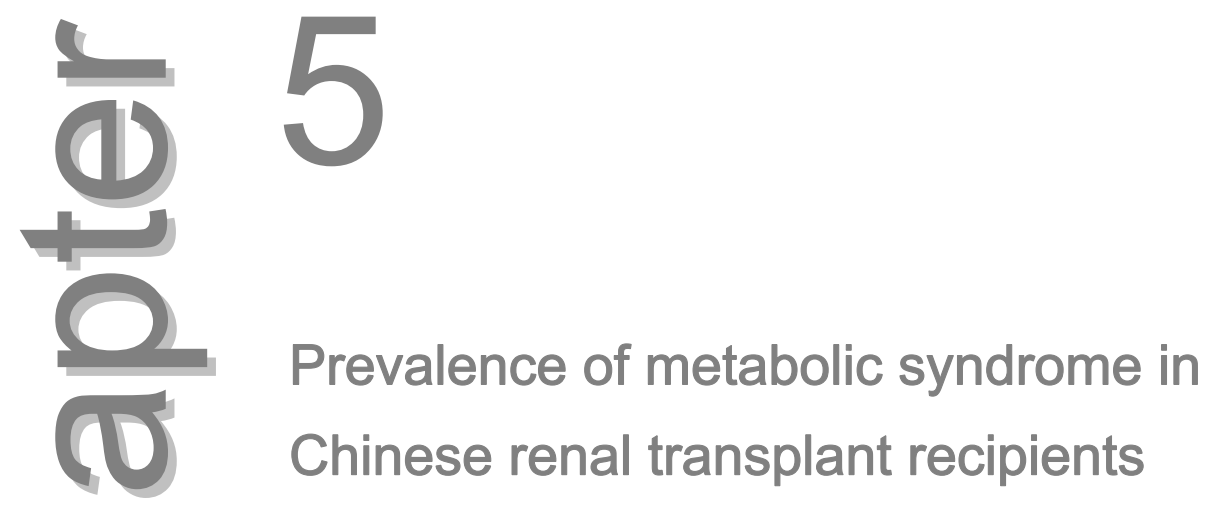

Chi Yuen Cheung, Hoi Wong Chan, Yan Lun Liu, Yiu Han Chan, Ho Sing Wong, Wai Leung Chak, Koon Shing Choi, Ka Foon Chau, Chun Sang Li

Hong Kong Medical Journal 2008; 14:379-84. 


\section{Abstract}

\section{Objective}

To investigate the prevalence of metabolic syndrome in Chinese renal transplant recipients, using two different sets of diagnostic criteria.

\section{Design}

Cross-sectional study.

\section{Setting}

Regional hospital, Hong Kong.

\section{Patients}

All Chinese patients who received solitary living-related or cadaveric kidney transplantation from 1 July 1997 to 31 December 2005 in our hospital with follow-up of more than six months were recruited. The diagnosis of metabolic syndrome was made according to the National Cholesterol Education Program-Adult Treatment Panel III (NCEP-ATPIII) criteria and the International Diabetes Federation criteria.

\section{Results}

Using the modified (Asian) NCEP-ATPIII criteria, a total of $39(32 \%)$ of 121 patients had metabolic syndrome, which included $20 / 69(29 \%)$ of the males and $19 / 52(37 \%)$ of the females. Using the International Diabetes Federation criteria, metabolic syndrome was diagnosed in $26 \%$ of the patients, $22 \%$ in males and $31 \%$ in females. In our patients, the most common component of metabolic syndrome was hypertension and the least common was low high-density-lipoprotein-cholesterol level. Low high-densitylipoprotein-cholesterol levels were significantly more common in female patients.

\section{Conclusion}

This study shows that there is a high prevalence of metabolic syndrome in our Chinese renal transplant recipients. 


\section{Introduction}

The metabolic syndrome (MS) is a cluster of interrelated common clinical entities, which include: obesity, insulin resistance, glucose intolerance, hypertension, and dyslipidaemia. It has been well recognised that MS is closely associated with atherosclerotic cardiovascular disease in the general population ${ }^{1}$. A community-based population study demonstrated that established cardiovascular disease risk factors are associated with the development of new-onset kidney disease ${ }^{2}$. Moreover, MS increases the risk of chronic kidney disease among US adults ${ }^{3}$. Recently it has been found that MS is also common in renal transplant recipients ${ }^{4}$. As in the general population, in renal transplant recipients, MS is associated with an increased risk of renal dysfunction and cardiovascular mortality ${ }^{4-6}$. However, most of the published studies were based on Caucasians, there being a lack of data in Chinese renal transplant recipients. Interestingly, in the general population, the prevalence of MS differs widely among ethnic groups and according to the definition used ${ }^{7-9}$. In the present study, we investigated the prevalence of MS in Chinese renal transplant recipients using different diagnostic criteria.

\section{Methods}

\section{Patients}

This was a cross-sectional study. All Chinese patients who received solitary living-related or cadaveric kidney transplantation from 1 July 1997 to 31 December 2005 in Queen Elizabeth Hospital, Hong Kong with follow-up of more than six months were recruited. The study was performed in accordance with the Declaration of Helsinki. Written consent was obtained from each patient. Demographic and clinical data were extracted from patient records.

\section{Immunosuppressive regimens}

Our patients were basically put on triple immunosuppressive therapy with either tacrolimus (Prograf, Astellas, Japan) or cyclosporine A (Neoral, Novartis, Switzerland), prednisolone and azathioprine. All patients received $500 \mathrm{mg}$ of methylprednisolone at induction, followed by intravenous hydrocortisone $100 \mathrm{mg}$ every six hours for three days and then oral prednisolone $30 \mathrm{mg}$ daily. The dose of prednisolone was gradually tapered after the first month at a rate of $2.5 \mathrm{mg}$ every two weeks and maintained at $7.5 \mathrm{mg}$ daily. Azathioprine was given at a dose of $1.5 \mathrm{mg} / \mathrm{kg}$ daily since day 1 after the transplant. Cyclosporine was initially administered orally as a loading dose of $10 \mathrm{mg} / \mathrm{kg}$ 
within 12 hours of surgery and continued as $5 \mathrm{mg} / \mathrm{kg}$ twice daily. In this study, an abbreviated formula based on a limited sampling strategy was used to estimate the cyclosporine area under 12-hour concentration-time curve $\left(\mathrm{AUC}_{0-12}\right)$. Calculation of cyclosporine $\mathrm{AUC}_{0-12}$ depended on the formula: 452.4 $+\mathrm{C}_{0} \times 17.5+\mathrm{C}_{1.5} \times 1.89\left(\mathrm{C}_{0}\right.$ : cyclosporine trough level; $\mathrm{C}_{1.5}$ : 1.5-hour postdose cyclosporine level). ${ }^{10}$ The dose of cyclosporine was gradually titrated to maintain an abbreviated $\mathrm{AUC}_{0-12}$ of around $6000-8000 \mathrm{ng} \mathrm{x} \mathrm{h} / \mathrm{ml}$ in the first three months post-transplant and $4000-6000 \mathrm{ng} \times \mathrm{h} / \mathrm{ml}$ thereafter ${ }^{11}$. On the other hand, tacrolimus was administered orally with a loading dose of $0.3 \mathrm{mg} / \mathrm{kg}$ within 12 hours of surgery and then $0.15 \mathrm{mg} / \mathrm{kg}$ twice daily. Abbreviated tacrolimus $\mathrm{AUC}_{0-12}$ monitoring was used. Calculation of tacrolimus $A_{U C} C_{0-12}$ depended on the formula: $16.2+C_{2} \times 2.4+C_{4} \times 5.9\left(C_{2}\right.$ : 2-hour postdose tacrolimus level; $\mathrm{C}_{4}$ : 4-hour postdose tacrolimus level). Based on a previous pilot study in stable patients on tacrolimus in our centre, the $\mathrm{AUC}_{0-12}$ value was kept at around 100-150 $\mathrm{ng} \mathrm{x} \mathrm{h/ml}$ in the first three months and around $80-100 \mathrm{ng} \mathrm{x} \mathrm{h/ml} \mathrm{thereafter.}{ }^{12}$ Since 2001 , some of our patients did receive an interleukin-2 receptor antagonist during induction therapy; patients on cyclosporine were given basiliximab (Simulect, Novartis, Switzerland) while those on tacrolimus were given daclizumab (Zenapax, Roche, NJ, US). Basiliximab was given at a dose of $20 \mathrm{mg}$ around 2-hour pre-transplantation and a second dose after four days. Daclizumab was given as a $1 \mathrm{mg} / \mathrm{kg}$ infusion around two hours before transplantation and then every 14 days for four doses.

Acute rejection was defined as any episode with the relevant clinical and laboratory signs and symptoms and all such episodes were confirmed by renal biopsy. Our protocol for treating acute cellular rejection entailed $500 \mathrm{mg}$ methylprednisolone given intravenously for three days. In case of steroidresistant rejection, appropriate antibody therapy was started.

\section{Measurements}

Subjects came back to our centre at 8:00 am after an 8-to-12-hour overnight fast. Fasting blood samples were drawn to determine serum creatinine, triglyceride, and high-density-lipoprotein (HDL) cholesterol and plasma glucose concentrations. Low-density lipoprotein (LDL) cholesterol concentration was calculated using the Friedewald formula. ${ }^{13}$ Hypertension was defined as (i) the administration of antihypertensive agents and/or a history of this disorder; (ii) a systolic blood pressure greater than $130 \mathrm{mmHg}$; or (iii) a diastolic blood pressure greater than $85 \mathrm{mmHg}$. Weight, height, and waist circumference (midway between the iliac crest and the 10th rib) were also measured. 
Post-transplant diabetes mellitus (PTDM) was defined as a fasting blood glucose of more than $7 \mathrm{mM}(126 \mathrm{mg} / \mathrm{dl})$ on two occasions at any time after transplantation or requiring use of oral hypoglycaemic agents and/or insulin, in patients with no previous history of diabetes mellitus.

\section{Diagnostic criteria for metabolic syndrome}

The diagnosis of MS was made according to the National Cholesterol Education Program-Adult Treatment Panel III (NCEP-ATPIII) criteria ${ }^{14}$ and the International Diabetes Federation (IDF) criteria $^{15}$. The five thresholds used were: (i) serum triglyceride level $\geq 1.69 \mathrm{mmol} / \mathrm{l}(\geq 150 \mathrm{mg} / \mathrm{dl})$ or specific treatment for this lipid abnormality, (ii) serum $\mathrm{HDL}$-cholesterol level $<1.04 \mathrm{mmol} / \mathrm{l}(<40 \mathrm{mg} / \mathrm{dl})$ in $\mathrm{men}$ or $<1.29 \mathrm{mmol} / \mathrm{l}(<50 \mathrm{mg} / \mathrm{dl})$ in women or specific treatment for this lipid abnormality, (iii) systolic blood pressure $\geq 130 \mathrm{~mm} \mathrm{Hg}$ and/or diastolic blood pressure $\geq 85 \mathrm{~mm} \mathrm{Hg}$ (high blood pressure) or use of antihypertensive medication, (iv) fasting plasma glucose level $\geq 100 \mathrm{mg} / \mathrm{dl}(\geq 5.6 \mathrm{mmol} / \mathrm{l})$ or use of antidiabetic medication, and $(\mathrm{v})$ waist girth $>102 \mathrm{~cm}$ for men or $>88 \mathrm{~cm}$ for women (original NCEP-ATPIII criteria) and waist girth $\geq 90 \mathrm{~cm}$ for men or $\geq 80 \mathrm{~cm}$ for women (modified NCEP-ATPIII criteria for Asians). Because the original cut-off for abdominal obesity in the NCEP definition (waist circumference $>102 \mathrm{~cm}$ for men and $>88 \mathrm{~cm}$ for women) were shown to be inappropriate for Asian populations and the number of subjects who met these criteria was extremely low $^{7,8,16}$, we used Asian cut-off limits $7,8,15,16$.

\section{National Cholesterol Education Program-Adult Treatment Panel III criteria}

Subjects who had three or more of the risk factors were judged as having MS (MS group), and having two or less risk factors were judged as not having the condition (non-MS group).

\section{International Diabetes Federation criteria}

Subjects with central obesity (defined as waist circumference $\geq 90 \mathrm{~cm}$ for men or $\geq 80 \mathrm{~cm}$ for women in Chinese) plus two or more of the risk factors were judged as having MS.

\section{Statistical analysis}

The Statistical Package for the Social Sciences (Windows version 15.0; SPSS Inc, Chicago [IL], US) was used to perform the analyses. Continuous data were expressed as means and standard deviations and categorical data as 
percentages. Continuous data were analysed by independent sample $t$ tests to detect the differences between groups and categorical data by the Chi-square test. A $P$-value of $<0.05$ was considered as statistically significant.

\section{Results}

\section{Demographic and transplant characteristics of patients with and without metabolic syndrome (according to the National Cholesterol Education Program-Adult Treatment Panel III criteria for Asians)}

Table 5.1 shows the background data for renal transplant patients with or without MS. The mean follow-up duration after kidney transplantation was 63 (standard deviation, 29) months. Using the modified (Asian) NCEP-ATPIII criteria, a total of $39(32 \%)$ of 121 patients had MS. Compared to the non-MS group, in those with MS, the mean age was greater $(P=0.010)$, PTDM and hypertension were more prevalent $(P=0.013$ and $P=0.002$ respectively), and body mass index and waist circumference were greater $(P<0.001$ in both cases). The MS group also had higher mean serum triglyceride levels $(P=0.026)$, and more severe proteinuria $(P=0.038)$. Other clinical variables did not differ significantly. Both groups were receiving similar doses of steroids during the study and the proportions receiving tacrolimus or cyclosporine were also similar $(P=0.452)$. In all, 15 patients in this cohort were taking on lipidlowering agents.

\section{Percentage of patients with metabolic syndrome according to diagnostic criteria}

Using the modified (Asian) NCEP-ATPIII criteria, 39 (32\%) of 121 patients had MS including $20(29 \%)$ of 69 males and $19(37 \%)$ of 52 females. Using the original NCEP-ATPIII criteria, MS was diagnosed in $18 \%$ of patients: $16 \%$ of the males and $21 \%$ of the females. Using the IDF criteria, MS was diagnosed in $26 \%$ of patients: $22 \%$ of the males and $31 \%$ of the females (Table 5.2 ). 
Table 5.1 Demographic and transplant characteristics of patients with / without metabolic syndrome (MS) by modified (Asian) National Cholesterol Education Program-Adult Treatment Panel III criteria.

\begin{tabular}{lccc}
\hline & $\mathrm{MS}$ & Non-MS & $P$-value* \\
& $\mathrm{n}=39$ & $\mathrm{n}=82$ & \\
\hline Age of recipient (years) & $42 \pm 10$ & $38 \pm 10$ & $0.010^{*}$ \\
Male & $20(51)$ & $49(60)$ & 0.379 \\
Donor source & & & 0.572 \\
$\quad$ Living & $3(8)$ & $9(11)$ & \\
$\quad$ Cadaveric & $36(92)$ & $73(89)$ & \\
Diabetes Mellitus & & & \\
Pre-transplant & $11(28)$ & $1(1)$ & $<0.001^{*}$ \\
Post-transplant & $12(31)$ & $10(12)$ & $0.013^{*}$ \\
Duration of Transplant, (years) & $5.1 \pm 2.1$ & $5.3 \pm 2.3$ & 0.633 \\
Waist circumference (cm) & $90.3 \pm 9.6$ & $78.1 \pm 10.0$ & $<0.001^{*}$ \\
Body mass index (kg/m $\left.{ }^{2}\right)$ & $25 \pm 5$ & $21 \pm 3$ & $<0.001^{*}$ \\
Weight gain at 1-year post transplant (kg) & $6 \pm 7$ & $3 \pm 6$ & $0.017^{*}$ \\
Hepatitis B status & $5(13)$ & $13(16)$ & 0.661 \\
Calcineurin inhibitors & & & \\
$\quad$ Tacrolimus & $19(49)$ & $34(41)$ & 0.452 \\
$\quad$ Cyclosporine & $20(51)$ & $48(59)$ & \\
Use of interleukin-2 receptor antagonist & $20(51)$ & $44(54)$ & 0.807 \\
Prednisolone dosage (mg) & 7.5 & 7.5 & 1.000 \\
Use of ACEl or ARB & $4(10)$ & $5(6)$ & 0.415 \\
Triglyceride (mM) & $2.0 \pm 1.1$ & $1.5 \pm 1.1$ & $0.026^{*}$ \\
HDL cholesterol (mM) & $1.5 \pm 0.5$ & $1.7 \pm 0.5$ & 0.370 \\
Fasting glucose (mM) & $5.6 \pm 0.8$ & $5.2 \pm 0.8$ & 0.188 \\
Hypertension & $39(100)$ & $64(78)$ & $0.002^{*}$ \\
SCr at 6 months(uM) & $160 \pm 60$ & $162 \pm 66$ & 0.792 \\
SCr at 12 months(uM) & $151 \pm 55$ & $158 \pm 55$ & 0.510 \\
Proteinuria (g/day) & $0.81 \pm 1.44$ & $0.29 \pm 0.71$ & $0.038^{*}$ \\
Albuminuria (mg/day) & $62 \pm 76$ & $52 \pm 75$ & 0.680 \\
CMV infection & $7(18)$ & $11(13)$ & 0.512 \\
Acute rejection & $7(18)$ & $20(24)$ & 0.426 \\
\hline
\end{tabular}

Values are expressed as mean \pm SD or number (percentage). MS, metabolic syndrome; ACEI, angiotensin converting enzyme inhibitors; ARB, angiotensin II receptor blockers; CMV, cytomegalovirus; HDL, high-density lipoprotein; SCr, serum creatinine; * Continuous variables were analyzed with the use of t-tests, all categorical data were analyzed with the use of chi-square test.

Table 5.2 Percentage of patients with metabolic syndrome according to different diagnostic criteria.

\begin{tabular}{lcccc}
\hline & \multicolumn{4}{c}{ Prevalence of metabolic syndrome (\%) } \\
& $\mathrm{n}$ & 1 & 2 & 3 \\
\hline Male & 69 & 29 & 16 & 22 \\
Female & 52 & 37 & 21 & 31 \\
Total & 121 & 32 & 18 & 26 \\
\hline
\end{tabular}

1. Modified (Asian) NCEP-ATP III criteria - Waist girth $>80 \mathrm{~cm}$ in women or $>90 \mathrm{~cm}$ in men; 2 . Original NCEP-ATP III criteria - Waist girth $\geq 88 \mathrm{~cm}$ in women or $\geq 102 \mathrm{~cm}$ in men; 3 . IDF criteria Waist girth $\geq 80 \mathrm{~cm}$ in women or $\geq 90 \mathrm{~cm}$ in men. NCEP-ATP III denotes National Cholesterol Education Program-Adult Treatment Panel III, and IDF International Diabetes Federation. 


\section{Prevalence of metabolic syndrome and its components as defined by the modified (Asian) National Cholesterol Education Program- Adult Treatment Panel III criteria criteria}

In our Chinese renal transplant recipients, the most common component of MS was hypertension and the least common was low HDL-cholesterol. Low HDLcholesterol was significantly more common in female patients $(14 \%$ vs. $2 \%$, $P=0.009$ ). However, there was no significant difference in the occurrence of other MS components between males and females (Table 5.3).

Table 5.3 Crude prevalence of metabolic syndrome and its components as defined by the modified (Asian) National Cholesterol Education Program-Adult Treatment Panel III criteria.

\begin{tabular}{lcccc}
\hline Component & $\begin{array}{c}\text { Total } \\
(\mathrm{n}=121)\end{array}$ & $\begin{array}{c}\text { Men } \\
(\mathrm{n}=69)\end{array}$ & $\begin{array}{c}\text { Women } \\
(\mathrm{n}=52)\end{array}$ & $P$ value \\
\hline Central obesity (\%) & 37 & 33 & 42 & 0.312 \\
Low HDL-cholesterol (\%) & 7 & 2 & 14 & $0.009^{*}$ \\
High TG (\%) & 42 & 42 & 42 & 0.975 \\
Hypertension (\%) & 86 & 84 & 89 & 0.490 \\
Hyperglycemia (\%) & 36 & 38 & 35 & 0.729 \\
Metabolic syndrome (\%) & 32 & 29 & 37 & 0.379 \\
\hline
\end{tabular}

HDL denotes high-density lipoprotein, and TG triglyceride.

\section{Discussion}

In the general population, the prevalence of MS differs widely among ethnic groups depending on the definition of MS used ${ }^{7-9}$. In a US study, its prevalence was 24.7 to $26.7 \%$ using the original NCEP-ATPIII criteria ${ }^{3,9}$. By contrast, in a Japanese population its prevalence was $12.4 \%$ using the same NCEP criteria and $21.2 \%$ according to the modified (Japanese) criteria ${ }^{17}$. de Vries et al. ${ }^{4}$ applied the consensus definition (NCEP-ATPIII) of MS to the kidney transplant population in the Netherlands. They reported that $63 \%$ of Caucasian renal transplant patients had MS. Porrini et $\mathrm{al}^{5}$ reported that $37.7 \%$ of Spanish renal transplantation recipients had MS using modified NCEP criteria, while Armstrong et al..$^{18}$ reported that $50 \%$ of Australian renal transplant recipients had MS according to the original NCEP criteria. These various reports suggest that MS is more prevalent in Caucasian renal transplant recipients than the general Caucasian population. However, there was only a slight difference in the prevalence of MS between the general population and renal transplant patients in Japan ${ }^{19}$. This discrepancy may therefore be related to differences in lifestyle, eating habits, or the prevalence and degree of obesity among Japanese and Caucasian populations. In the InterASIA study, $\mathrm{Gu}$ et al. ${ }^{7}$ showed that $15.1 \%$ of the Chinese adults aged $35-74$ years had MS by the 
modified NCEP (Asian) criteria. In another study involving a Hong Kong Chinese working population, the crude prevalence of MS ranged from 8.9 to $13.4 \%$ depending on the criteria used ${ }^{20}$. In the present study, we showed that MS was more prevalent in our Chinese renal transplant recipients than that reported in the literature for the general population. To the best of our knowledge, this is the first study showing the prevalence of MS in Chinese renal transplant recipients.

In our study, body mass index and waist circumference of the MS group were significantly greater than in the non-MS group. As in the general population, being overweight was a major clinical feature of $M S$ in renal transplant recipients. Insulin resistance is the central pathophysiological feature underlying $\mathrm{MS}^{21}$. In renal transplant recipients, factors other than obesity may contribute to insulin resistance. High-dose immunosuppressive therapy in the early post-transplant period, namely steroids and calcineurin inhibitors, may play a major role. Indeed, early high-dose steroid usage, together with acute rejection, have been associated with insulin resistance ${ }^{22,23}$. In our study, all patients received the same immunosuppressive regimen as well as the same amount of maintenance steroids. Thus, we were unable to assess the relationship between steroid dosage and the occurrence of MS. However, acute rejection was not particularly associated with subsequent development of MS. Similarly, none of our patients were on a calcineurin inhibitor-free regimen, and thus we could not evaluate their role in the occurrence of MS. Hjelmesaeth et al. $^{23}$ have demonstrated an association between cytomegalovirus (CMV) disease and insulin resistance, possibly via inducing release of cytokines such as tumour necrosis factor-alpha ${ }^{24,25}$. Our data, however, could not demonstrate any independent relationship between CMV disease and the development of MS.

Our study revealed that MS was more prevalent in the female patients (37\% vs. $29 \%$ ), which was consistent with the general adult population in China ${ }^{7}$. This difference might be due to a higher prevalence of low HDL-cholesterol in women compared to men, which may be due to different cut-off values used in men and women. de Vries et al. ${ }^{4}$ also reported that patients with MS were more often female. In contrast, some reports have shown that MS was more common in male renal transplant recipients ${ }^{5,19}$, indicating that in renal transplant recipients, gender predisposition of MS may differ widely between ethnic groups $\mathrm{s}^{3,7-9,16,17}$.

In our study, PTDM was more prevalent in the MS group, consistent with a previous report by Porrini et $a l^{5}{ }^{5}$ In their longitudinal study, they showed that MS was a prominent risk factor for PTDM. Obesity and dyslipidaemia, which 
are components of MS, are associated with insulin resistance, one of the most important causative elements in the pathophysiology of type 2 diabetes ${ }^{26,27}$. Our approach to treating dyslipidaemias in renal transplant recipients is consistent with that advocated by the NKF-K/DOQI working group ${ }^{28}$. There is a particular emphasis given to the high cardiovascular risks associated with kidney transplantation. Based almost entirely upon adverse results and benefits with therapy in the general population, three subgroups of renal allograft recipients with distinct lipid profiles are distinguished for particular attention. These are: (1) those with triglyceride levels $>5.65 \mathrm{mmol} / /$ (>500 $\mathrm{mg} / \mathrm{dl}$ ); (2) those with LDL levels $>2.59 \mathrm{mmol} / \mathrm{l}(>100 \mathrm{mg} / \mathrm{dl})$; and (3) those with LDL levels $\leq 2.59 \mathrm{mmol} / \mathrm{l}(\leq 100 \mathrm{mg} / \mathrm{dl})$, triglycerides levels $>2.26 \mathrm{mmol} / \mathrm{l}(>200 \mathrm{mg} / \mathrm{dl})$ and non-HDL cholesterol levels $>3.36 \mathrm{mmol} / \mathrm{l}(>130 \mathrm{mg} / \mathrm{dl})$. They were all treated with lipid-lowering agents after failure of control with lifestyle modification.

In the present study, the diagnosis of MS was made according to the NCEPATPIII criteria and IDF criteria, as they are easily applicable in a clinical setting and widely used in different studies. Our study showed that the prevalence of MS was differed according to the criteria used, being slightly lower by IDF criteria (which recognises central obesity as an essential component). At present, there is no consensus on which diagnostic criteria for MS are best suited for renal transplant recipients. Further longitudinal studies of cardiovascular disease and renal allograft function are needed to clarify this issue.

It has been reported that MS is a risk factor for renal dysfunction in the general population $^{2,3}$. In heart transplantation, Valantine et al. ${ }^{29}$ suggested that a 'metabolic milieu' may modify the process of chronic transplant dysfunction. In longitudinal studies, de Vries et $a l^{4}$ and Porrini et al. ${ }^{5}$ suggested that MS is associated with impaired renal allograft function. Different mechanisms have been proposed for the association between MS and impaired renal function. Obesity may contribute to renal dysfunction in many ways-excess excretory load, renal sodium retention, hyperinsulinaemia, insulin resistance, or renal lipotoxicity ${ }^{30-33}$. Moreover, obesity is associated with worsening proteinuria in renal transplant recipients ${ }^{18}$. Finally, glucose intolerance, hypertension and dyslipidaemia (all components of MS), directly damage the kidneys through renal or systemic atherosclerosis ${ }^{34-37}$. Our series did not demonstrate a significant difference in renal function between patients with and without MS, probably because they were from a cross-sectional study and the sample size was small.

In conclusion, our present study showed a high prevalence of MS in our Chinese renal transplant recipients, more so in females than males. Prevalence 
varied according to the different diagnostic criteria used. By the IDF criteria, which cites central obesity as an essential component, its prevalence was slightly lower. 


\section{References}

1. Eckel RH, Grundy SM, Zimmet PZ. The metabolic syndrome. Lancet 2005;365:1415-28.

2. Fox CS, Larson MG, Leip EP, Culleton B, Wilson PW, Levy D. Predictors of new-onset kidney disease in a community-based population. JAMA 2004;291:844-50.

3. Chen J, Muntner P, Hamm LL, Jones DW, Batuman V, Fonseca V, Whelton PK, He J. The metabolic syndrome and chronic kidney disease in U.S. adults. Ann Intern Med 2004;140:16774.

4. de Vries AP, Bakker SJ, van Son WJ, van der Heide JJ, Ploeg RJ, The HT, de Jong PE, Gans RO.. Metabolic syndrome is associated with impaired long-term renal allograft function; not all component criteria contribute equally. Am J Transplant 2004;4:1675-83.

5. Porrini E, Delgado P, Bigo C, Alvarez A, Cobo M, Checa MD, Hortal L, Fernández A, García JJ, Velázquez S, Hernández D, Salido E, Torres A. Impact of metabolic syndrome on graft function and survival after cadaveric renal transplantation. Am J Kidney Dis 2006;48:134-42.

6. Holdaas H, Fellstrom B, Jardine A, Gimpelewicz C, Staffler B, Logan J. ALERT investigators: prevalence and cosequences of metabolic syndrome in a renal transplant population [abstract]. Am J Soc Nephrol 2004;15:572A.

7. Gu D, Reynolds K, Wu X, Chen J, Duan X, Reynolds RF, Whelton PK, He J; InterASIA Collaborative Group. Prevalence of the metabolic syndrome and overweight among adults in China. Lancet 2005;365:1398-405.

8. Park HS, Oh SW, Cho SI, Choi WH, Kim YS. The metabolic syndrome and associated lifestyle factors among South Korean adults. Int J Epidemiol 2004;33:328-36.

9. Ford ES, Giles $\mathrm{WH}$, Mokdad AH. Increasing prevalence of the metabolic syndrome among U.S. adults. Diabetes Care 2004;27:2444-9.

10. Tsang WK, Ho YW, Tong KL, Chan WH, Chan A. Safety, tolerability, and pharmacokinetics of Sandimmun Neoral: conversion study in stable renal transplant recipients. Transplant Proc 1996;28:1330-2.

11. International Neoral Renal Transplantation Study Group. Cyclosporine microemulsion (Neoral) absorption profiling and sparse-sample predictors during the first 3 months after renal transplantation. Am J Transplant 2002;2:148-56.

12. Wong KM, Shek CC, Chau KF, Li CS. Abbreviated tacrolimus area-under-curve monitoring for renal transplant recipients. Am J Kidney Dis 2000;35:660-6.

13. Friedewald WT, Levy RI, Fredrickson DS. Estimation of the concentration of low-density lipoprotein cholesterol in plasma, without use of the preparative ultracentrifuge. Clin Chem 1972;18:499-502.

14. Grundy SM, Brewer HB Jr, Cleeman JI, Smith SC Jr, Lenfant C; Amercian Heart Association; National Heart, Lung, and Blood Institute. Definition of metabolic syndrome: Report of the National Heart, Lung, and Blood Institute/American Heart Association conference on scientific issues related to definition. Circulation 2004;109:433-8.

15. Alberti KG, Zimmet P, Shaw J; IDF Epidemiology Task Force Consensus Group. The metabolic syndrome -a new worldwide definition. Lancet 2005;366:1059-62.

16. Tan CE, Ma S, Wai D, Chew SK, Tai ES. Can we apply the National Cholesterol Education Program Adult Treatment Panel definition of the metabolic syndrome to Asians? Diabetes Care 2004;27:1182-6.

17. Tanaka $\mathrm{H}$, Shiohira $\mathrm{Y}$, Uezu $\mathrm{Y}$, Higa A, Iseki K. Metabolic syndrome and chronic kidney disease in Okinawa, Japan. Kidney Int 2006;69:369-74.

18. Armstrong KA, Campbell SB, Hawley CM, Nicol DL, Johnson DW, Isbel NM. Obesity is associated with worsening cardiovascular risk factor profiles and proteinuria progression in renal transplant recipients. Am J Transplant 2005;5:2710-8.

19. Naganuma T, Uchida J, Kinoshita $Y$, Kuroki $Y$, Takemoto $Y$, Yoshimura R, Sugimura $K$, Nakatani T. The prevalence of metabolic syndrome in Japanese renal transplant recipients. Nephrology (Carlton) 2007;12:413-7. 
20. Ko GT, Cockram CS, Chow CC, Yeung V, Chan WB, So WY, Chan NN, Chan JC. High prevalence of metabolic syndrome in Hong Kong Chinese-comparison of three diagnostic criteria. Diabetes Res Clin Pract 2005;69:160-8.

21. Reaven GM. Banting lecture 1988. Role of insulin resistance in human disease. Diabetes 1988;37:1595-607.

22. Hjelmesaeth J, Hartmann A, Midtvedt K, Aakhus S, Stenstrøm J, Mørkrid L, Egeland T, Tordarson $\mathrm{H}$, Fauchald P. Metabolic cardiovascular syndrome after renal transplantation. Nephrol Dial Transplant 2001;16:1047-52.

23. Hjelmesaeth $\mathrm{J}$, Midtvedt $\mathrm{K}$, Jenssen $\mathrm{T}$, Hartmann $\mathrm{A}$. Insulin resistance after renal transplantation: impact of immunosuppressive and antihypertensive therapy. Diabetes Care 2001;24:2121-6.

24. Koskinen PK, Kallio EA, Tikkanen JM, Sihvola RK, Häyry PJ, Lemström KB. Cytomegalovirus infection and cardiac allograft vasculopathy. Transpl Infect Dis 1999;1:115-26.

25. Moller DE. Potential role of TNF-alpha in the pathogenesis of insulin resistance and type 2 diabetes. Trends Endocrinol Metab 2000;11: 212-7.

26. Hanson RL, Imperatore G, Bennett PH, Knowler WC. Components of the "metabolic syndrome" and incidence of type 2 diabetes. Diabetes 2002;51:3120-7.

27. McLaughlin T, Abbasi F, Cheal K, Chu J, Lamendola C, Reaven G. Use of metabolic markers to identify overweight individuals who are insulin resistant. Ann Intern Med 2003;139:802-9.

28. Kasiske B, Cosio FG, Beto J, Bolton K, Chavers BM, Grimm R Jr, Levin A, Masri B, Parekh R, Wanner C, Wheeler DC, Wilson PW; National Kidney Foundation. Clinical practice guidelines for managing dyslipidemias in kidney transplant patients: a report from the Managing Dyslipidemias in Chronic Kidney Disease Work Group of the National Kidney Foundation Kidney Disease Outcomes Quality Initiative. Am J Transplant 2004;4(Suppl 7):13S-53S.

29. Valantine H, Rickenbacker P, Kemna M, Hunt S, Chen YD, Reaven G, Stinson EB. Metabolic abnormalities characteristic of dysmetabolic syndrome predict the development of transplant coronary artery disease: a prospective study. Circulation 2001;103:2144-52.

30. Kubo M, Kiyohara Y, Kato I, Iwamoto H, Nakayama K, Hirakata H, Fujishima M. Effect of hyperinsulinemia on renal function in a general Japanese population: the Hisayama study. Kidney Int 1999;55:2450-6.

31. Wu Y, Liu Z, Xiang Z, Zeng C, Chen Z, Ma X, Li L. Obesity-related glomerulopathy: insights from gene expression profiles of the glomeruli derived from renal biopsy samples. Endocrinology 2006;147:44-50.

32. Bagby SP. Obesity-initiated metabolic syndrome and the kidney: a recipe for chronic kidney disease? J Am Soc Nephrol 2004;15:2775-91.

33. Chalmers L, Kaskel FJ, Bamgbola O. The role of obesity and its bioclinical correlates in the progression of chronic kidney disease. Adv Chronic Kidney Dis 2006;13:352-64.

34. Nelson RG, Bennett PH, Beck GJ, Tan M, Knowler WC, Mitch WE, Hirschman GH, Myers BD. Development and progression of renal disease in Pima Indians with non-insulin-dependent diabetes mellitus. Diabetic Renal Disease Study Group. N Engl J Med 1996;335:1636-42.

35. Humphrey LL, Ballard DJ, Frohnert PP, Chu CP, O'Fallon WM, Palumbo PJ. Chronic renal failure in non-insulin-dependent diabetes mellitus. A population-based study in Rochester, Minnesota. Ann Intern Med 1989;111:788-96.

36. Hunsicker LG, Adler S, Caggiula A, England BK, Greene T, Kusek JW, Rogers NL, Teschan $\mathrm{PE}$. Predictors of the progression of renal disease in the Modification of Diet in Renal Disease Study. Kidney Int 1997;51:1908-19.

37. Muntner P, Coresh J, Smith JC, Eckfeldt J, Klag MJ. Plasma lipids and risk of developing renal dysfunction: the atherosclerosis risk in communities study. Kidney Int 2000;58:293-301. 



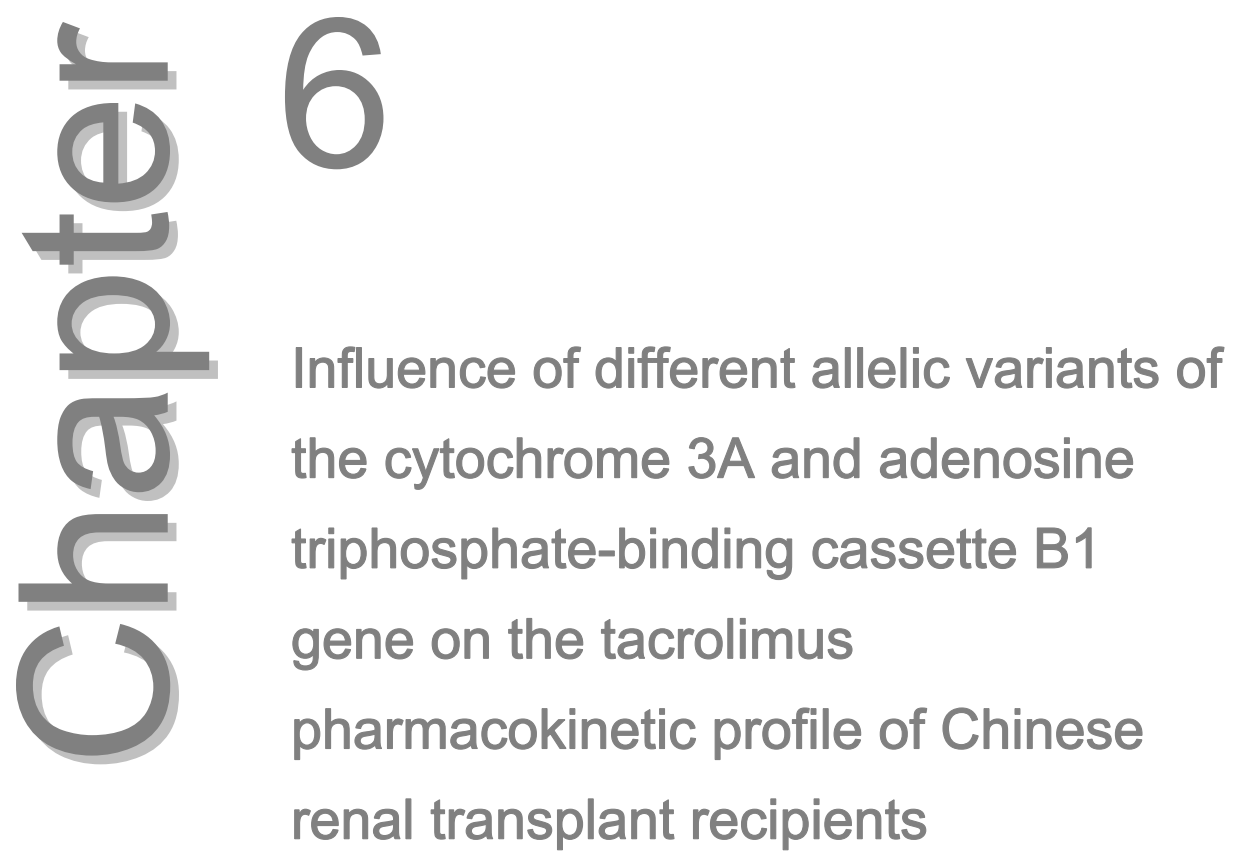

Chi Yuen Cheung, Robert A.M. Op den Buijsch, Kim Ming Wong, Hoi Wong Chan, Ka Foon Chau, Chun Sang Li, Kay Tai Leung, Tze Hoi Kwan, Johan E. de Vries, Petal A.H.M. Wijnen, Marja P. van Dieijen-Visser; Otto Bekers

Pharmacogenomics 2006; 7:563-574 


\section{Abstract}

\section{Background and aim}

Tacrolimus has a narrow therapeutic window and a wide interindividual variation in its pharmacokinetics. Cytochrome P450 3A (CYP3A) and the adenosine triphosphatebinding cassette $B 1$ (ABCB1) gene encoding protein, multidrug resistance-1 (MDR1) or P-glycoprotein play an important role in the tacrolimus disposition. Therefore this study evaluates whether CYP3A and ABCB1 polymorphisms are associated with the area under the time tacrolimus concentration curve $\left(\mathrm{AUC}_{0-12}\right)$ calculated using a two time point sample strategy.

\section{Materials and methods}

The CYP3A and ABCB1 genotypes are determined by real-time polymerase chain reaction (PCR) fluorescence resonance energy transfer (FRET) assays in 103 Chinese renal transplant recipients and consequently related to their dose-normalized $A_{U-12}$ $\left(\mathrm{dnA} \cup \mathrm{C}_{0-12}\right)$.

\section{Results}

A significant allele-dependent effect (Kruskal Wallis; $P<0.001$ ) is observed between the CYP3A5*3 polymorphism and the $\mathrm{dnAUC}_{0-12}$. Multiple regression analysis showed that the CYP $3 A 5^{\star} 3$ polymorphism is the most significant independent variable and explained $35 \%$ of the dose requirement variability in relation to tacrolimus use. Regarding the ABCB1 G2677T/A and C3435T polymorphisms, a trend is observed between the different genotypes and the dnAUC 0 -12.

\section{Conclusion}

The CYP3A5*3 polymorphism may be an important factor in determining the dose requirement for tacrolimus and genotyping can help determine the initial daily dose needed by individual patients for adequate immunosuppression. 


\section{Introduction}

The calcineurin inhibitor tacrolimus that is used worldwide for primary immunosuppression following renal transplantation has a narrow therapeutic index, which makes close therapeutic drug monitoring necessary to prevent both sub-therapeutic blood levels as well as toxic blood levels. Subtherapeutic tacrolimus blood levels increase the risk of transplant rejection ${ }^{1-3}$, while toxic tacrolimus blood levels may lead to severe side effects such as nephrotoxicity and neurotoxicity ${ }^{4-6}$. The high interindividual variability in tacrolimus pharmacokinetics complicates the realization of this narrow therapeutic index ${ }^{7,8}$. Although tacrolimus trough $\left(\mathrm{C}_{0}\right)$ levels have been shown to provide a reliable indication of the total drug exposure ${ }^{9}$, their usefulness in differentiating graft rejection episodes from nephrotoxicity has been questioned ${ }^{2,10}$. A more accurate estimation of the tacrolimus exposure by making 12 hour pharmacokinetic profiles may lead to a lower incidence of acute rejection like in the case of cyclosporine ${ }^{11,12}$. Since obtaining complete 12 hour pharmacokinetic profiles for every renal transplant patient is not feasible in clinical practice, parameters have been examined that strongly correlate with the 12 hour pharmacokinetic profile. Recent studies showed higher correlations with the 12 hour pharmacokinetic profiles of tacrolimus when a limited sampling point sample strategy is used instead of $\mathrm{C}_{0}$ levels alone ${ }^{13-17}$. Additionally, the two time point sample strategy used in the present study is able to calculate reliable the area under the time tacrolimus concentration curve or $\mathrm{AUC}_{0-12}$ in renal transplant patient groups. ${ }^{15,17}$ The cytochrome P450 (CYP) 3A isoenzymes mainly represented by CYP3A4 and CYP3A5 have been identified as the major enzymes responsible for the disposition of tacrolimus. ${ }^{18}$ Although a number of CYP3A4 polymorphisms have been identified (website Human Cytochrome P450 (CYP) Allele Nomenclature Committee ${ }^{101}$ ), these are rare and therefore do not contribute significantly to CYP3A4 expression variability. The single nucleotide polymorphism (SNP) CYP3A5 6986G or *3 displays a sequence variability in intron 3 that creates a cryptic splice site and encodes an aberrantly spliced mRNA with a premature stop codon, leading to the absence of protein expression. This CYP $3 A 5^{*} 3$ polymorphism occurred homozygously in $90 \%$ of the Caucasians, $73 \%$ of the Chinese and in $30 \%$ of the AfricanAmerican population ${ }^{19-21}$. Although several studies ${ }^{22-31}$ have described the association between the CYP $3 A 5^{*} 3$ polymorphism and tacrolimus $\mathrm{C}_{0}$ levels, the present study examines the associations with the CYP3A polymorphisms using a more accurate approach to determine the tacrolimus exposure in renal transplant patients. Tacrolimus is also a substrate for the adenosine triphosphate-binding cassette $\mathrm{B} 1$ ( $\mathrm{ABCB} 1$ ) gene encoding protein multidrug resistance-1 (MDR1) or P-glycoprotein. ABCB1 is an ATP-dependent efflux pump that contributes to the protection of the body from environmental toxins 
and drugs like tacrolimus by limiting their absorption from the gut lumen or increasing their biliary and urinary excretion ${ }^{32}$. Three partly linked polymorphisms in the ABCB1 gene located on exons 12, 21 and 26 have been studied widely and these polymorphisms account for the major haplotypes encountered in Caucasians. Whereas two of these ABCB1 polymorphisms, C1236T and C3435T, result in silent mutations, the ABCB1 G2677T/A polymorphism in exon 21 is non-synonymous and results in an amino acid exchange (Ala893Ser/Thr). A number of studies already have reported that there seems to be no association between the ABCB1 polymorphisms and tacrolimus dose-normalized trough $\left(\mathrm{dnC}_{0}\right)$ levels ${ }^{25-27,30,31,33}$ or the dosenormalized area under the time tacrolimus concentration curve $\left(\mathrm{dnAUC}_{0-12}\right)^{34,35}$. However, some studies found a correlation between individual ABCB1 polymorphisms $^{23,24,36}$ or the ABCB1 $1236 \mathrm{C}-2677 \mathrm{G}-3435 \mathrm{C}$ haplotype ${ }^{37}$ and a higher tacrolimus dose. The present study evaluates in Chinese renal transplant recipients the impact of CYP3A and ABCB1 polymorphisms on the $\mathrm{dnAUC}_{0-12}$ which is calculated according to a two time point sampling strategy. Furthermore, we described two new real-time polymerase chain reaction (PCR) fluorescence resonance energy transfer (FRET) assays to determine the genotype for the CYP3A5 A6986G and ABCB1 C1236T polymorphism.

\section{Patients and methods}

\section{Study population}

A total of 103 Chinese renal transplant recipients who received tacrolimus as part of the immunosuppressive therapy and had regular follow-up in Queen Elizabeth Hospital or Tuen Mun Hospital in Hong Kong were included in this retrospective study. There was no change in the daily tacrolimus dose for at least two weeks. Patients were advised to avoid St. John's wort and grapefruit juice which may affect the tacrolimus concentration. None of the patients included were taking medication known to have interaction with tacrolimus, such as calcium channel blockers, anti-epileptics, anti-mycotics and macrolide antibiotics. Additionally, patients who suffered from gastrointestinal disease, liver disease or other disorders that may alter the absorption of tacrolimus were excluded. Apart from tacrolimus and steroids, these patients were normally put on azathioprine, however some patients preferred to use mycophenolic acid on advice of their private physician. The dosage of azathioprine was $1.5 \mathrm{mg} / \mathrm{kg} /$ day while the dosage of mycophenolic acid was $0.5 \mathrm{gram}$ twice daily. The initial tacrolimus dosage, administrated twice daily, was $0.3 \mathrm{mg} / \mathrm{kg} / \mathrm{day}$ for all patients. The daily tacrolimus dose was then adjusted according to the $\mathrm{AUC}_{0-12}$ value, which was kept at around $100-150 \mathrm{ng} \times \mathrm{hr} / \mathrm{ml}$ in the first three 
months. After three months the target $\mathrm{AUC}_{0-12}$ value was decreased to around $80-100 \mathrm{ng} \times \mathrm{hr} / \mathrm{ml}$ for long term maintenance. These $A \cup C_{0-12}$ values were based on our previous pilot study ${ }^{15}$ and the experiences obtained in our transplantation centers. The steroid regimen for the first month was $30 \mathrm{mg} / \mathrm{day}$ of oral prednisolone, progressively tapered by $2.5 \mathrm{mg}$ every two weeks until a daily maintenance dose of $5 \mathrm{mg}$. Demographic as well as clinical data were collected at the time of the tacrolimus blood sample collection.

\section{Tacrolimus concentration determination}

Tacrolimus blood concentrations were determined 2 (C2) and 4 (C4) hours after the morning tacrolimus administration in ethylene diamine tetra-acetic acid (EDTA) whole blood using a semi-automated microparticle enzyme immunoassay (MEIA) on an Imx II clinical analyser (Abbott Laboratories, Abbott Park, IL, USA). The Imx II does not cross-react enormously with the most important tacrolimus metabolite produced by CYP3A5, 13-O-demethyl tacrolimus, which has a minor immunosuppressive effect. Furthermore, a few metabolites show significant cross reactivity with the antibody but were present at low concentrations compared to tacrolimus ${ }^{27}$. The two tacrolimus blood concentrations determined were used to calculate the $\mathrm{AUC}_{0-12}$ according to the equation based strategy as described by our group ${ }^{15}: \mathrm{AUC}_{0-12}=16.2+2.4 \times$ $\mathrm{C} 2+5.9 \times \mathrm{C} 4$. The $\mathrm{dnAUC}_{0-12}$ was calculated by dividing the $\mathrm{AUC}_{0-12}$ by the corresponding 24 hour dose on a milligrams per kilogram basis.

\section{Ethics}

The study was performed in accordance to the Declaration of Helsinki and its amendments. The protocol was approved by the Medical Ethics Committee of the Queen Elizabeth Hospital in Hong Kong and written informed consent for participation in this study was obtained from all patients.

\section{DNA isolation}

Genomic DNA was extracted from 103 Chinese renal transplant recipients by using $200 \mu \mathrm{l}$ EDTA anti-coagulated blood for isolation with a QIAamp blood mini kit (Qiagen, Leusden, the Netherlands) according to the manufacturers' instructions.

\section{Genotyping of CYP3A and ABCB1 gene polymorphisms}

Real-time PCR FRET assays were used for genotyping the CYP3A4 A-392G, CYP3AP1 G-44A, ABCB1 G2677T/A and C3435T polymorphisms with the same primers and probes as described in the original publications ${ }^{38-41}$. The real-time PCR FRET assays for the CYP3A5 A6986G and ABCB1 C1236T 
polymorphisms were designed, optimised and validated in our laboratory. The presence of the expected polymorphisms was confirmed by sequencing the different allelic variants of CYP3A5 and ABCB1 according to a direct sequence procedure on a capillary sequencer $A B I$ Prism $3100^{\circledR}$ using the Bridge version 1.1 sequence kit (both products from Applied Biosystems, Fostercity, USA). Genotyping for the CYP3A5 A6986G polymorphism was performed using the primers F16: 5'-TTT gCC TCT TTg TAC TTC TTC ATC-'3 (sense; 172835-858) and R16: 5'- Tag TTg TAC gAC ACA Cag CAA CC-'3 (anti-sense; 173335-313) to amplify a $501 \mathrm{bp}$ part from the CYP3A5 gene which covers the A6986G polymorphism in intron 3 (Genbank acces no: AF280107). Detection was carried out using the anchor probe CYP316R640: 5'-CCC TgT TTg gAC CAC ATT ACC CTT-'3 (sense; 173214-237) which was labelled at the 5' end with LCRed 640 and phosphorylated at the 3'- end to block extension and the sensor probe CYP3A5A16: 5'-gAg CTC TTT TgT CTT TCA ATA TCT CT-'3 (sense; 173187-212) which is complementary to the CYP3A5 6986A or *1 allele with the polymorphic nucleotide indicated underlined. This $3^{\prime}$-fluorescein labelled anchor probe binds with a distance of one base 5 ' to the detection probe. The PCR mixture contained $3.3 \mu \mathrm{l}$ sterile water; $2.0 \mathrm{mmol} / \mathrm{l} \mathrm{MgCl} ; 1.0 \mu \mathrm{l}$ LC Faststart DNA Master Hybridisation Probes (Roche Diagnostics $\mathrm{GmbH}$, Mannheim, Germany), $0.60 \mu \mathrm{mol} / \mathrm{l}$ of each primer, and $0.20 \mu \mathrm{mol} / / \mathrm{l}$ of both anchor and sensor probe (TIB MOLBIOL, Berlin, Germany). After adding $1.0 \mu \mathrm{l}$ containing 50-100 ng genomic DNA to the PCR mixture, the total volume is $10 \mu \mathrm{l}$. The PCR protocol included the following steps: a) denaturation for ten minutes at $95^{\circ} \mathrm{C}$ b) 45 cycles at $95^{\circ} \mathrm{C}$ for ten seconds; $55^{\circ} \mathrm{C}$ for ten seconds and $72^{\circ} \mathrm{C}$ for 20 seconds (all $20^{\circ} \mathrm{C} /$ second). After amplification was completed, a melting curve was recorded by cooling to $45^{\circ} \mathrm{C}\left(20^{\circ} \mathrm{C} /\right.$ second) holding at $45^{\circ} \mathrm{C}$ for two minutes and then heating slowly to $75^{\circ} \mathrm{C}$ at $0.1^{\circ} \mathrm{C} /$ second. Moreover, genotyping for the ABCB1 C1236T polymorphism is performed using the primers F35: 5'-gTT CCT ATA TCC TgT gTC TgT gAA T-'3 (sense; 208-32) and R35: 5'-AgT CTA gCT CgC ATg ggT CAT C-'3 (anti-sense; 448-27) to amplify a $241 \mathrm{bp}$ part from the ABCB1 gene which covers the C1236T polymorphism in exon 12 (Genbank access no: M29432). Detection of the $A B C B 1 C 1236 \mathrm{~T}$ polymorphism was carried out using the anchor probe A35: 5'-gCC ACC gTC TgC CCA CTC TgC AC-3 (anti-sense; 343-321) which is labelled at the 3'- end with fluorescence and binds with a distance of one base 5' to the sensor probe. This 5' LCRed640 labelled sensor probe P35: TTC Agg TTC AgA CCC TTC AAg (anti-sense; 319-299) which is phosphorylated at the 3 ' end to block extension from the anchor probe and is complementary to the ABCB1 1236T polymorphism which is indicated underlined. The PCR mixture for the $A B C B 1$ C1236T polymorphism contained: $2.95 \mu$ l sterile water; $2.0 \mathrm{mmol} / \mathrm{l} \mathrm{MgCl} 2 ; 1.0 \mu \mathrm{l} \mathrm{LC} \mathrm{Faststart} \mathrm{DNA} \mathrm{Master} \mathrm{Hybridization} \mathrm{Probes;}$ (Roche Diagnostics $\mathrm{GmbH}$, Mannheim, Germany) $0.5 \mu \mathrm{M}$ of each primer and 
$0.225 \mu \mathrm{mol} / \mathrm{l}$ of both sensor and anchor probe (TIB MOLBIOL, Berlin, Germany). After adding 1.0 $\mu$ l containing 50-100 ng genomic DNA to the PCR mixture, the total volume was $10 \mu \mathrm{l}$. The PCR protocol included the following steps: denaturation for 10 minutes at $95^{\circ} \mathrm{C} ; 45$ cycles at $95^{\circ} \mathrm{C}$ for 5 seconds, $55^{\circ} \mathrm{C}$ for 10 seconds and $72^{\circ} \mathrm{C}$ for 20 seconds (all $20^{\circ} \mathrm{C} /$ second). After amplification was completed, a melting curve was recorded by heating to $95^{\circ} \mathrm{C}$ $\left(20^{\circ} \mathrm{C} /\right.$ second) holding at $95^{\circ} \mathrm{C}$ for 20 seconds; subsequently cooling to $40^{\circ} \mathrm{C}$ $\left(20^{\circ} \mathrm{C} /\right.$ second) holding at $40^{\circ} \mathrm{C}$ for 20 seconds and then heating slowly to $85^{\circ} \mathrm{C}$ at $0.2^{\circ} \mathrm{C} /$ second. All PCR and melting curve analysis were performed on the LightCycler (Roche Diagnostics, Almere, the Netherlands).

\section{Statistical analysis}

Statistical analysis of the data was performed with use of SPSS 12.0 software for windows (Chicago, IL, USA). To examine the population homogeneity of the patients, the genotype frequencies of the CYP3A and ABCB1 polymorphisms were tested against Hardy-Weinberg equilibrium by the Pearson's goodnessof-fit test. For analysis of the $\mathrm{dnAUC}_{0-12}(\mathrm{ng} \times \mathrm{hr} / \mathrm{ml}$ per $\mathrm{mg} / \mathrm{kg})$ and the daily tacrolimus dose $(\mathrm{mg} / \mathrm{kg} / \mathrm{day})$, two groups were compared using the non parametric Mann-Whitney test while the non parameteric Kruskal Wallis test was used to compare several groups. Stepwise multiple regression analyses was used to calculate the relative contribution of several genetic and nongenetic factors on the variability in the daily tacrolimus dose requirement. The genetic factors examined are the CYP $3 A^{*} 3$ polymorphism and three ABCB1 polymorphisms while the non-genetic factors examined are gender, age, serum creatinine concentration, time since transplantation and steroid dosing. $P$ values less than 0.05 were considered statistically significant. All values are expressed as median and range unless stated otherwise.

\section{Results}

\section{Demographic characteristics of patients}

Table 6.1 illustrates the characteristics of the 103 Chinese renal transplant patients that fulfilled the inclusion criteria and were enrolled in our study.

\section{Real-time PCR FRET assays for CYP3A5 A6986G and ABCB1 C1236T genotyping}

The melting point of the sensor probe covering the CYP3A5 A6986G polymorphism was $57^{\circ} \mathrm{C}$ when hybridised to the CYP3A5 $6986 \mathrm{G} / \mathrm{G}$ or ${ }^{*} 3{ }^{*} 3$ genotype and $62^{\circ} \mathrm{C}$ when hybridised to the CYP3A5 $6986 \mathrm{~A} / \mathrm{A}$ or ${ }^{*} 1 /{ }^{*} 1$ 
genotype. A heterozygous sample contained both type of targets and thus generated both peaks (Figure 6.1A). In addition, for the ABCB1 C1236T polymorphism, the melting point of the sensor probe was $56.5^{\circ} \mathrm{C}$ when hybridised to the $\mathrm{ABCB} 11236 \mathrm{CC}$ genotype and $62^{\circ} \mathrm{C}$ when hybridised to the ABCB1 1236TT genotype. A heterozygote sample for the ABCB1 C1236T polymorphism showed both melting peaks (Figure 6.1B). The presence of the expected polymorphisms was confirmed by sequencing 6 these different allelic variants of CYP3A5 and ABCB1 gene. The resulting characterised heterozygote samples were used as controls in each run performed.

Table 6.1 Demographic characteristics of the renal transplant recipients

\begin{tabular}{|c|c|}
\hline Demographic characteristics & \\
\hline Gender (male/female) & $58 / 45$ \\
\hline Age (years, mean $\pm S D$, (range)) & $43.1 \pm 11.1(21-77)$ \\
\hline Weight $(\mathrm{kg}$, mean $\pm \mathrm{SD}$, (range) $)$ & $62.5 \pm 11.4(37.4-87.8)$ \\
\hline Primary kidney disease & \\
\hline Glomerulonephritis & 57 \\
\hline Chronic pyelonephritis & 1 \\
\hline Diabetic nephropathy & 10 \\
\hline Hypertensive nephropathy & 9 \\
\hline Polycystic kidney disease & 2 \\
\hline Obstructive Uropathy & 3 \\
\hline Unknown & 18 \\
\hline Other & 3 \\
\hline Transplantation number & \\
\hline First & 97 \\
\hline Second & 6 \\
\hline Tacrolimus dose (mg/kg body weight/day, mean \pm SD, (range)) & $0.067 \pm 0.032(0.01-0.18)$ \\
\hline Tacrolimus conc. 2 hour post dose (ng/ml, mean \pm SD, (range)) & $13.5 \pm 4.30(5.7-29.4)$ \\
\hline Tacrolimus conc. 4 hour post dose (ng/ml, mean $\pm \mathrm{SD}$, (range)) & $8.7 \pm 2.60(2.3-16.4)$ \\
\hline $\mathrm{AUC}_{0-12}(\mathrm{ng} \times \mathrm{hr} / \mathrm{ml}$, mean, (range)) & $100.3(47.8-183.5)$ \\
\hline $\operatorname{DnAUC}_{0-12}(\mathrm{ng} \times \mathrm{hr} / \mathrm{ml}$ per $\mathrm{mg} / \mathrm{kg}$ body weight, mean, (range)) & $1940(300-11125)$ \\
\hline Use of azathiopurine/mycophenolate mofetil & $78 / 25$ \\
\hline Current steroid dose (mg, mean $\pm \mathrm{SD}$, (range)) & $6.98 \pm 2.37(4-25)$ \\
\hline Time since transplantation (days, mean, (range)) & $977(133-4982)$ \\
\hline Haemoglobin $(\mathrm{mmol} / \mathrm{l}$, mean \pm SD, (range) $)$ & $12.8 \pm 2.0(8.5-19)$ \\
\hline Haematocrit fraction (mean $\pm S D$, (range)) & $0.38 \pm 0.058(0.25-0.57)$ \\
\hline $\operatorname{ALAT}(\mathrm{U} / \mathrm{l}$, mean $\pm \mathrm{SD},($ range $))$ & $22 \pm 18(8-147)$ \\
\hline Serum albumin (g/l, mean $\pm \mathrm{SD}$, (range)) & $43 \pm 3.2(34-50)$ \\
\hline Serum creatinine $(\mu \mathrm{mol} / /$, mean $\pm \mathrm{SD}$, (range $))$ & $156 \pm 76(62-462)$ \\
\hline
\end{tabular}


A

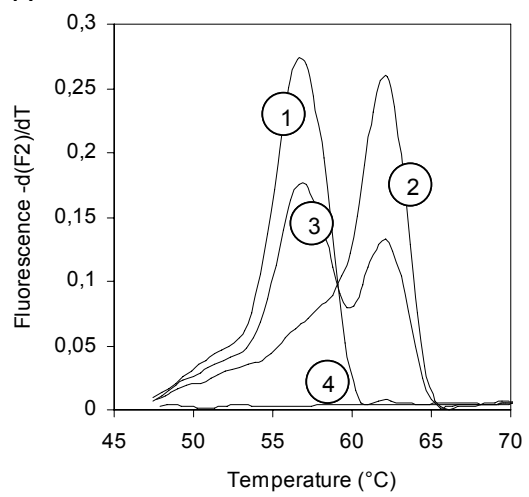

B

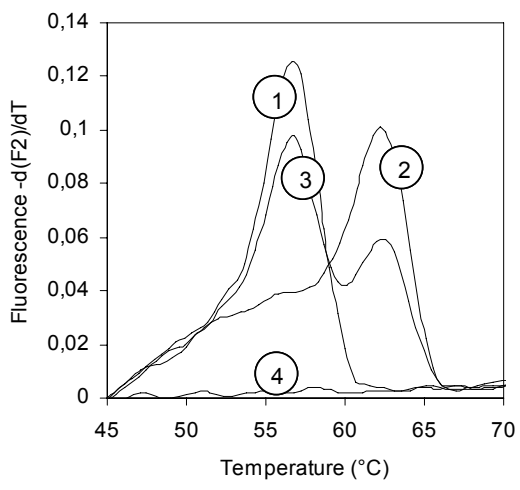

Figure 6.1 Genotyping of CYP3A5 A6986G and ABCB1 C1236T with allele specific fluorescent probes by derivative melting curve plots. The derivative melting curves are read in channel 2 for the detection of the CYP3A5 and the ABCB1 fragments.

A. The derivative melting curve is plotted for a sample homozygous for the CYP3A5 $6986 \mathrm{G}$ or * 3 allele $\left(1 ; \mathrm{Tm} 57^{\circ} \mathrm{C}\right)$; a sample homozygous for the CYP3A5 $6986 \mathrm{~A}$ or *1 allele $\left(2 ; \mathrm{Tm} 62^{\circ} \mathrm{C}\right)$ and a heterozygous sample $\left(3 ; \operatorname{Tm} 57^{\circ} \mathrm{C}\right.$ and $\left.62^{\circ} \mathrm{C}\right)$. B. The derivative melting curve is plotted for a sample homozygous for the ABCB1 1236C allele $\left(1 ; \mathrm{Tm} 56.5^{\circ} \mathrm{C}\right)$; a sample homozygous for the ABCB1 $1236 \mathrm{~T}$ allele $\left(2 ; \mathrm{Tm} 62^{\circ} \mathrm{C}\right)$ and a heterozygous sample $\left(3 ; \mathrm{Tm} 56.5^{\circ} \mathrm{C}\right.$ and $\left.62^{\circ} \mathrm{C}\right)$. Melting analysis of a no template control was also performed for both assays (4).

\section{The allele distribution of the different CYP3A and ABCB1 polymorphisms}

Table 6.2 shows both the different genotypes and the allele frequencies of the CYP3A and ABCB1 polymorphisms. In our population, we found no homozygous or heterozygous variant allele for the CYP3A4*1B polymorphism, which confirmed its very low frequency in the Chinese population. The allele frequencies found for the CYP3A5, CYP3AP1 and ABCB1 polymorphisms are in line with the literature $20,22,25$. The distribution of all polymorphisms examined is not significantly different from that predicted with the Hardy-Weinberg equilibrium (each $P>0.05$ ). The genetic linkage of CYP3AP1 G-44A with CYP3A5 A6986G as already described by previous studies ${ }^{42,43}$, was also confirmed in our study. 
Table 6.2 Allelic distribution of CYP3A, CYP3AP1 and ABCB1 variants in 103 Chinese renal transplant recipients

\begin{tabular}{lcccccc}
\hline SNP & $\mathrm{wt} / \mathrm{wt}$ & $\mathrm{wt} / \mathrm{m}$ & $\mathrm{m} / \mathrm{m}$ & \multicolumn{3}{c}{ Allele frequency $(\%)$} \\
\hline CYP3A4 & & & & $\mathrm{A}$ & $\mathrm{G}$ \\
A-392G & $103(100 \%)$ & $0(0 \%)$ & $0(0 \%)$ & 100 & 0 \\
CYP3A5 & & & & $\mathrm{A}$ & $\mathrm{G}$ \\
A6986G & $10(10 \%)$ & $38(37 \%)$ & $55(53 \%)$ & 28 & 72 \\
CYP3AP1 & & & & $\mathrm{G}$ & $\mathrm{A}$ \\
G-44A & $9(9 \%)$ & $40(39 \%)$ & $54(52 \%)$ & 28 & 72 & \\
ABCB1, exon 12 & & & & $\mathrm{C}$ & $\mathrm{T}$ & \\
C1236T & $8(8 \%)$ & $52(50 \%)$ & $43(42 \%)$ & 33 & 67 & $\mathrm{~A}$ \\
ABCB1, exon 21 & & $\mathrm{GT}: 32(31 \%)$ & $\mathrm{TT}: 19(19 \%)$ & $\mathrm{G}$ & $\mathrm{T}$ & 13 \\
G2677T/A & $26(25 \%)$ & $\mathrm{GA}: 16(15 \%)$ & $\mathrm{TA}: 10(10 \%)$ & 48 & 39 & \\
ABCB1, exon 26 & & & & $\mathrm{C}$ & $\mathrm{T}$ & \\
C3435T & $46(45 \%)$ & $43(42 \%)$ & $14(13 \%)$ & 66 & 34 & \\
\hline
\end{tabular}

\section{Effect of CYP3A and ABCB1 polymorphisms on tacrolimus dose requirements and pharmacokinetic profiles}

Table 6.3 shows a significant decrease in the $\mathrm{dnAUC}_{0-12}$ which strongly depends on whether the patients were carrier of none, one or two CYP3A5*1 alleles $(2143,1228$ and $920 \mathrm{ng} \times \mathrm{hr} / \mathrm{ml}$ per $\mathrm{mg} / \mathrm{kg}$; Kruskal Wallis, $P<0.001)$, respectively. Consequently, the daily tacrolimus dose was $80 \%$ higher in homozygous carriers of a CYP $3 A 5^{*} 1$ allele compared to homozygous carriers of the CYP3A $5^{\star} 3$ allele $(0.09 \mathrm{mg} / \mathrm{kg} /$ day versus $0.05 \mathrm{mg} / \mathrm{kg} /$ day; Kruskal Wallis, $P<0.001)$. This allele-dependent effect of the CYP3A5*3 polymorphism is also illustrated in Figure 6.2. Additionally, a significant correlation is found between the allelic variants of the CYP3AP1 G-44A polymorphism and both the dnAUC $\mathrm{C}_{0}$ 12 and the daily tacrolimus dose. Likely, this is caused by a very high linkage $(>98 \%)$ between CYP3A5*3 and CYP3AP1 -44A (only two patients differed in genotype) in our study. 

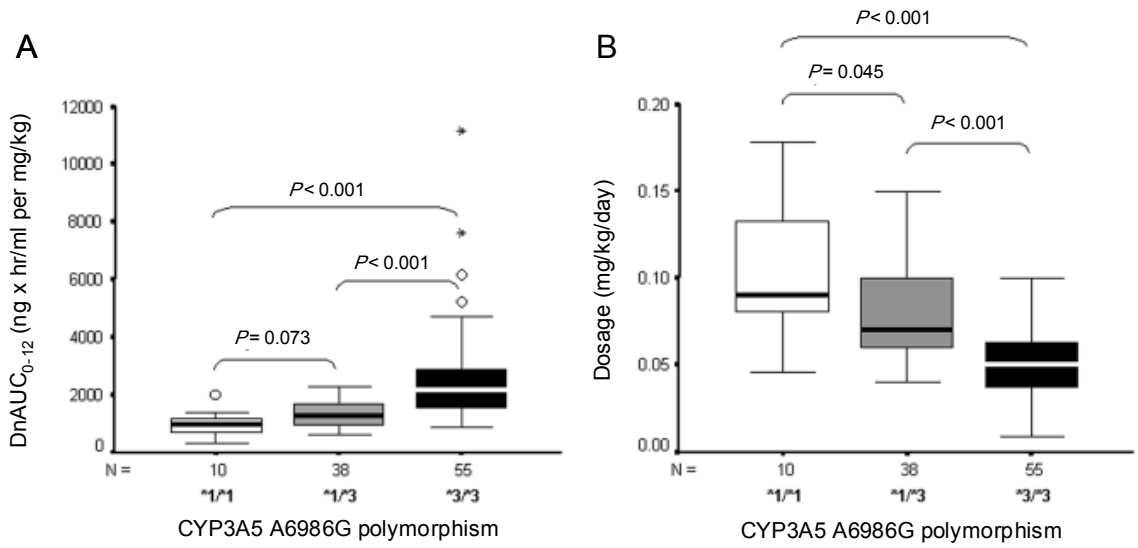

Figure 6.2 Influence of the CYP3A5 A6986G genotype on the pharmacological parameters recorded in 103 renal transplant recipients. A. The boxplot of the dose-normalized (dn)AUC ${ }_{0-12}$ (ng $\times \mathrm{hr} / \mathrm{ml}$ per $\mathrm{mg} / \mathrm{kg}$ body weight) clustered according to CYP3A5 A6986G genotype. B. The boxplot of the distribution of the daily tacrolimus dose (mg/kg body weight) clustered according to CYP3A5 A6986G genotype. $P$ values for the pairwise comparisons of each genotype are given. Open circles indicate an outlier value at more than 1.5 boxlengths above the box, while asterics indicate an extreme value at more than 3 box lengths above the box.

Regarding the $A B C B 1$ polymorphisms, we examined both the individual $A B C B 1$ polymorphisms and the $A B C B 1$ haplotypes present in the renal transplant patients. Table 6.3 shows the genetic effect of the three individual $A B C B 1$ polymorphisms on both the $\mathrm{dnAUC}_{0-12}$ and the daily tacrolimus dose. Individuals carrying the 2677TT or 3435TT genotype showed no significant difference in the dnAUC 0 -12 compared to individuals carrying the $2677 \mathrm{GG}$ or $3435 \mathrm{CC}$ genotype. However, as is shown in Table 6.3, individuals carrying the $2677 \mathrm{TT}$ or $3435 \mathrm{TT}$ genotype required a significantly higher daily tacrolimus dose than individuals carrying the 2677GG or 3435CC genotype (0.066 $\mathrm{mg} / \mathrm{kg} /$ day versus $0.053 \mathrm{mg} / \mathrm{kg} / \mathrm{day}$ and $0.073 \mathrm{mg} / \mathrm{kg} / \mathrm{day}$ versus 0.051 $\mathrm{mg} / \mathrm{kg} /$ day; Mann-Whitney, $P=0.033$ and $P=0.044$ ), respectively. In contrast to ABCB1 G2677T/A and C3435T, the allelic variants of the ABCB1 C1236T polymorphism showed no significant difference on the $\mathrm{dnAUC}_{0-12}$ and the daily tacrolimus dose. Additionally, we analysed the correlation between the ABCB1 haplotypes and the dnAUC $\mathrm{C}_{0-12}$ as well as the daily tacrolimus dose. 
Table 6.3 Influence of CYP3A, CYP3AP1 and ABCB1 genotypes on the daily tacrolimus dose and the dose-normalized (Dn)AUC $\mathrm{C}_{0-12}$.

\begin{tabular}{|c|c|c|c|}
\hline Genotype & Allelic status (n) & $\begin{array}{c}\text { Dose } \\
\text { (mg/kg/day) }\end{array}$ & $\begin{array}{c}\mathrm{DnAUC}_{0-12} \\
(\mathrm{ng} \times \mathrm{hr} / \mathrm{ml} \\
\text { per mg/kg) }\end{array}$ \\
\hline CYP3A5 & $* 1 / * 1(10)$ & $0.090(0.05-0.18)^{a}$ & $920(300-1981)^{\mathrm{a}}$ \\
\hline \multirow[t]{2}{*}{ A6986G } & *1/*3 (38) & $0.070(0.04-0.15)^{\mathrm{a}}$ & $1228(589-2266)^{a}$ \\
\hline & *3/*3 (55) & $0.050(0.01-0.10)^{\mathrm{a}}$ & $2143(827-11125)^{a}$ \\
\hline CYP3AP1 & $\mathrm{G} / \mathrm{G} \quad(9)$ & $0.090(0.05-0.18)^{a}$ & $929(300-1981)^{a}$ \\
\hline \multirow[t]{2}{*}{ G-44A } & $\mathrm{A} / \mathrm{G}(40)$ & $0.070(0.04-0.15)^{a}$ & $1298(589-2265)^{a}$ \\
\hline & $\mathrm{A} / \mathrm{A}(54)$ & $0.050(0.01-0.10)^{\mathrm{a}}$ & $2156(827-11125)^{a}$ \\
\hline ABCB1 & $\mathrm{C} / \mathrm{C} \quad(8)$ & $0.060(0.03-0.15)$ & $1484(875-5166)$ \\
\hline \multirow[t]{2}{*}{ C1236T } & $\mathrm{C} / \mathrm{T}(52)$ & $0.060(0.01-0.18)$ & $1494(300-11125)$ \\
\hline & $\mathrm{T} / \mathrm{T}(43)$ & $0.063(0.01-0.15)$ & 1651 (589-7579) \\
\hline ABCB1 & G/G (26) & $0.053(0.03-0.09)^{b}$ & $1887(891-6166)$ \\
\hline \multirow[t]{4}{*}{ G2677T/A } & $\mathrm{G} / \mathrm{T}(32)$ & $0.070(0.01-0.18)$ & $1365(300-7579)$ \\
\hline & $\mathrm{G} / \mathrm{A}(16)$ & $0.050(0.01-0.15)$ & $1864(676-11125)$ \\
\hline & T/A (10) & $0.056(0.05-0.13)$ & $1765(805-2870)$ \\
\hline & $\mathrm{T} / \mathrm{T}(19)$ & $0.066(0.02-0.15)^{b}$ & $1473(589-4532)$ \\
\hline ABCB1 & $\mathrm{C} / \mathrm{C}(46)$ & $0.052(0.01-0.15)^{b}$ & $1882(676-11125)$ \\
\hline \multirow[t]{2}{*}{ C3435T } & $\mathrm{C} / \mathrm{T}(43)$ & $0.063(0.03-0.18)$ & $1466(300-6166)$ \\
\hline & $\mathrm{T} / \mathrm{T}(14)$ & $0.073(0.02-0.15)^{b}$ & $1332(589-4532)$ \\
\hline CYP3A5 - ABCB1 & *3/*3 - GG (17) & $0.048(0.03-0.08)$ & 2097 (1056-6166) \\
\hline \multirow[t]{8}{*}{ A6986G - G2677T/A } & *3/*3 - GA/GT/TA (26) & $0.050(0.01-0.10)$ & 2369 (827-11125) \\
\hline & *3/*3 - TT (12) & $0.063(0.02-0.09)$ & 1694 (1237-4532) \\
\hline & ${ }^{*} 1 /{ }^{*} 3-\mathrm{GG}(8)$ & $0.068(0.04-0.09)$ & 1346 (913-2168) \\
\hline & *1/*3 - GA/GT/TA (24) & $0.073(0.05-0.15)^{c}$ & $1271(691-1973)^{\mathrm{c}}$ \\
\hline & ${ }^{*} 1 /{ }^{*} 3-\mathrm{TT}(6)$ & $0.104(0.05-0.15)^{\mathrm{C}}$ & $788(589-2266)^{\mathrm{c}}$ \\
\hline & ${ }^{*} 1 /{ }^{*} 1-\mathrm{GG}(1)$ & 0.0787 & 891 \\
\hline & *1/*1 - GA/GT/TA (8) & $0.110(0.05-0.18)^{c}$ & $878(300-1981)^{\mathrm{c}}$ \\
\hline & $* 1 /{ }^{*} 1-\mathrm{TT}(1)$ & 0.0800 & $1106^{*}$ \\
\hline CYP3A5 - ABCB1 & ${ }^{*} 3 /{ }^{*} 3-\mathrm{CC}(28)$ & $0.046(0.01-0.08)$ & $2120(1056-11125)$ \\
\hline \multirow[t]{8}{*}{ A6986G - C3435T } & $* 3 / * 3-\mathrm{CT}(21)$ & $0.059(0.03-0.10)$ & $2179(827-6166)$ \\
\hline & ${ }^{*} 3 /{ }^{*} 3-\mathrm{TT}(6)$ & $0.055(0.02-0.09)$ & $1845(1322-4532)$ \\
\hline & ${ }^{*} 1 / * 3-\mathrm{CC}(15)$ & $0.069(0.04-0.15)^{\mathrm{c}}$ & $1106(870-2168)^{c}$ \\
\hline & *1/*3-CT (16) & $0.073(0.05-0.13)^{c}$ & $1271(691-1882)^{c}$ \\
\hline & *1/*3 - TT (7) & $0.098(0.05-0.15)^{c}$ & $841(589-2266)^{c}$ \\
\hline & ${ }^{*} 1 /{ }^{*} 1-\operatorname{CC}(3)$ & $0.090(0.08-0.13)^{c}$ & $891(676-950)^{c}$ \\
\hline & $* 1 / * 1-\mathrm{CT}(6)$ & $0.11(0.05-0.18)^{c}$ & $977(300-1981)^{\mathrm{c}}$ \\
\hline & *1/*1 - TT (1) & 0.800 & 1106 \\
\hline
\end{tabular}

Values are indicated as median (range), ${ }^{a} P<0.001$ (Kruskal Wallis); ${ }^{b} P<0.05$ (Mann-Whitney), ${ }^{\mathrm{C}} P<0.05$ (Bonferroni), when the designated CYP3A5 - ABCB1 genotype combination is compared to the reference genotype combination, which is CYP3A5 - ABCB1 G2677T/A * $3{ }^{*} 3-\mathrm{GG}$ and CYP3A5-ABCB1 C3435T *3/*3 - CC, respectively.

Table 6.4 illustrates that in contrast to the two individual ABCB1 polymorphisms, no significant difference or trend was observed between the $A B C B 1$ haplotypes and the $\mathrm{dnAUC}_{0-12}$ as well as the daily tacrolimus dose. Moreover, using stepwise multiple regression analysis to examine the relative contribution of the non-genetic and genetic factors to the daily tacrolimus dose 
variability, the CYP3A5*3 polymorphism appears to be the most significant independent variable when considering the daily tacrolimus dose as a dependent variable. The CYP3A5*3 polymorphism can explain $35.3 \%$ $(P<0.001)$ of the variation in the daily tacrolimus dose observed in the renal transplant recipient population. Furthermore, gender $(9.9 \% ; P<0.001)$ and the ABCB1 C3435T polymorphism (3.7\%; $P<0.009)$ have a significant contribution in the variation of the daily tacrolimus dose. The two ABCB1 polymorphisms C1236T and G2677T/A, ABCB1 haplotypes and the non-genetic factors: age, serum creatinine concentration, time since transplantation and steroid dosing have no significant contribution on the variation of the daily tacrolimus dose.

Table 6.4 ABCB1 haplotypes in correlation to tacrolimus dose and dose-normalized (Dn)AUC $\mathrm{A}_{0-12}$

\begin{tabular}{cccccll}
\hline C1236T & G2677T/A & C3435T & $\mathrm{n}$ & $\begin{array}{c}\text { Frequency } \\
(\%)\end{array}$ & $\begin{array}{c}\text { Dose } \\
(\mathrm{mg} / \mathrm{kg} / \mathrm{day})\end{array}$ & $\begin{array}{c}\mathrm{DnAUC}_{0-12} \\
(\mathrm{ng} \times \mathrm{hr} / \mathrm{ml} \\
\text { per } \mathrm{mg} / \mathrm{kg})\end{array}$ \\
\hline CC & GG & CC & 4 & 3.9 & $0.064(0.03-0.08)$ & $1484(1301-5166)$ \\
CC & GA & CC & 4 & 3.9 & $0.054(0.03-0.15)$ & $1862(875-3948)$ \\
CT & GG & CC & 11 & 10.7 & $0.070(0.03-0.09)$ & $1073(891-4002)$ \\
CT & GG & CT & 2 & 1.9 & 0.034 & 4519 \\
CT & GT & CC & 2 & 1.9 & 0.067 & 1650 \\
CT & GT & CT & 15 & 14.6 & $0.070(0.03-0.18)$ & $1227(300-4702)$ \\
CT & GT & TT & 2 & 1.9 & 0.056 & 2156 \\
CT & GA & CC & 11 & 10.7 & $0.050(0.01-0.13)$ & $1846(676-11125)$ \\
CT & TA & CC & 1 & 1.0 & 0.050 & 1918 \\
CT & TA & CT & 8 & 7.8 & $0.056(0.05-0.13)$ & $1765(805-2870)$ \\
TT & GG & CC & 9 & 8.7 & $0.050(0.03-0.08)$ & $1919(1438-3717)$ \\
TT & GT & CC & 2 & 1.9 & 0.021 & 4814 \\
TT & GT & CT & 11 & 10.7 & $0.080(0.05-0.10)$ & $1325(837-2309)$ \\
TT & GA & CC & 1 & 1.0 & 0.039 & 2933 \\
TT & TA & CC & 1 & 1.0 & 0.072 & 1106 \\
TT & TT & CT & 7 & 6.7 & $0.063(0.05-0.08)$ & $1685(1237-2626)$ \\
TT & TT & TT & 12 & 11.7 & $0.075(0.02-0.15)$ & $1277(589-4532)$ \\
\hline
\end{tabular}

Figure 6.3 suggests that a combined analysis of the CYP3A5*3 and ABCB1 G2677T/A or ABCB1 C3435T polymorphism may be helpful to identify those individuals that require a strong aberrant daily tacrolimus dose, although the contribution of the individual ABCB1 polymorphisms on the daily tacrolimus dose variation is not significant or minor compared to the CYP3A5*3 polymorphism. 

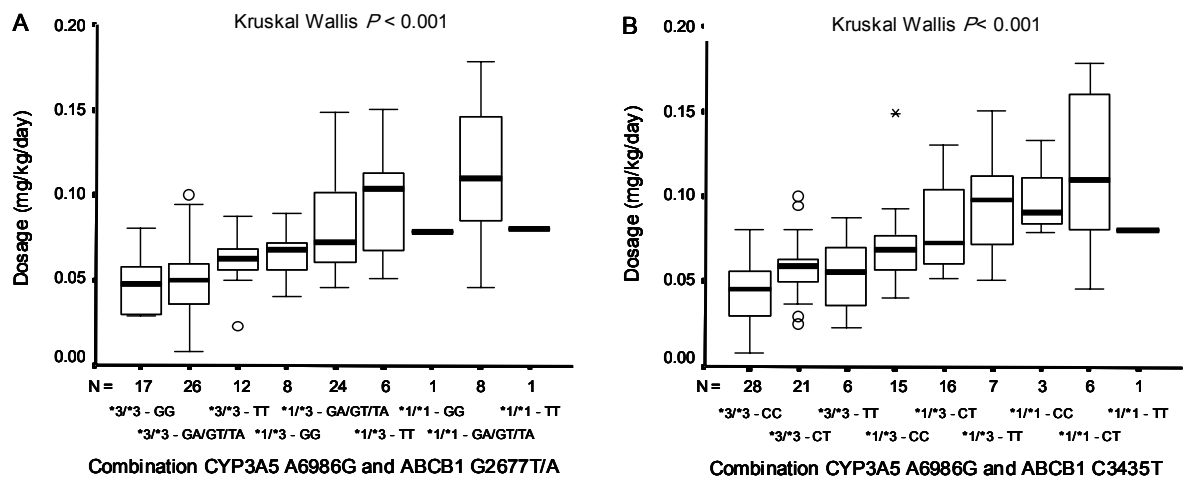

Figure 6.3 The boxplot of the distribution of the daily tacrolimus dose $(\mathrm{mg} / \mathrm{kg})$ clustered according to the combination of CYP3A5 A6986G and ABCB1 G2677T/A genotypes. B. The boxplot of the distribution of the daily tacrolimus dose $(\mathrm{mg} / \mathrm{kg}$ body weight) clustered according to the combination of CYP3A5 A6986G and ABCB1 C3435T genotypes. A $P$ value is given for comparison of several groups of both CYP3A5 and ABCB1 genotype combinations. Open circles indicate an outlier value at more than 1.5 boxlengths below/above the box, while asterics indicate an extreme value at more than 3 box lengths above the box.

\section{Discussion}

Although most centres still use $\mathrm{C}_{0}$ levels for monitoring tacrolimus there are conflicting data about the correlation with the systemic tacrolimus exposure. Several studies reported a reasonable squared correlation between $\mathrm{C}_{0}$ levels and $\mathrm{AUC}_{0-12}$ of tacrolimus ${ }^{44-46}$, while other studies found very poor correlations ${ }^{13-16,47,48}$. Recently, Scholten et al. ${ }^{17}$ reported a reduction of the $95 \%$ prediction interval by $50 \%$, when a two point sampling strategy was used consisting of a $\mathrm{C}_{0}$ level and a second sample obtained between two and four hour post dose. Moreover, Scholten et al. ${ }^{17}$ evaluated the predictive performance of the two time point sample strategy used in the present study and confirmed its suitability. It is known that several non-genetic factors can modulate the post-operative CYP3A phenotype, especially in the early period after transplantation ${ }^{49}$. Therefore, it is important to demonstrate with close drug monitoring of tacrolimus that steady state blood concentrations have been achieved in order to examine the genotype-phenotype associations more accurately. Therapeutic drug monitoring of tacrolimus can be performed accurately using complete $\mathrm{AUC}_{0-12}$ or an $\mathrm{AUC}_{0-12}$ calculated by a limited sampling strategy. In the present study a limited sampling strategy is used to calculate the $\mathrm{AUC}_{0-12}$ in 103 Chinese renal transplant recipients. To the best of our knowledge, two recent studies ${ }^{34,35}$ previously examined, in Japanese renal 
transplant recipients, the association between the CYP3A5*3 and the ABCB1 C3435T polymorphism and the pharmacokinetic parameters; $(\mathrm{dn}) \mathrm{C}_{0}$, $(\mathrm{dn}) \mathrm{AUC}_{0-12},(\mathrm{dn}) \mathrm{C}_{\max }, \mathrm{T}_{\max }$ and $\mathrm{t}_{1 / 2}$. Although several studies found a significant effect of CYP3A5 3 polymorphism ${ }^{22-24,26-31,35}$ on tacrolimus levels or dosages, the number homozygous carriers of the CYP3A5*1 polymorphism was limited in these studies. Recently, Zhang et al. ${ }^{25}$ correlated the different genotypes of the $\mathrm{CYP} \mathrm{A} 5^{*} 3$ and $\mathrm{ABCB} 1 \mathrm{C} 3435 \mathrm{~T}$ polymorphism of 118 Chinese renal transplant recipients with their corresponding $\mathrm{C}_{0}$ levels and daily tacrolimus dosages respectively, one week, one month and three months after transplantation. Our findings showed in line with the results of Zhang et al. ${ }^{25} \mathrm{a}$ strong significant genetic effect between the CYP3A5*3 polymorphism and both the dnAUC 0 -12 and the daily tacrolimus dose. After a mean time of 2.5 years post transplantation, carriers of the CYP $3 A 5^{*} 3$ polymorphism still require a remarkable lower daily tacrolimus dose compared to carriers of the CYP3A5*1 polymorphism. An estimation of the contribution of the different CYP3A and ABCB1 polymorphisms in the variation of the daily tacrolimus dose is performed by Haufroid et al. ${ }^{27}$. They found that the CYP3A5*3 polymorphism is with a relative contribution of $38 \%$ the most significant independent variable when considering the daily tacrolimus dose as dependent variable, which is in line with the findings observed in the present study. The significant contribution of the gender in the variation of the daily tacrolimus dose is also found by Kuypers et al. ${ }^{14}$ although they examined the influence of several non-genetic variables within the first year after transplantation. However, no significant contribution is observed for the time since transplantation in the variation of the daily tacrolimus dose in contrast to the findings observed by Haufroid et al. ${ }^{27}$. Despite the ABCB1 G2677T/A and C3435T polymorphisms showed a significant genetic effect after correlating these ABCB1 polymorphisms with the daily tacrolimus dose, no significant contribution is found using multiple regression analysis for the two individual $A B C B 1$ polymorphisms or ABCB1 haplotype. Our findings seem therefore in contrast to several other studies which reported that carriers of the $3435 \mathrm{CC}$ allele $\mathrm{al}^{23,24,36}$ and 1236C-2677G$3435 \mathrm{C}$ or $2677 \mathrm{GG}-3435 \mathrm{CC}$ haplotype required a higher daily tacrolimus dose $^{37}$. However, the significant genetic effect for ABCB1 polymorphisms or haplotypes found in these studies is like in our study not as pronounced as it is for the CYP3A5*3 polymorphism. The minor influence of the ABCB1 polymorphisms compared to the CYP $3 A 5^{*} 3$ polymorphism on the tacrolimus pharmacokinetics combined with the differences regarding pharmacokinetic parameter used $\left(\mathrm{C}_{0}\right.$ or $\left.\mathrm{AUC}_{0-12}\right)$, the genetic (single SNP versus haplotype) analyses that were performed, the number of transplant patients included, and the difference in inclusion criteria for the transplant recipients may explain the differences in genotype-phenotype associations found by these studies. Also after combining the CYP3A5*3 polymorphism with the ABCB1 G2677T/A or 
C3435T polymorphism, the extra part of the variation in $\mathrm{dnAUC}_{0-12}$ and daily tacrolimus dose that can be clarified above the CYP $3 A 5^{*} 3$ polymorphism is marginal.

\section{Highlights}

- The calcineurin inhibitor tacrolimus, an immunosuppressant used in transplantation therapy, has unpredictable drug levels and therefore requires close therapeutic drug monitoring in order to minimize the risk of under- or overimmunosuppression.

- Tacrolimus is metabolized by the cytochrome P450 3A (CYP3A) isoenzymes, which is quantitatively the most important metabolic route of tacrolimus. Additionally, tacrolimus is also a substrate for the adenosine triphosphate-binding cassette $B 1$ (ABCB1) gene encoding protein multidrug resistance-1 (MDR1) or P-glycoprotein.

- The present study used a two time point sampling strategy to calculate the area under the time tacrolimus concentration curve $\left(\mathrm{AUC}_{0-12}\right)$ and correlated these dose-normalized $\mathrm{AUC}_{0-12}$ with the corresponding CYP3A and $A B C B 1$ genotypes in 103 Chinese renal transplant recipients.

- Several single nucleotide polymorphisms (SNPs) recently identified in CYP3A and ABCB1 gene may elucidate the interindividual differences in the tacrolimus pharmacokinetics.

- The CYP3A5*3 allele, which results in the absence of the functional CYP3A5 protein, has been strongly associated with a higher $\mathrm{dnAUC}_{0-12}$ and consequently a lower daily tacrolimus dose. The different genotypes of the ABCB1 G2677T/A and C3435T SNPs showed a weaker association with the $\mathrm{dnAUC}_{0-12}$ as well as the daily tacrolimus dose.

- Multiple regression analysis demonstrates that the CYP3A5*3 allele is the most important independent variable among several genetic and nongenetic variables examined in the renal transplant recipients.

- Knowing the impact of the CYP3A5*3 allele on the tacrolimus disposition, genotyping prior transplantation may help to assess the initial daily dose needed by individual patients for adequate immunosuppression. 


\section{Outlook and conclusion}

Tacrolimus has a narrow therapeutic index which requires close monitoring of the drug concentration in order to achieve an optimal efficiency and minimizing the risks of acute rejection and drug overdose. The polymorphisms present in CYP3A and ABCB1 can explain their variability in expression and activity and thus clarify the interindividual differences in the tacrolimus pharmacokinetics. The majority of studies that examined the CYP3A and ABCB1 genotypephenotype association were based on tacrolimus $C_{0}$ levels, despite the fact that an $\mathrm{AUC}_{0-12}$ is the best way to determine the tacrolimus exposure. To the best of our knowledge only two studies reported an association between the CYP $3 A 5^{*} 3$ polymorphism and both the different pharmacokinetic parameters of tacrolimus and the daily tacrolimus dose. Furthermore, several studies reported an association between CYP $3 A^{*} 3$ polymorphism and the tacrolimus $\mathrm{C}_{0}$ levels obtained within the early period after transplantation. However, non-genetic parameters have then also a large impact on the tacrolimus concentration in this period. The present study calculated an $\mathrm{AUC}_{0-12}$ according to a two time point sampling strategy for 103 Chinese renal transplant patients with a wide time interval starting on at least three months post-transplantation. Our results clearly point out that the CYP3A5*3 polymorphism is strongly allele-dependent associated with both the $\mathrm{dnAUC}_{0-12}$ and the daily tacrolimus dose in renal transplant recipients. A weaker significant association is found for the ABCB1 G2677T/A and ABCB1 C3435T polymorphisms. Multiple regression analysis demonstrates that the $\mathrm{CYP} \mathrm{A} 5^{*} 3$ polymorphism is the most important independent variable among several genetic and non-genetic variables examined in the renal transplant recipients. Therefore, CYP3A5 genotyping prior transplantation may contribute to determine the initial tacrolimus dose required for individual patients. 


\section{References}

1. Laskow, DA, Vincenti F, Neylan JF, Mendez R, Matas AJ. An open-label, concentrationranging trial of FK506 in primary kidney transplantation: a report of the United States Multicenter FK506 Kidney Transplant Group. Transplantation 1996;62:900-5.

2. Kershner, RP, Fitzsimmons WE. Relationship of FK506 whole blood concentrations and efficacy and toxicity after liver and kidney transplantation. Transplantation 1996;62:920-6.

3. Undre NA, van Hooff J, Christiaans M Vanrenterghem Y, Donck J, Heeman U, Kohnle M, Zanker B, Land W, Morales JM, Andres A, Schafer A, Stevenson P. Low systemic exposure to tacrolimus correlates with acute rejection. Transplant Proc1999;31:296-8.

4. Winkler, M, Christians U. A risk-benefit assessment of tacrolimus in transplantation. Drug Saf 1995;12:348-57.

5. McMaster, P, Mirza DF, Ismail T, Vennarecci G, Patapis P, MayerAD. Therapeutic drug monitoring of tacrolimus in clinical transplantation. Ther Drug Monit 1995;17:602-5.

6. Staatz CE, Tett SE. Clinical pharmacokinetics and pharmacodynamics of tacrolimus in solid organ transplantation. Clin Pharmacokinet 2004;43:623-53.

-• Excellent review regarding the clinical pharmacokinetics of tacrolimus.

7. Spencer CM, Goa KL, Gillis JC. Tacrolimus. An update of its pharmacology and clinical efficacy in the management of organ transplantation. Drugs 1997;54:925-75.

8. Venkataramanan R, Swaminathan A, Prasad T, Jain A, Zuckerman S, Warty V, McMichael J, Lever J, Burckart G, Starzl T. Clinical pharmacokinetics of tacrolimus. Clin Pharmacokinet 1995;29:404-30.

9. Shaw LM, Holt DW, Keown P, Venkataramanan R, Yatscoff RW. Current opinions on therapeutic drug monitoring of immunosuppressive drugs. Clin Ther 1999;21:1632-52; discussion 1631.

10. Backman L, Nicar M, Levy M, Distant D, Eisenstein C, Renard T, Goldstein R, Husberg B, Gonwa T, Klintmalm G. Whole blood and plasma levels of FK 506 after liver transplantation: correlation with toxicity. Transplant Proc 1994;26:1804.

11. Lindholm A, Kahan BD. Influence of cyclosporine pharmacokinetics, trough concentrations, and AUC monitoring on outcome after kidney transplantation. Clin Pharmacol Ther 1993;54: 205-18.

12. Primmett DR, Levine M, Kovarik JM, Mueller EA, Keown PA. Cyclosporine monitoring in patients with renal transplants: two- or three-point methods that estimate area under the curve are superior to trough levels in predicting drug exposure. Ther Drug Monit 1998;20: 276-83.

13. Armendariz Y, Pou L, Cantarell C, Lopez R, Perello M, Capdevila L. Evaluation of a limited sampling strategy to estimate area under the curve of tacrolimus in adult renal transplant patients. Ther Drug Monit 2005;27:431-4.

14. Kuypers DR, Claes K, Evenepoel P, Maes B, Coosemans W, Pirenne J, Vanrenterghem Y. Time-related clinical determinants of long-term tacrolimus pharmacokinetics in combination therapy with mycophenolic acid and corticosteroids: a prospective study in one hundred de novo renal transplant recipients. Clin Pharmacokinet 2004;43:741-62.

15. Wong KM, Shek CC, Chau KF, Li CS. Abbreviated tacrolimus area-under-the-curve monitoring for renal transplant recipients. Am J Kidney Dis 2000;35:660-6.

- Study describing a two time point sample strategy that is able to predict reliable the AUCO12 in renal transplant recipients.

16. Ragette R, Kamler M, Weinreich G, Teschler H,Jakob H. Tacrolimus pharmacokinetics in lung transplantation: new strategies for monitoring. J Heart Lung Transplant 2005;24:1315-9.

17. Scholten EM, Cremers SC, Schoemaker RC, Rowshani AT, van Kan EJ, den Hartigh J, Paul LC, de Fijter JW. AUC-guided dosing of tacrolimus prevents progressive systemic overexposure in renal transplant recipients. Kidney Int 2005;67:2440-7.

18. Sattler M, Guengerich FP, Yun CH, Christians U, Sewing KF. Cytochrome P-450 3A enzymes are responsible for biotransformation of FK506 and rapamycin in man and rat. Drug Metab Dispos 1992;20:753-61. 
19. Hustert E, Haberl M, Burk O, Wolbold R, He YQ, Klein K, Nuessler AC, Neuhaus P, Klattig J, Eiselt R, Koch I, Zibat A, Brockmoller J, Halpert JR, Zanger UM, Wojnowski L. The genetic determinants of the CYP3A5 polymorphism. Pharmacogenetics 2001;11:773-9.

20. Xie HG, Wood AJ, Kim RB, Stein CM, Wilkinson GR. Genetic variability in CYP3A5 and its possible consequences. Pharmacogenomics 2004;5:243-72.

•• Excellent review regarding the CYP3A5 iso-enzyme.

21. van Schaik RH, van der Heiden IP, van den Anker JN, Lindemans J. CYP3A5 variant allele frequencies in Dutch Caucasians. Clin Chem 2002;48:1668-71.

22. Zhao Y, Song M, Guan D, Bi S, Meng J, Li Q, Wang W. Genetic polymorphisms of CYP3A5 genes and concentration of the cyclosporine and tacrolimus. Transplant Proc 2005;37: $178-81$.

23. Zheng H, Webber S, Zeevi A, Schuetz E, Zhang J, Bowman P, Boyle G, Law Y, Miller S, Lamba J, Burckart GJ. Tacrolimus dosing in pediatric heart transplant patients is related to CYP3A5 and MDR1 gene polymorphisms. Am J Transplant 2003;3:477-83.

24. Zheng H, Zeevi A, Schuetz E, Lamba J, McCurry K, Griffith BP, Webber S, Ristich J, Dauber J, lacono A, Grgurich W, Zaldonis D, McDade K, Zhang J, Burckart GJ. Tacrolimus dosing in adult lung transplant patients is related to cytochrome P4503A5 gene polymorphism. $\mathrm{J}$ Clin Pharmacol 2004;44:135-40.

25. Zhang X, Liu ZH, Zheng JM, Chen ZH, Tang Z, Chen JS, Li LS. Influence of CYP3A5 and MDR1 polymorphisms on tacrolimus concentration in the early stage after renal transplantation. Clin Transplant 2005;19:638-43.

- Study describing the association in a Chinese renal transplant recipient population between the CYP3A5*3 and MDR1 C3435T polymorphisms and both the tacrolimus C0 level and the daily tacrolimus dose 1 week, 1 month and 3 months after transplantation.

26. Hesselink DA, van Schaik RH, van der Heiden IP, van der Werf M, Gregoor PJ, Lindemans J, Weimar W, van Gelder T. Genetic polymorphisms of the CYP3A4, CYP3A5, and MDR-1 genes and pharmacokinetics of the calcineurin inhibitors cyclosporine and tacrolimus. Clin Pharmacol Ther 2003;74:245-54.

27. Haufroid V, Mourad M, Van Kerckhove V, Wawrzyniak J, De Meyer M, Eddour DC, Malaise J, Lison D, Squifflet JP, Wallemacq P. The effect of CYP3A5 and MDR1 (ABCB1) polymorphisms on cyclosporine and tacrolimus dose requirements and trough blood levels in stable renal transplant patients. Pharmacogenetics 2004;14:147-54.

28. Thervet E, Anglicheau D, King B, Schlageter MH, Cassinat B, Beaune P, Legendre C, Daly AK. Impact of cytochrome p450 3A5 genetic polymorphism on tacrolimus doses and concentration-to-dose ratio in renal transplant recipients. Transplantation 2003;76:1233-5.

29. MacPhee IA, Fredericks S, Mohamed M, Moreton M, Carter ND, Johnston A, Goldberg L, Holt DW. Tacrolimus pharmacogenetics: the CYP3A5*1 allele predicts low dose-normalized tacrolimus blood concentrations in whites and South Asians. Transplantation 2005;79: 499-502.

30. Goto M, Masuda S, Kiuchi T, Ogura Y, Oike F, Okuda M, Tanaka K, Inui K. CYP3A5*1carrying graft liver reduces the concentration/oral dose ratio of tacrolimus in recipients of living-donor liver transplantation. Pharmacogenetics 2004;14:471-8.

31. Mai I, Perloff ES, Bauer S, Goldammer M, Johne A, Filler G, Budde K, Roots I. MDR1 haplotypes derived from exons 21 and 26 do not affect the steady-state pharmacokinetics of tacrolimus in renal transplant patients. Br J Clin Pharmacol 2004;58:548-53.

32. Schwab M, Eichelbaum M, Fromm MF. Genetic polymorphisms of the human MDR1 drug transporter. Ann Rev Pharmacol Toxicol 2003;43:285-307.

33. Hebert MF, Dowling AL, Gierwatowski C, Lin YS, Edwards KL, Davis CL, Marsh CL, Schuetz EG, Thummel KE. Association between ABCB1 (multidrug resistance transporter) genotype and post-liver transplantation renal dysfunction in patients receiving calcineurin inhibitors. Pharmacogenetics 2003;13:661-74.

34. Tada H, Tsuchiya N, Satoh S, Kagaya H, Li Z, Sato K, Miura M, Suzuki T, Kato T, Habuchi T. Impact of CYP3A5 and MDR1(ABCB1) C3435T polymorphisms on the pharmacokinetics of tacrolimus in renal transplant recipients. Transplant Proc 2005;37:1730-2. 
35. Tsuchiya N, Satoh S, Tada H, Li Z, Ohyama C, Sato K, Suzuki T, Habuchi T, Kato T. Influence of CYP3A5 and MDR1 (ABCB1) polymorphisms on the pharmacokinetics of tacrolimus in renal transplant recipients. Transplantation 2004;78:1182-7.

- First study that demonstrated in Japanese renal transplant recipients an association between the CYP3A5*3 polymorphism and the pharmacokinetic parameters such as $(\mathrm{dnC})$, $\operatorname{dn}(A \cup C 0-12), d n C m a x$, Tmax, and $t 1 / 2$.

36. MacPhee IA, Fredericks S, Tai T, Syrris P, Carter ND, Johnston A, Goldberg L, Holt DW. Tacrolimus pharmacogenetics: polymorphisms associated with expression of cytochrome p4503A5 and P-glycoprotein correlate with dose requirement. Transplantation 2002;74: 1486-9.

- Study that first described the association between the pseudogene CYP3AP1 G-44A polymorphism and the tacrolimus $\mathrm{CO}$ levels and tacrolimus dose. Additionally, a multi-genetic approach was first used by this research group.

37. Anglicheau D, Verstuyft C, Laurent-Puig P, Becquemont L, Schlageter MH, Cassinat B, Beaune $P$, Legendre $C$, Thervet $E$. Association of the multidrug resistance- 1 gene singlenucleotide polymorphisms with the tacrolimus dose requirements in renal transplant recipients. J Am Soc Nephrol 2003;14:1889-96.

38. Dally $H$, Bartsch $H$, Jager B, Edler L, Schmezer $P$, Spiegelhalder $B$, Dienemann $H$, Drings $P$, Kayser K, Schulz V, Risch A. Genotype relationships in the CYP3A locus in Caucasians. Cancer Lett 2004;207:95-9.

39. Arjomand-Nahad F, Diefenbach K, Landt O, Gaikovitch E, Roots I. Genotyping of the triallelic variant G2677T/A in MDR1 using LightCycler with locked-nucleic-acid-modified hybridization probes. Anal Biochem 2004;334:201-3.

40. Nauck M, Stein U, von Karger S, Marz W, Wieland H. Rapid detection of the C3435T polymorphism of multidrug resistance gene 1 using fluorogenic hybridization probes. Clin Chem 2000;46:1995-7.

41. von Ahsen N, Richter M, Grupp C, Ringe B, Oellerich M, Armstrong VW. No influence of the MDR-1 C3435T polymorphism or a CYP3A4 promoter polymorphism (CYP3A4-V allele) on dose-adjusted cyclosporin A trough concentrations or rejection incidence in stable renal transplant recipients. Clin Chem 2001;47:1048-52.

42. Kuehl P, Zhang J, Lin Y, Lamba J, Assem M, Schuetz J, Watkins PB, Daly A, Wrighton SA, Hall SD, Maurel P, Relling M, Brimer C, Yasuda K, Venkataramanan R, Strom S, Thummel K, Boguski MS, Schuetz E. Sequence diversity in CYP3A promoters and characterization of the genetic basis of polymorphic CYP3A5 expression. Nat Genet 2001;27:383-91.

43. Paulussen A, Lavrijsen K, Bohets $H$, Hendrickx J, Verhasselt P, Luyten W, Konings $F$, Armstrong $\mathrm{M}$. Two linked mutations in transcriptional regulatory elements of the CYP3A5 gene constitute the major genetic determinant of polymorphic activity in humans. Pharmacogenetics 2000;10:415-24.

44. Jorgensen K, Povlsen J, Madsen S, Madsen M, Hansen H, Pedersen A, Heinsvig EM, Poulsen J. C2 (2-h) levels are not superior to trough levels as estimates of the area under the curve in tacrolimus-treated renal-transplant patients. Nephrol Dial Transplant 2002;17: 1487-90.

45. Kimikawa M, Kamoya K, Toma H, Teraoka S. Effective oral administration of tacrolimus in renal transplant recipients. Clin Transplant 2001;15:324-9.

46. Braun F, Schutz E, Peters B, Talaulicar R, Grupp C, Undre N, Schafer A, Armstrong VW, Oellerich M, Ringe B. Pharmacokinetics of tacrolimus primary immunosuppression in kidney transplant recipients. Transplant Proc 2001;33:2127-8.

47. Pisitkun T, Eiam-Ong S, Chusil S, Praditpornsilpa K, Pansin P,Tungsanga K. The roles of C4 and AUCO-4 in monitoring of tacrolimus in stable kidney transplant patients. Transplant Proc 2002;34:3173-5.

48. Stolk LM, Van Duijnhoven EM, Christiaans MH, van Hooff JP. Trough levels of tacrolimus. Ther Drug Monit 2002;24:573; author reply 573-4.

49. Thummel KE. A genetic test for immunosuppressant dose selection? Pharmacogenetics 2004;14:145-6.

101. http://www.imm.ki.se/CYPalleles/default.htm. 

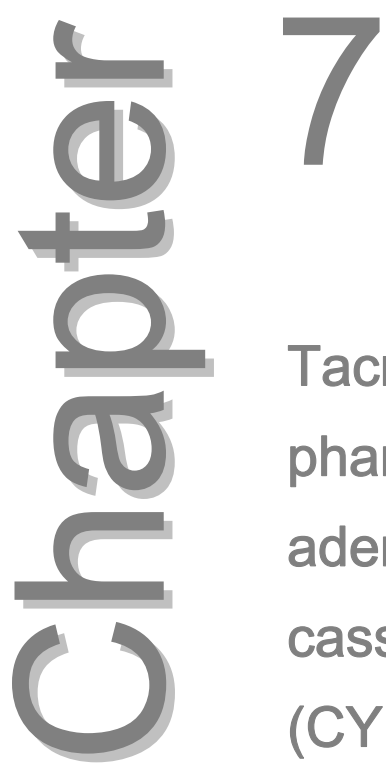

Tacrolimus pharmacokinetics and pharmacogenetics: influence of adenosine triphosphate-binding cassette B1 (ABCB1) and cytochrome (CYP) 3A polymorphisms

Robert A.M. Op den Buijsch, Maarten H.L. Christiaans, Leo M.L. Stolk, Johan E. de Vries, Chi Yuen Cheung, Nas A. Undre, Johannes P. van Hooff, Marja P. van Dieijen-Visser, Otto Bekers

Fundamental \& Clinical Pharmacology 2007;21:427-35 


\section{Abstract}

\section{Background and aim}

Tacrolimus, an immunosuppressant used after organ transplantation, has a narrow therapeutic range and its pharmacokinetic variability complicates its daily dose assessment. P-glycoprotein (P-gp), encoded by the adenosine triphosphate-binding cassette B1 (ABCB1) and the cytochrome (CYP) 3A4 and 3A5 enzymes appear to play a role in the tacrolimus metabolism.

\section{Materials and methods}

In the present study, two different renal transplant recipients groups are used to examine the influence of $A B C B 1$ and CYP3A polymorphisms on the daily tacrolimus dose and several pharmacokinetic parameters. In total 63 Caucasian renal transplant recipients divided into 26 early [median (range) of the days since transplantation -16 (3-74)] and 37 late post-transplant recipients [median (range) of the days since transplantation -1465 (453-4128)] were genotyped for ABCB1 and CYP3A polymorphisms. The pharmacokinetic parameters of tacrolimus were determined for all renal transplant recipients and correlated with their corresponding genotypes.

\section{Results}

A significant difference in allele frequencies of the CYP3A4*1B $(P=0.028)$ and CYP3A5*1 $(P=0.022)$ alleles was observed between the early and late post-transplant recipient groups. Significant higher dose-normalized trough levels $\left(\mathrm{dnC}_{0}\right)$, dosenormalized area under the curve $\left(\operatorname{dn} A \cup C_{0-12}\right)$, and dose-normalized maximum concentration ( $\mathrm{dnC}_{\max }$ ) were observed for carriers of the CYP3A5*3 variant allele in both renal transplant patient groups. Except for the daily tacrolimus dose $(P=0.025)$ no significant differences were observed for carriers of the CYP3A4*1B variant allele. Neither the individual ABCB1 polymorphisms nor the ABCB1 haplotypes were associated with any pharmacokinetic parameter.

\section{Conclusion}

We noticed that patients carrying a CYP3A5*1 allele require a twofold higher tacrolimus dose compared to homozygous carriers of the CYP3A5*3 variant allele to maintain the target dnAUC $\mathrm{C}_{0-12}$. Therefore, genotyping for the CYP3A5*3 variant allele can contribute to a better and more individualized immunosuppressive therapy in transplant patients. 


\section{Introduction}

The immunosuppressant tacrolimus is used worldwide in transplant patients although its narrow therapeutic window and high pharmacokinetic variability complicate the establishment of a dosage regime ${ }^{1,2}$. Therefore, close therapeutic drug monitoring for tacrolimus is required to prevent the risk of subtherapeutic or toxic blood concentrations. Sub-therapeutic tacrolimus blood concentrations increase the risk of transplant rejection enormously ${ }^{3-5}$, while high tacrolimus blood concentrations may lead to severe side effects such as nephrotoxicity, neurotoxicity and hyperglycemia ${ }^{6-8}$. Tacrolimus is similar to numerous other clinically used drugs, a substrate for P-glycoprotein (P-gp) and cytochrome P450 3A (CYP3A) enzymes. P-gp is encoded by the adenosine triphosphate (ATP)-binding cassette B1 (ABCB1) gene and co-expressed with the CYP3A enzymes in the liver and intestines. CYP3A4 and CYP3A5 are the most important members of the CYP3A subfamily, ${ }^{9,10}$. The differences in expression levels and activity of $A B C B 1$ and CYP3A may explain the interindividual variations in the tacrolimus pharmacokinetics. P-gp is an ATPdependent membranous transporter that contributes to the protection of the body from environmental toxins and drugs such as tacrolimus by limiting their absorption from the intestine and promoting the efflux into bile and urine ${ }^{11}$. Three partly linked polymorphisms in the ABCB1 gene located on exons 12, 21 and 26 were studied extensively. Two of these ABCB1 polymorphisms, C1236T and C3435T, result in silent mutations while the ABCB1 G2677T/A polymorphism in exon 21 is non-synonymous and results in an amino acid exchange (Ala893Ser/Thr). A number of studies found no association between the ABCB1 genotypes and tacrolimus trough $\left(\mathrm{C}_{0}\right)$ concentrations ${ }^{12-17}$ or the pharmacokinetic parameters: area under the time/ tacrolimus concentration curve $\left(A \cup C_{0-12}\right)$, the maximum concentration $\left(C_{\max }\right)$, the time that the maximum concentration is reached $\left(T_{\max }\right)$ and the half-life time $\left(\mathrm{t}_{1 / 2}\right)^{18,19}$. However, some other studies found an association between the tacrolimus $\mathrm{C}_{0}$ concentrations, the daily tacrolimus dose and individual $A B C B 1$ polymorphisms ${ }^{20,21}$ or the ABCB1 haplotypes ${ }^{22}$. Homozygotes for the CYP3A4*1B and CYP3A5*3 variant allele carry at position -392 an $A$ and at position 6986 a $G$, respectively. Moreover, homozygotes for the CYP3A4*1B variant allele show an altered CYP3A4 enzyme activity while homozygotes for the CYP3A5*3 variant allele show no CYP3A5 enzyme activity. A number of studies demonstrated the impact of the CYP3A5*3 variant allele on tacrolimus $C_{0}$ concentrations ${ }^{12-17,23-25}$, the pharmacokinetic parameters: $\mathrm{AUC}_{0-12}, \mathrm{C}_{\max }, \mathrm{T}_{\max }, \mathrm{t}_{1 / 2}{ }^{18,19}$ and the daily tacrolimus dose in different transplant patient groups. However, the influence of CYP3A4*1B and ABCB1 C1236T variant alleles on these pharmacokinetic parameters of tacrolimus was never examined. In the present study, a complete 12-h pharmacokinetic profile is recorded for all transplant patients to 
examine the association between the CYP3A4 A-392G, CYP3A5 A6986G, CYP3AP1 G-44A polymorphisms and the three $A B C B 1$ polymorphisms C1236T, G2677T/A, C3435T on the pharmacokinetic parameters in an early and a late post-transplant recipient group. Furthermore, the influence of several clinical parameters was determined on the variation in pharmacokinetic parameters in the two renal transplant recipient groups.

\section{Patients and methods}

\section{Study population}

In total 63 Caucasian renal transplant recipients (of whom a complete 12-h time-tacrolimus concentration curve was performed) were divided into two different groups. Group I included early post-transplant patients with a short median time since transplantation [16 (3-74) days], while group II included late post-transplant patients with a long median time since transplantation [1465 (453-4128) days]. Moreover, in group I eight patients used calcium channel blockers which are known to interact with tacrolimus, whereas patients included in group II used no medication known to interfere with tacrolimus. In addition, patients that suffer from gastrointestinal, liver disease or other disorders that may alter the absorption of tacrolimus were disqualified for inclusion in both groups. Prior to the blood sample collection, there had been no tacrolimus dose change for at least three days in the two groups. After overnight fasting the blood samples were collected immediately before $\left(\mathrm{C}_{0}\right)$ and $0.5\left(\mathrm{C}_{0.5}\right), 1\left(\mathrm{C}_{1}\right)$, $2\left(\mathrm{C}_{2}\right), 3\left(\mathrm{C}_{3}\right), 4\left(\mathrm{C}_{4}\right), 5\left(\mathrm{C}_{5}\right), 7.5\left(\mathrm{C}_{7.5}\right)$ and $12\left(\mathrm{C}_{12}\right)$ hours after the morning tacrolimus administration. Patients were not allowed to take food until one hour after ingesting the tacrolimus dose and were advised to avoid grapefruit juice after transplantation to prevent alterations in the tacrolimus metabolism. Demographic as well as clinical data were determined at the time of recording the 12 hour time tacrolimus concentration curve.

\section{Ethics}

The study was performed in accordance to the Declaration of Helsinki and its amendments. The protocol was approved by the local Medical Ethics Committee, and written informed consent for participation in this study was obtained from all patients.

\section{Tacrolimus concentration determinations}

The tacrolimus blood concentrations were determined in ethylenediaminetetraacetic acid (EDTA)-added whole blood samples, using a method based on a microparticle enzyme immunoassay with a monoclonal antibody (IMX II assay and a high-pressure liquid chromotography (HPLC) tandem mass spectrometry 
(MS/MS) assay. The immunoassay IMX II is linear from 1.5 to 30 microg/l. The repeatability of a low (5 microg/l) tacrolimus concentration is $6.7 \%$; medium (11 microg/l) tacrolimus concentration $7.2 \%$ and the high $(22 \mathrm{microg} / \mathrm{l})$ tacrolimus concentration $6,6 \%$. The limit of quantification was $1.5 \mathrm{microg} / \mathrm{l}$. Additionally, the HPLC tandem MS/MS assay is linear from 1 to $300 \mathrm{microg} / \mathrm{l}$. Intra-assay precision was $3.4 \%, 2,2 \%$ and $3.0 \%$ and accuracy was $102 \%, 94 \%$ and $94 \%$ at $3.04,6.23$ and 13.0 microg/l $(n=6)$, respectively. Inter-assay precision was $8.2 \%, 5,2 \%, 4,6 \%$ and accuracy was $102 \%, 94 \%$ and $93 \%(n=9)$, respectively. The limit of quantification was 1.0 microg/l. The laboratory is a participatory in an International Tacrolimus Proficiency Testing Scheme.

The tacrolimus $\mathrm{C}_{0}$ concentration and the peak blood concentration $\left(\mathrm{C}_{\max }\right)$ during the time interval assessed were determined directly from the time versus tacrolimus blood concentration data. Additionally, the area under the time/concentration curve $\left(\mathrm{AUC}_{0-12}\right)$ was calculated from the time versus tacrolimus concentration plot using the linear trapezoidal rule in MWPharm 3.50 (Mediware, Groningen, the Netherlands). Dose-normalized $(\mathrm{dn}) \mathrm{C}_{0}$, dosenormalized $(\mathrm{dn}) \mathrm{AUC}_{0-12}$ and dose-normalized $(\mathrm{dn}) \mathrm{C}_{\max }$ were calculated by dividing the $\mathrm{C}_{0}, \mathrm{AUC}_{0-12}$ and $\mathrm{C}_{\max }$, respectively, by the corresponding morning dose on a milligram per kilogram basis.

\section{DNA isolation}

Genomic DNA isolation of 63 renal transplant recipients was performed by using $200 \mu \mathrm{l}$ EDTA-anti-coagulated blood sample with a QIAamp blood mini kit (Qiagen, Leusden, the Netherlands) according to the manufacturers' instructions.

\section{Genotyping of ABCB1 and CYP3A gene polymorphisms}

Real-time polymerase chain reaction (PCR)-fluorescence resonance energy transfer (FRET) assays were used for genotyping, ABCB1 G2677T/A, ABCB1 C3435T, CYP3A4 A-392G and CYP3AP1 G-44A using the same primers and probes as in other studies ${ }^{26-29}$. In Table 7.1 the sequences of the primers and the probes are illustrated. Regarding the ABCB1 C1236T and CYP3A5 A6986G polymorphisms real-time PCR-FRET assays were performed as described earlier ${ }^{30}$. Although it is known that CYP3A5 A6986G polymorphism influences CYP3A5 activity, in the present study the known linkage between the G-44A polymorphism in the pseudo-enzyme CYP3AP1 and CYP3A5 A6986G polymorphism was also determined. For each polymorphism, heterozygote samples were sequenced according to a direct sequence procedure on a capillary sequencer $A B I$ Prism $3100^{\circledR}$ using the Bridge version 1.1 sequence kit (both products from Applied Biosystems, Fostercity, USA) and for each assay control samples with known genotypes were run in parallel with study samples. 


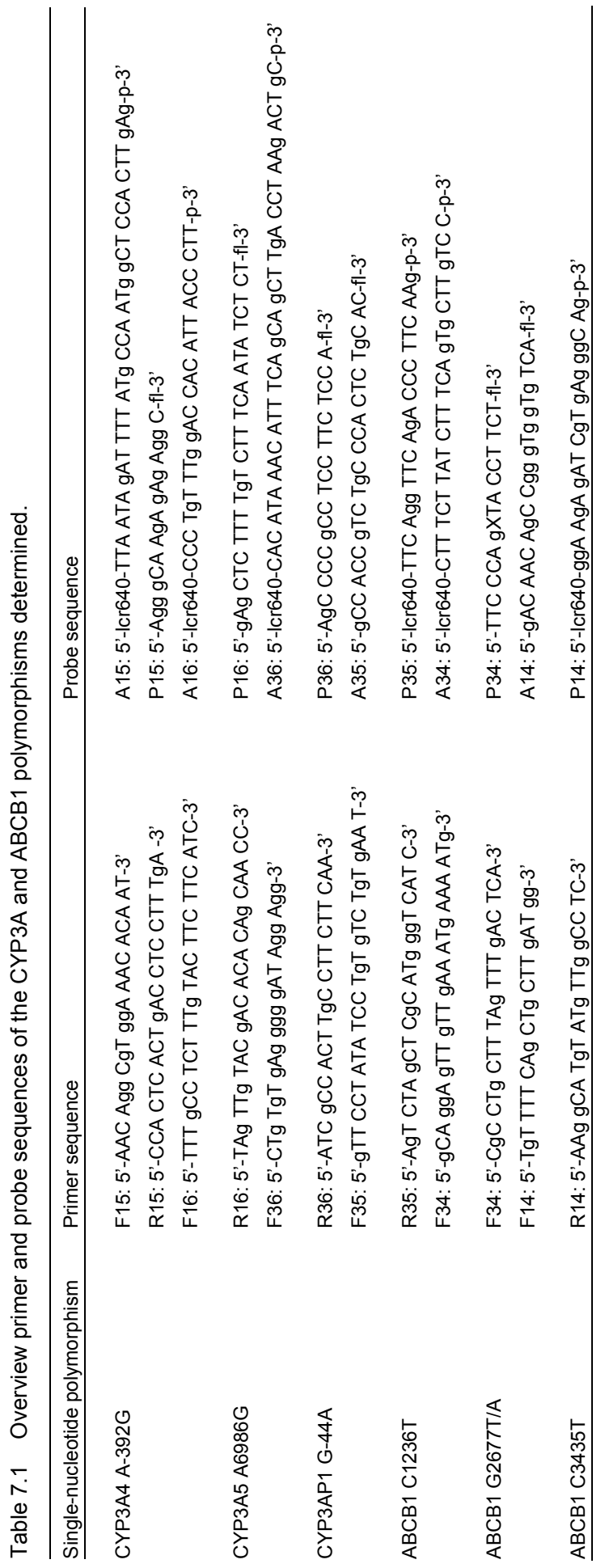




\section{Statistical analysis}

Statistical analysis of the data was performed with the use of the statistical software SPSS 11.0 for Windows (Chicago, IL, USA). Correlations between pharmacokinetic parameters and clinical variables were evaluated using stepwise multiple regression analysis. To examine the population homogeneity of the patients, the genotype frequencies of the ABCB1 and CYP3A polymorphisms were tested against Hardy-Weinberg equilibrium by the Pearson's goodness-of-fit test ${ }^{31}$. Allele frequencies of the early and late posttransplant recipient groups were compared using the $\chi^{2}$ test. For analysis of the daily tacrolimus dose $(\mathrm{mg} / \mathrm{kg} /$ day $), \quad \mathrm{dnC}_{0}(\mathrm{ng} / \mathrm{ml}$ per $\mathrm{mg} / \mathrm{kg}), \quad \mathrm{dnAUC}_{0-12}$ (ng $\times \mathrm{hr} / \mathrm{ml}$ per $\mathrm{mg} / \mathrm{kg}$ ), and $\mathrm{dnC}_{\max }(\mathrm{ng} / \mathrm{ml}$ per $\mathrm{mg} / \mathrm{kg})$, groups were compared using non-parametric statistical tests. To compare two groups we used the Mann-Whitney test, and to compare several groups the Kruskal Wallis test. $P$-values less than 0.05 were considered statistically significant. All values are expressed as median and range unless stated otherwise.

\section{Results}

\section{Influence of clinical and genetic parameters on the variation in pharmacokinetic tacrolimus parameters}

The characteristics of the early post-transplant (group I) as well as the late post-transplant (group II) recipients who were enrolled in our study are shown in Table 7.2 .

Table 7.2 Demographic characteristics of the two renal transplant recipients groups.

\begin{tabular}{|c|c|c|c|}
\hline \multicolumn{2}{|c|}{ Demographic characteristics } & Group I & Group II \\
\hline \multicolumn{2}{|c|}{ Gender (male/female) } & $18 / 8$ & $24 / 13$ \\
\hline \multicolumn{2}{|c|}{ Age (years, mean $\pm S D$ ) } & $43.0 \pm 13.2$ & $51.3 \pm 10.9$ \\
\hline \multicolumn{2}{|c|}{ Body Mass Index $\left(\mathrm{kg} / \mathrm{m}^{2}\right.$, mean $\left.\pm \mathrm{SD}\right)$} & $23.3 \pm 4.40$ & $25.6 \pm 3.42$ \\
\hline \multirow[t]{3}{*}{ Transplantation numbe } & First & 20 & 30 \\
\hline & Second & 5 & 6 \\
\hline & Third or more & 1 & 1 \\
\hline \multicolumn{2}{|c|}{ Use of azothiopurine/MMF/rapamycine } & 1 & 29 \\
\hline \multicolumn{2}{|c|}{ Time since transplantation (days, median, (range)) } & $16(3-74)$ & $1465(453-4128)$ \\
\hline \multirow{2}{*}{\multicolumn{2}{|c|}{ 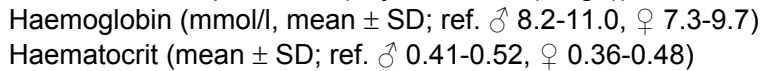 }} & $5.43 \pm 1.08$ & $8.52 \pm 0.83$ \\
\hline & & $0.25 \pm 0.07$ & $0.41 \pm 0.04$ \\
\hline \multicolumn{2}{|c|}{$\operatorname{ALAT}(\mathrm{U} / \mathrm{l}$, mean $\pm \mathrm{SD}$; ref. $\delta<45, q<35)$} & $34 \pm 34$ & $24 \pm 13$ \\
\hline \multicolumn{2}{|c|}{ Serum albumin (g/l, mean $\pm \mathrm{SD}$; ref. 34-45) } & $30.7 \pm 3.86$ & $37.0 \pm 3.84$ \\
\hline \multicolumn{2}{|c|}{ 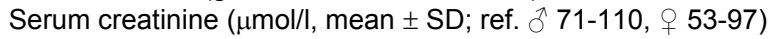 } & $331 \pm 293$ & $128 \pm 29$ \\
\hline \multicolumn{2}{|c|}{ Creatinine clearance $^{a}(\mathrm{ml} / \mathrm{min}$, mean $\pm \mathrm{SD}$; ref. 90-140) } & $37.5 \pm 28.4$ & $58.0 \pm 26.6$ \\
\hline
\end{tabular}

ref. the reference values applied in the Clinical Chemistry and Haematology Laboratory of the University Hospital Maastricht. $\delta$ male, $q$ female, MMF is mycophenolate mofetil, ${ }^{a}$ creatinine clearance is determined with the Cockcroft-Gault equation. 
The influence of different clinical (gender, age, body mass index (BMI), haemoglobin, haematocrit, ALAT, serum albumin, serum creatinine, creatinine clearance) and genetic (CYP3A4 A-392G, CYP3A5 A6986G, ABCB1 C1236T, G2677T/A, C3435T) parameters was examined on the variation in the tacrolimus pharmacokinetic parameters in all post-transplant recipients. Table 7.3 illustrates the influence of independent clinical and genetic parameters on the variability of pharmacokinetic tacrolimus parameters. In the early posttransplant recipient group the time since transplantation and the haemoglobin concentration correlated significantly with $\mathrm{dnC}_{0}, \mathrm{dnAU \textrm {C } _ { 0 - 1 2 }}$ and $\mathrm{dnC}_{\max }$ whereas the CYP3A5 A6986G polymorphism and the body mass index (BMI) were found to have a significant influence on the variability of $\mathrm{dnC}_{0}, \mathrm{dnAUC} \mathrm{C}_{0-12}$ and $\mathrm{dnC}_{\max }$ in the late post-transplant recipient group. The clinical and genetic parameters: age, haematocrit, ALAT, serum creatinine, creatinine clearance and the polymorphisms CYP3A4 A-392G, ABCB1 C1236T, ABCB1 G2677T/A and $A B C B 1$ C3435T show no significant correlation with any of the pharmacokinetic parameters in both renal transplant recipient groups.

Tabel 7.3 Influence of independent clinical and genetic parameters on the pharmacokinetic parameters of an early (group I) and a late (group II) post-transplant recipient group.

\begin{tabular}{|c|c|c|c|c|}
\hline Group & Dependent parameter & Independent parameter & Partial $r^{2}$ & ${ }^{a} P$ value \\
\hline I & Tacrolimus dose & $\begin{array}{l}\text { CYP3A5 A6986G polymorphism } \\
\text { Model } r^{2}: 0.531\end{array}$ & 0.531 & $<0.001$ \\
\hline I & $\mathrm{DnC}_{0}$ & $\begin{array}{l}\text { Time since transplantation } \\
\text { Haemoglobin } \\
\text { Model } r^{2}: 0.692\end{array}$ & $\begin{array}{l}0.613 \\
0.079\end{array}$ & $\begin{array}{l}<0.001 \\
<0.001\end{array}$ \\
\hline I & DnAUC $_{0-12}$ & $\begin{array}{l}\text { Time since transplantation } \\
\text { Haemoglobin } \\
\text { Model } r^{2}: 0.620\end{array}$ & $\begin{array}{l}0.528 \\
0.092\end{array}$ & $\begin{array}{l}<0.001 \\
<0.001\end{array}$ \\
\hline I & $\mathrm{DnC}_{\max }$ & $\begin{array}{l}\text { Time since transplantation } \\
\text { Haemoglobin } \\
\text { Model } r^{2}: 0.635\end{array}$ & $\begin{array}{l}0.405 \\
0.230\end{array}$ & $\begin{array}{l}<0.001 \\
<0.001\end{array}$ \\
\hline II & Tacrolimus dose & $\begin{array}{l}\text { CYP3A5 A6986G polymorphism } \\
\text { Model } r^{2}: 0.354\end{array}$ & 0.354 & $<0.001$ \\
\hline II & $\mathrm{DnC}_{0}$ & $\begin{array}{l}\text { CYP3A5 A6986G polymorphism } \\
\text { Body mass index (BMI) } \\
\text { Gender } \\
\text { Model } r^{2}: 0.418\end{array}$ & $\begin{array}{l}0.175 \\
0.157 \\
0.086\end{array}$ & $\begin{array}{r}0.010 \\
0.001 \\
<0.001\end{array}$ \\
\hline II & $\operatorname{DnAUC}_{0-12}$ & $\begin{array}{l}\text { CYP3A5 A6986G polymorphism } \\
\text { Body mass index (BMI) } \\
\text { Model } r^{2}: 0.335\end{array}$ & $\begin{array}{l}0.190 \\
0.145\end{array}$ & $\begin{array}{l}0.007 \\
0.001\end{array}$ \\
\hline II & $\mathrm{DnC}_{\max }$ & $\begin{array}{l}\text { CYP3A5 A6986G polymorphism } \\
\text { Body mass index (BMI) } \\
\text { Serum Albumin } \\
\text { Model } r^{2}: 0.412\end{array}$ & $\begin{array}{l}0.226 \\
0.109 \\
0.077\end{array}$ & $\begin{array}{r}0.003 \\
0.001 \\
<0.001\end{array}$ \\
\hline
\end{tabular}

$P$ value belonging to the partial $r^{2}$. $\mathrm{DnC}_{0}$, dose-normalized trough level, dnAUC $\mathrm{C}_{0-12}$, dose-normalized area under the curve, $\mathrm{DnC}_{\max }$ dose-normalized maximum concentration. Tested independent parameters were gender, age, body mass index (BMI), haemoglobin, haematocrit, ALAT, serum albumin, serum creatinine, creatinine clearance (Cockcroft-Gault), CYP3A4 A-392G, CYP3A5 A6986G, ABCB1 C1236T, G2677T/A, C3435T. 


\section{Allele distribution of the different ABCB1 and CYP3A polymorphisms}

Table 7.4 and 7.5 show the genotype frequencies of the different CYP3A and CYP3AP1 polymorphisms that were determined for the 26 early and 37 late post-transplant recipients. The genotype frequencies of the two renal transplant recipient groups were not significantly different from that predicted by the Hardy-Weinberg equation.

Table 7.4 Influence of ABCB1, CYP3A and CYP3AP1 allelic variants on the pharmacokinetic tacrolimus parameters of the early post-transplant recipients.

\begin{tabular}{lcccccc}
\hline Genotype & $\begin{array}{r}\mathrm{N} \\
\text { No }\end{array}$ & $\begin{array}{c}\text { Allelic } \\
\text { status }\end{array}$ & Dose & DnC $_{0}$ & DnAUC $_{0-12}$ & DnC $_{\max }$ \\
\hline CYP3A4 & 21 & ${ }^{*} 1 \mathrm{~A} /{ }^{*} 1 \mathrm{~A}$ & $0.28(0.04-0.80)^{\mathrm{a}}$ & $90(40-1329)$ & $1782(824-15721)$ & $383(89-1535)$ \\
A-392G & 5 & ${ }^{*} 1 \mathrm{~A} /{ }^{*} 1 \mathrm{~B}$ & $0.50(0.43-0.79)^{\mathrm{a}}$ & $59(32-107)$ & $1275(922-1796)$ & $216(184-338)$ \\
& 0 & ${ }^{*} 1 \mathrm{~B} /{ }^{*} 1 \mathrm{~B}$ & ---- & ---- & ---- & --- \\
CYP3A5 & 1 & ${ }^{*} 1 /^{*} 1$ & 0.78 & 32 & 922 & 184 \\
A6986G & 9 & ${ }^{*} 1 /^{*} 3$ & $0.50(0.35-0.80)^{\mathrm{a}}$ & $59(40-107)^{\mathrm{a}}$ & $1220(824-1796)^{\mathrm{a}}$ & $216(89-380)^{\mathrm{a}}$ \\
& 16 & ${ }^{*} 3 /^{*} 3$ & $0.25(0.04-0.59)^{\mathrm{a}}$ & $118(45-1329)^{\mathrm{a}}$ & $1975(839-15721)^{\mathrm{a}}$ & $435(90-1535)^{\mathrm{a}}$ \\
CYP3AP1 & 1 & $\mathrm{G} / \mathrm{G}$ & 0.78 & 32 & 922 & 184 \\
G-44A & 10 & $\mathrm{G} / \mathrm{A}$ & $0.49(0.12-0.80)^{\mathrm{a}}$ & $60(40-107)^{\mathrm{a}}$ & $1248(824-1796)^{\mathrm{a}}$ & $236(89-381)^{\mathrm{a}}$ \\
& 15 & $\mathrm{~A} / \mathrm{A}$ & $0.25(0.04-0.59)^{\mathrm{a}}$ & $123(45-1329)^{\mathrm{a}}$ & $2030(839-15721)^{\mathrm{a}}$ & $454(90-1535)^{\mathrm{a}}$ \\
\hline
\end{tabular}

Tacrolimus dose $(\mathrm{mg} / \mathrm{kg} / \mathrm{day}), \mathrm{dnC}_{0}$, dose-normalized trough concentration $(\mathrm{ng} / \mathrm{ml} \mathrm{per} \mathrm{mg} / \mathrm{kg}$ ), $\mathrm{dnAUC}_{0-12}(\mathrm{ng} \times \mathrm{hr} / \mathrm{ml}$ per $\mathrm{mg} / \mathrm{kg})$ dose-normalized area under the curve, $\mathrm{dnC}_{\max }$ dose-normalized maximum concentration $(\mathrm{ng} / \mathrm{ml}$ per $\mathrm{mg} / \mathrm{kg})$. Values are indicated as median and (range), ${ }^{a} P<0.05$; (Mann-Whitney).

Table 7.5 Influence of ABCB1, CYP3A and CYP3AP1 allelic variants on the pharmacokinetic tacrolimus parameters of the late posttransplant recipients.

\begin{tabular}{|c|c|c|c|c|c|c|}
\hline Genotype & $\begin{array}{l}\text { N } \\
\text { No }\end{array}$ & $\begin{array}{l}\text { Allelic } \\
\text { status }\end{array}$ & Dose & $\mathrm{DnC}_{0}$ & DnAUC $_{0-12}$ & $\mathrm{DnC}_{\max }$ \\
\hline CYP3A4 & 36 & $* 1 \mathrm{~A} /{ }^{*} 1 \mathrm{~A}$ & $05(0.02-0.14)$ & $276(70-669)$ & 4642 (1355-11994) & 775 (294-1729) \\
\hline A-392G & 1 & $* 1 \mathrm{~A} /{ }^{*} 1 \mathrm{~B}$ & 0.067 & 121 & 2766 & 504 \\
\hline & 0 & ${ }^{*} 1 \mathrm{~B} /{ }^{*} 1 \mathrm{~B}$ & ---- & ---- & ---- & ---- \\
\hline YYP3A5 & 0 & $* 1 / * 1$ & ----- & ----- & ---- & ---- \\
\hline A6986G & 5 & $* 1 / * 3$ & $0.10(0.05-0.14)^{a}$ & $87.4(70-248)^{a}$ & $1663(1355-4057)^{a}$ & $461(294-646)^{\mathrm{a}}$ \\
\hline YYP3 & $\begin{array}{r}32 \\
0\end{array}$ & & - & ----- & ----- & ----- \\
\hline G-44A & $\begin{array}{r}8 \\
29\end{array}$ & $\begin{array}{l}\mathrm{G} / \mathrm{A} \\
\mathrm{A} / \mathrm{A}\end{array}$ & $\begin{array}{l}0.07(0.02-0.14)^{a} \\
0.04(0.02-0.11)^{a}\end{array}$ & $\begin{array}{c}161(70-669)^{\mathrm{a}} \\
283(118-640)^{\mathrm{a}}\end{array}$ & $\begin{array}{l}2990(1355-11994)^{a} \\
4761(2227-11504)^{a}\end{array}$ & $\begin{array}{l}544(294-1729)^{a} \\
810(465-1493)^{a}\end{array}$ \\
\hline
\end{tabular}

Tacrolimus dose $\left(\mathrm{mg} / \mathrm{kg} /\right.$ day), $\mathrm{dnC}_{0}$, dose-normalized trough concentration $(\mathrm{ng} / \mathrm{ml} \mathrm{per} \mathrm{mg} / \mathrm{kg}$ ), $\mathrm{dnAUC}_{0-12}(\mathrm{ng} \times \mathrm{hr} / \mathrm{ml}$ per $\mathrm{mg} / \mathrm{kg})$ dose-normalized area under the curve, $\mathrm{dnC}_{\max }$ dose-normalized maximum concentration $\left(\mathrm{ng} / \mathrm{ml}\right.$ per $\mathrm{mg} / \mathrm{kg}$ ). Values are indicated as median and (range), ${ }^{a} P<0.05$; (Mann-Whitney). 


\section{Effect of ABCB1 and CYP3A polymorphisms on the daily tacrolimus dose and the pharmacokinetic parameters}

In the present study, we found that neither the individual $A B C B 1$ polymorphisms nor the $A B C B 1$ haplotypes were associated with the daily tacrolimus dose and the pharmacokinetic parameters; $\operatorname{dnC}_{0,} \operatorname{dnAUC}_{0-12}$ and $\mathrm{dnC}_{\max }$.

Table 7.4 shows a trend between the heterozygote carriers of the CYP3A4*1B variant allele in both the daily tacrolimus dose and the pharmacokinetic tacrolimus parameters compared to the homozygote carriers of the CYP3A4*1A allele. However, except for the daily tacrolimus dose $(0.28 \mathrm{vs} .0 .50$ $\mathrm{mg} / \mathrm{kg} /$ day; Mann-Whitney, $P=0.025)$, no significant differences were found between the pharmacokinetic parameters for tacrolimus and the different CYP3A4 A-392G genotypes in the early post-transplant recipient group.

Additionally, Table 7.4 demonstrates a significant decrease in the pharmacokinetic tacrolimus parameters $\mathrm{dnC}_{0}, 118 \mathrm{vs} .59 \mathrm{ng} / \mathrm{ml}$ per mg/kg; dnAUC ${ }_{0-12}$

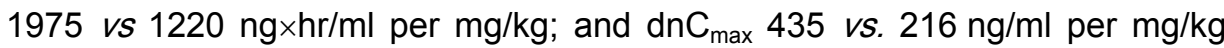
when renal transplant recipients were carriers of none or one CYP3A5*1 allele. Consequently, the daily tacrolimus dose was significantly higher in heterozygous carriers of the CYP $3 A 5^{*} 3$ variant allele compared to homozygous carriers of the CYP3A5*3 variant allele $(0.50$ vs. $0.25 \mathrm{mg} / \mathrm{kg} /$ day; MannWhitney, $P=0.001$ ). Regarding the late post-transplant recipients included in group II, a similar genetic effect is found for CYP3A5*1 allele in association with the pharmacokinetic tacrolimus parameters and the daily tacrolimus dose, as is shown in Table7.5. Because there is only one heterozygous carrier of the CYP3A4*1B variant allele among the late post-transplant group, no statistical analyses could be performed between the CYP3A4*1B genotypes and the pharmacokinetic tacrolimus parameters. Although we observed a significant difference in the daily tacrolimus dose as well as in the $\operatorname{dnC}_{0}, \operatorname{dnAUC} \mathrm{C}_{0-12}$ and $\mathrm{dnC}_{\max }$ for only the CYP3A5*3 variant allele, it is not clear whether the CYP3A4*1B variant allele has, similarly to the CYP3A5*3 variant allele, an important contribution to the pharmacokinetic variability of tacrolimus, particularly, knowing that in this study all individuals carrying a CYP3A4*1B variant allele also carry at least one CYP3A5*1 allele. To examine the influence of the CYP3A4*1B variant allele solely, we selected those renal transplant recipients in group I who were heterozygous for the CYP3A5*1 allele. One renal transplant patient was heterozygous for the CYP3A4*1B variant allele and homozygote for the CYP3A5*1 allele. Five renal transplant patients were carriers of both one CYP3A4*1B variant allele and one CYP3A5*1 allele. Additionally, another four renal transplant recipients were homozygous for the CYP3A4*1A allele and heterozygous for one CYP3A5*1 allele. Figure 7.1 illustrates that renal transplant recipients who were heterozygous for the CYP3A4*1B and CYP3A5*3 variant allele show no significantly higher daily 
tacrolimus dose or lower $\mathrm{dnAUC}_{0-12}$ compared to patients that were only heterozygous for the CYP3A4*1B variant allele.

A

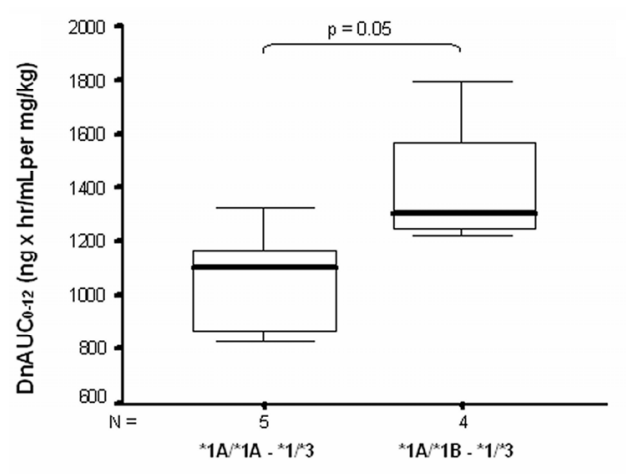

Combination of CYP3A4 and CYP3A5 polymorphisms
B

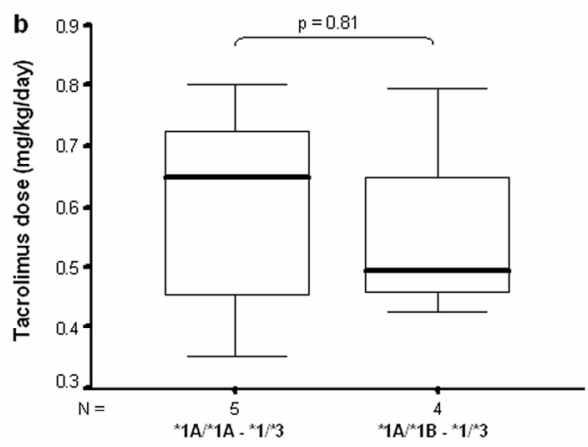

Combination of CYP3A4 and CYP3A5 polymorphisms

Figure 7.1 Box plot of the distribution of $(A)$ the dose-normalized $(\mathrm{Dn}) \mathrm{AUC}_{0-12}(\mathrm{ng} \times \mathrm{hr} / \mathrm{ml}$ per $\mathrm{mg} / \mathrm{kg}$ ) and (B) the tacrolimus dose (mg/kg/day) clustered according to the combination of CYP3A4 A-392G and CYP3A5 A6986G genotypes. $P$ values are given for the pairwise comparisons of each genotype combination.

\section{Discussion}

In the early post-transplant recipient group, the time since transplantation and the haemoglobin concentration contributes significantly to the variability of the pharmacokinetic tacrolimus parameters $\mathrm{dnC}_{0}, \mathrm{dnAUC}_{0-12}$ and $\mathrm{dnC}_{\max }$ while in the late post-transplant recipient group the CYP3A5 A6986G polymorphism and the BMI have an important influence on the variability of different pharmacokinetic tacrolimus parameters. Previously, Haufroid et al. ${ }^{12}$ reported a significant contribution of the CYP3A5 A6986G polymorphism and the time since transplantation on the variation of tacrolimus $\mathrm{C}_{0}$ concentrations and the tacrolimus dose requirement. Additionally, we also demonstrated in a stable Chinese renal transplant recipient population that the CYP3A5 A6986G polymorphism is the most significant independent variable when considering the daily tacrolimus dose as a dependent variable ${ }^{30}$. Kuypers et al. ${ }^{32}$ found higher tacrolimus peak concentrations for female renal transplant recipients compared to their male counterparts and a significantly higher tacrolimus $\mathrm{AUC}_{0}$ 12 in female recipients six months after transplantation. Furthermore, Kuypers et al. ${ }^{32}$ found lower tacrolimus trough concentrations with increasing age. 
Although some earlier studies ${ }^{20-22}$ reported a weak significant association between ABCB1 genotypes or haplotypes with tacrolimus $\mathrm{C}_{0}$ concentrations of the transplant patients, no differences were found between either the different ABCB1 polymorphisms or the ABCB1 haplotypes and the pharmacokinetic tacrolimus parameters in the two renal transplant recipient groups. Recently, Fredericks et al. ${ }^{33}$ reported, after examining 206 stable renal transplant recipients that the individual $A B C B 1$ polymorphisms and $A B C B 1$ haplotypes show a relatively minor association with the tacrolimus pharmacokinetics which implies that genotyping for ABCB1 polymorphisms seems to be of minor importance for predicting the daily tacrolimus dose regime. CYP3A enzymes are responsible for the most important metabolic route of tacrolimus, namely its demethylation to 13-O-demethyltacrolimus ${ }^{34-37}$. Because of the lack of CYP3A5 activity caused by the CYP3A5*3 variant allele, transplant patients who were homozygous for the CYP3A5*3 variant allele required an almost twofold lower daily tacrolimus dose and achieved even a higher $\mathrm{dnC}_{0}, \mathrm{dnAUC}_{0-12}$ and $\mathrm{dn} \mathrm{C}_{\max }$ compared with the transplant recipients who carry at least one CYP3A5*1 allele. Although in the present study a trend was observed between the different CYP3A4 A-392G genotypes and the pharmacokinetic tacrolimus parameters, the contribution of this CYP3A4*1B variant allele seemed limited. After selecting two renal transplant recipient groups - one group with the genotype combination CYP3A4 * $1 \mathrm{~A} /{ }^{*} 1 \mathrm{~A}-\mathrm{CYP} 3 \mathrm{~A} 5{ }^{*} 1{ }^{*} 3$ and the other with the genotype combination CYP3A4 *1A ${ }^{*} 1 B$ - CYP3A5 *1/*3 - no significant differences were observed between these groups and the daily tacrolimus dose as well as the $d_{n} C_{0}, d n A U C_{0-12}$ and $d n n C_{\max }$. This may indicate that the influence of the CYP3A4 *1B variant allele is restricted and that at least most of the genetic effect is being caused by the CYP3A5 A6986G polymorphism. On the other hand, Hesselink et al. reported that the CYP3A4*1B variant allele has a significant influence on the daily tacrolimus dose though they observed a $80 \%$ overlap between the CYP3A4*1B and CYP3A5*1 allele ${ }^{15}$. Although tacrolimus is a substrate of CYP3A4, our findings with a limited number of patients suggest that if there is an influence of this CYP3A4*1B polymorphism, it is probably caused by the strong linkage between CYP3A4*1B and CYP3A5*1. In conclusion, it appears that carriers of CYP3A5*1 allele included, in either the early or the late post-transplant recipient group, show a twofold lower $\mathrm{dnC}_{0}$, $\mathrm{dnAUC}_{0-12}$ and $\mathrm{dnC}_{\max }$ for tacrolimus compared with homozygous carriers of a CYP3A5*3 variant allele. Thus carriers of a CYP3A5*1 allele require a twofold higher tacrolimus dose compared with homozygous carriers of a CYP3A ${ }^{\star} 3$ variant allele. Therefore, we conclude that genotyping for the CYP $3 A 5^{\star} 3$ variant allele is of great value to determine the initial and maintenance oral tacrolimus dose. By doing so the risk of under- or over-immunosuppression in individual renal transplant recipients will be minimized. 


\section{References}

1. Spencer CM, Goa KL, Gillis JC. Tacrolimus. An update of its pharmacology and clinical efficacy in the management of organ transplantation. Drugs 1997;54:925-75.

2. Venkataramanan R, Swaminathan A, Prasad T, Jain A, Zuckerman S, Warty V, McMichael J, Lever J, Burckart G, Starzl T. Clinical pharmacokinetics of tacrolimus. Clin Pharmacokinet 1995:29:404-30.

3. Kershner RP, Fitzsimmons WE. Relationship of FK506 whole blood concentrations and efficacy and toxicity after liver and kidney transplantation. Transplantation 1996;62:920-6.

4. Laskow DA, Vincenti F, Neylan JF, Mendez R, Matas AJ. An open-label, concentrationranging trial of FK506 in primary kidney transplantation: a report of the United States Multicenter FK506 Kidney Transplant Group. Transplantation 1996;62:900-5.

5. Undre NA, van Hooff J, Christiaans M, Vanrenterghem Y, Donck J, Heeman U, Kohnle M, Zanker B, Land W, Morales JM, Andres A, Schafer A, Stevenson P. Low systemic exposure to tacrolimus correlates with acute rejection. Transplant Proc 1999;31:296-8.

6. McMaster P, Mirza DF, Ismail T, Vennarecci G, Patapis P, Mayer AD. Therapeutic drug monitoring of tacrolimus in clinical transplantation. Ther Drug Monit 1995;17:602-5.

7. Staatz CE, Tett SE. Clinical pharmacokinetics and pharmacodynamics of tacrolimus in solid organ transplantation. Clin Pharmacokinet 2004;43:623-53.

8. Winkler M, Christians U. A risk-benefit assessment of tacrolimus in transplantation. Drug Saf 1995;12:348-57.

9. Saeki T, Ueda K, Tanigawara Y, Hori R, Komano T. Human P-glycoprotein transports cyclosporin A and FK506. J Biol Chem 1993;268:6077-80.

10. Kamdem LK, Streit F, Zanger UM, Brockmoller J, Oellerich M, Armstrong VW, Wojnowski L. Contribution of CYP3A5 to the in vitro hepatic clearance of tacrolimus. Clin Chem 2005;51:1374-81.

11. Schwab M, Eichelbaum M, Fromm MF. Genetic polymorphisms of the human MDR1 drug transporter. Annu Rev Pharmacol Toxicol 2003;43:285-307.

12. Haufroid V, Mourad M, Van Kerckhove V, Wawrzyniak J, De Meyer M, Eddour DC, Malaise J, Lison D, Squifflet JP, Wallemacq P. The effect of CYP3A5 and MDR1 (ABCB1) polymorphisms on cyclosporine and tacrolimus dose requirements and trough blood levels in stable renal transplant patients. Pharmacogenetics 2004;14:147-54.

13. Haufroid V, Wallemacq P, Vankerckhove V, Elens L, De Meyer M, Eddour DC, Malaise J, Lison D, Mourad M. CYP3A5 and ABCB1 Polymorphisms and Tacrolimus Pharmacokinetics in Renal Transplant Candidates: Guidelines from an Experimental Study. Am J Transplant 2006;6:2706-13.

14. Mai I, Perloff ES, Bauer S, Goldammer M, Johne A, Filler G, Budde K, Roots I. MDR1 haplotypes derived from exons 21 and 26 do not affect the steady-state pharmacokinetics of tacrolimus in renal transplant patients. Br J Clin Pharmacol 2004;58:548-53.

15. Hesselink DA, van Schaik RH, van der Heiden IP, van der Werf M, Gregoor PJ, Lindemans J, Weimar W, van Gelder T. Genetic polymorphisms of the CYP3A4, CYP3A5, and MDR-1 genes and pharmacokinetics of the calcineurin inhibitors cyclosporine and tacrolimus. Clin Pharmacol Ther 2003;74:245-54.

16. Mourad M, Wallemacq P, De Meyer M, Brandt D, Van Kerkhove V, Malaise J, Chaib Eddour $D$, Lison D, Haufroid V. The influence of genetic polymorphisms of cytochrome P450 3A5 and $A B C B 1$ on starting dose- and weight-standardized tacrolimus trough concentrations after kidney transplantation in relation to renal function. Clin Chem Lab Med 2006;44:1192-8.

17. Roy JN, Barama A, Poirier C, Vinet B, Roger M. Cyp3A4, Cyp3A5, and MDR-1 genetic influences on tacrolimus pharmacokinetics in renal transplant recipients. Pharmacogenet Genomics 2006;16:659-65.

18. Tsuchiya N, Satoh S, Tada H, Li Z, Ohyama C, Sato K, Suzuki T, Habuchi T, Kato T. Influence of CYP3A5 and MDR1 (ABCB1) polymorphisms on the pharmacokinetics of tacrolimus in renal transplant recipients. Transplantation 2004;78:1182-7. 
19. Tada H, Tsuchiya N, Satoh S, Kagaya H, Li Z, Sato K, Miura M, Suzuki T, Kato T, Habuchi T. Impact of CYP3A5 and MDR1(ABCB1) C3435T polymorphisms on the pharmacokinetics of tacrolimus in renal transplant recipients. Transplant Proc 2005;37:1730-2.

20. MacPhee IA, Fredericks S, Tai T, Syrris P, Carter ND, Johnston A, Goldberg L, Holt DW. Tacrolimus pharmacogenetics: polymorphisms associated with expression of cytochrome p4503A5 and P-glycoprotein correlate with dose requirement. Transplantation 2002;74: 1486-9.

21. Asano $\mathrm{T}$, Nishimoto $\mathrm{K}$, Hayakawa $\mathrm{M}$. Increased tacrolimus trough levels in association with severe diarrhea, a case report. Transplant Proc 2004;36:2096-7.

22. Anglicheau D, Verstuyft $C$, Laurent-Puig $P$, Becquemont $L$, Schlageter $M H$, Cassinat $B$, Beaune $\mathrm{P}$, Legendre $\mathrm{C}$, Thervet $\mathrm{E}$. Association of the multidrug resistance-1 gene singlenucleotide polymorphisms with the tacrolimus dose requirements in renal transplant recipients. J Am Soc Nephrol 2003;14:1889-96.

23. MacPhee IA, Fredericks S, Mohamed M, Moreton M, Carter ND, Johnston A, Goldberg L, Holt DW. Tacrolimus pharmacogenetics: the CYP3A5*1 allele predicts low dose-normalized tacrolimus blood concentrations in whites and South Asians. Transplantation 2005;79: 499-502.

24. Zhao Y, Song M, Guan D, Bi S, Meng J, Li Q, Wang W. Genetic polymorphisms of CYP3A5 genes and concentration of the cyclosporine and tacrolimus. Transplant Proc 2005;37: $178-81$.

25. Zhang X, Liu ZH, Zheng JM, Chen ZH, Tang Z, Chen JS, Li LS. Influence of CYP3A5 and MDR1 polymorphisms on tacrolimus concentration in the early stage after renal transplantation. Clin Transplant 2005;19:638-43.

26. Dally H, Bartsch H, Jager B, Edler L, Schmezer P, Spiegelhalder B, Dienemann H, Drings $P$, Kayser K, Schulz V, Risch A. Genotype relationships in the CYP3A locus in Caucasians. Cancer Lett 2004;207:95-9.

27. Nauck M, Stein U, von Karger S, Marz W, Wieland H. Rapid detection of the C3435T polymorphism of multidrug resistance gene 1 using fluorogenic hybridization probes. Clin Chem 2000;46:1995-7.

28. von Ahsen N, Richter M, Grupp C, Ringe B, Oellerich M, Armstrong VW. No influence of the MDR-1 C3435T polymorphism or a CYP3A4 promoter polymorphism (CYP3A4-V allele) on dose-adjusted cyclosporin A trough concentrations or rejection incidence in stable renal transplant recipients. Clin Chem 2001;47:1048-52.

29. Arjomand-Nahad F, Diefenbach K, Landt O, Gaikovitch E, Roots I. Genotyping of the triallelic variant G2677T/A in MDR1 using LightCycler with locked-nucleic-acid-modified hybridization probes. Anal Biochem 2004;334:201-3.

30. Cheung CY, Op den Buijsch RA, Wong KM, Chan HW, Chau KF, Li CS, Leung KT, Kwan TH, de Vrie JE, Wijnen PA, van Dieijen-Visser MP, Bekers O. Influence of different allelic variants of the CYP3A and ABCB1 genes on the tacrolimus pharmacokinetic profile of Chinese renal transplant recipients. Pharmacogenomics 2006;7:563-74.

31. Sasieni PD. From genotypes to genes: doubling the sample size. Biometrics 1997;53: 1253-61.

32. Kuypers DR, Claes K, Evenepoel P, Maes B, Coosemans W, Pirenne J, Vanrenterghem Y. Time-related clinical determinants of long-term tacrolimus pharmacokinetics in combination therapy with mycophenolic acid and corticosteroids: a prospective study in one hundred de novo renal transplant recipients. Clin Pharmacokinet 2004;43:741-62.

33. Fredericks S, Moreton M, Reboux S, Carter ND, Goldberg L, Holt DW, MacPhee IA. Multidrug Resistance Gene-1 (MDR-1) Haplotypes Have a Minor Influence on Tacrolimus Dose Requirements. Transplantation 2006;82:705-8.

34. Sattler M, Guengerich FP, Yun CH, Christians U, Sewing KF. Cytochrome P-450 3A enzymes are responsible for biotransformation of FK506 and rapamycin in man and rat. Drug Metab Dispos 1992;20:753-61.

35. Karanam BV, Vincent SH, Newton DJ, Wang RW, Chiu SH. FK 506 metabolism in human liver microsomes: investigation of the involvement of cytochrome P450 isozymes other than CYP3A4. Drug Metab Dispos 1994;22:811-4. 
36. Vincent SH, Karanam BV, Painter SK, Chiu SH. In vitro metabolism of FK-506 in rat, rabbit, and human liver microsomes: identification of a major metabolite and of cytochrome P450 3A as the major enzymes responsible for its metabolism. Arch Biochem Biophys 1992;294: 454-60.

37. Lampen A, Christians U, Guengerich FP, Watkins PB, Kolars JC, Bader A, Gonschior AK, Dralle $\mathrm{H}$, Hackbarth I, Sewing KF. Metabolism of the immunosuppressant tacrolimus in the small intestine: cytochrome P450, drug interactions, and interindividual variability. Drug Metab Dispos 1995;23:1315-24. 



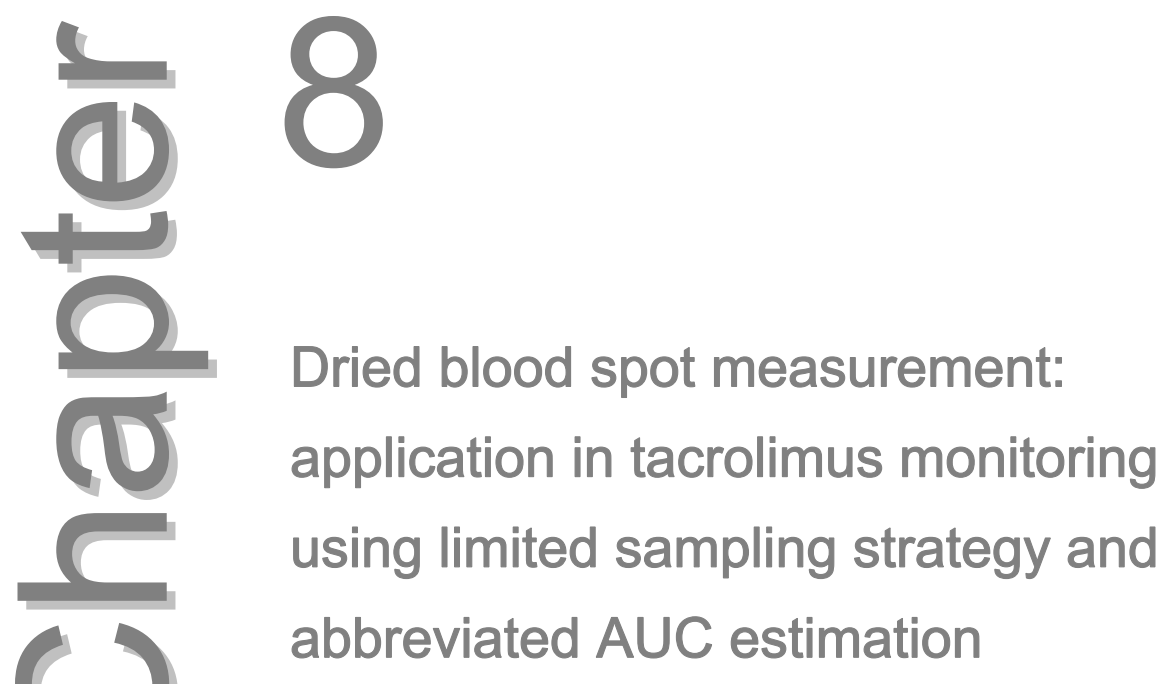

Chi Yuen Cheung, Jacques van der Heijden, Karin Hoogtanders, Maarten Christiaans, Yan Lun Liu, Yiu Han Chan, Koon Shing Choi, Afke van de Plas, Chi Chung Shek, Ka Foon Chau, Chun Sang Li, Johannes van Hooff, Leo Stolk

Transplant International 2008; 21:140-145. 


\section{Abstract}

Dried blood spot (DBS) sampling and high-performance liquid chromatography-tandem mass spectrometry (HPLC-MS), have been developed in monitoring tacrolimus levels. Our center favors the use of limited sampling strategy and abbreviated formula to estimate the $\mathrm{AUC}_{0-12}$. However, it is inconvenient for patients because they have to wait in the center for blood sampling. We investigated the application of DBS method in tacrolimus level monitoring using limited sampling strategy and abbreviated AUC estimation approach. Duplicate venous samples were obtained at each time point $\left(\mathrm{C}_{0}\right.$, $\mathrm{C}_{2}$ and $\mathrm{C}_{4}$ ). To determine the stability of blood samples, one venous sample was sent to our laboratory immediately. The other duplicate venous samples, together with simultaneous fingerprick blood samples, were sent to the University of Maastricht in the Netherlands. Thirty six patients were recruited and 108 sets of blood samples were collected. There was a highly significant relationship between $\mathrm{AUC}_{0-12}$ estimated from venous blood samples and fingerprick blood samples $\left(r^{2}=0.96, P<0.0001\right)$. Moreover, there was excellent correlation between whole blood venous tacrolimus levels in the two centers $\left(r^{2}=0.97 ; P<0.0001\right)$. The blood samples were stable after long distance transport. DBS sampling can be used in centers using limited sampling and abbreviated $\mathrm{AUC}_{0-12}$ strategy as drug monitoring. 


\section{Introduction}

Tacrolimus has a narrow therapeutic index with wide interpatient and intrapatient variation in pharmacokinetics ${ }^{1}$. As a result, therapeutic drug monitoring (TDM) is essential. TDM is usually performed using ethylenediamine tetraacetic acid (EDTA) anticoagulated blood, obtained by venous sampling by physicians, nurses or phlebotomists.

Dried blood spot sampling (DBS) is common for screening of metabolic disorders in newborns ${ }^{2}$. Moreover, its use in TDM has been reported for several drugs such as antimalarials and antiretrovirals ${ }^{3,4}$. Recently a method for measurement of tacrolimus level, based on DBS and high-performance liquid chromatography-tandem mass spectrometry (HPLC-MS), has been developed ${ }^{5}$. Preliminary results showed that DBS is promising for routine tacrolimus monitoring of stable renal transplant recipients ${ }^{6}$.

The gold standard of determining the drug exposure is the estimation of the area under concentration-time curve $\left(\mathrm{AUC}_{0-12}\right)$. $A \mathrm{UC}_{0-12}$ should be estimated from six or more concentration-time points. However, its routine clinical use is limited by the need for multiple blood sampling. Patients need to stay in centers for long time and it is also inconvenient to the clinical staff. Majority of the published data use whole blood trough level $\left(\mathrm{C}_{0}\right)$ for dose monitoring and titration of tacrolimus therapy. It has been shown that $\mathrm{C}_{0}$ has a poor correlation with $\mathrm{AUC}_{0-12}{ }^{7-8}$. Our center favors the use of limited sampling strategy and abbreviated formula to estimate the $\mathrm{AUC}_{0-12}$, which allows better prediction of drug exposure ${ }^{9}$. However, it is inconvenient for the patients because they have to stay in the center for at least two hours waiting for blood sampling. Moreover, blood sampling in center may involve a long journey and absence from work duty. The potential advantage of DBS is that the patients can stay at home. They can obtain capillary blood themselves with an automatic lancet and the drop of blood is applied to sampling paper. After drying, the paper with the blood spot sample is sent by mail to the laboratory for analysis.

This is a collaborative study with the Department of Clinical Pharmacy, University of Maastricht in the Netherlands. In this study, we investigated the application of DBS method in tacrolimus level monitoring using limited sampling strategy and abbreviated $\mathrm{AUC}_{0-12}$ estimation approach. Moreover, we also studied the stability of blood samples after storage and long distance transport.

\section{Methods}

The study was approved by the ethical committee. Stable kidney transplant recipients who received tacrolimus-based immunosuppressive therapy and had follow up in Queen Elizabeth Hospital, Hong Kong were recruited in the study. 
Written consent was obtained from each patient. Blood samples for the measurement of whole blood tacrolimus levels were collected. Limited sampling strategy and abbreviated AUC0-12 estimation were used in our center for tacrolimus monitoring. Calculation of tacrolimus AUC0-12 was by the formula: $16.2+\mathrm{C} 2$ * $2.4+\mathrm{C} 4$ * 5.9 [C2: 2-h postdose tacrolimus level; C4: 4-h postdose tacrolimus level]9. Based on our previous pilot study in stable patients on tacrolimus, AUC0-12 value was kept at around 100-150 $\mathrm{ng} \times \mathrm{h} / \mathrm{ml}$ in first three months and around $80-100 \mathrm{ng} \times \mathrm{h} / \mathrm{ml}$ after three months. Some centers also found very high coefficients of correlation between 3 time-point strategy and the complete AUC0-12 9-13. The regression equation using 3 time-point derived in our group was: $13.3+1.2 \times \mathrm{C} 0+2.4 \times \mathrm{C} 2+5.6 \times \mathrm{C} 49$. Thus C0 was also obtained in this study.

For each patient, duplicate venous samples were obtained at each time point $\left(\mathrm{C}_{0}, \mathrm{C}_{2}\right.$ and $\left.\mathrm{C}_{4}\right)$. To determine the stability of blood samples after long distance transport, one venous sample was sent to our laboratory immediately for measurement of whole blood tacrolimus level using HPLC-MS ${ }^{14}$. The other duplicate venous samples, together with simultaneous drawn fingerprick blood samples, were sent to the Department of Clinical Pharmacy, University of Maastricht in the Netherlands for measurement of tacrolimus levels by HPLC$\mathrm{MS}^{5}$.

Fingerprick blood samples were collected using spring-loaded lancets and collected from the fingertip. The first drop was discarded and the next drop collected to fill an 8-mm pre-marked circle on the sampling paper (no. 10,535,097, obtained from Whatman Schleicher \& Schuell, Dassel, Germany). The procedure was performed by the patients. Volume of the blood drops was approximately $30 \mathrm{ul}$ and blood spots of about 9-10-mm diameter were produced. The blood spots were allowed to dry at room temperature for three hours and packed in sealable plastic minibags. The samples were then stored at room temperature and sent to the laboratory in University of Maastricht by airmail. The transit time from Hong Kong to Maastricht was approximately 24 hours. On arrival in the laboratory, the blood spots were inspected. Requirements are complete, homogenous, and symmetric filling of the 8-mm circle and dark-red color on both sides of the paper. Paper disks with a diameter of $7.5 \mathrm{~mm}$ were punched out with an electromagnetic driven hole puncher. DBS sampling and assay were compared with venous sampling and our routine assay in venous blood.

\section{Statistical analysis}

MedCalc statistical package (MedCalc Software, Mariakerke, Belgium) was used for data analysis. Data was expressed as mean $+/$ - standard deviation or median (range) where appropriate. Whole blood tacrolimus levels and 
estimated abbreviated AUC from different assays were compared using linear regression analyses. Passing-Bablok regression analysis and the Bland-Altman method were also used ${ }^{15,16}$. A $P$-value of less than 0.05 was considered to be statistically significant.

\section{Results}

Thirty six patients were recruited in this study and 108 sets of blood samples were collected $\left(\mathrm{C}_{0}, \mathrm{C}_{2}\right.$ and $\mathrm{C}_{4}$ for each patient). The mean age of patients was 46.8 +/- 8.6 (range 29.8-62.6) years. All patients had isolated kidney transplantation. The median interval between transplant and blood sampling was 38 months (range: two months to ten years). The duration of storage of DBS samples before analysis was $40+/-14$ (range: 16-78) days.

Fingerprick sampling was well tolerated and accepted by the patients. None of the patient complained of serious discomfort. They found the sampling easy to perform. Of the 108 fingerprick samples collected, only two samples were unsuitable for analysis due to the incomplete filling of the pre-drawn circle. No samples were lost during delivery.

\section{Comparison of venous HPLC-MS (Hong Kong) tacrolimus levels with venous HPLC-MS (Netherlands) tacrolimus levels ( $n=106)$}

Linear regression analysis showed a highly significant relationship between venous blood tacrolimus levels using HPLC-MS (Netherlands) and venous blood tacrolimus levels using HPLC-MS (Hong Kong) $\left(r^{2}=0.97, P<0.0001\right)$.

The Passing-Bablok regression equation was: Venous tacrolimus levels (Netherlands) $(\mathrm{ug} / \mathrm{l})=1.06(95 \% \mathrm{Cl} 1.03$ to 1.09$) *$ Venous tacrolimus levels (Hong Kong) (ug/l) $-0.33(95 \% \mathrm{Cl}-0.59$ to -0.06$)$. There is a small but significant difference from the line of identity. A Bland-Altman analysis showed that venous tacrolimus levels (Netherlands) tends to be higher than the venous tacrolimus levels (Hong Kong) and the mean difference was $1 \%$ of mean tacrolimus levels. The $95 \%$ limits of agreement were $19.2 \%$ to $-17.3 \%$.

\section{Comparison of fingerprick HPLC-MS tacrolimus levels with venous HPLC-MS (Netherlands) tacrolimus levels ( $n=106)$}

Linear regression analysis showed a highly significant relationship between venous blood tacrolimus levels using HPLC-MS (Netherlands) and fingerprick blood samples $\left(r^{2}=0.96, p<0.0001\right)$ (Figure 8.1).

The Passing-Bablok regression equation was: Venous tacrolimus levels (Netherlands) $(\mathrm{ug} / \mathrm{l})=0.95(95 \% \mathrm{Cl} 0.89$ to 1.00$){ }^{*}$ Fingerprick tacrolimus levels $(\mathrm{ug} / \mathrm{l})-0.39(95 \% \mathrm{Cl}-0.83$ to 0.04$)$. There is no significant difference from the 
line of identity. A Bland-Altman analysis showed that fingerprick tacrolimus levels tends to be slightly higher than the venous tacrolimus levels and the mean difference was $11 \%$ of the mean tacrolimus levels. The $95 \%$ limits of agreement were $36.1 \%$ to $-14.1 \%$ (Figure 8.2 ).

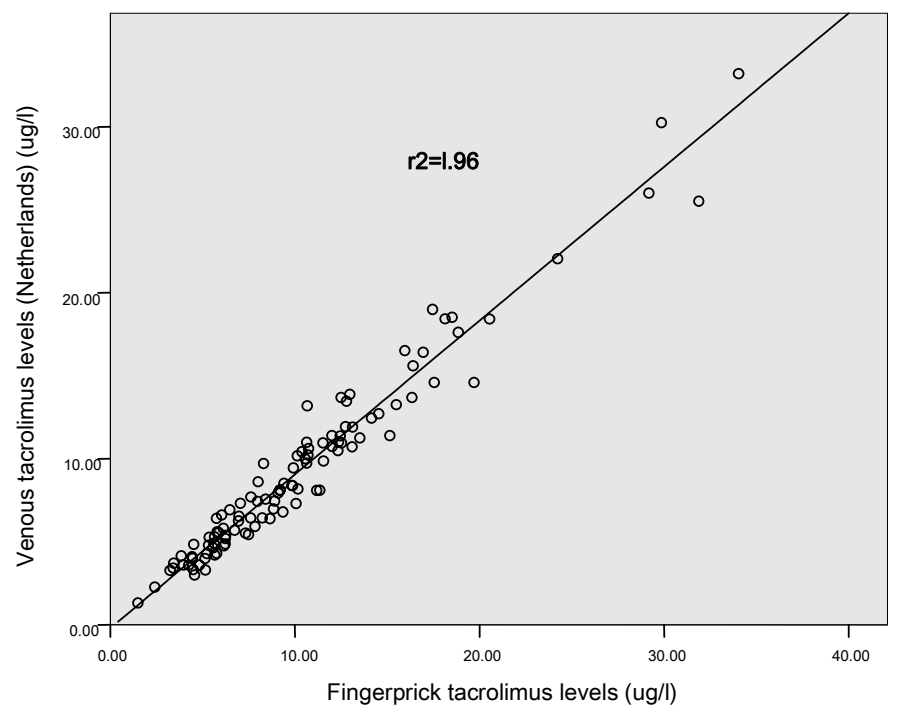

Figure 8.1 Linear regression analysis: Fingerprick tacrolimus level versus venous blood tacrolimus level measured in the same center

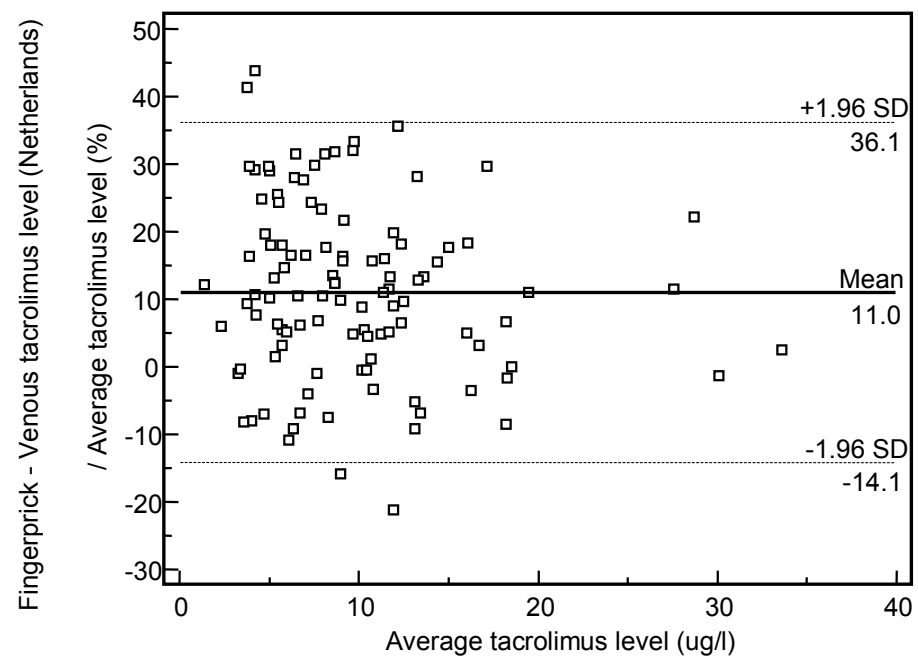

Figure 8.2 Bland Altman analysis of the difference (\% of average) between fingerprick tacrolimus level and venous blood tacrolimus level measured in the same center. 


\section{Comparison of fingerprick HPLC-MS tacrolimus $\mathrm{AUC}_{0-12}$ with venous HPLC-MS (Netherlands) tacrolimus $\mathrm{AUC}_{0-12}: 2$ time-point sampling strategy $(n=36)$}

Linear regression analysis showed a highly significant relationship between $\mathrm{AUC}_{0-12}$ estimated from venous blood samples using HPLC-MS (Netherlands) and fingerprick blood samples $\left(r^{2}=0.96, P<0.0001\right)$ (Figure 8.3).

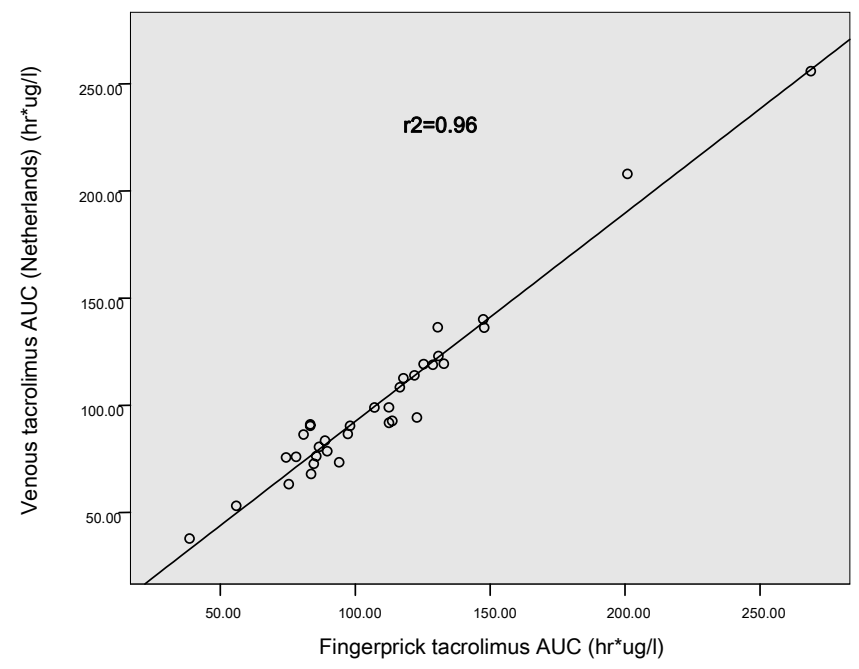

Figure 8.3 Linear regression analysis: Fingerprick tacrolimus $\mathrm{AUC}_{0-12}$ versus venous blood tacrolimus $\mathrm{AUC}_{0-12}$ using 2 time-point strategy measured in the same center.

The Passing-Bablok regression equation was: Venous tacrolimus $\mathrm{AUC}_{0-12}$ (Netherlands) $\left(\mathrm{hr}{ }^{*} \mathrm{ug} / \mathrm{l}\right)=0.98(95 \% \mathrm{Cl} 0.90$ to 1.08$){ }^{*}$ Fingerprick tacrolimus $\mathrm{AUC}_{0-12}\left(\mathrm{hr}{ }^{*} \mathrm{ug} / \mathrm{l}\right)-5.93(95 \% \mathrm{Cl}-17.33$ to 2.98$)$. There is no significant difference from the line of identity. A Bland-Altman analysis showed that fingerprick tacrolimus $A \cup C_{0-12}$ tends to be higher than the venous tacrolimus $A \cup C_{0-12}$ and the mean difference was $7.8 \%$ of mean tacrolimus $A U_{0-12}$. The $95 \%$ limits of agreement were $25.1 \%$ to $-9.4 \%$ (Figure 8.4 ). 


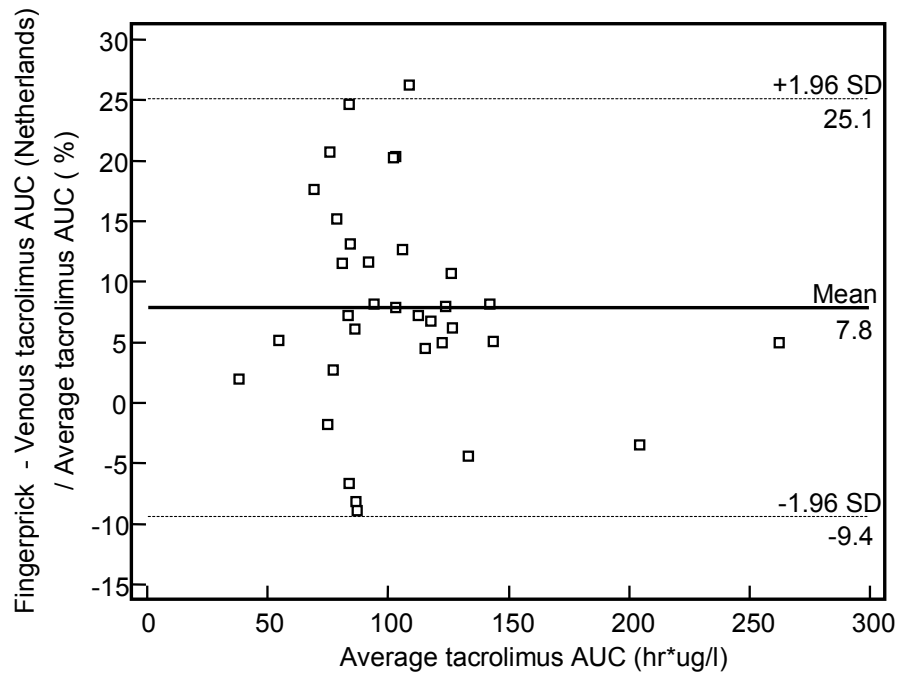

Figure 8.4 Bland Altman analysis of the difference (\% of average) between fingerprick tacrolimus $A \cup C_{0-12}$ and venous blood tacrolimus $A \cup C_{0-12}$ measured in the same center.

\section{Comparison of fingerprick HPLC-MS tacrolimus $\mathrm{AUC}_{0-12}$ with venous HPLC-MS (Netherlands) tacrolimus $\mathrm{AUC}_{0-12}: 3$ time-point sampling strategy $(n=36)$}

Linear regression analysis showed a highly significant relationship between $\mathrm{AUC}_{0-12}$ estimated from venous blood samples using HPLC-MS (Netherlands) and fingerprick blood samples $\left(r^{2}=0.96, P<0.0001\right)$.

The Passing-Bablok regression equation was: Venous tacrolimus $\mathrm{AUC}_{0-12}$ (Netherlands) $(\mathrm{hr} u \mathrm{ug} / \mathrm{l})=0.97(95 \% \mathrm{Cl} 0.90$ to 1.06$)$ * Fingerprick tacrolimus $\mathrm{AUC}_{0-12}\left(\mathrm{hr}^{*} \mathrm{ug} / \mathrm{l}\right)-5.24(95 \% \mathrm{Cl}-15.99$ to 2.97$)$. There is no significant difference from the line of identity. A Bland-Altman analysis showed that fingerprick tacrolimus $A \cup C_{0-12}$ tends to be higher than the venous tacrolimus $\mathrm{AUC}_{0-12}$ and the mean difference was $8.3 \%$ of mean tacrolimus $\mathrm{AUC}_{0-12}$. The $95 \%$ limits of agreement were $25.7 \%$ to $-9 \%$. 


\section{Discussion}

This study has shown that the tacrolimus levels measured from fingerprick blood samples using HPLC-MS has an excellent correlation with those obtained from venous blood sampling using the same method in the same center $\left(r^{2}=0.96 ; P<0.0001\right)$. The difference between them is small $(11 \%$ of the mean tacrolimus level). It is of limited clinical significance in view of the relatively wide range of target tacrolimus level used in most centers.

Our group has validated the use of limited sampling strategy $\left(\mathrm{C}_{2}\right.$ and $\left.\mathrm{C}_{4}\right)$ and abbreviated formula to estimate the $\mathrm{AUC}_{0-12}$ which allows better prediction of drug exposure. In this study, we found that the $\mathrm{AUC}_{0-12}$ estimated from fingerprick samples had a high correlation with those estimated from venous blood sampling using same method in the same center $\left(r^{2}=0.96 ; P<0.0001\right)$. Moreover, the mean difference between the two methods was $7.8 \%$ of mean tacrolimus levels. This difference is of limited clinical significance. Similar results were also found when 3 time-point sampling strategy was used for estimating abbreviated $\mathrm{AUC}_{0-12}$.

We found that there was excellent correlation between whole blood venous tacrolimus levels using HPLC-MS in the two centers $\left(r^{2}=0.97 ; P<0.0001\right)$. The mean difference between the venous tacrolimus levels measured in the two centers was $1 \%$ only. The assay was reproducible and the blood samples remained stable after storage and long distance journey.

Our results demonstrate that it is justifiable to use dried blood spot sampling as an alternative for conventional venous sampling. We have shown that selfadministered fingerprick blood sampling for tacrolimus levels is practical to implement. It is highly convenient for patients, especially those who have follow up in transplant centers where limited sampling strategy is used for drug monitoring.

In conclusion, there was no significant difference between the abbreviated $\mathrm{AUC}_{0-12}$ estimated from venous blood samples and fingerprick blood samples. The blood samples were stable after storage and long distance transport. 


\section{References}

1. Staatz CE, Tett SE. Clinical pharmacokinetics and pharmacodynamics of tacrolimus in solid organ transplantation. Clin Pharmacokinet 2004;43:623-53.

2. Chace DH, Kalas TA, Naylor EW. Use of tandem mass spectrometry for multianalyte screening of dried blood specimens from newborns. Clin Chem 2003;49:1797-817.

3. Malm M, Lindegardh N, Bergquist $\mathrm{Y}$. Automated solid-phase extraction method for the determination of piperaquine in capillary blood applied onto sampling paper by liquid chromatography. J Chromatogr B Analyt Technol Biomed Life Sci 2004;809:43-9.

4. Koal T, Burhenne H, Romling R, et al. Quantification of antiretroviral drugs in dried blood spot samples by means of liquid chromatography/tandem mass spectrometry. Rapid Commun Mass Spectrom 2005;19:2995-3001.

5. Hoogtanders K, van der Heijden J, Christiaans M, Edelbroek P, van Hooff JP, Stolk LM.. Therapeutic drug monitoring of tacrolimus with the dried blood spot method. J Pharm Biomed Anal 2007;44:658-64.

6. Hoogtanders K, van der Heijden J, Christiaans M, van de Plas A, van Hooff J, Stolk L. Dried blood spot measurement of tacrolimus is promising for patient monitoring. Transplantation 2007;83:237-8.

7. Stolk L, Van Duijnhoven EM, Christiaans MHL, van Hooff JP. Trough levels of tacrolimus (discussion). Therapeutic Drug Monitoring 2002;24:573-4.

8. Pisitkun T, Elam-Ong S, Chusil S, Praditpornsilpa K, Pansin P, Tungsanga K. The roles of C4 and AUC $0-4$ in monitoring of tacrolimus in stable kidney transplant patients. Transplant Proc 2002;34:3173-5.

9. Wong KM, Shek CC, Chau KF, Li CS. Abbreviated tacrolimus area-under-the-curve monitoring for renal transplant recipients. Am J kidney Dis 2000;35:660-6.

10. Aumente Rubio MD, Arizón del Prado JM, López Malo de Molina MD, Cárdenas Aranzana M, Segura Saint-Gerons J, López Granados A, Rodriguez Esteban E, Mesa Rubio D, Romo Peñas E, Segura Saint-Gerons C. Clinical pharmacokinetics of tacrolimus in heart transplantation: new strategies of monitoring. Transplant Proc 2003;35:1988-91.

11. Scholten EM, Cremers SC, Schoemaker RC, Rowshani AT, van Kan EJ, den Hartigh J, Paul LC, de Fijter JW. AUC-guided dosing of tacrolimus prevents progressive systemic overexposure in renal transplant recipients. Kidney Int 2005;67:2440-7.

12. Pisitkun T, Eiam-Ong S, Chusil S, Praditpornsilpa K, Pansin P, Tungsanga $K$. The roles of $C 4$ and AUCO-4 in monitoring of tacrolimus in stable kidney transplant patients. Transplant Proc 2002;34:3173-5.

13. Ragette R, Kamler M, Weinreich G, Teschler H, Jakob H. Tacrolimus pharmacokinetics in lung transplantation: new strategies for monitoring. J Heart Lung Transplant 2005;24:1315-9.

14. Chan YH, Ho CS, Shek CC, Wong KM, Chak WL, Choi KS, Chau KF, Chau KF, Li CS. Measurement of whole blood tacrolimus level by high performance liquid chromatography tandem mass spectrometry in renal transplant recipients-a single center perspective. Hong Kong J Nephrol 2005;7:65-9.

15. Passing $\mathrm{H}$, Bablok $\mathrm{W}$. A new biometrical procedure for testing the equality of measurements from two different analytical methods. Application of linear regression procedures for method comparison studies in clinical chemistry, Part I. J Clin Chem Clin Biochem 1983;21:709-20.

16. Bland JM, Altman JG. Statistical methods for assessing agreement between two methods of clinical measurement. Lancet 1986;1:307-10. 


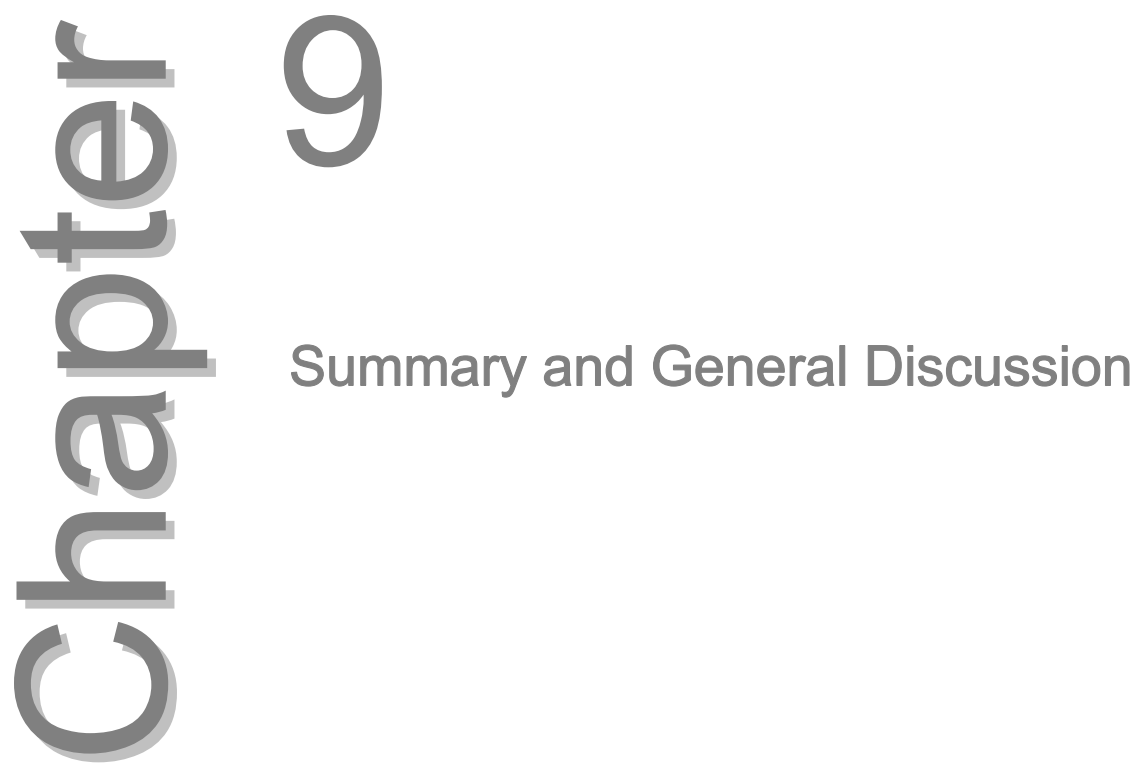


Many studies have issued differences in clinical outcome of renal transplantation between recipients treated by cyclosporine versus tacrolimus. However, firm data about these items in a Chinese population is lacking. Moreover, although many randomized controlled trials comparing cyclosporine versus tacrolimus in de novo renal transplant recipients have been performed, none of these studies have compared the allocation of the treatment groups for paired kidneys, i.e. randomization of both kidneys of the same donor over the two treatment arms. In this thesis some of these questions are addressed.

\section{Efficacy}

A recent meta-analysis comparing the efficacy of tacrolimus and cyclosporine in renal transplant recipients ${ }^{1}$ showed a significant lower rate of graft loss at six months (odds ratio 0.56, 95\% confidence interval $0.36-0.86$ ) in tacrolimustreated patients, and this effect persisted up to three years. Moreover, there was a lower acute rejection rate (odds ratio $0.69,95 \%$ confidence interval $0.60-0.79$ ) and steroid resistant rejection rate (odds ratio $0.49,95 \%$ confidence interval 0.37-0.64) in tacrolimus-treated recipients at one year. The ELITESymphony trial, a large randomized controlled trial comparing low-dose tacrolimus (target trough level 3-7 ng/ml) with standard-dose cyclosporine (target trough level 150-300 ng/ml for three months, 100-200 ng/ml thereafter), low-dose cyclosporine (target trough level 50-100 $\mathrm{ng} / \mathrm{ml}$ ) and low-dose sirolimus (target trough level $4-8 \mathrm{ng} / \mathrm{ml}$ ), was published in $2007^{2}$. In this trial, patients randomized towards the low-dose tacrolimus group had a significant better graft survival (odds ratio for graft failure 0.54) and lower acute rejection rate (odds ratio 0.48) compared to the other treatment groups. However, only a small proportion of the patients in the meta-analysis were from Chinese/Asian descent ${ }^{1}$. There was even no Asian center participated in the ELITE-Symphony trial $^{2}$. Therefore, it remains unclear whether the improvement in efficacy of tacrolimus over cyclosporine is also present in Chinese renal transplant population.

As shown in Chapter 2, we performed a paired kidney study in 66 Chinese deceased renal transplant recipients who were randomized towards tacrolimusor cyclosporine- based immunosuppressive therapy. The odds ratio for acute rejection was 0.55 in tacrolimus-treated recipients. However, the difference in acute rejection rate between both treatment groups was not statistically significant. This was probably due to the small number of patients included and an overall modest rejection rate $(21 \%)$ which was numerically comparable to the meta-analysis ${ }^{1}$. In an extension study (not yet published) involving 76 recipients with a mean follow-up of more than six years, the difference in acute rejection rate became statistically significant (tacrolimus $18.4 \%$ versus 
cyclosporine $42.1 \%$ ). Because of the small number of patients included in our trial, no difference in graft survival could be expected.

Using paired kidney design in our study can allow us to exclude the donorrelated bias and investigate the relative impact of tacrolimus and cyclosporine more directly. Moreover, in order to assure optimal drug exposure, abbreviated AUC approach was employed for therapeutic drug monitoring of both cyclosporine and tacrolimus in our center. Although many centers prefer the concept of $\mathrm{C} 2$ monitoring for cyclosporine microemulsion nowadays, its ability to improve efficacy is still not generally accepted ${ }^{3}$. A summary of the relative efficacy of tacrolimus- and cyclosporine micro-emulsion-based immunosuppression on rejection and graft survival is shown in Table 9.1.

Table 9.1 Comparison of the efficacy of tacrolimus-based immunosuppression versus cyclosporine-microemulsion-based immunosuppression.

\begin{tabular}{lcc}
\hline & Tacrolimus & Cyclosporine microemulsion \\
\hline Acute rejection & $\downarrow$ & \\
Steroid-resistant rejection & $\downarrow$ & \\
Recurrent rejection & $\downarrow$ & \\
Rescue of CNI-resistant acute rejection & + & - \\
Graft survival at 5 years & $\uparrow$ & \\
\hline
\end{tabular}

$\mathrm{CNI}=$ calcineurin inhibitor

\section{Renal function}

Differences between cyclosporine and tacrolimus in renal function have been summarized recently ${ }^{4}$. An overview of the main statements are given in Chapter 1 Table 1.4.

Kaplan et al. performed an analysis on a database with patients who received paired kidneys from the same donor, and were treated by either cyclosporine or tacrolimus upon discharge ${ }^{5}$. Serum creatinine was significantly lower in the tacrolimus group. However, there are few drawbacks in this study. First of all, it is not a randomized controlled trial. Moreover, patients were not treated according to fixed criteria and that it is not known if the patients were kept on the drugs they received upon discharge.

In chapter 2, we also investigated the difference in renal function between paired kidneys from the same donor, of which one kidney was transplanted in a patient receiving cyclosporine and the other in a patient receiving tacrolimus in the same center. Donor and center bias can be excluded and differences in renal function can be attributed directly towards the immunosuppressive drugs. Dosage of both drugs was adjusted according to the estimated abbreviated 
$\mathrm{AUC}_{0-12}$. Patients treated with tacrolimus had a significant better creatinine clearance from 6-month after transplant onward and a lesser decline in creatinine clearance. An extension of this study showed that the improved creatinine clearance was sustained up to 6-year follow-up. The results could be explained by the lower nephrotoxicity of tacrolimus and/or less efficacy of cyclosporine in the suppression of the immune response, resulting in more (subclinical) rejection, eventually leading towards chronic allograft dysfunction. The superiority of low-dose tacrolimus in maintaining renal function after kidney transplant was also confirmed in a recently published ELITE-Symphony Study ${ }^{2}$. It has been shown that patients receiving the tacrolimus regimen had the highest GFR at 12-month follow-up.

\section{Interleukin-2 receptor antagonist}

Several multicenter, randomized, placebo-controlled studies have consistently demonstrated that in combination with cyclosporine, the interleukin-2 (IL-2) receptor antagonists (basiliximab or daclizumab) could result in a significant $30-40 \%$ reduction in the incidence of biopsy-proven acute rejection ${ }^{6-10}$. On the other hand, randomized comparative studies of IL-2 receptor antagonists induction versus no induction in patients receiving tacrolimus-based immunosuppression are lacking. As a result, a single center prospective study to investigate the efficacy and safety of adding daclizumab to a tacrolimusazathioprine-prednisolone-based therapy in Chinese first deceased renal transplant recipients was performed (Chapter 3 ). In this immunological low-risk renal transplant population, the incidence of acute rejection was $19 \%$ in the standard group versus $11 \%$ in the daclizumab group ( $P=0.37$ ).

Although IL-2 receptor antagonists are widely applied in tacrolimus-based immunosuppression, few data support the use of IL-2 receptor antagonists in immunological low-risk renal transplant recipients. Considering some of the largest clinical trials using tacrolimus-based immunosuppressive therapy, the biopsy-proven acute rejection rate shown in the control arm (tacrolimus, mycophenolate mofetil and corticosteroids) in the Zenapax trial (364 patients) ${ }^{11}$ and the Carmen study (538 patients) $)^{12}$ was $12 \%$ and $16.5 \%$ respectively, which is comparable to the $12 \%$ acute rejection rate in the ELITE-Symphony trial (401 patients on tacrolimus, mycophenolate mofetil, corticosteroids, and daclizumab) ${ }^{2}$. The additional benefit of adding IL-2 receptor antagonists to these regimens seems to be limited. 


\section{Hyperglycemia after transplantation}

The incidence of post-transplant hyperglycemia differs considerably, mainly depending on the definition used and the ethnicity of the study population. Interpretation is often hampered by the fact that many patients have a period of transient hyperglycemia in the early phase after transplantation.

Nowadays use of criteria of the American Diabetes Association (ADA)/World Health Organization (WHO) has been advocated ${ }^{13}$. The detection of "prediabetic state" (impaired fasting glucose (IFG) and/or impaired glucose tolerance (IGT)) is also important, because of the increased risk of development of diabetes and cardiovascular risks ${ }^{14}$. Fasting glucose is commonly used in clinical setting for diagnosis of diabetes when compared to Oral Glucose Tolerance Test (OGTT) because of its simplicity. However, it is less sensitive and specific than an OGTT in diagnosis ${ }^{15,16}$. Armstrong KA et al. have shown that the prevalence of post- transplant diabetes mellitus (PTDM) is much higher with OGTT and fasting blood glucose alone will miss $65 \%$ of patients with diabetes in renal transplant recipients ${ }^{17}$. Moreover, fasting glucose alone will also ignore the diagnosis of IGT. IGT itself can only be diagnosed with OGTT and has been shown to have a great correlation with diabetes and cardiovascular risks ${ }^{18,19}$. Clinical trials seldom included OGTT to determine the exact incidence of glycemic abnormality in kidney transplant recipients.

Recently, a randomized trial designed by Vincenti et al. was published. Both tacrolimus and cyclosporine were compared with PTDM or IFG within first six months post-transplant as primary end-point ${ }^{20}$. The difference in incidence and severity of abnormal glucose metabolism (AGM) between the tacrolimus and cyclosporine were confirmed. However, there was a high frequency of AGM in both arms (33.6\% in tacrolimus group versus $26 \%$ in cyclosporine group). This might be related to the lack of standardization of steroid dosages in the trial. On the basis of the knowledge of the pathophysiology of AGM, one could have predicted that the incidence of AGM will be high and more patients on tacrolimus than on cyclosporine will develop AGM in clinical setting with high dosages of steroids. Moreover, WHO/ADA criteria were applied at three and six months without defining the dosage of steroids and levels of tacrolimus at these time points in the study. Given the considerable effect of steroids and tacrolimus on insulin resistance and insulin secretion respectively, use of WHO/ADA criteria gives clinical useful information only when applied in a controlled setting such as in the maintenance phase without infection or rejection, and with stable defined low dosages of steroids and tacrolimus levels ${ }^{21}$. In Chapter 4, we estimated the prevalence of AGM (PTDM + IFG + IGT) in a cross sectional study by using ADA criteria. The overall prevalence of AGM was $31.9 \%$ (38\% in tacrolimus treated patients and $27 \%$ in cyclosporine treated patients). Although numerically different, this difference was not 
statistically significant between the tacrolimus- and cyclosporine-treated groups. Limited sampling strategy and abbreviated AUC was used for drug monitoring and titration in our center. The target abbreviated $\mathrm{AUC}_{0-12}$ for tacrolimus was around $80-100 \mathrm{ng} \times \mathrm{h} / \mathrm{ml}$ after three months, corresponding a tacrolimus trough level at around $6 \mathrm{ng} / \mathrm{ml}$. As has been shown by van Duijnhoven et al., decreasing the tacrolimus trough level from 9.5 to $6.4 \mathrm{ng} / \mathrm{ml}$ improves insulin secretion with $\pm 30 \%{ }^{22}$. Another study also confirmed that the impairment in insulin secretion could be predicted by a tacrolimus trough level $\geq 10.8 \mathrm{ng} / \mathrm{ml}$, corresponding to an $\mathrm{AUC}_{0-12} \geq 200 \mathrm{ng} \times \mathrm{h} / \mathrm{ml}$. As a result, maintaining a low tacrolimus trough level may diminish the development of impaired glucose metabolism ${ }^{23}$. On the other hand, the overall high prevalence of AGM is probably related to the use of maintenance steroids $(7.5 \mathrm{mg})$ in all of our patients. Steroids have a very strong effect on glucose metabolism, e.g. to maintain normoglycemia in a patient using $10 \mathrm{mg}$ of prednisolone, insulin output has to be increased by $250 \%{ }^{24}$.

There are many other differences between tacrolimus and cyclosporine. It is well established that tacrolimus-treated patients have a better cardiovascular risk profile due to lower lipids and lower blood pressure ${ }^{25,26}$ and that the renal function is better preserved in tacrolimus-treated patients (as discussed above). It is unknown whether these positive effects are offset by the increased incidence of AGM.

Hyperglycemia after transplantation is most probably a symptom of an underlying metabolic syndrome uncovered by immunosuppression. High risk patients for AGM should be given OGTT before transplantation ${ }^{21}$. Patients identified as high-risk group may benefit from pre-transplant lifestyle intervention such as exercise training and reducing obesity. Only by using tacrolimus in combination with steroids will more patients develop AGM than with other agents in combination with steroids. Two large European randomized trials showed that steroid avoidance is possible in a tacrolimusbased immunosuppressive regimen, with a low incidence of PTDM ${ }^{11,12}$. In low risk patients, tacrolimus has benefits over cyclosporine in terms of better cardiovascular risk profile and better preservation of renal function. For high risk patients, there are two main options: steroid-free tacrolimus-based (with an unproven increased chance of worse long-term graft survival) or steroid + cyclosporine-based (with the proven increased cardiovascular risk profile and worse preservation of renal function $)^{27}$. 


\section{Metabolic syndrome}

In the general population, the prevalence of metabolic syndrome (MS) differs widely among ethnic groups and depends according to the definition of MS used $^{28-30}$. de Vries et al. applied the consensus definition (NCEP-ATPIII) of MS to the kidney transplant population in the Netherlands and reported that $63 \%$ of Caucasian renal transplant patients had $\mathrm{MS}^{31}$. Porrini et al. reported that $37.7 \%$ of Spanish renal transplantation recipients had MS by the modified NCEP criteria $^{32}$ while Armstrong et al. reported that $50 \%$ of Australian renal transplant recipients had MS by the original NCEP criteria $^{33}$. All these reports of Caucasian renal transplant recipients suggested that MS is more prevalent in renal transplant recipients compared with the general population. On the other hand, it was demonstrated that there was only a slight difference in the prevalence of MS between the general population and renal transplant patients in $\operatorname{Japan}^{34}$. This discrepancy may be related to the difference in lifestyle, eating habits, or the prevalence and degree of obesity between Japanese and Caucasian populations. In Chapter 5, we showed that MS was more prevalent in our Chinese renal transplant recipients when compared with the general population as shown in the literature ${ }^{35,36}$.

In our study, body mass index and waist circumference of the MS group were significantly greater than those of the non-MS group. Similar to the general population, overweight is a major clinical feature of $\mathrm{MS}$ in renal transplant recipients. Weight gain after renal transplantation has particularly been linked with physical inactivity ${ }^{37}$. Insulin resistance is the central pathophysiological feature underlying $\mathrm{MS}^{38}$. In renal transplant recipients, factors other than obesity, especially the use of corticosteroids, may contribute to an increase in insulin resistance. Moreover, chronic corticosteroid use, will induce the accumulation of truncal fat ${ }^{39}$. This process will also amplify MS. As a result, steroid-withdrawal/avoidance will counteract the development of MS.

In Chapter 5, we showed that PTDM was more prevalent in the MS group, which was consistent with the previous report by Porrini et al. ${ }^{32}$. They showed that MS was a prominent risk factor for PTDM in their longitudinal study. Obesity and dyslipidaemia, which are components of MS, are associated with insulin resistance, one of the most important causative elements in the physiopathological process of type 2 diabetes ${ }^{40,41}$.

It has been reported that MS is a risk factor for renal dysfunction in the general population ${ }^{42,43}$. In heart transplantation, Valantine et al. suggested that a 'metabolic milieu' may modify the process of chronic transplant dysfunction. ${ }^{44}$ De Vries et al. ${ }^{31}$ and Porrini ${ }^{32}$ suggested that the presence of MS is associated with impaired renal allograft function in renal transplantation recipients in longitudinal studies. Different possible mechanisms have been proposed for the association between MS and impaired renal function. Obesity can 
contribute to renal dysfunction in many ways: excess excretory load, renal sodium retention, hyperinsulinaemia, insulin resistance, or renal lipotoxicity ${ }^{45-48}$. Moreover, obesity is associated with worsening of proteinuria in renal transplant recipients ${ }^{33}$. Glucose intolerance, hypertension and dyslipidaemia, components of MS, can directly damage the kidneys through renal or systemic atherosclerosis ${ }^{49-52}$.

Apart from renal allograft dysfunction, $M S$ is also associated with atherosclerotic events ${ }^{53}$. Factors contributing to MS are closely interconnected and define a very high-risk population for atherosclerotic events. Clustering of both traditional and non-traditional risk factors in renal transplant recipients with MS contribute to the greater incidence of atherosclerotic events in this population. Cardiovascular mortality is the most important cause of graft loss in addition to renal graft dysfunction. It is therefore conceivable that people with the highest susceptibility to consequences of MS were already deceased before the start of this cross-sectional study. As a result, the study may have suffered from a healthy survivor bias. Further longitudinal and intervention studies are needed to assess the full impact of the metabolic syndrome on long-term renal allograft loss and atherosclerotic events in our Chinese renal transplant recipients. Moreover, physical activity levels in renal transplant recipients remain low, even after succesful transplantation and are therefore an important cause of increase in weight gain. Exercise capacity and muscle strength in renal transplant recipients are significantly lower compared to healthy controls and comparable to patients undergoing hemodialysis ${ }^{54}$. These findings underscore the importance of exercise training and increasing physical activity levels in renal transplant recipients.

\section{Pharmacogenetics}

Tacrolimus is well known for its large inter- and intra-individual variation in the dosage requirement to reach target levels. Therefore, therapeutic drug monitoring (TDM) is necessary. The common practice is that a peri-operative standard dose (generally $0.2 \mathrm{mg} / \mathrm{kg} /$ day) is started and the dose is adjusted according to the measured levels. By knowing the pre-transplant factors that can explain at least part of this variation, the starting dose can be individualized and better adjusted in the early phase after transplantation, with a lower chance of under- or over-immunosuppression. At a later stage, one can have better prediction when TDM is necessary, e.g. at the introduction of a factor known to influence the absorption and/or metabolism of tacrolimus.

The absorption and metabolism of tacrolimus are regulated by enzyme systems, especially ABCB1 (MDR-1) and cytochrome P450 (CYP) subtypes $3 A 4$ and $3 A 5$. Part of the described variation could be explained by differences 
in activity of these enzyme systems. Indications for this are the well-known pharmacokinetic interactions of tacrolimus with other drugs that are metabolized by these enzyme systems.

Mutations within the genes of these enzyme systems result in single nucleotide polymorphisms (SNPs) possibly resulting in a different activity of that enzyme system.

There has been conflicting pubished data about the influence of the polymorphisms of the ABCB1 (MDR-1) system on the pharmacokinetics of tacrolimus. A number of studies have already reported that there seems to be no association between the ABCB1 polymorphisms and tacrolimus dosenormalized trough levels $\left(\mathrm{dnC}_{0}\right)^{55-59}$ or the dose-normalized area under the time tacrolimus concentration curve $\left(\mathrm{dnAUC}_{0-12}\right)^{60,61}$. However, some studies found a correlation between individual $A B C B 1$ polymorphisms and a higher tacrolimus dose $e^{62-64}$. Because of differences in design and study populations it might be that a polymorphism, that has a minor influence on the tacrolimus blood concentrations, demonstrates contrasting results among these studies. Moreover, there are several SNPs that may occur together, resulting in different haplotypes. The correlation of these haplotypes with the pharmacokinetics of tacrolimus has not yet been described extensively. In one study, a correlation between the ABCB1 1236C-2677G-3435C haplotype and a higher tacrolimus dose was found ${ }^{65}$. An overview of published data on the correlation of the main SNPs in the ABCB1 system on tacrolimus blood levels are given in Table 9.2.

In this thesis, we studied the correlation of these polymorphisms with

1. the 2-point limited sampling $\operatorname{dnAUC}_{0-12}$ in stable Chinese transplant recipients (Chapter 6)

2. the 9-point dnAUC 0 -12 in 2 groups of Caucasian transplant recipients: early and late after transplantation (Chapter 7)

In Chapter 7, 63 Caucasian renal transplant recipients were described who had a complete 9-point 12-hour AUC of tacrolimus: 26 patients within three months after transplantation (median 16 days, early phase group) and 37 patients over one year after transplantation (median 1465 days, late phase group). They were typed for three SNPs in the ABCB1 system. Neither the individual ABCB1 polymorphisms nor the $A B C B 1$ haplotypes were associated with any pharmacokinetic parameter. 
Table 9.2 ABCB1 genetic polymorphism and effects on dose-normalized concentrations of tacrolimus.

\begin{tabular}{|c|c|c|c|c|c|}
\hline $\begin{array}{l}\text { Patient } \\
\text { population }\end{array}$ & $\mathrm{N}$ & $\begin{array}{l}\text { Genotype } \\
\text { Exon }\end{array}$ & Mutation & $\begin{array}{c}\text { Effect of mutation of } \\
\text { dose-normalized } \\
\text { blood concentration }\end{array}$ & Reference \\
\hline Adult renal & 103 & $\begin{array}{l}\text { Exon } 21 \\
\text { Exon } 26\end{array}$ & $\begin{array}{c}\text { g2677G }>(T, A) \\
\text { g3435C }>T\end{array}$ & $\begin{array}{l}\text { Neutral } \\
\text { Neutral }\end{array}$ & Chapter 6 \\
\hline Adult renal & 63 & $\begin{array}{l}\text { Exon } 21 \\
\text { Exon } 26\end{array}$ & $\begin{array}{c}\text { g2677G }>(T, A) \\
\text { g3435C }>T\end{array}$ & $\begin{array}{l}\text { Neutral } \\
\text { Neutral }\end{array}$ & Chapter 7 \\
\hline Adult renal & 206 & $\begin{array}{l}\text { Exon } 12 \\
\text { Exon } 21 \\
\text { Exon } 26 \\
\text { Haplotype }\end{array}$ & $\begin{array}{c}\mathrm{g} 1236 \mathrm{C}>\mathrm{T} \\
\mathrm{g} 2677 \mathrm{G}>(\mathrm{T}, \mathrm{A}) \\
\mathrm{g} 3435 \mathrm{C}>\mathrm{T} \\
\text { Exons } 12.21,26\end{array}$ & $\begin{array}{c}\text { Neutral } \\
\text { Increased } \\
\text { Increased } \\
\text { Increased }\end{array}$ & 73 \\
\hline Adult renal & 180 & Exon 26 & g3435C > T & Increased & 64 \\
\hline Adult renal & 118 & Exon 26 & g3435C>T & Neutral & 55 \\
\hline Adult renal & 92 & Exon 26 & $\mathrm{~g} 3435 \mathrm{C}>\mathrm{T}$ & Increased & 74 \\
\hline Adult lung & 91 & $\begin{array}{l}\text { Exon } 12 \\
\text { Exon } 21 \\
\text { Exon } 26 \\
\text { Haplotype }\end{array}$ & $\begin{array}{c}\text { g1236C }>\mathrm{T} \\
\mathrm{g} 2677 \mathrm{G}>(\mathrm{T}, \mathrm{A}) \\
\mathrm{g} 3435 \mathrm{C}>\mathrm{T} \\
\text { Exons } 12,21,26\end{array}$ & $\begin{array}{l}\text { Increased } \\
\text { Increased } \\
\text { Increased } \\
\text { Increased }\end{array}$ & 75 \\
\hline Adult lung & 83 & $\begin{array}{l}\text { Exon } 21 \\
\text { Exon } 26\end{array}$ & $\begin{array}{c}\mathrm{g} 2677 \mathrm{G}>(\mathrm{T}, \mathrm{A}) \\
\mathrm{g} 3435 \mathrm{C}>\mathrm{T}\end{array}$ & $\begin{array}{l}\text { Minimal } \\
\text { Minimal }\end{array}$ & 63 \\
\hline Adult renal & 81 & $\begin{array}{c}\text { Exon } 1 \\
\text { Exon } 12 \\
\text { Exon } 21 \\
\text { Exon } 26 \\
\text { Haplotype }\end{array}$ & $\begin{array}{c}\mathrm{g}-129 \mathrm{~T}>\mathrm{C} \\
\mathrm{g} 1236 \mathrm{C}>\mathrm{T} \\
\mathrm{g} 2677 \mathrm{G}>(\mathrm{T}, \mathrm{A}) \\
\mathrm{g} 3435 \mathrm{C}>\mathrm{T} \\
\text { Exons } 12,21,26\end{array}$ & $\begin{array}{c}\text { Neutral } \\
\text { Increased } \\
\text { Increased } \\
\text { Neutral } \\
\text { Increased }\end{array}$ & 65 \\
\hline Adult renal & 73 & $\begin{array}{l}\text { Exon } 21 \\
\text { Exon } 26 \\
\text { Haplotype }\end{array}$ & $\begin{array}{c}\mathrm{g} 2677 \mathrm{G}>(\mathrm{T}, \mathrm{A}) \\
\text { g3435C>T } \\
\text { Exons } 21,26\end{array}$ & $\begin{array}{l}\text { Neutral } \\
\text { Neutral } \\
\text { Neutral }\end{array}$ & 58 \\
\hline Adult renal & 64 & Exon 26 & g3435C > T & Neutral & 56 \\
\hline $\begin{array}{l}\text { Pediatric } \\
\text { cardiac }\end{array}$ & 63 & $\begin{array}{l}\text { Exon } 21 \\
\text { Exon } 26\end{array}$ & $\begin{array}{c}\text { g2677G }>(T, A) \\
\text { g3435C }>T\end{array}$ & $\begin{array}{l}\text { Increased } \\
\text { Increased }\end{array}$ & 62 \\
\hline Adult liver & 50 & Exon 26 & g3435C>T & Increased & 76 \\
\hline Adult renal & 50 & $\begin{array}{l}\text { Exon } 12 \\
\text { Exon } 21 \\
\text { Exon } 26 \\
\text { Haplotype }\end{array}$ & $\begin{array}{c}\mathrm{g} 1236 \mathrm{C}>\mathrm{T} \\
\mathrm{g} 2677 \mathrm{G}>(\mathrm{T}, \mathrm{A}) \\
\mathrm{g} 3435 \mathrm{C}>\mathrm{T} \\
\text { Exons } 12,21,26\end{array}$ & $\begin{array}{l}\text { Neutral } \\
\text { Neutral } \\
\text { Neutral } \\
\text { Neutral }\end{array}$ & 57 \\
\hline Adult renal & 44 & $\begin{array}{c}\text { Exon 1b } \\
\text { Exon 2 } \\
\text { Exon 11 } \\
\text { Exon 21 } \\
\text { Exon 26 } \\
\text { Cumulative }\end{array}$ & $\begin{array}{c}g-129 T>C \\
g 61 A>G \\
g 1199 G>A \\
g 2677 G>(T, A) \\
g 3435 C>T\end{array}$ & $\begin{array}{c}\text { Neutral } \\
\text { Neutral } \\
\text { Neutral } \\
\text { Neutral } \\
\text { Neutral } \\
\text { Increased }\end{array}$ & 77 \\
\hline Adult renal & 39 & Exon 26 & g3435C>T & Neutral & 60 \\
\hline Adult renal & 30 & $\begin{array}{l}\text { Exon } 21 \\
\text { Exon } 26\end{array}$ & $\begin{array}{c}\mathrm{g} 2677 \mathrm{G}>(\mathrm{T}, \mathrm{A}) \\
\mathrm{g} 3435 \mathrm{C}>\mathrm{T}\end{array}$ & $\begin{array}{l}\text { Neutral } \\
\text { Neutral }\end{array}$ & 61 \\
\hline Adult renal & 24 & $\begin{array}{l}\text { Exon } 21 \\
\text { Exon } 26\end{array}$ & $\begin{array}{c}\text { g2677G }>(T, A) \\
\text { g3435C > T }\end{array}$ & $\begin{array}{l}\text { Neutral } \\
\text { Neutral }\end{array}$ & 78 \\
\hline
\end{tabular}


In Chapter 6, 103 Chinese renal transplant recipients were studied at a mean of nearly three years after transplant. By a two-point limited sampling algorithm, $\mathrm{dnAUC}_{0-12}$ was calculated and correlated with SNPs in the ABCB1 system and the ABCB1 haplotypes. Individuals carrying the 2677TT or 3435TT genotype has a significantly lower $d n A \cup C_{0-12}$. No correlation was found between ABCB1 system haplotype and $\mathrm{dnAUC}_{0-12}$. In multiple regression analysis the 2677TT and 3435TT genotype was not shown to be significant if the CYP3A polymorphism was included. Therefore, the published correlation of SNPs of the ABCB1 system with dnAUC of tacrolimus might be related to genetic linkage of the ABCB1 system with other polymorphisms, such as the CYP3A system.

Polymorphism in CYP3A5 such as CYP3A5*1 is associated with a higher dose (and lower blood levels) of tacrolimus. The frequency of these alleles depends on the population studies: the CYP3A5*1 allele is present in $15 \%$ of the Caucasian, $45 \%$ of the African-American ${ }^{66}$, and $25 \%$ of the Chinese population $^{67}$.

Since many genetic differences exist between races, it is important to examine whether the described polymorphisms are related to differences in pharmacokinetic and dosing of tacrolimus within the Chinese transplant population. In Chapter 6 , a strong significant genetic effect between CYP3A5*3 polymorphism and both the $\operatorname{dnAUC}_{0-12}$ and the daily tacrolimus dose is demonstrated in Chinese stable renal transplant recipients. In fact, the CYP $3 A 5^{\star} 3$ polymorphism may explain $35.3 \%$ of the variation in the daily tacrolimus dose observed in the renal transplant recipients. In Chapter 7, a study involving Caucasian population, significantly higher $\mathrm{dnC}_{0}, \operatorname{dn} A \cup \mathrm{C}_{0-12}$ and $\mathrm{dnC}_{\text {max }}$ is demonstrated in carriers of the CYP3A5*3 allele in both early and late post renal transplant recipient groups than in patients homozygous for CYP3A5*1. Since the CYP3A5*1 allele was over-represented in the early phase group, we concluded that a complete pharmacokinetic profile is more frequently requested for renal transplant recipients carrying this allele, suggesting that these patients have more difficulties in achieving and maintaining tacrolimus concentrations compared to homozygous carriers of the CYP $3 A 5^{\star} 3$ variant. This might be of importance for the Chinese population in which the CYP3A5*1 allele has a much higher prevalence than in the Caucasian population. In Chapter 2, the incidence of acute rejection in the tacrolimus-treated Chinese recipients was $15 \%$. This is comparable with the acute rejection rate in tacrolimus-mycophenolate mofetil-corticosteroids-treated Caucasian renal transplant recipients ${ }^{11,12}$. Possible explanations for not finding a higher rejection rate (as a consequence of lower dnAUC in CYP3A5*1 patients) might be the higher starting dose of $0.3 \mathrm{mg} / \mathrm{kg} / \mathrm{day}$ (instead of $0.2 \mathrm{mg} / \mathrm{kg} / \mathrm{day}$ as commonly used in Caucasians) and the increase in tacrolimus dose early post-transplant based on the tacrolimus blood levels. 
Genotyping for CYP3A5 to predict the ideal initial dose of tacrolimus remains the most promising option for a pharmacogenetic strategy. However, recently Hesselink et al. did not found an association between CY3A5 genotype and risk of acute rejection in tacrolimus-treated renal transplant recipients in a randomized controlled trial (CYP3A5 genotype is not associated with a higher risk of acute rejection in tacrolimus-treated renal transplant recipients) ${ }^{68}$.

\section{Application of dried blood spot in renal transplantation}

Dried blood spot sampling (DBS) is commonly used for screening of metabolic disorders in newborns ${ }^{69}$. Its use in therapeutic drug monitoring (TDM) has been reported for medications such as antimalarials and antiretrovirals ${ }^{70,71}$. Recently, it has been shown that self-administered fingerprick testing for cyclosporine blood levels is practical to implement ${ }^{72}$. However, literature concerning its use in tacrolimus monitoring in renal transplant recipients is scarce. In Chapter 8, we investigated the application of DBS and high-performance liquid chromatography tandem-mass spectrometry (HPLC-MS) in tacrolimus monitoring. We found that there is an excellent correlation between the drug levels and the estimated abbreviated $\mathrm{AUC}_{0-12}$ obtained from venous blood sampling and fingerprick blood samples $\left(r^{2}=0.96, P<0.0001\right)$. Moreover, we showed that the assay is reproducible and the blood samples remain stable despite of storage and long-distance journey. DBS sampling is especially convenient for patients who have follow-up in transplant centers where limited sampling strategy is used for drug monitoring because the patients do not need to stay in transplant centers for at least two hours waiting for blood sampling. They can stay at home and perform the blood sampling themselves. In addition, home fingerprick sampling is proving useful for the more intensive follow-up of patients taking medication which would interact with the immunosuppressive agents. Use of fingerprick testing at home could provide a significant advantage to the physician by allowing the drug levels to be available at clinic visits, if samples were provided to the laboratory by the patients in advance. This approach would reduce the number of scheduled visits solely for venepuncture, with benefits for both the patients and clinic staff. Furthermore, our patients found the sampling easy to perform after careful instructions. Only two out of the 108 blood samples were unsuitable for analysis due to inadequate volume of blood. Thus it is justifiable to use DBS sampling as an alternative for conventional venous sampling in TDM in renal transplant recipients. However, this technique is not suitable for all patients and a careful assessment is required to ensure that the patients are happy with the procedure and are considered reliable to take the samples at appropriate time. 


\section{Conclusion}

The most challenging topic in renal transplantation nowadays is how to improve the long-term renal graft survival. Because many of the studies are performed in non-Chinese population, it is important to perform studies in the Chinese renal transplant recipients. In this thesis, it has been shown that tacrolimus is also more effective than cyclosporine in preserving renal function and prolongation of graft survival in a Chinese transplant population. Addition of IL-2 receptor antagonist seems to confer no additional benefit in terms of efficacy to them.

PTDM and metabolic syndrome has been shown to affect both the long-term renal allograft function and cardiovascular events after renal transplantation. Previous studies revealed a higher incidence of PTDM in tacrolimus-treated patients. However, the risk of development of diabetes with tacrolimus can be diminished by avoidance or early withdrawal of steroid and tacrolimus level reduction. MS is becoming an increasing problem after renal transplantation. Potential factors related to MS are physical inactivity and use of corticosteroids. Therefore, these factors have to be aggressively dealt with.

TDM is the gold standard for monitoring and titration of tacrolimus in order to ensure adequate immunosuppression but avoid nephrotoxicity and other side effects. Pharmacogenetics had generated considerable enthusiasm in transplantation medicine recently. Pharmacogenetic studies have led to a further understanding of the genetic basis of the variable pharmacokinetics of immunosuppressants. We show that patients expressing CYP3A5 require higher dose of tacrolimus to reach target concentrations than CYP3A5 nonexpressors. Genetic screening of transplant recipients for CYP3A5 expression may help to guide individual tacrolimus dosing. However, further prospective and intervention study involving genetic profile and transplant outcome is required in order to achieve the aim of personalized medicine.

Application of DBS in tacrolimus monitoring may provide a convenient yet accurate alternative for those who cannot come back to transplant center for blood sampling. 


\section{References}

1. Webster AC, Woodroffe RC, Taylor RS, Chapman JR, Craig JC. Tacrolimus versus ciclosporin as primary immunosuppression for kidney transplant recipients: meta-analysis and meta-regression of randomised trial data. BMJ 2005;331:810-21.

2. Ekberg H, Tedesco-Silva H, Demirbas A, Vítko S, Nashan B, Gürkan A, Margreiter R, Hugo C, Grinyó JM, Frei U, Vanrenterghem Y, Daloze P, Halloran PF; ELITE-Symphony Study. Reduced exposure to calcineurin inhibitors in renal transplantation. N Engl J Med 2007;357: 2562-75.

3. Knight SR, Morris PJ. The clinical benefits of cyclosporine C2-level monitoring: a systematic review. Transplantation 2007;83;1525-35.

4. van Hooff JP, Gelens M, Boots JM, van Duijnhoven EM, Dackus J, Christiaans MHL. Preservation of renal function and cardiovascular risk factors. Transplant Proc 2006;38: 1987-91.

5. Kaplan B, Schold JD, Meier-Kriesche H. Long-term graft survival with Neoral and tacrolimus: a paired kidney analysis. JASN 2003;14:2980-4.

6. Nashan B, Moore R, Amlot P, Schmidt AG, Abeywickrama K, Soulillou JP. for the CHIB 201 International Study Group . Randomised trial of basiliximab versus placebo for control of acute cellular rejection in renal allograft recipients. Lancet 1997;350:1193-8 .

7. Kahan BD, Rajagopalan PR, Hall M for the United States Simulect Renal Study Group. Reduction of the occurrence of acute cellular rejection among renal allograft recipients treated with basiliximab, a chimeric anti-interleukin-2-receptor monoclonal antibody. Transplantation 1999;67:276-84.

8. Ponticelli C, Yussim C, Cambi V, Legendre C, Rizzo G, Salvadori M, Kahn D, Kashi H, Salmela K, Fricke L, Heemann U, Garcia-Martinez J, Lechler R, Prestele H, Girault D on behalf of the Simulect Phase IV Study Group . A randomized, double-blind trial of basiliximab immunoprophylaxis plus triple therapy in kidney transplant recipients. Transplantation 2001; $72: 1261-7$.

9. Nashan B, Light S, Hardie IR, Lin A, Johnson JR for the Daclizumab Double Therapy Study Group. Reduction of acute renal allograft rejection by daclizumab. Transplantation 1999;67: 110-5.

10. Vincenti F, Kirkman R, Light S, Bumgardner G, Pescovitz M, Halloran P, Neylan J, Wilkinson A, Ekberg H, Gaston R, Backman L, Burdick J. for the Daclizumab Triple Therapy Study Group. Interleukin-2-receptor blockade with daclizumab to prevent acute rejection in renal transplantation. N Engl J Med 1998;338:161-5.

11. ter Meulen CG, van Riemsdijk I, Hené RJ, Christiaans MH, Borm GF, van Gelder T, Hilbrands LB, Weimar W, Hoitsma AJ. Steroid-withdrawal at 3 days after renal transplantation with antiIL-2 receptor alpha therapy: a prospective, randomized, multicenter study. Am J Transplant. 2004;4:803-10.

12. Rostaing L, Cantarovich D, Mourad G, Budde K, Rigotti P, Mariat C, Margreiter R, Capdevilla L, Lang P, Vialtel P, Ortuño-Mirete J, Charpentier B, Legendre C, Sanchez-Plumed J, Oppenheimer F, Kessler M; CARMEN Study Group. Corticosteroid-free immunosuppression with tacrolimus, mycophenolate mofetil, and daclizumab induction in renal transplantation. Transplantation 2005;79:807-14.

13. Report of the expert committee on the diagnosis and classification of diabetes mellitus. Diabetes care 2003;26 (suppl 1):S5-S20.

14. Heldgaard PE, Olivarius Nde F, Hindsberger C, Henriksen JE. Impaired fasting glycaemia resembles impaired glucose tolerance with regard to cardiovascular risk factors: populationbased, cross-sectional study of risk factors for cardiovascular disease. Diabet Med 2004;21: 363-70.

15. Is fasting glucose sufficient to define diabetes? Epidemiological data from 20 European studies. The DECODE-study group. European Diabetes Epidemiology Group. Diabetes Epidemiology: Collaborative analysis of Diagnostic Criteria in Europe. Diabetologia 1999;42: 647. 
16. Standards of medical care in diabetes-2006. Diabetes Care 2006;29(Suppl 1):S4-42.

17. Armstrong KA, Prins JB, Beller EM, Campbell SB, Hawley CM, Johnson DW, Isbel NM. Should glucose tolerance test be performed in all renal transplant recipients? Clin J Am Soc Nephrol 2006;1:100-8.

18. Leiter LA, Ceriello A, Davidson JA, Hanefeld M, Monnier L, Owens DR, Tajima N, Tuomilehto J; International Prandial Glucose Regulation Study Group. Postprandial glucose regulation: New data and new implications. Clin Ther 2005;27(Suppl 2):S42-56.

19. Tominaga M, Eguchi H, Manaka H, Igarashi K, Kato T, Sekikawa A. Impaired glucose tolerance is a risk factor for cardiovascular disease, but not impaired fasting glucose. The Funagata Diabetes Study. Diabetes Care 1999;22:920-4.

20. Vincenti F, Friman S, Scheuermann E, Rostaing L, Jenssen T, Campistol JM, Uchida K, Pescovitz MD, Marchetti P, Tuncer M, Citterio F, Wiecek A, Chadban S, El-Shahawy M, Budde K, Goto N; DIRECT (Diabetes Incidence after Renal Transplantation: Neoral C Monitoring Versus Tacrolimus) Investigators. Results of an international, randomized trial comparing glucose metabolism disorders and outcome with cyclosporine versus tacrolimus. Am J Transplant 2007;7:1506-14.

21. van Hooff JP, Christiaans MH, van Duijnhoven EM. Tacrolimus and posttransplant diabetes mellitus in renal transplantation. Transplantation 2005;79:1465-9.

22. Boots JM, van Duijnhoven EM, Christiaans MH, Wolffenbuttel BH, van Hooff JP. Glucose metabolism in renal transplant recipients on tacrolimus: the effect of steroid withdrawal and tacrolimus trough level reduction. J Am Soc Nephrol 2002;13:221-7.

23. David-Neto E, Lemos FC, Fadel LM, Agena F, Sato MY, Coccuza C, Pereira LM, de Castro MC, Lando VS, Nahas WC, lanhez LE. The dynamics of glucose metabolism under calcineurin inhibitors in the first year after renal transplantation in nonobese patients. Transplantation 2007;84:50-5.

24. Christiansen E, Andersen HB, Rasmussen K, Christensen NJ, Olgaard K, Kirkegaard P, Tronier B, Vølund A, Damsbo P, Burcharth F. Pancreatic beta-cell function and glucose metabolism in human segmental pancreas and kidney transplantation. Am J Physiol 1993; 264:E441-E449.

25. Artz MA, Boots JM, Ligtenberg G, Roodnat JI, Christiaans MH, Vos PF, Blom HJ, Sweep FC, Demacker PN, Hilbrands LB. Improved cardiovascular risk profile and renal function in renal transplant patients after randomized conversion from cyclosporine to tacrolimus. J Am Soc Nephrol 2003;14:1880-8.

26. Boots JM, Christiaans MHL, van Hooff JP. Effect of immunosuppressive agents on long-term survival of renal transplant recipients: focus on the cardiovascular risk. Drugs 2004;64: 2047-73.

27. van Hooff JP, Christiaans MHL, van Duijnhoven EM. Glucose metabolic disorder after transplantation. Am J Transplant 2007;7:1435-6.

28. Pannier B, Thomas F, Eschwège E, Bean K, Benetos A, Leocmach Y, Danchin N, Guize L. Cardiovascular risk markers associated with the metabolic syndrome in a large French population: the "SYMFONIE" study. Diabetes Metab 2006;32(5 Pt 1):467-74.

29. Park HS, Oh SW, Cho SI, Choi WH, Kim YS. The metabolic syndrome and associated lifestyle factors among South Korean adults. Int. J. Epidemiol 2004;33:328-36.

30. Ford ES, Giles WH, Mokdad AH. Increasing prevalence of the metabolic syndrome among U.S. adults. Diabetes Care 2004;27:2444-9.

31. de Vries AP, Bakker SJ, van Son WJ, van der Heide JJ, Ploeg RJ, The HT, de Jong PE, Gans RO. Metabolic syndrome is associated with impaired long-term renal allograft function; not all component criteria contribute equally. Am. J. Transplant 2004;4:1675-83.

32. Porrini E, Delgado P, Bigo C, Alvarez A, Cobo M, Checa MD, Hortal L, Fernández A, García JJ, Velázquez S, Hernández D, Salido E, Torres A. Impact of metabolic syndrome on graft function and survival after cadaveric renal transplantation. Am. J. Kidney Dis. 2006;48: 134-42.

33. Armstrong KA, Campbell SB, Hawley CM, Nicol DL, Johnson DW, Isbel NM. Obesity is associated with worsening cardiovascular risk factor profiles and proteinuria progression in renal transplant recipients. Am. J. Transplant 2005;5:2710-8. 
34. Naganuma T, Uchida J, Kinoshita Y, Kuroki Y, Takemoto Y, Yoshimura R, Sugimura K, Nakatani T. The prevalence of metabolic syndrome in Japanese renal transplant recipients. Nephrology (Carlton). 2007;12:413-7.

35. Gu D, Reynolds K, Wu X, Chen J, Duan X, Reynolds RF, Whelton PK, He J; InterASIA Collaborative Group. Prevalence of the metabolic syndrome and overweight among adults in China. Lancet 2005;365:1398-405.

36. Ko GT, Cockram CS, Chow CC, Yeung V, Chan WB, So WY, Chan NN, Chan JC. High prevalence of metabolic syndrome in Hong Kong Chinese-comparison of three diagnostic criteria. Diabetes Res Clin Pract 2005;69:160-8.

37. van den Ham EC, Kooman JP, Christiaans MH, van Hooff JP. Relation between steroid dose, body composition and physical activity in renal transplant patients. Transplantation 2000;69: 1591-8.

38. Reaven GM. Banting lecture 1988. Role of insulin resistance in human disease. Diabetes 1998;37:1595.

39. van den Ham EC, Kooman JP, Christiaans ML, van Hooff JP. The influence of early steroid withdrawal on body composition and bone mineral density in renal transplantation patients. Transpl Int 2003;16:82-7.

40. Hanson RL, Imperatore G, Bennett PH, Knowler WC. Components of the 'metabolic syndrome' and incidence of type 2 diabetes. Diabetes 2002;51:3120-27.

41. McLaughlin T, Abbasi F, Cheal K, Chu J, Lamendola C, Reaven G. Use of metabolic markers to identify overweight individuals who are insulin resistant. Ann Intern Med 2003;139:802-9.

42. Fox CS, Larson MG, Leip EP, Culleton B, Wilson PW, Levy D. Predictors of new-onset kidney disease in a community-based population. JAMA 2004;291:844-50.

43. Chen J, Muntner P, Hamm LL, Jones DW, Batuman V, Fonseca V, Whelton PK, He J. The metabolic syndrome and chronic kidney disease in U.S. adults. Ann Intern Med 2004;140: 167-74.

44. Valantine H, Rickenbacker P, Kemna M, Hunt S, Chen YD, Reaven G, Stinson EB. Metabolic abnormalities characteristic of dysmetabolic syndrome predict the development of transplant coronary artery disease: A prospective study. Circulation 2001;103:2144-52.

45. Kubo M, Kiyohara Y, Kato I, Iwamoto H, Nakayama K, Hirakata H, Fujishima M. Effect of hyperinsulinemia on renal function in a general Japanese population: The Hisayama study. Kidney Int 1999;55:2450-56.

46. Wu Y, Liu Z, Xiang Z, Zeng C, Chen Z, Ma X, Li L. Obesity-related glomerulopathy: Insights from gene expression profiles of the glomeruli derived from renal biopsy samples. Endocrinology 2006;147:44-50.

47. Bagby SP. Obesity-initiated metabolic syndrome and the kidney: A recipe for chronic kidney disease? J Am Soc Nephrol 2004;15:2775-91.

48. Chalmers L, Kaskel FJ, Bamgbola O. The role of obesity and its bioclinical correlates in the progression of chronic kidney disease. Adv. Chronic Kidney Dis 2006;13:352-64.

49. Nelson RG, Bennett PH, Beck GJ, Tan M, Knowler WC, Mitch WE, Hirschman GH, Myers BD. Development and progression of renal disease in Pima Indians with non-insulindependent diabetes mellitus. Diabetic Renal Disease Study Group. N Engl J Med 1996;335: 1636-42.

50. Humphrey LL, Ballard DJ, Frohnert PP, Chu CP, O'Fallon WM, Palumbo PJ. Chronic renal failure in non-insulin-dependent diabetes mellitus. A population-based study in Rochester, Minnesota. Ann Intern Med 1989;111:788-96.

51. Hunsicker LG, Adler S, Caggiula A, England BK, Greene T, Kusek JW, Rogers NL, Teschan $\mathrm{PE}$. Predictors of the progression of renal disease in the Modification of Diet in Renal Disease Study. Kidney Int 1997;51:1908-19.

52. Muntner P, Coresh J, Smith JC, Eckfeldt J, Klag MJ. Plasma lipids and risk of developing renal dysfunction: The atherosclerosis risk in communities study. Kidney Int 2000;58: 293-301.

53. Courivaud C, Kazory A, Simula-Faivre D, Chalopin JM, Ducloux D. Metabolic syndrome and atherosclerotic events in renal transplant recipients. Transplantation 2007;83:1577-81. 
54. van den Ham EC, Kooman JP, Schols AM, Nieman FH, Does JD, Franssen FM, Akkermans MA, Janssen PP, van Hooff JP. Similarities in skeletal muscle strength and exercise capacity between renal transplant and hemodialysis patients. Am J Transplant 2005;5:1957-65.

55. Zhang X, Liu ZH, Zheng JM, Chen ZH, Tang Z, Chen JS, Li LS. Influence of CYP3A5 and MDR1 polymorphisms on tacrolimus concentration in the early stage after renal transplantation. Clin Transplant 2005;19:638-43.

56. Hesselink DA, van Schaik RH, van der Heiden IP, van der Werf M, Gregoor PJ, Lindemans J, Weimar W, van Gelder T. Genetic polymorphisms of the CYP3A4, CYP3A5, and MDR-1 genes and pharmacokinetics of the calcineurin inhibitors cyclosporine and tacrolimus. Clin Pharmacol Ther 2003;74:245-54.

57. Haufroid V, Mourad M, Van Kerckhove V, Wawrzyniak J, De Meyer M, Eddour DC, Malaise J, Lison D, Squifflet JP, Wallemacq P. The effect of CYP3A5 and MDR1 (ABCB1) polymorphisms on cyclosporine and tacrolimus dose requirements and trough blood levels in stable renal transplant patients. Pharmacogenetics 2004;14:147-54.

58. Mai I, Perloff ES, Bauer S, Goldammer M, Johne A, Filler G, Budde K, Roots I. MDR1 haplotypes derived from exons 21 and 26 do not affect the steady-state pharmacokinetics of tacrolimus in renal transplant patients. Br J Clin Pharmacol 2004;58:548-53.

59. Hebert MF, Dowling AL, Gierwatowski C, Lin YS, Edwards KL, Davis CL, Marsh CL, Schuetz EG, Thummel KE. Association between ABCB1 (multidrug resistance transporter) genotype and post-liver transplantation renal dysfunction in patients receiving calcineurin inhibitors. Pharmacogenetics 2003;13:661-74.

60. Tada H, Tsuchiya N, Satoh S, Kagaya H, Li Z, Sato K, Miura M, Suzuki T, Kato T, Habuchi T. Impact of CYP3A5 and MDR1(ABCB1) C3435T polymorphisms on the pharmacokinetics of tacrolimus in renal transplant recipients. Transplant Proc 2005;37:1730-2.

61. Tsuchiya N, Satoh S, Tada H, Li Z, Ohyama C, Sato K, Suzuki T, Habuchi T, Kato T. Influence of CYP3A5 and MDR1 (ABCB1) polymorphisms on the pharmacokinetics of tacrolimus in renal transplant recipients. Transplantation 2004;78:1182-7.

62. Zheng H, Webber S, Zeevi A, Schuetz E, Zhang J, Bowman P, Boyle G, Law Y, Miller S, Lamba J, Burckart GJ. Tacrolimus dosing in pediatric heart transplant patients is related to CYP3A5 and MDR1 gene polymorphisms. Am J Transplant 2003;3:477-83.

63. Zheng H, Zeevi A, Schuetz E, Lamba J, McCurry K, Griffith BP, Webber S, Ristich J, Dauber J, lacono A, Grgurich W, Zaldonis D, McDade K, Zhang J, Burckart GJ. Tacrolimus dosing in adult lung transplant patients is related to cytochrome P4503A5 gene polymorphism. J Clin Pharmacol 2004;44:135-40.

64. MacPhee IA, Fredericks S, Tai T, Syrris P, Carter ND, Johnston A, Goldberg L, Holt DW. Tacrolimus pharmacogenetics: Polymorphisms associated with expression of cytochrome p4503A5 and P-glycoprotein correlate with dose requirement. Transplantation 2002;74: 1486-9.

65. Anglicheau D, Verstuyft C, Laurent-Puig P, Becquemont L, Schlageter MH, Cassinat B, Beaune $\mathrm{P}$, Legendre $\mathrm{C}$, Thervet $\mathrm{E}$. Association of the multidrug resistance-1 gene singlenucleotide polymorphisms with the tacrolimus dose requirements in renal transplant recipients. J Am Soc Nephrol 2003;14:1889-96.

66. Kuehl P, Zhang J, Lin Y, Lamba J, Assem M, Schuetz J, Watkins PB, Daly A, Wrighton SA, Hall SD, Maurel P, Relling M, Brimer C, Yasuda K, Venkataramanan R, Strom S, Thummel K, Boguski MS, Schuetz E. Sequence diversity in CYP3A promoters and characterization of the genetic basis of polymorphic CYP3A5 expression. Nat Genet 2001;27:383-91.

67. Balram C, Zhou Q, Cheung YB, Lee EJ. CYP3A5*3 and * 6 single nucleotide polymorphisms in three distinct Asian populations. Eur J Clin Pharmacol 2003;59:123-6.

68. Hesselink DA, van Schaik RH, van Agteren M, de Fijter JW, Hartmann A, Zeier M, Budde K, Kuypers DR, Pisarski P, Le Meur Y, Mamelok RD, van Gelder T. CYP3A5 genotype is not associated with a higher risk of acute rejection in tacrolimus-treated renal transplant recipients. Pharmacogenet Genomics 2008;18:339-48.

69. Chace DH, Kalas TA, Naylor EW. Use of tandem mass spectrometry for multianalyte screening of dried blood specimens from newborns. Clin Chem 2003;49:1797-817. 
70. Malm M, Lindegardh N, Bergquist $\mathrm{Y}$. Automated solid-phase extraction method for the determination of piperaquine in capillary blood applied onto sampling paper by liquid chromatography. J Chromatogr B Analyt Technol Biomed Life Sci 2004;809:43-9.

71. Koal T, Burhenne H, Romling R, Svoboda M, Resch K, Kaever V. Quantification of antiretroviral drugs in dried blood spot samples by means of liquid chromatography/tandem mass spectrometry. Rapid Commun Mass Spectrom 2005;19:2995-3001.

72. Yonan N, Martyszczuk R, Machaal A, Baynes A, Keevil BG. Monitoring of cyclosporine levels in transplant recipients using self-administered fingerprick sampling. Clin Transplant. 2006; 20:221-5.

73. Fredericks S, Moreton M, Reboux S, Carter ND, Goldberg L, Holt DW, MacPhee IA. Multidrug resistance gene-1 (MDR-1) haplotypes have a minor influence on tacrolimus dose requirements. Transplantation 2006;82:705-8.

74. Akbas SH, Bilgen T, Keser I, Tuncer M, Yucetin L, Tosun O, Gultekin M, Luleci G. The effect of MDR1 (ABCB1) polymorphism on the pharmacokinetic of tacrolimus in Turkish renal transplant recipients. Transplant Proc 2006;38:1290-2.

75. Wang J, Zeevi A, McCurry K, Schuetz E, Zheng H, lacono A, McDade K, Zaldonis D, Webber $\mathrm{S}$, Watanabe RM, Burckart GJ. Impact of ABCB1 (MDR1) haplotypes on tacrolimus dosing in adult lung transplant patients who are CYP3A5 $* 3 /{ }^{*} 3$ non-expressors. Transpl Immunol 2006; 15:235-40.

76. Wei-lin W, Jing J, Shu-sen Z, Li-hua W, Ting-bo L, Song-feng Y, Sheng Y. Tacrolimus dose requirement in relation to donor and recipient $A B C B 1$ and CYP3A5 gene polymorphisms in Chinese liver transplant patients. Liver Transpl 2006;12:775-80.

77. Roy JN, Barama A, Poirier C, Vinet B, Roger M. Cyp3A4, Cyp3A5, and MDR-1 genetic influences on tacrolimus pharmacokinetics in renal transplant recipients. Pharmacogenet Genomics 2006;16:659-65.

78. Mourad M, Mourad G, Wallemacq P, Garrigue V, Van Bellingen C, Van Kerckhove V, De Meyer M, Malaise J, Eddour DC, Lison D, Squifflet JP, Haufroid V. Sirolimus and tacrolimus trough concentrations and dose requirements after kidney transplantation in relation to CYP3A5 and MDR1 polymorphisms and steroids. Transplantation 2005;80:977-84. 
Samenvatting 


\section{Samenvatting}

In dit proefschrift worden enkele vraagstellingen besproken samenhangend met het gebruik van immunosuppressiva in een groep Chinese ontvangers van een niertransplantatie.

\section{Tacrolimus en Cyclosporine: effectiviteit en nierfunktie}

In hoofdstuk 2 staan de resultaten beschreven van onze studie naar verschillen in klinische uitkomstparameters van 66 postmortale Chinese niertransplantaties behandeld met cyclosporine of tacrolimus. De effectiviteit van deze twee immuunsuppressiva zijn weliswaar vaker onderzocht, maar die studies hebben als nadeel dat er tussen beide onderzoeksgroepen ook verschillen bestaan in de herkomst van de donornier. Daarnaast werden die studies vaak in verschillende centra uitgevoerd. In onze studie is dit vermeden door randomisatie van beide nieren van dezelfde donor naar de twee behandelingsarmen en het transplanteren in één transplantatiecentrum. Zo'n studie werd niet eerder verricht. Tevens werd de dosering geoptimaliseerd van zowel cyclosporine als tacrolimus door deze te baseren op verkorte AUC (area under the curve)-berekeningen en niet op alleen dalspiegels. De resultaten van de studie tonen een halvering van het relatieve risico op het optreden van acute rejectie in patiënten die met tacrolimus werden behandeld. Dit verschil was in deze studie statistisch niet significant, mogelijk samenhangend met het relatief geringe aantal geincludeerde patiënten en het gematigde rejectiepercentage. In een - nog niet gepubliceerde - vervolgstudie waarin 76 patiënten gedurende tenminste zes jaar vervolgd werden, was het acute rejectie percentage wel statistisch significant verschillend: tacrolimus $18.4 \%$ t.o.v. cyclosporine $42.1 \%$.

Tevens werd in deze studie aangetoond dat patiënten die behandeld werden met tacrolimus - i.p.v. cyclosporine - vanaf zes maanden na transplantatie een betere nierfunktie hebben en dat de nierfunktie ook minder verslechterde (Hoofdstuk 2). Essentieel hierbij is dat door de direkte vergelijking van de funktie van beide nieren van één donor donor- en centrumbias uitgesloten zijn en dat de verschillen in nierfunktie direkt toe te schrijven zijn aan verschillen in het gebruikte immunosuppressivum. In de nog niet gepubliceerde vervolgstudie werd aangetoond dat dit verschil tot zes jaar follow-up blijft bestaan.

Mogelijke verklaringen voor het gevonden verschil zijn een lagere nefrotoxiciteit van tacrolimus en/of verminderde efficiëntie van cyclosporine in het vermijden van (subklinische) rejectie, eventueel leidend tot chronische transplantaat disfunktie.

Een recente grote studie, de ELITE-Symphony studie, bevestigt de betere nierfunktie in tacrolimus-behandelde patiënten op 1 jaar na transplantatie. 


\section{Interleukin-2 receptor antagonist}

Het is aangetoond dat het toevoegen van interleukine-2 receptor antagonist (basiliximab of daclizumab) aan een cyclosporine-bevattend immuunsuppressief schema het optreden van biopsie-bewezen rejectie met 30-40\% wordt gereduceerd. Dit was nog niet onderzocht in gerandomiseerde studies bij het gebruik van een tacrolimus-bevattende immuunsuppressief schema. In hoofdstuk 3 is een prospectieve studie beschreven naar de effectiviteit en veiligheid van het toevoegen van daclizumab aan Chinese ontvangers van een $1^{\mathrm{e}}$ postmortale niertransplantatie behandeld met tacrolimus, azathioprine en prednisolon. De incidentie van het optreden van acute rejectie was niet significant verschillend tussen beide groep: $19 \%$ in de controle-groep en $11 \%$ indien daclizumab was toegevoegd. Er waren ook geen verschillen in het optreden van infecties, cardiovasculaire bijwerkingen en transplantaat- en patiëntoverleving. Geconcludeerd werd, dat niet aangetoond is dat het toevoegen van daclizumab aan bovengenoemd immuunsuppressief schema aan patiënten met een laag immunologisch risico op acute afstoting zinvol is.

\section{Hyperglycemie en metabool syndroom}

In hoofdstuk 4 en 5 wordt gekeken naar het optreden van hyperglycemie en het metabool syndroom in een populatie Chinese ontvangers van een niertransplantatie.

In een groep van 119 Chinese niertransplantatie patiënten behandeld met 7.5 mg prednisolon en cyclosporine of tacrolimus, werd cross-sectioneel gekeken naar het percentage patiënten met een abnormale glucose metabolisme (AGM) volgens de ADA (American Diabetes Association)-criteria. Bij patiënten die niet bekend waren met Post Transplantatie Diabetes Mellitus en een nuchter glucose $>5.6 \mathrm{mmol} / \mathrm{l}$ hadden werd een orale glucose tolerantie test (OGTT) verricht. De resultaten van deze studie staan beschreven in hoofdstuk 4 . Het percentage patiënten met AGM was $38 \%$ in de tacrolimus groep en $27 \%$ in de cyclosporine groep (verschil niet statistisch significant). Dit percentage komt overeen met het percentage dat in Kaukasische patiënten is gevonden.

In hoofdstuk 5 werd de incidentie van het metabool syndroom cross-sectioneel gemeten in een Chinese groep ontvangers van een niertransplantatie. Bekend is dat dit percentage in ontvangers van een niertransplantaat hoger is dan in de algehele bevolking en in Kaukasiers varieert van 38-63\%. Het optreden van het metabool syndroom is geassocieerd met een verminderde nierfunktie en atherosclerotische ziektes. In deze groep patiënten was het percentage patiënten met een metabool syndroom $32 \%$. 


\section{Pharmacogenetica}

Tacrolimus heeft een grote inter- en intraindividuele variatie in de dosering ter bereiken van de streefwaarde. Daarom is hierbij Therapeutic Drug Monitoring (TDM) nodig. Door voorafgaand aan de transplantatie de factoren te kennen die (een deel van) deze variatie verklaren, kan de dosering tacrolimus beter geindividualiseerd worden met een geringere kans op onder- of overdosering. Ook kan daarmee in een later stadium beter voorspeld worden wanneer TDM nodig is, bijv. bij de introductie van een geneesmiddel waarvan bekend is dat dit de absorptie of metabolisme van tacrolimus verandert.

Enzymsystemen van belang bij de absorptie en metabolisme van tacrolimus zijn met name ABCB1 (MDR-1) en cytochrome P450 (CYP) subtypes 3A4 en 3A5. Door mutaties in de genen hiervan kan de activiteit veranderen. Deze mutaties kunnen in verschillende bevolkingsgroepen in verschillende mate aanwezig zijn.

In dit proefschrift hebben we de correlatie van polymorfismes bestudeerd in relatie tot:

1. Een 2-punts verkorte AUC genormaliseerd voor de dosering ( $\left.d n A \cup C_{0-12}\right)$ in 103 stabiele Chinese ontvangers van een niertransplantaat (Hoofdstuk 6)

2. Een 9-punt dnAUC $\mathrm{C}_{0-12}$ in twee groepen Kaukasische ontvangers van een niertransplantaat: 26 vroeg en 37 laat na transplantatie (Hoofdstuk 7)

In hoofdstuk 6, werden de Chinese ontvangers van een niertransplantaat ongeveer drie jaar na transplantatie onderzocht op mutaties in het ABCB1 systeem en de correlatie hiervan met de $\operatorname{dnAUC}_{0-12}$. $\mathrm{Er}$ werd geen correlatie gevonden tussen $A B C B 1$ systeem haplotype en dnAUC $C_{0-12}$. Patiënten met het $2677 T T$ of $3435 T T$ genotype hadden een significant lagere dnAUC $_{0-12}$ welke verdween indien het CYP3A polymorfisme werd geincludeerd in het model. De conclusie was dat de gepubliceerde correlatie tussen mutaties in het ABCB1 systeem en $\mathrm{dnAUC}_{0-12}$ van tacrolimus komt door genetische linkage van het ABCB1 systeem met andere polymorfismes, zoals het CYP3A system.

Polymorfisme in CYP3A5 was geassocieerd met de dosis (en dnAUC ${ }_{0-12}$ ) van tacrolimus. De frequentie van het CYP3A5*1 polymorfisme is hoger in de Chinese populatie (t.o.v. de Kaukasische populatie) en verklaarde ruim 35\% van de variatie in dagelijkse tacrolimus dosis.

In hoofdstuk 7 beschrijven we een onderzoek bij 63 Kaukasische ontvangers van een niertransplantatie waarvan een compleet 9-punts 12-uurs AUC van tacrolimus beschikbaar was: 26 patiënten waren onderzocht binnen 3 maanden na transplantatie en 37 patiënten tenminste 1 jaar na transplantatie. Zij werden getypeerd voor polymorfismes in het ABCB1 systeem en CYP3A. 
Noch de individuele polymorfismes van het $A B C B 1$ systeem, noch de $A B C B 1$ haplotypes waren geassocieerd met enige farmacokinetische parameter. Daarentegen hadden dragers van het CYP $3 A 5^{\star} 3$ allel zowel in de vroege als late groep een significant hogere spiegels $\left(\mathrm{dnC}_{0}, \mathrm{dnAUC}_{0-12}\right.$ en $\left.\mathrm{dnC}_{\max }\right)$. De frequentie van het CYP3A5*1 allel was in de vroege groep hoger dan verwacht o.b.v. prevalentie in de bevolking. Gepostuleerd werd dat deze patiënten na transplantatie mogelijk meer problemen hadden met het bereiken van de streefwaardes voor tacrolimus dan homozygote dragers van het CYP3A5 3 variant. Dit kan van belang zijn in de Chinese bevolking, alwaar het CYP3A5 1 allel een vaker voorkomt dan in de Kaukasische populatie. Het voorafgaand aan de transplantatie bepalen van de CYP3A5 genotype zou kunnen bijdragen aan het optimaleseren van de initiële tacrolimus dosering.

\section{Dried Blood Spot in niertransplantatie}

Dried blood spot (DBS) wordt frequent toegepast in de neonatologie en is ook toepasbaar bij antimalaria en anti-HIV medicatie. Tot nu toe werd het echter niet toegepast voor TDM van tacrolimus. In hoofdstuk 8 wordt de toepassing van DBS beschreven bij 36 Chinese ontvangers van een niertransplantatie. In totaal waren er 108 DBS monsters afgenomen middels een vingerprik, waarvan slechts twee niet beoordeelbaar waren. De correlatie tussen de bloedwaardes en de berekende verkorte $\mathrm{AUC}_{0-12}$ van monsters verkregen via veneuze bloedafnames (bepaald in Hong Kong) en vingerprik m.b.v. DBS (bepaald in Maastricht) was uitstekend $\left(r^{2}=0.96, P<0.0001\right)$. De test was reproduceerbaar en de monsters bleven stabiel ondanks de langdurige reis. Het voordeel van DBS voor patiënten is m.n. dat in de thuissituatie op de gewenste tijden een monsterafname plaats kan vinden i.p.v. afname in een ziekenhuis met extra reistijden en wachttijden bij de prikdienst. Bovendien kan de uitslag bekend zijn t.t.v. een poliklinisch bezoek. 

Acknowledgement 


\section{Acknowledgement}

After all those years, I have got a list of people who have helped and inspired me during my doctoral study, for which I would like to express thanks.

I would like to express my deep and sincere gratitude to my promoter, Professor J.P. van Hooff, for his guidance during my overseas training in University Hospital Maastricht. He motivated me to conceive and develop the main idea of the thesis. His perpetual energy and enthusiasm in research have a remarkable influence on my entire career in the field of kidney transplant research. Without his guidance and inspiration, this thesis could not be successfully completed.

I owe my most sincere gratitude to Dr. Chun Sang Li, Nephrology Team Head and my supervisor in Queen Elizabeth Hospital. Besides giving me full support to continue the research work in Hong Kong, he also gave me untiring help during my difficult moments.

I am deeply grateful to my co-promoter, Dr. M.H.L. Christiaans, for his detailed and constructive comments, and for his important support throughout this thesis.

I wish to express my warm and sincere thanks to Dr. Leo Stolk, Jaques van der Heijden and Karin Hoogtanders, from Department of Clinical Pharmacy in University Hospital Maastricht, for their guidance and support in the dried blood spot method for tacrolimus monitoring project.

I further express my gratitude to Professor M.P. van Dieijen-Visser, Otto Bekers, Johan de Vries and Robert A.M. Op den Buijsch, from Department of Clinical Chemistry in University Hospital Maastricht, for their support in pharmacogenetics project. Special thanks to Robert. We are both interested in pharmacogenetics and now he is one of my best friends.

I wish to extend my warmest thanks to Dr. Chung Ki Li, Dr. Ka Foon Chau, Dr. Man Po Lee and Dr. Yiu Han Chan for their advice and support in my research work in renal transplantation and kidney disease in HIV patients.

Furthermore, Dr. Francis Wong has always been a constant source of encouragement during my career. He used to be my senior but now we no longer work together in the same hospital. However, he is still my good friend.

I wish to thank Hoi Wong, Allen Liu and Kay Tai, my colleagues and good friends in Queen Elizabeth Hospital, for the data collection and data processing in the research work.

In this project, I have collaborated with many colleagues for whom I have great regard, and I wish to thank to all those who helped me with my work especially all renal nurses in Queen Elizabeth Hospital and Miss Angela Wong, our transplant coordinator. 
I wish to thank Etienne, Anke and Marleen, for helping me a lot when I started my clinical research work in the University Hospital Maastricht. Moreover, I would also like to express my thanks to Tiny Wouters for preparing this thesis. My deepest appreciation goes to my daddy, Ki Yuen and mummy, Lai King for their unflagging love and support throughout my life. I remember their constant support when I encountered any difficulties. Last but not the least, I owe my special loving thanks to my wife, Winnie. They all let me own a happy family. 

List of publications 


\section{List of publications}

1. Wong KM, Cheung CY, Chan YH, Chak WL, Choi KS, Chau KF, Li CS. Tacrolimus versus cyclosporine as primary prophylactic therapy after cadaveric renal transplant: two-year survival study. Transplant Proc 2000: 32(7): 1721-2.

2. Chan YH, Wong KM, Choi KS, Chak WL, Cheung CY, Chau KF, Li CS. Clinical manifestations and progression of IgM mesangial nephropathy: a single center prospective. Hong Kong J Nephrol 2000; 2(1):23-6.

3. Chak WL, Wong KM, Choi KS, Chan YH, Cheung CY, Chau KF, Li CS. Effects of peritoneal dialysate acidity on the net ultrafiltration and solute removal in patients on intermittent peritoneal dialysis. Hong Kong J Nephrol 2000; 2(1):50-3.

4. Wong KM, Chak WL, Tsang DN, Cheung CY, Chan YH, Choi KS, Lam TW, Chau KF, Li CS. Long term outcome in hepatitis B sero-positive oriental renal transplant recipients. Transplant Proc 2001: 33(1-2): 1242-4.

5. Wong KM, Chan YH, Cheung CY, Chak WL, Choi KS, Leung SH, Leung J, Tsang DN, Chau KF, Li CS. Cefepime versus vancomycin plus netilmicin therapy for continuous ambulatory peritoneal dialysis-associated peritonitis. Am J Kidney Dis 2001; 38(1): 127-31.

6. Wong KM, Chak WL, Cheung CY, Chan YH, Chau KF, Li CS. Hypokalemic metabolic acidosis attributed to cough mixture abuse. Am J Kidney Dis 2001; 38(2): 390-4.

7. Cheung CY, Wong KM, Chan YH, Chak WL, Choi KS, Chan SK, Chau KF, Li CS. False positive antineutrophil cytoplasmic antibody in a patient with infective endocarditis. Hong Kong J Nephrol 2001; 3(1): 41-4.

8. Chan YH, Wong KM, Kwok CH, Cheung CY, Chak WL, Chau KF, Li CS. Atypical presentation of calciphylaxis in a renal failure patient: Successful treatment with unfractionated heparin. Hong Kong $\mathrm{J}$ Nephrol 2001; 3(2): 103-6.

9. Chak WL, Wong KM, Kwok CH, Choi KS, Chan YH, Cheung CY, Chau KF, Li CS. Obstructive uropathy in two Chinese patients with lupus interstitial cystitis. Hong Kong J Nephrol 2002; 4(2): 101-4.

10. Chan YH, Wong KM, Cheung CY, Kwok CH, Chau KF, Li CS. Mesenteric lymphadenopathy caused by Penicillium marneffei in a renal transplant recipient. Hong Kong J Nephrol 2003; 5(1): 51

11. Wong KM, Liu YL, Leung KT, Choi KS, Chau KF, Li PC, Li CS, Lee KC, Cheung $\mathrm{CY}$, Chan YH, Lee MP. Corticosteroid therapy in a Chinese patient with nephropathy associated with human immunodeficiency virus infection. Hong Kong Med J. 2004; 10(3):201-5. 
12. Cheung CY, Op den Buijsch RA, Wong KM, Chan HW, Chau KF, Li CS, Leung KT, Kwan TH, de Vrie JE, Wijnen PA, van Dieijen-Visser MP, Bekers $O$. Influence of different allelic variants of the CYP3A and ABCB1 genes on the tacrolimus pharmacokinetic profile of Chinese renal transplant recipients. Pharmacogenomics. 2006; 7(4):563-74.

13. Cheung CY, Wong KM, Chan HW, Liu YL, Chan YH, Wong HS, Chak WL, Choi KS, Chau KF, Li CS. Paired kidney analysis of tacrolimus and cyclosporine microemulsion-based therapy in Chinese cadaveric renal transplant recipients. Transpl Int 2006; 19(8): 657-66.

14. Loong HH, Cheung CY, Lam YK. A not-so-uncommon presentation of an uncommon disease: nasal natural killer/T-cell lymphoma. Hong Kong Med J. 2006; 12(6):470-2.

15. Cheung CY, Wong KM, Lee MP, Liu YL, Kwok H, Chung R, Chau KF, Li $\mathrm{CK}$, Li CS . Prevalence of chronic kidney disease in Chinese HIV-infected patients. Nephrol Dial Transplant. 2007; 22(11):3186-90.

16. Op den Buijsch RA, Christiaans MH, Stolk LM, de Vries JE, Cheung CY, Undre NA, van Hooff JP, van Dieijen-Visser MP, Bekers O. Tacrolimus pharmacokinetics and pharmacogenetics: influence of adenosine triphosphate-binding cassette B1 (ABCB1) and cytochrome (CYP) $3 \mathrm{~A}$ polymorphisms. Fundam Clin Pharmacol. 2007; 21(4):427-35.

17. Cheung CY, van der Heijden J, Hoogtanders K, Christiaans M, Liu YL, Chan YH, Choi KS, van de Plas A, Shek CC, Chau KF, Li CS, van Hooff J, Stolk L. Dried blood spot measurement: application in tacrolimus monitoring using limited sampling strategy and abbreviated AUC estimation. Transpl Int. 2008; 21(2): 140-5.

18. Wijnen PA, Op den Buijsch RA, Cheung SC, van der Heijden J, Hoogtanders K, Stolk LM, van Dieijen-Visser MP, Neef C, Drent M, Bekers O. Genotyping with a dried blood spot method: A useful technique for application in pharmacogenetics. Clin Chim Acta. 2008; 388(1-2):189-91.

19. Cheung CY, Liu YL, Wong KM, Chan HW, Chan YH, Wong HS, Chak WL, Choi KS, Chau KF, Li CS. Can Daclizumab reduce acute rejection and improve long term renal function in tacrolimus-based primary renal transplant recipients. Nephrology (Carlton). 2008; 13(3):251-5.

20. Chan HW, Cheung CY, Liu YL, Chan YH, Wong HS, Chak WL, Choi KS, Chau KF, Li CS. Prevalence of abnormal glucose metabolism in Chinese renal transplant recipients: a single centre study. Nephrol Dial Transplant. 2008; 23(10): 3337-42.

21. Cheung CY, Chan HW, Liu YL, Chan YH, Wong HS, Chak WL, Choi KS, Chau KF, Li CS. Prevalence of metabolic syndrome in Chinese renal transplant recipients. Hong Kong Med J. 2008; 14(5): 379-84. 
22. Cheung CY, Wu TC, Chan YH, Lee KC, Chan HW, Chau KF, Li CS. Coexisting cutaneous aspergillosis and pulmonary tuberculosis in a renal transplant recipient. Hong Kong J Nephrol 2008; 10(2): 74-7.

23. Cheung CY, Chan OK, Chan YH, Lee KC, Chan PT, Lau TC, Shek CC, Chau KF, Li CS. A rare cause of nephrotic syndrome: lipoprotein glomerulopathy. Hong Kong Med J. 2009; 15(1): 57-60.

24. Cheung CY, Chan HW, Liu YL, Chau KF, Li CS. Long-term graft function with tacrolimus and cyclosporine in renal transplantation: paired kidney analysis. Nephrology (Carlton) 2008;13:251-255

25. Cheung CY, Chan HW, Liu YL, Chau KF, Li CS. Impact of delayed graft function on renal function and graft survival in deceased kidney transplantation. (Submitted).

26. Cheung CY, Chan YH, Chan HW, Chau KF, Li CS. Optimal body mass index which can predict long-term graft outcome in Chinese renal transplant recipients. (Submitted) 
Curriculum Vitae 


\section{Curriculum Vitae}

Name: $\quad$ Cheung Chi Yuen, Simon

Sex: $\quad$ Male

Date of Birth: $\quad$ 22/1/1970

Place of Birth: Hong Kong

Nationality: $\quad$ Chinese

Religion: Roman Catholic

Secondary School: Wah Yan College, Kowloon (1982-1989)

University: $\quad$ Faculty of Medicine, The University of Hong Kong (1989-1994)

\section{Appointments in hospital}

\section{Internship}

1. Department of Paediatrics, Queen Elizabeth Hospital, Hong Kong (1/7/199430/9/1994)

2. Department of Medicine, Queen Elizabeth Hospital, Hong Kong (1/10/1994$31 / 12 / 1994)$

3. Department of Surgery, Kwong Wah Hospital, Hong Kong (1/1/199531/3/1995)

4. Department of Surgery, Tung Wah Hospital, Hong Kong (1/4/199530/6/1995)

\section{Medical Officer}

1. Department of Anaesthesia and Intensive Care , Yan Chai Hospital, Hong Kong (1/7/1995-31/12/1995)

2. Department of Medicine, Queen Elizabeth Hospital, Hong Kong (1/1/1996 to now)

\section{Year of basic physician training: 1/1/1996 to 31/3/2000}

1. Acute medicine in Queen Elizabeth Hospital

2. Critical care medicine in Queen Elizabeth Hospital

3. Rehabilitation medicine in Kowloon Hospital and Buddhist Hospital

\section{Education}

MBBS (Hong Kong): The University of Hong Kong: 6/1994

MRCP (United Kingdom): Royal College of Physicians: 1/2000

Fellow of Hong Kong College of Physicians: 11/2003

Fellow of Hong Kong Academy of Medicine: 5/2004

\section{Subspecialty}

Nephrology

Advanced Internal Medicine

Overseas training in Nephrology (16/9/2002-15/3/2003)

Renal Unit, University of Maastricht, Maastricht, the Netherlands 


\section{Medical Society Membership}

Full registration in Hong Kong Medical Council

Full registration in General Medical Council

Member of Hong Kong Medical Association

Full member of Hong Kong Society of Nephrology

Full member of Hong Kong Society of Transplantation

\section{Activities of current appointment}

Inpatient and outpatient care of renal and general ward patients

Supervision and provision of training to house officers

Teaching of medical students

Education of medical and nursing staff

Public health education

Organization of clinical research projects

Participation in organization of MRCP examinations in 2001 and 2005

Auditor of discharge summary for Queen Elizabeth Hospital

Member of canteen consultative committee in Queen Elizabeth Hospital

Subcommittee members of International Society of Peritoneal Dialysis conference in Hong Kong 2006

\section{Award in presentation}

Best Oral Presentation in Hong Kong Annual Scientific Meeting 2005. (1011/9/05)

A Single Center and Paired Kidney Analysis of Tacrolimus and Neoral-based Therapy in Chinese Cadaveric Renal Transplant Recipients.

\section{International meeting presentation}

1. A single center study of tuberculous peritonitis complicating continuous ambulatory peritoneal dialysis in Hong Kong. $49^{\text {th }}$ Japanese Society of Dialysis Therapy in Kobe, Japan (6/2004)

2. MDR-1 and CYP P450 gene polymorphisms and 12-hr AUC pharmacokinetics of tacrolimus. TransplantAsia 2004 in Singapore $(12 / 2004)$

3. Single center study of CAPD catheters placement using Seldinger technique. EuroPD in Prague, Czech Republic (10/2005)

4. Prevalence of chronic kidney disease in Chinese HIV-infected patients. AIDS 2006 in Toronto, Canada (8/2006)

5. Allelic variants of uridine diphosphate-glucuronosyltransferase (UGT) 2B7 had no influence on tacrolimus pharmacokinetics. World Congress of Nephrology in Rio de Janeiro, Brazil (4/2007)

6. Dried blood spot measurement: Application in tacrolimus monitoring using limited sampling strategy and abbreviated AUC estimation. XXII International Congress of the Transplantation Society in Sydney, Australia (8/2008) 


\section{Speaker in local meeting}

1. Therapeutic drug monitoring of tacrolimus. Annual Scientific Meeting in Hong Kong (10/2006)

\section{Speaker in overseas meeting}

1. Asia Pacific Summit: Addressing the Challenges in Solid Organ Transplantation in Sapporo, Japan (14-15/7/2007)

\section{Guest lecturer}

1. Master of Science in International Pharmaceutical Science.

Pharmaceutical Science, College of Life Science and Technology, University of Hong Kong SPACE (16/2/2008)

\section{Journal reviewer}

1. Hong Kong Journal of Nephrology

2. Peritoneal Dialysis International

3. Clinical Pharmacokinetics

4. Expert Opinion on Pharmacotherapy 